\title{
EUROPEAN SCIENTIFIC ASSESSMENT OF THE ATMOSPHERIC EFFECTS OF AIRCRAFT EMISSIONS
}

\author{
G. P. BRASSEUR,,+ R. A. COX,§ D. HAUGLUSTAINE, $\uparrow+$ I. ISAKSEN, \\ J. LELIEVELD, ** D. H. LISTER, †† R. SAUSEN, + †. SCHUMANN,
}

A. WAHNER $\S$ and P. WIESEN $\uparrow$

$\ddagger$ Service d'Aéronomie du CNRS, Verrières-le-Buisson, France; $\S$ Department of Chemistry, University of Cambridge, Cambridge, U.K.; §Service d'Aéronomie du CNRS, Verrières-le-Buisson, France; $\uparrow$ Department of Geophysics, University of Oslo, Oslo, Norway; ** Institute of Marine and Atmospheric Research, Utrecht, The Netherlands; $\dagger$ Propulsion Department, DERA, Farnborough, U.K.; $\$$ Institut für Physik der Atmosphäre, DLR Oberpfaffenhofen, Germany; §§ Institut für Chemie und Dynamik, der Geosphäre 3, Forschungszentrum, Jülich, Germany; and $\uparrow$ Bergische Universität, Wuppertal, Germany

\section{INTRODUCTION}

During the 20th century, the world's transportation system has changed dramatically with the gradual emergence of a large fleet of commercial aircraft. Today, thousands of aircraft carry each year several millions of passengers all over the world. The size of the world's fleet has increased constantly over the past decades and is expected to do so in the future. As a result of improvements in the aircraft technology, the nature of the fleet has evolved and will change further in the future.

Today, the major fraction of the commercial fleet is provided by jet aircraft which cruise for the most part in the upper troposphere and lower stratosphere (typically 9-12 km altitude) at subsonic speed. Since the early 1970s, however, a small European fleet of 13 Concorde aircraft have been in commercial operation; these aircraft fly supersonically at cruising altitudes of $16.5 \mathrm{~km}$. In the future, this fleet might expand with new aircraft operating at even higher levels (17-22 km).

In spite of substantial improvements in engine technology, aircraft operations result in the emission of gaseous and particle effluents, including carbon dioxide, water, hydrocarbons, carbon monoxide, nitrogen oxides, sulphur, soot, etc. In the early 1970s, Crutzen (1971) recognised the role played by the nitrogen oxides in the destruction of stratospheric ozone, and Johnston (1971) suggested that the projected

* Author to whom correspondence should be addressed. On leave in 1996 from the National Center for Atmospheric Research, Boulder, CO, U.S.A.

$\dagger$ Also at the National Center for Atmospheric Research, Boulder, CO, U.S.A. fleet of supersonic aircraft, which would release large amounts of $\mathrm{NO}_{x}$, had the potential to destroy large amounts of stratospheric ozone, and hence to produce a major environmental threat. Studies conducted in the 1970s within the U.S. Climatic Impact Assessment Program (CIAP), the French Comite sur les Conséquences des Vols Stratosphériques (COVOS), and the British Committee on the Meteorological Effects of Stratospheric Aircraft (COMESA), attempted to quantify these effects. Our understanding of the chemical and dynamical processes occurring in the stratosphere has, however, improved so dramatically over the last decades that the conclusions reached 20 years ago are no longer fully valid and need to be reconsidered.

Since the late 1980s, concern has been expressed over the atmospheric impact of the current (and future) fleet of subsonic aircraft. Assessments performed within WMO/UNEP $(1992,1995)$ revealed that the state of knowledge was inadequate to assess the impact of aviation emissions conclusively. Therefore several national and international projects were initiated in Europe (see e.g. Held, 1990; Schumann, 1990; Johnson et al., 1992; Beck et al., 1992; ANAE, 1994; Deutscher Bundestag, 1994; ANCAT, 1995; Gardner et al., 1997a; Schumann, 1997, etc.). Starting in 1992, scientific investigations were carried out under the sponsorship of the European Commission (EC) (Amanatidis and Angeletti, 1997). Similar initiatives have taken place in the United States primarily within the Atmospheric Effects of Aviation Project (AEAP) sponsored by NASA. The AEAP's Subsonic Assessment (SASS) project is assessing the atmospheric effects of current and future world fleets of subsonic aircraft. Both European and American programmes have highlighted our limited understanding of the physical and chemical processes occurring in the 
upper troposphere and lower stratosphere where these aircraft are flying. The magnitude of the atmospheric changes caused by aircraft emissions depends not only on these anthropogenic perturbations, but also on natural sources and processes which are not yet well quantified.

In response to the requests expressed by governments and industry, scientific reports and assessments on the potential impacts of current and future fleets of aircraft have been produced (UNEP/WMO, 1995; IPCC, 1996) or are being prepared with the involvement of several international organisations (UNEP, WMO, IPCC, and ICAO). The purpose of this report prepared on behalf of the European Commission is to review our current understanding of chemical and dynamical processes in the upper troposphere and lower stratosphere, and to assess how these processes could be perturbed as a result of current and future aircraft emissions. Specifically, perturbations in the atmospheric abundance of ozone and in climate forcing, as predicted by atmospheric models, will be presented. Our goal is to compile and evaluate scientific information related to the atmospheric impact of subsonic and supersonic aircraft emissions and to review the state of knowledge concerning the various aspects of this problem.

In the next section of this report, the issues and scientific questions relevant to the problem of aircraft perturbations will be presented. The key physical and chemical processes occurring in the troposphere and stratosphere will be discussed in Section 3. Estimates of air traffic and aircraft emissions will be given in Section 4. Sections 5 and 6 will review our understanding of the atmospheric impact of aircraft emissions at small and large scale, respectively. The effect of aircraft emissions on climate forcing will be discussed in Section 7. Finally, conclusions will be provided in Section 8.

\section{THE ISSUES}

Aircraft engines release in the troposphere and lower stratosphere a number of chemical compounds which could potentially affect the ozone layer and contribute to climate change. The largest fraction of these effluents is released over Europe, the North American continent, and the North Atlantic corridor between 10 and $12 \mathrm{~km}$ altitude. The global amount of chemical compounds emitted by current and future fleets of subsonic and supersonic aircraft [carbon dioxide $\left(\mathrm{CO}_{2}\right)$, water $\left(\mathrm{H}_{2} \mathrm{O}\right)$, nitrogen oxides $\left(\mathrm{NO}_{x}\right)$, hydrocarbons $(\mathrm{HC})$, sulphur dioxide $\left(\mathrm{SO}_{2}\right)$, sulphate and soot particles], as well as their geographical distribution has been estimated, but significant uncertainties remain with reference to particles. The largest fraction of the engine effluents is injected in the troposphere, where current aircraft operate most of the time. However, since the cruising altitude of commercial aircraft is $30-40 \%$ of the time above the tropo- pause, emissions of combustion products within the stratosphere must also be considered. The impact of aircraft operations in these two atmospheric regions will be considered in this report.

Over the last decades, air traffic has increased substantially, but, as a result of improving technologies, fuel consumption and pollutant emissions by aircraft engines has increased less rapidly than traffic. These emissions must be compared with known natural sources of the corresponding chemical compounds, but here again, large uncertainties are associated with these sources.

Carbon dioxide is one of the gases released to the atmosphere by aircraft engines. This compound traps infra-red terrestrial radiation and, therefore, is believed to enhance the greenhouse effect. However, the current worldwide aircraft fleet produces only $2-3 \%$ of the fossil fuel $\mathrm{CO}_{2}$ released in the atmosphere, so that the impact of aviation on greenhouse warming through $\mathrm{CO}_{2}$ is expected to be limited, at least under present conditions. However, the relative contribution of aircraft $\mathrm{CO}_{2}$ could evolve in the future as air traffic is increasing by $5-6 \%$ per year and the corresponding fuel consumption by $3-4 \%$ per year.

The impact on the atmosphere of water released by aircraft engines could be more significant. Contrails (visible as linear clouds in satellite data) cover about $0.4 \%$ of the sky over Central Europe and about $1 \%$ of the sky over the North Atlantic ocean (annual average). These numbers have to be compared with the $20 \%$ cover by natural cirrus clouds. Although the direct greenhouse effect by water vapour emitted by aircraft seems to be negligible, the radiative effect of the contrails could be significant, although not well quantified. Thin contrails are expected to warm the Earth's system, while thick contrails probably lead to cooling. The release of water by aircraft could also enhance the frequency of occurrence of polar stratospheric clouds in the stratosphere. These clouds provide sites on which heterogeneous reactions take place, and are responsible for nitrogen oxide conversion and chlorine activation in polar regions and ozone destruction.

The release by aircraft engines of solid particles or liquid aerosols in the atmosphere (sulphates, soot) coupled to the release of water could affect the radiative balance in the vicinity of the tropopause. In addition to their direct radiative effect, and their role in cloud formation, these particles may enhance significantly the importance of heterogeneous chemistry and could lead to ozone depletion in the lower stratosphere. Heterogeneous chemistry in the troposphere is not well understood, and needs to be further investigated.

Nitrogen oxides which are also released by aircraft are of particular importance, since they have the potential to modify the abundance of ozone in the upper troposphere/lower stratosphere, and hence to further perturb radiative forcing on the climate system. 
Although there is no unambiguous observational evidence for changes in the ozone abundance caused by aircraft operations, models indicate that such changes could occur. In the middle stratosphere, nitrogen oxides destroy ozone through a well-established catalytic cycle, and interact with other chemical families (hydrogen, chlorine, bromine). In the troposphere and lower stratosphere, the presence of nitrogen oxides and hydrocarbons leads to ozone production.

Recent model calculations which account for heterogeneous chemistry on aerosol particles in the lower stratosphere suggest smaller effects on ozone than thought a few years ago. The impact of $\mathrm{NO}_{x}$ (e.g. by a future fleet of supersonic aircraft) on stratospheric ozone will depend, however, on the future abundance of halogen compounds in the atmosphere. In the upper troposphere, however, the current fleet of commercial aircraft may already have increased the abundance of nitrogen oxides in the northern hemisphere by a substantial amount with significant increases in the concentration of upper tropospheric ozone. Ozone itself is an important greenhouse gas, whose radiative forcing efficiency is strongest near the tropopause. It is also a strong oxidant and a source of hydroxyl radicals which destroy pollutants such as hydrocarbons and carbon monoxide in the atmosphere. Changes in the column abundance of ozone is expected to modify the biological doses of harmful solar ultraviolet radiation reaching the Earth's surface: stratospheric ozone depletion could therefore have a damaging effect on the biosphere and cause an increasing number of human skin cancers.

Although much work has been carried out in the past to quantify the perturbations associated with the operation of commercial subsonic and supersonic aircraft in the atmosphere, a large number of uncertainties remain and need to be addressed (see Fig. 1). One major concern is the potential for redistribution of ozone in the upper troposphere and lower stratosphere, leading to changes in the Earth's climate. A second concern is related to the climatic impact of increasing abundances and changing size distributions of particles released by aircraft in the atmosphere with potential changes in cloudiness and in the related radiative balance.

To address these issues, our understanding of the natural processes occurring in the troposphere and lower stratosphere needs to be improved. For example, it is crucial to gain a better understanding of the mechanisms that govern the dispersion (and hence the lifetime) of aircraft effluents and specifically smallscale transport processes in the altitude range where aircrafts are operating. In this regard, the exchanges of mass through the tropopause and other atmospheric barriers need to be understood in detail. The factors that determine the budget of key chemical constituents in the upper troposphere/lower stratosphere also require more attention. For example, the relative

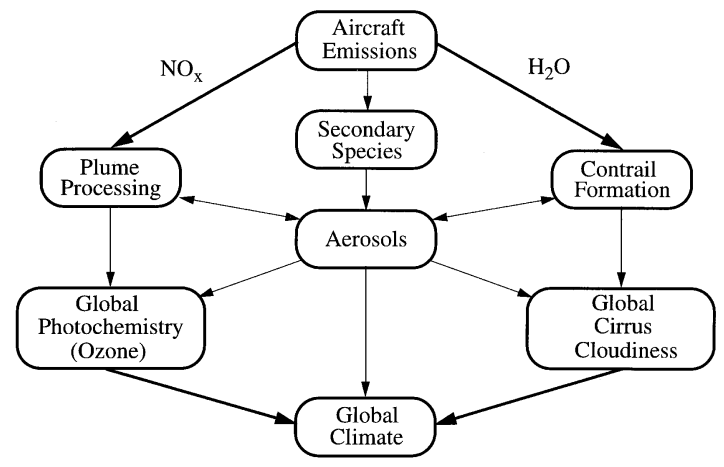

Fig. 1. Major potential impacts of aircraft emissions.

strength of the $\mathrm{NO}_{x}$ sources from aircraft engines and from lightning discharges remains poorly understood, which limits our ability to quantify the impact of aircraft on tropospheric ozone. In addition, the distribution of the $\mathrm{NO}_{x}$ compounds from sources other than aircraft, which is highly variable in space and time, is poorly known, despite their importance in the ozone budget. It is therefore important to study through field observations the behaviour of chemical compounds in the vicinity of the tropopause, and to conduct laboratory work to assess, for example, the importance of heterogeneous chemical conversions on atmospheric particles. Models are crucial for the interpretation of these data and for predictions of future climatic changes. A major emphasis should be on model evaluation through comparison of model results against available observations.

Table 1 summarises the environmental issues associated with aircraft operations in the troposphere and stratosphere. In the next sections of this report, the most important of these issues will be reviewed and discussed in more detail. This will build on the knowledge presented in earlier assessments. The emphasis will be on recent estimates of current and future aircraft emissions, small- and medium-scale dispersion of engine effluents, and on model assessment of aircraft impact on the atmospheric ozone and climate. The next section will present our understanding of chemical and dynamical processes in the background atmosphere.

\section{PHYSICS AND CHEMISTRY OF THE ATMOSPHERE}

\subsection{Introduction}

In order to assess the impacts of pollutants on the atmosphere and consequent changes to climate and the environment at the surface of the Earth, there is a need to understand the physical and chemical processes occurring in the natural atmosphere and the coupling between them which constitutes the Earth's atmospheric system. Emissions from the current fleet of aircraft are injected mainly into the free troposphere and to an increasing extent into the 
Table 1. Major potential impact of chemical compounds released by aircraft in the troposphere and stratosphere

\begin{tabular}{|c|c|}
\hline $\mathrm{CO}_{2}$ & IR radiative forcing and associated climate impact \\
\hline \multirow[t]{4}{*}{$\mathrm{H}_{2} \mathrm{O}$} & IR radiative forcing and associated climate impact \\
\hline & Formation of contrails and cirrus clouds and associated climate impact \\
\hline & Formation of polar stratospheric clouds and related impact on heterogeneous chemistry \\
\hline & Source of $\mathrm{HO}_{x}$ and impact on atmospheric chemistry \\
\hline \multirow{5}{*}{$\mathrm{NO}_{x}$} & Formation of ozone in the upper troposphere and associated climate impact \\
\hline & Increase in the abundance of tropospheric $\mathrm{OH}$ \\
\hline & Enhanced catalytic ozone destruction in the middle stratosphere and associated climate impact \\
\hline & Reduction in stratospheric ozone depletion by $\mathrm{HO}_{x}, \mathrm{ClO}_{x}, \mathrm{BrO}_{x}$ and associated climate impact \\
\hline & $\begin{array}{l}\text { Conversion to } \mathrm{HNO}_{3} \text { and formation of type I polar stratospheric clouds with potential chlorine } \\
\text { activation and ozone depletion }\end{array}$ \\
\hline \multirow[t]{3}{*}{ Hydrocarbons } & Formation of tropospheric ozone \\
\hline & Conversion of $\mathrm{ClO}_{x}$ to $\mathrm{HCl}$ \\
\hline & Conversion of $\mathrm{NO}_{x}$ to PAN \\
\hline $\mathrm{CO}$ & Perturbation in tropospheric ozone and $\mathrm{HO}_{x}$ budgets \\
\hline \multirow[t]{3}{*}{ Soot } & Condensation nuclei and ice kernels \\
\hline & Increased surface area for heterogeneous reactions \\
\hline & Radiative absorber and associate climate impact \\
\hline \multirow[t]{5}{*}{$\mathrm{SO}_{2}$} & Source of $\mathrm{H}_{2} \mathrm{SO}_{4}$ in young plume \\
\hline & Source of sulphate aerosols and associated climate impact \\
\hline & Change in cirrus cloud properties and related climate impact \\
\hline & Activation of soot as cloud condensation nuclei and ice nuclei \\
\hline & Increase in particle surface area with $\mathrm{NO}_{x}$ reduction, chlorine activation and ozone depletion \\
\hline
\end{tabular}

stratosphere which are both regions of major concern for both climate impact and the surface environment. Because most of the ozone column resides in the lower stratosphere, small changes in ozone abundance in the low stratosphere, occurring as a result of $\mathrm{NO}_{x}$ injection, could have a large impact on the surface UV flux. In addition, because of the radiative properties and temperature structure of the atmosphere, changes in ozone have their largest impact on climate when they occur in the upper troposphere and lower stratosphere. Similarly, the impact of water and aerosols is also important at these altitudes because these material are in low abundance and have slow cycling times in this region of the atmosphere. Although great progress has been made in recent years towards the quantitative understanding of the atmospheric processes in the middle atmosphere and in the Earth's boundary layer, the region of the lower stratosphere and upper troposphere, in which significant trends, for example in ozone, have already been observed globally, is poorly understood.

The objective of this section is to summarise what is known about the basic structure of the atmosphere, the physical and chemical processes which control its composition, and the likely effect of certain pollutants on that composition, with particular reference to the regions of the atmosphere impacted by aircraft. The chemical coupling between the various families of trace gases, including those emitted from aircraft, is described. The details and specific effects of some of the pollutants from aircraft, which are topics of current research and at this point in time is somewhat speculative and is largely derived from models which have not been validated, are not discussed in detail. In Section 6, model calculations which utilise the best available knowledge of the science have been used to assess the impact of specified scenarios for current and future aviation operations.

\subsection{Temperature structure of the atmosphere}

In the absence of motions, the thermal structure of the atmosphere is determined by a balance between heating by absorption of solar radiation and cooling by terrestrial emission in the infra-red. Large departures from this simple balance are induced by dynamics, which are discussed in more detail in Section 3.5.

Figure 2 shows the variation of temperature with height in the atmosphere. Boundaries between different atmospheric regions are marked by sharp changes in the temperature variation (or lapse rate) with height. The stratosphere is heated from above mainly by the absorption by ozone of solar ultraviolet radiation. The troposphere is heated mainly from below by convective transport and thermal radiation emitted from the Earth's surface. Convection is triggered in the troposphere because warm air in contact with the ground underlies colder air aloft. In the stratosphere, on the other hand, convection is suppressed so chemicals reside there longer than they do in the troposphere.

The upper troposphere/lower stratosphere (UT/ LS), which is the focus of this review, lies between 8 and $25 \mathrm{~km}$ altitude. The boundary between the troposphere and the stratosphere lies at about 9-12 km at mid-latitudes, depending on season, and at about $17 \mathrm{~km}$ in the tropics. Transfer of material between the two regions, termed stratosphere/troposphere exchange, is a complex process but broadly net transport from troposphere to stratosphere occurs predominantly at low latitudes with net downward transport at high latitudes. Since a large fraction of aircraft operations is taking place in the vicinity of the 


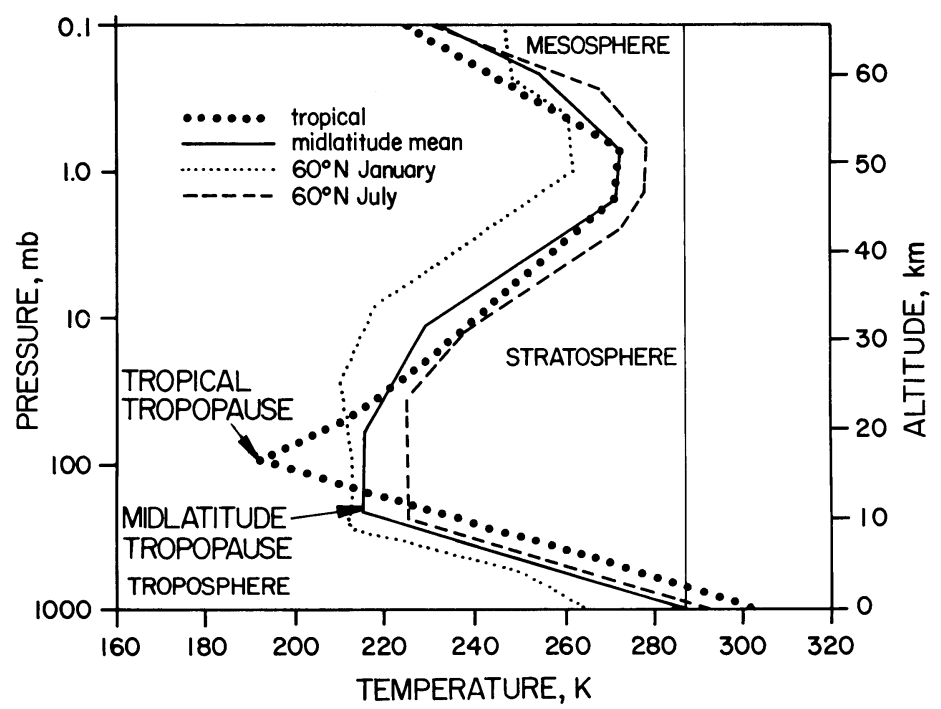

Fig. 2. The vertical profile of mean temperature and its use to define the troposphere and the stratosphere at different latitudes (from SORG, 1988).

Table 2. Mean composition of the troposphere and typical trace gas lifetimes

\begin{tabular}{|c|c|c|c|}
\hline Species & Formula & $\begin{array}{l}\text { Volume mixing } \\
\text { ratio }\end{array}$ & Lifetime \\
\hline Nitrogen & $\mathrm{N}_{2}$ & 0.781 & $1.5 \times 10^{7} \mathrm{yr}$ \\
\hline Oxygen & $\mathrm{O}_{2}$ & 0.209 & $4000 \mathrm{yr}$ \\
\hline \multirow[t]{2}{*}{ Water vapour } & $\mathrm{H}_{2} \mathrm{O}$ (surface) & 0.01 & Days \\
\hline & $\mathrm{H}_{2} \mathrm{O}$ (tropopause) & $10 \mathrm{ppmv}$ & Weeks \\
\hline Argon & $\mathrm{Ar}$ & $9.3 \times 10^{-3}$ & Accumulates \\
\hline Carbon dioxide & $\mathrm{CO}_{2}$ & $360 \mathrm{ppmv}$ & $50-200 \mathrm{yr}$ \\
\hline Methane & $\mathrm{CH}_{4}$ & $1.73 \mathrm{ppmv}$ & $9 \mathrm{yr}$ \\
\hline Nitrous oxide & $\mathrm{N}_{2} \mathrm{O}$ & 313 ppbv & $130 \mathrm{yr}$ \\
\hline \multirow[t]{2}{*}{ Ozone } & $\mathrm{O}_{3}$ (surface) & $5-50 \mathrm{ppbv}$ & Weeks \\
\hline & $\mathrm{O}_{3}$ (tropopause) & 100 ppbv & Months \\
\hline \multirow[t]{2}{*}{ Carbon monoxide } & $\mathrm{CO}$ (surface) & $50-200$ ppbv & 2 months \\
\hline & CO (tropopause) & $50-100 \mathrm{ppbv}$ & $0.05 \mathrm{yr}$ \\
\hline Nitrogen oxides & $\mathrm{NO}_{x}$ (surface) & $0.01-1 \mathrm{ppbv}$ & Days \\
\hline$\left(\mathrm{NO}_{x}=\mathrm{NO}+\mathrm{NO}_{2}\right)$ & $\mathrm{NO}_{\mathrm{x}}$ (tropopause) & $0.05-0.5 \mathrm{ppbv}$ & Weeks \\
\hline \multirow[t]{2}{*}{ Sulphur dioxide } & $\mathrm{SO}_{2}$ (surface) & $0.01-1 \mathrm{ppbv}$ & Days \\
\hline & $\mathrm{SO}_{2}$ (tropopause) & $10-50 \mathrm{pptv}$ & Weeks \\
\hline
\end{tabular}

tropopause, a good understanding of stratospheretroposphere exchanges is required to assess the fate of aircraft effluents. More detailed discussion of the basic radiative dynamical and transport features are given in Section 3.5.

\subsection{Chemistry of the troposphere}

3.3.1. Oxidation processes and $\mathrm{O}_{3}$ formation. The atmosphere is an oxidising environment, ultimately due to the abundance of $\mathrm{O}_{2}$ from photosynthetic activity (Table 2). However, molecular oxygen is relatively inert, and the oxidation capacity is exerted through the formation of ozone (e.g. Isaksen, 1988).

In fact, the atmospheric lifetimes of many trace gases are determined by hydroxyl radicals, which are formed through the photolysis of ozone by ultraviolet radiation in the presence of water vapour:

$$
\begin{aligned}
\mathrm{O}_{3}+h v(<315 \mathrm{~nm}) & \rightarrow \mathrm{O}\left({ }^{1} \mathrm{D}\right)+\mathrm{O}_{2} \\
\mathrm{O}\left({ }^{1} \mathrm{D}\right)+\mathrm{H}_{2} \mathrm{O} & \rightarrow 2 \mathrm{OH} .
\end{aligned}
$$

Only $10 \%$ of the atmospheric ozone column occurs in the troposphere; however, through the formation of $\mathrm{OH}$ it controls the atmospheric oxidation efficiency and the lifetime of most surface emitted trace gases. These reactions limit the $\mathrm{OH}$ lifetime to a few seconds. On a global scale, about three-quarters of all $\mathrm{OH}$ reacts with carbon monoxide and most of the rest with methane. Destruction of $\mathrm{CO}$ and hydrocarbons by $\mathrm{OH}$ initiates radical reaction sequences in which ozone is formed and $\mathrm{OH}$ is replenished in the presence of $\mathrm{NO}_{x}$. Main reaction pathways are thus 
initiated by:

$$
\begin{gathered}
\mathrm{CH}_{4}+\mathrm{OH}\left(+\mathrm{O}_{2}\right) \rightarrow \mathrm{CH}_{3} \mathrm{O}_{2}+\mathrm{H}_{2} \mathrm{O} \\
\mathrm{CH}_{3} \mathrm{O}_{2}+\mathrm{NO} \rightarrow \mathrm{CH}_{3} \mathrm{O}+\mathrm{NO}_{2} .
\end{gathered}
$$

Subsequent to these reactions, photolysis of $\mathrm{NO}_{2}$ by visible light releases the $\mathrm{NO}$ again. This leads to the formation of ozone, which in turn can yield $\mathrm{OH}$ via reactions (3.1) and (3.2):

$$
\begin{gathered}
\mathrm{NO}_{2}+h v(\lambda<420 \mathrm{~nm}) \rightarrow \mathrm{NO}+\mathrm{O} \\
\mathrm{O}+\mathrm{O}_{2}+\mathrm{M} \rightarrow \mathrm{O}_{3}+\mathrm{M} .
\end{gathered}
$$

M symbolises a third molecule (usually $\mathrm{N}_{2}$ or $\mathrm{O}_{2}$ ) that dissipates excess energy. The recurrent release of NO from $\mathrm{NO}_{2}$ in atmospheric oxidation processes, through reaction (3.5), causes $\mathrm{NO}_{x}$ to act catalytically in the formation of ozone. Further, the reaction intermediate $\mathrm{CH}_{3} \mathrm{O}$ from reaction (3.4) reacts to form formaldehyde $\left(\mathrm{CH}_{2} \mathrm{O}\right)$, which can photodissociate or react with $\mathrm{OH}$ and produce $\mathrm{HO}_{2}$ radicals:

$\mathrm{CH}_{3} \mathrm{O}+\mathrm{O}_{2} \rightarrow \mathrm{CH}_{2} \mathrm{O}+\mathrm{HO}_{2}$

$\mathrm{CH}_{2} \mathrm{O}+h v(\lambda<360 \mathrm{~nm})\left(+2 \mathrm{O}_{2}\right) \rightarrow 2 \mathrm{HO}_{2}+\mathrm{CO}$

$$
\mathrm{CH}_{2} \mathrm{O}+\mathrm{OH}\left(+\mathrm{O}_{2}\right) \rightarrow \mathrm{HO}_{2}+\mathrm{H}_{2} \mathrm{O}+\mathrm{CO} \text {. }
$$

The hydroperoxy radicals $\left(\mathrm{HO}_{2}\right)$ from reactions (3.7)-(3.9) can react with $\mathrm{NO}$ to form $\mathrm{NO}_{2}$, hence $\mathrm{O}_{3}$, which directly and indirectly (through $\mathrm{O}_{3}$ photolysis) regenerates $\mathrm{OH}$ :

$$
\begin{gathered}
\mathrm{HO}_{2}+\mathrm{NO} \rightarrow \mathrm{OH}+\mathrm{NO}_{2} \\
\mathrm{NO}_{2}+\mathrm{h} v(\lambda<420 \mathrm{~nm}) \rightarrow \mathrm{NO}+\mathrm{O} \\
\mathrm{O}+\mathrm{O}_{2}+\mathrm{M} \rightarrow \mathrm{O}_{3}+\mathrm{M} .
\end{gathered}
$$

The final reaction product from hydrocarbon and $\mathrm{CO}$ oxidation in the atmosphere is carbon dioxide:

$$
\mathrm{CO}+\mathrm{OH}\left(+\mathrm{O}_{2}\right) \rightarrow \mathrm{CO}_{2}+\mathrm{HO}_{2} .
$$

This reaction also yields $\mathrm{HO}_{2}$ that converts $\mathrm{NO}$ into $\mathrm{NO}_{2}$ and thus contributes to $\mathrm{O}_{3}$ formation and regeneration of $\mathrm{OH}$ [reactions (3.10), (3.5)-(3.6)].

It should be emphasised that the above reaction scheme assumes the presence of nitrogen oxides, which are also destroyed by photochemical oxidation. A dominant $\mathrm{NO}_{x}$ destruction reaction is with $\mathrm{OH}$, leading to the formation of nitric acid:

$$
\mathrm{NO}_{2}+\mathrm{OH}+\mathrm{M} \rightarrow \mathrm{HNO}_{3}+\mathrm{M} \text {. }
$$

An additional important $\mathrm{NO}_{x}$ removal mechanism is heterogeneous destruction on wet surfaces, in particular of cloud droplets and aerosols (Dentener and Crutzen, 1993). This mechanism is initiated by the formation of nitrate radicals:

$$
\begin{gathered}
\mathrm{NO}_{2}+\mathrm{O}_{3} \rightarrow \mathrm{NO}_{3}+\mathrm{O}_{2} \\
\mathrm{NO}_{3}+\mathrm{NO}_{2} \rightleftharpoons \mathrm{N}_{2} \mathrm{O}_{5} \quad(T \text { dependent }) \\
\mathrm{N}_{2} \mathrm{O}_{5}+\mathrm{H}_{2} \mathrm{O}(\mathrm{aq}) \rightarrow 2 \mathrm{HNO}_{3} .
\end{gathered}
$$

Since $\mathrm{NO}_{3}$ radicals rapidly photodissociate during daylight, heterogeneous $\mathrm{NO}_{x}$ removal is only significant during the night. Further, $\mathrm{N}_{2} \mathrm{O}_{5}$ is thermally unstable, so that its lifetime is longest during winter. In fact, the $\mathrm{NO}_{x}$ lifetime is relatively constant throughout the year in northern mid-latitudes, being dominated by reaction (3.12) during summer and by reactions (3.13)-(3.15) during winter. In relatively polluted environments the aerosol surface reaction (3.15) dominates, while in relatively clean parts of the atmosphere $\mathrm{N}_{2} \mathrm{O}_{5}$ loss on clouds is more important.

In general, $\mathrm{HNO}_{3}$ formation in the troposphere is conceived as a sink for $\mathrm{NO}_{x}$ and $\mathrm{OH}$, because both wet and dry deposition are very efficient $\mathrm{HNO}_{3}$ removal processes. However, its "physical" lifetime increases strongly with altitude so that its "chemical" lifetime gains importance. Hence, in the tropopause region, the lifetime of $\mathrm{HNO}_{3}$ is to a large extent determined by photolysis, e.g. being several weeks in the mid-latitude summer. In addition to in situ $\mathrm{NO}_{x}$ sources such as lightning and aircraft emissions, $\mathrm{HNO}_{3}$ destruction becomes a dominant $\mathrm{NO}_{x}$ source, acting as a "reservoir" species.

In polluted air, a significant fraction of $\mathrm{NO}_{x}$ is captured in peroxyacetyl nitrate (PAN), which is formed in the breakdown of non-methane hydrocarbons:

$$
\mathrm{CH}_{3} \mathrm{COO}_{2}+\mathrm{NO}_{2} \rightleftharpoons \mathrm{CH}_{3} \mathrm{COO}_{2} \mathrm{NO}_{2}
$$

( $T$ dependent).

PAN is thermolabile and the above equilibrium usually tends to the left in the boundary layer. For example, its lifetime is an hour or less during summer. However, if PAN is lofted to the colder-free troposphere by convection, its lifetime can increase by several orders of magnitude. In this case transport distances can be thousands of kilometres. Subsequently, after descent of the air parcel, PAN may become subject to higher temperatures so that it thermally decomposes. In fact, observations indicate that PAN is prevalent in most of the troposphere, in particular in the northern hemisphere (Singh et al., 1990, 1996). Hence, its thermal breakdown can release $\mathrm{NO}_{x}$ in locations remote from source regions and contribute to photochemical ozone formation, although model calculations suggest that this effect is relatively minor in the cold upper troposphere (Moxim et al., 1996).

An additional $\mathrm{NO}_{x}$ reservoir species is pernitric acid $\left(\mathrm{HNO}_{4}\right)$. It is formed by

$$
\mathrm{NO}_{2}+\mathrm{HO}_{2}+\mathrm{M} \rightarrow \mathrm{HNO}_{4}+\mathrm{M} \text {. }
$$

This compound is also thermolabile, so that its mixing ratio near the surface is very small. However, in the cold tropopause region its abundance can be significant (Singh et al., 1996). The $\mathrm{HNO}_{4}$ breakdown at tropopause altitudes is controlled by photolysis and reaction with $\mathrm{OH}$, limiting its lifetime to several days. 
The availability of $\mathrm{NO}_{x}$ is a controlling factor in photochemical $\mathrm{O}_{3}$ formation and the concentration of $\mathrm{OH}$. In particular, at low ambient $\mathrm{NO}_{x}$ mixing ratios emissions of $\mathrm{NO}_{x}$ can enhance $\mathrm{O}_{3}$ production (Liu et al., 1987). Figure 3 shows that both $\mathrm{OH}$ and $\mathrm{O}_{3}$ are efficiently enhanced through $\mathrm{NO}_{x}$ emissions at ambient levels below about $0.1-0.2$ ppbv, while this efficiency reduces at further $\mathrm{NO}_{x}$ increases. Therefore, it is important to accurately determine the amount of $\mathrm{NO}_{x}$ and $\mathrm{NO}_{x}$ reservoir species near the tropopause to quantify photochemical processes and assess the $\mathrm{O}_{3}$ and $\mathrm{OH}$ perturbations caused by aircraft emissions.

Since water vapour concentrations are low in the tropopause region, $\mathrm{OH}$ formation through reactions (3.1) and (3.2) is limited at these altitudes. However, some partly oxygenated higher hydrocarbons, in particular acetone $\left(\mathrm{CH}_{3} \mathrm{COCH}_{3}\right)$, can play an important role in the local $\mathrm{OH}$ budget. Measurements in the free troposphere over the Pacific Ocean indicate that the production and lifetime of these compounds is sufficient to significantly affect the background atmosphere (Singh et al., 1995). Their breakdown through photolysis and oxidation by $\mathrm{OH}$ yields formaldehyde, which constitutes a net radical source through reaction (3.8), i.e.

$$
\begin{gathered}
\mathrm{CH}_{3} \mathrm{COCH}_{3}+h v\left(+2 \mathrm{O}_{2}\right) \rightarrow \mathrm{CH}_{3} \mathrm{COO}_{2}+\mathrm{CH}_{3} \mathrm{O}(3.18) \\
\mathrm{CH}_{3} \mathrm{O}+\mathrm{O}_{2} \rightarrow \mathrm{CH}_{2} \mathrm{O}+\mathrm{HO}_{2} .
\end{gathered}
$$

On the other hand, reaction (3.18) also yields peroxyacetyl radicals which form PAN and sequester $\mathrm{NO}_{x}$ through reaction (3.16). The abundance and fate of oxygenated hydrocarbons may thus affect the $\mathrm{NO}_{x}$ and $\mathrm{OH}$ chemistry near the tropopause which, currently, is an area of active research that is highly relevant for the chemistry of aircraft exhausts.

An additional important anthropogenic component of the troposphere is sulphur dioxide $\left(\mathrm{SO}_{2}\right)$. In fact, the tropospheric budget of reactive sulphur is dominated by anthropogenic emissions, in particular in the northern hemisphere (Langner and Rodhe, 1991). The $\mathrm{SO}_{2}$ oxidation is largely controlled by cloud processes (Penkett et al., 1979). After dissolution and dissociation into $\mathrm{HSO}_{3}^{-}$and $\mathrm{SO}_{3}^{2-}$, the oxidation occurs mostly through $\mathrm{H}_{2} \mathrm{O}_{2}$ and $\mathrm{O}_{3}$ in the aqueous phase, which can be schematically represented by the overall reaction mechanism:

$$
\mathrm{SO}_{2}+\mathrm{H}_{2} \mathrm{O}(\mathrm{aq})+0.5 \mathrm{O}_{2} \rightarrow \mathrm{SO}_{4}^{2-}+2 \mathrm{H}^{+} \text {. }
$$

The sulphate formed is removed by precipitation or released to the gas phase by cloud evaporation (most clouds evaporate rather than precipitate). A relatively small fraction of $\mathrm{SO}_{2}$ in the atmosphere $(\sim 20 \%)$ is oxidised in the gas phase by $\mathrm{OH}$, represented by the overall reaction

$$
\mathrm{SO}_{2}+\mathrm{OH}\left(+\mathrm{H}_{2} \mathrm{O}, \mathrm{O}_{2}\right) \rightarrow \mathrm{H}_{2} \mathrm{SO}_{4}+\mathrm{H}_{2} \mathrm{O}+\mathrm{HO}_{2} .
$$

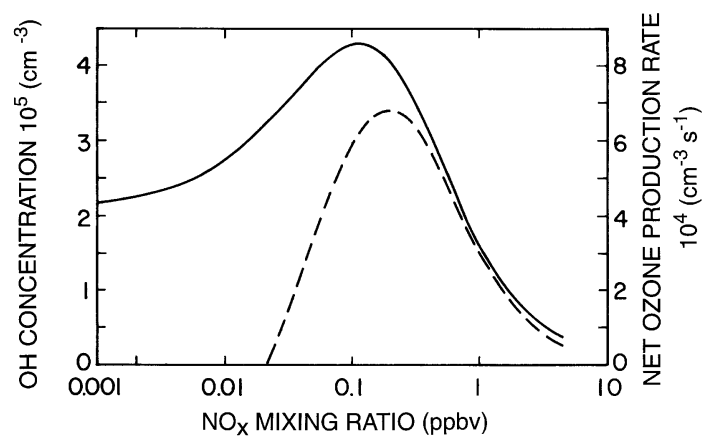

Fig. 3. Model calculated $\mathrm{OH}$ concentration (solid curve) and net photochemical $\mathrm{O}_{3}$ production rate $\left[\mathrm{P}\left(\mathrm{O}_{3}\right)\right]$ (dashed curve) as a function of ambient $\mathrm{NO}_{x}$ (Ehhalt and Rohrer, 1995). Conditions represent the lower mid-latitude troposphere during spring. $\mathrm{OH}$ and $\mathrm{P}\left(\mathrm{O}_{3}\right)$ increase at $\mathrm{NO}_{x}$ mixing ratios up to about $0.1-0.2 \mathrm{ppbv}$, whereas they decrease at further addition of $\mathrm{NO}_{x}$.

Sulphuric acid has a low vapour pressure so that it rapidly condenses onto aerosols or other available surfaces. At low ambient aerosol levels, $\mathrm{H}_{2} \mathrm{SO}_{4}$ nucleates and forms new particles, which is an important aerosol source (in terms of number concentration) in the background atmosphere. Since clouds form on hygroscopic aerosol particles, anthropogenic increases in aerosol number concentrations can affect the number of cloud condensation nuclei, and thus the microphysical and radiative properties of clouds (Twomey et al., 1984). In addition, anthropogenic increases of the aerosol number and mass concentrations enhance the planetary albedo (Charlson et al., 1992). These aerosol effects by sulphur compounds, other condensable species and dust are expected to play an important role in the atmospheric radiation balance (IPCC, 1996). Although these processes are most important in the lower atmosphere, Sassen et al. (1995) drew attention to the possibility that cirrus cloud microphysics can be affected by sulphate particles as well. Nevertheless, the mechanisms of cloud perturbations in the upper troposphere still need to be determined (Baker, 1997).

3.3.2. Trace gas sources and sinks. In recent decades, rapid increases of trace gas concentration have been observed in the atmosphere, being attributed to growing anthropogenic sources (IPCC, 1996; WMO, 1995). Carbon dioxide has increased by about $30 \%$ during the past two centuries to a current level of $360 \mathrm{ppmv}$, to a large extent due to fossil fuel combustion (Table 3). Removal of excess $\mathrm{CO}_{2}$ from the atmosphere partly occurs through ocean uptake, accounting for a loss of $2.0 \pm 0.8 \mathrm{Pg} \mathrm{yr}^{-1}$ (IPCC, 1996). This results in a $\mathrm{CO}_{2}$ lifetime of a few hundred years. It should be emphasised that this refers to removal of $\mathrm{CO}_{2}$ from the atmosphere-climate system, not to the relatively short-term cycling of $\mathrm{CO}_{2}$ between the atmosphere and biosphere. The $\mathrm{CO}_{2}$ lifetime is further reduced by forest regrowth, enhanced terrestrial carbon storage by $\mathrm{CO}_{2}$ fertilisation and nitrogen 
Table 3. Estimated trace gas sources (IPCC, 1994; WMO, 1995; Lee et al., 1997) (Ranges are expressed in parentheses)

\begin{tabular}{|c|c|c|c|c|c|}
\hline Source & $\begin{array}{c}\mathrm{CO}_{2}^{\mathrm{a}} \\
\left(\mathrm{Pg} \mathrm{yr}^{-1}\right)\end{array}$ & $\begin{array}{c}\mathrm{CH}_{4} \\
\left(\mathrm{Tg} \mathrm{yr}^{-1}\right)\end{array}$ & $\begin{array}{c}\mathrm{CO} \\
\left(\operatorname{Tg~yr}^{-1}\right)\end{array}$ & $\begin{array}{c}\mathrm{NMHC} \\
\left(\mathrm{TgC} \mathrm{yr}^{-1}\right)\end{array}$ & $\begin{array}{c}\mathrm{NO}_{x} \\
\left(\mathrm{TgNyr}^{-1}\right)\end{array}$ \\
\hline $\begin{array}{l}\text { Energy use } \\
\text { Aircraft }\end{array}$ & $5.5(5-6)^{b}$ & $100(70-120)$ & $500(300-900)$ & $70(60-100)$ & $\begin{array}{l}22(20-24) \\
0.6(0.4-0.9)\end{array}$ \\
\hline Biomass burning & $1.6(0.6-2.6)^{\mathrm{c}}$ & $40(20-80)$ & $600(400-700)$ & $40(30-90)$ & $8(3-13)$ \\
\hline Vegetation & & & $100(60-160)$ & $500(230-800)$ & \\
\hline Soils & & & & & $7(5-12)$ \\
\hline Lightning & & & & & $5(2-20)$ \\
\hline Enteric fermentation & & $85(65-100)$ & & & \\
\hline Rice paddies & & $60(20-100)$ & & & \\
\hline Animal waste & & $30(20-40)$ & & & \\
\hline Landfills & & $40(20-70)$ & & & \\
\hline $\mathrm{NH}_{3}$ oxidation & & & & & $0.9(0-1.6)$ \\
\hline $\mathrm{N}_{2} \mathrm{O}$ destruction & & & & & $0.6(0.4-1)^{\mathrm{d}}$ \\
\hline Domestic sewage & & $25(20-30)$ & & & \\
\hline Wetlands & & $115(55-150)$ & & & \\
\hline Oceans & & $10(5-50)$ & $50(20-200)$ & $50(20-150)$ & \\
\hline Freshwaters & & $5(1-10)$ & & & \\
\hline Termites & & $20(10-50)$ & & & \\
\hline Total & $7.1(6-8.2)$ & $530(450-620)$ & $1250(780-1960)$ & $660(340-1140)$ & $44(30-73)$ \\
\hline
\end{tabular}

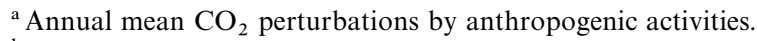

${ }^{\mathrm{b}}$ Includes cement production.

${ }^{\mathrm{c}}$ Includes all forms of land-use change

${ }^{\mathrm{d}} \mathrm{NO}_{y}$ produced in the stratosphere and transported to the troposphere.

deposition, although the contributions by these processes are uncertain by a factor of two. The current rate of $\mathrm{CO}_{2}$ accumulation in the atmosphere is 3-3.5 $\mathrm{Pg} \mathrm{yr}^{-1}$, i.e. an increase of about $0.5 \%$ per year (IPCC, 1996).

Methane is released to a large extent through biogenic processes, being strongly affected by human influences. Biogenic methane emissions are controlled by bacterial production from decay of organic matter under anoxic conditions (methanogenesis) and consumption by methanotrophic organisms. The remaining processes determine the release to the atmosphere from natural soils, rice fields and water columns. In addition, domestic cattle and escape of $\mathrm{CH}_{4}$ from the mining, distribution and use of fossil fuels are important man-made sources (Table 3). Global estimates of source strengths and distributions are highly uncertain, although models can be used to constrain the global $\mathrm{CH}_{4}$ source strength by estimating sink processes. It is known that most methane is destroyed in the atmosphere by its reaction with $\mathrm{OH}(\sim 90 \%)$. A relatively small fraction is removed by bacterial oxidation in aerated soils. Model calculated $\mathrm{OH}$ abundances can be tested through simulations of methyl chloroform, which is also largely controlled by $\mathrm{OH}$, and of which sources and atmospheric distributions are relatively well quantified (Prinn et al., 1995). Thus, a global day-and-night mean $\mathrm{OH}$ concentration of about $10^{6}$ molecules $\mathrm{cm}^{-3}$ has been derived. By also accounting for additional, minor sink processes and the annual methane increase, this constrains the total $\mathrm{CH}_{4}$ source to about 500-600 $\mathrm{Tg} \mathrm{yr}^{-1}$. The $\mathrm{CH}_{4}$ lifetime in the atmosphere is about $9 \mathrm{yr}$.
Source estimates of non-methane hydrocarbons (NMHC) and carbon monoxide are also associated with considerable uncertainty. For example, isoprene and terpene emissions from natural forests may contribute $400-800 \mathrm{TgC} \mathrm{yr}^{-1}$, and $\mathrm{C} 2-\mathrm{C} 6$ hydrocarbon emissions from oceans may amount to 20-150 $\mathrm{TgC} \mathrm{yr}^{-1}$ (WMO, 1995). Unfortunately, indirect constraints of $\mathrm{NMHC}$ and $\mathrm{CO}$ emissions through model calculated $\mathrm{OH}$ oxidation are not yet possible. Due to their short lifetimes of weeks to months the atmospheric distributions of these compounds are highly variable in space and time so that the currently available measurement data sets are insufficient to construct global concentration distributions. The breakdown of $\mathrm{CH}_{4}$ and $\mathrm{NMHC}$ in the atmosphere contributes significantly to the global $\mathrm{CO}$ source, approximately $1000-1500 \mathrm{TgC} \mathrm{yr}^{-1}$. Further, biomass burning is an important source of $\mathrm{CO}$. Although the total amount of carbon consumed in fossil fuel combustion is several times larger compared to biomass burning, incomplete combustion at relatively lower temperatures leads to higher $\mathrm{CO} / \mathrm{CO}_{2}$ ratios in biomass burning exhausts. NMHC and $\mathrm{CO}$ are predominantly removed from the atmosphere by $\mathrm{OH}$ oxidation. A CO fraction of about $10 \%$ is removed by soil uptake, while some soluble reaction intermediates from NMHC oxidation are lost by precipitation.

As indicated in Section 3.3.1, photochemical ozone formation in most of the troposphere is controlled by the catalytic action of $\mathrm{NO}_{x}$. Since the lifetime of $\mathrm{NO}_{x}$ in the lower troposphere is about a day, accurate determination of the three-dimensional source distributions and their strengths is essential. Natural $\mathrm{NO}_{x}$ sources are dominated by soil emissions and 
lightning, both inherently variable in space and time. Much NO is emitted by tropical soils, however, a large fraction is captured by the vegetation before it reaches the atmosphere. The global soil source is estimated at $5-12 \mathrm{TgN} \mathrm{yr}^{-1}$ (Table 3 ). $\mathrm{NO}_{x}$ production from lightning is assumed to be proportional to the convective available potential energy of thunderstorms. Continental thunderstorms have most energy so that lightning $\mathrm{NO}_{x}$ production over land prevails. The total strength of this source has been subject of much debate, yielding estimates varying from 2 to 100 $\mathrm{TgN} \mathrm{yr}^{-1}$. Recent studies have constrained the estimates to below $20 \mathrm{TgN} \mathrm{yr}^{-1}$, while the lower part of the above range, $2-10 \mathrm{TgN} \mathrm{yr}^{-1}$, is considered to be most likely (Lawrence et al., 1995). Another source of $\mathrm{NO}_{x}$ in the upper part of the troposphere is downward transport from the stratosphere in middle and high latitudes, which may contribute $\sim 0.6 \mathrm{TgN} \mathrm{yr}^{-1}$ (Table 3).

In the contemporary atmosphere anthropogenic $\mathrm{NO}_{x}$ emissions, mostly related to fossil fuel use, dominate the global budget of reactive nitrogen (Table 3 ). Biomass burning $\mathrm{NO}_{x}$ releases are also significant, contributing 3-13 $\mathrm{TgN} \mathrm{yr}^{-1}$. Since temperatures are higher in fossil fuel combustion compared to biomass burning, the contribution by $\mathrm{NO}_{x}$ that is formed from molecular oxygen and nitrogen in air is highest in the latter, while both sources emit $\mathrm{NO}_{x}$ from the conversion of organic nitrogen. It should be stressed that the $\mathrm{NO}_{x}$ lifetime is short and transport distances of surface emitted $\mathrm{NO}_{x}$ limited. Hence, the industrialised part of the world and areas of intense biomass burning in the tropics are subject to large atmospheric $\mathrm{NO}_{x}$ perturbations while large areas, e.g. over the remote oceans are still relatively pristine. It follows that aircraft emissions, making up only about $1 \%$ of the total anthropogenic source, can occur in regions that are still unperturbed so that their impact may be comparatively large. Since photochemical $\mathrm{O}_{3}$ formation responds non-linearly to $\mathrm{NO}_{x}$ perturbations, being dependent on the prevailing background $\mathrm{NO}_{x}$ levels, traffic $\mathrm{NO}_{x}$ emissions in the polluted boundary layer have a smaller impact on $\mathrm{O}_{3}$ than aircraft $\mathrm{NO}_{x}$ emissions in the upper troposphere. Nevertheless, $\mathrm{NO}_{x}$ abundances in the tropopause region are not accurately quantified which renders the assessment of aircraft emissions difficult.

\subsection{Chemistry of the stratosphere}

The chemistry of the stratosphere, relating to the photochemical production and catalytic destruction of ozone, is described by a highly complex and coupled system involving a large number of elementary gas-phase reactions (Brasseur and Solomon, 1986; Wayne, 1991). The knowledge of this atmospheric chemistry has developed over the last $25 \mathrm{yr}$, stimulated by concern over the potential threat to the ozone layer from pollutants such as NO emissions from high-flying aircraft and CFCs. In 1985, it was concluded (WMO, 1985) that the basic photochemi- cally driven processes controlling ozone were reasonably well defined, but a number of uncertainties were highlighted, for example where conditions in the atmosphere might favour heterogeneous reactions. The discovery of the Antarctic ozone hole in 1985 (Farman et al., 1985) was not predicted by the theory and indeed surprised the scientific community. Subsequent research has dramatically changed our perception of how ozone is influenced by the interaction of chemical change and dynamical motions in the atmosphere, particularly in the lower stratosphere. In addition to photochemical reactions, an important role for heterogeneous reactions has been identified. At the same time observations have revealed that, apart from the polar ozone depletions in the Antarctic and, more recently in the arctic, there has been a steady decline in global ozone over the past decade or so, which is widely regarded as being a result of chemical destruction by chlorine and bromine pollutants (WMO, 1994).

In the present discussion, the basic gas-phase chemistry operating in the middle and upper stratosphere $(25-55 \mathrm{~km})$ will be summarised, and also the new developments in understanding of the coupling between photochemistry and heterogeneous chemistry occurring on aerosols and polar stratospheric clouds, which is important in the lower stratosphere, especially at high latitudes.

3.4.1. Chemical balance of ozone. Ozone is present in the Earth's atmosphere at all altitudes from the surface up to at least $100 \mathrm{~km}$. The bulk of the ozone resides in the stratosphere with a maximum in concentration at about $25 \mathrm{~km}$ of approximately $5 \times 10^{12}$ molecules $\mathrm{cm}^{-3}$. Its concentration is controlled chemically by a number of other trace species. Table 4 shows a summary of the approximate mixing ratios of the main stratospheric trace constituents in the lower, middle and upper stratosphere. The values are taken from Brasseur and Solomon (1986), and, in the case of lower stratospheric water vapour, from Dessler et al. (1995).

Atmospheric ozone is formed by combination of atomic and molecular oxygen,

$$
\mathrm{O}\left({ }^{3} \mathrm{P}\right)+\mathrm{O}_{2}+\mathrm{M} \rightarrow \mathrm{O}_{3}+\mathrm{M}
$$

where $\mathrm{M}$ is a third body required to carry away the energy and momentum released in the combination reaction. At altitudes above approximately $20 \mathrm{~km}$, the net production of $\mathrm{O}$ atoms results almost exclusively from photodissociation of molecular $\mathrm{O}_{2}$ by short wavelength ultraviolet radiation:

$$
\mathrm{O}_{2}+h v(\lambda<243 \mathrm{~nm}) \rightarrow \mathrm{O}+\mathrm{O}
$$

At lower altitudes and particularly in the troposphere, $\mathrm{O}$ atom formation from the photo-dissociation of nitrogen dioxide by long-wavelength ultraviolet radiation is more important:

$$
\mathrm{NO}_{2}+h v(\lambda<400 \mathrm{~nm}) \rightarrow \mathrm{NO}+\mathrm{O}\left({ }^{3} \mathrm{P}\right) .
$$


Table 4. Approximate trace gas composition of the stratosphere

\begin{tabular}{lccc}
\hline & \multicolumn{3}{c}{ Mixing ratio $(\mathrm{ppb})$} \\
\cline { 2 - 4 } Trace gas & $40 \mathrm{~km}$ & $25 \mathrm{~km}$ & $15 \mathrm{~km}$ \\
\hline $\mathrm{O}_{3}$ & 5100 & 5900 & 89 \\
$\mathrm{~N}_{2} \mathrm{O}$ & 21 & 150 & 300 \\
$\mathrm{NO}$ & 10 & 1.1 & 0.25 \\
$\mathrm{NO}_{2}$ & 3.7 & 1.2 & 0.19 \\
$\mathrm{HNO}_{3}$ & 4.2 & 6.9 & 0.94 \\
$\mathrm{H}_{2} \mathrm{O}$ & 5000 & 3500 & 6000 to 40,000 \\
$\mathrm{OH}$ & 0.12 & $9.5\left(10^{-4}\right)$ & $3.5\left(10^{-5}\right)$ \\
$\mathrm{HO}$ & $9.8\left(10^{-2}\right)$ & $6.7\left(10^{-3}\right)$ & $1.7\left(10^{-4}\right)$ \\
$\mathrm{HCl}$ & 1.4 & 0.81 & 0.06 \\
$\mathrm{ClO}_{\mathrm{ClONO}}$ & 1.0 & 0.04 & - \\
$\mathrm{CH}_{4}$ & $3.0\left(10^{-2}\right)$ & 0.83 & - \\
$\mathrm{CO}$ & 300 & 940 & 1500 \\
$\mathrm{H}_{2}$ & 25 & 20 & 50 \\
& 600 & 500 & 500 \\
\hline
\end{tabular}

Thus, in the lower atmosphere, there is a strong coupling between ozone and nitrogen oxides, and net production of ozone occurs through the reactions discussed in the section on tropospheric chemistry.

Ozone itself is photodissociated by both UV and visible light:

$$
\mathrm{O}_{3}+h v \rightarrow \mathrm{O}_{2}+\mathrm{O}
$$

but this reaction, together with the combination reaction (3.20), only serves to partition the "odd oxygen" species between $\mathrm{O}$ and $\mathrm{O}_{3}$. The processes producing odd oxygen, reactions (3.20) and (3.21), are balanced by chemical and physical loss processes. Until the 1960s, chemical loss of odd oxygen was attributed only to the reaction

$$
\mathrm{O}\left({ }^{3} \mathrm{P}\right)+\mathrm{O}_{3} \rightarrow \mathrm{O}_{2}+\mathrm{O}_{2}
$$

originally proposed by Chapman in 1930. It is now known that ozone in the stratosphere is destroyed predominantly by catalytic cycles involving homogeneous gas-phase reactions of active free radical species in the $\mathrm{HO}_{x}, \mathrm{NO}_{x}, \mathrm{ClO}_{x}, \mathrm{BrO}_{x}$ families:

$$
\begin{gathered}
\mathrm{X}+\mathrm{O}_{3} \rightarrow \mathrm{XO}+\mathrm{O}_{2} \\
\mathrm{XO}+\mathrm{O} \rightarrow \mathrm{XO}+\mathrm{O}_{2} \\
\hline \text { Net: } \mathrm{O}+\mathrm{O}_{3} \rightarrow \mathrm{O}_{2}+\mathrm{O}_{2}
\end{gathered}
$$

where the catalyst $\mathrm{X}$ is $\mathrm{H}, \mathrm{OH}, \mathrm{NO}, \mathrm{Cl}$ and $\mathrm{Br}$. Thus, these species can control the abundance and distribution of ozone in the stratosphere with varying degrees of efficiency depending on the respective rate coefficients of reactions (3.25) and (3.27) and the local abundance of the radicals. Assignment of the relative importance and the prediction of the future impact of these catalytic species are dependent on a detailed understanding of the chemical reactions which form, remove and inter-convert the active components of each family. This in turn requires knowledge of the atmospheric life cycles of the hydrogen, nitrogen and halogen-containing precursor and sink molecules, which control the overall abundance of the $\mathrm{HO}_{x}$, $\mathrm{NO}_{x}$ and $\mathrm{ClO}_{x}$ species. The precursor molecules, e.g. $\mathrm{N}_{2} \mathrm{O}, \mathrm{CFCs}, \mathrm{CH}_{4}$, enter the stratosphere from the troposphere by upward transport, whilst the sink molecules, e.g. $\mathrm{HNO}_{3}, \mathrm{HCl}$ are removed from the stratosphere by downward transport to the troposphere, where they are removed by deposition at the surface, mainly via precipitation.

The balance between the production and destruction of ozone is established rapidly on time scales of less than $1 \mathrm{~d}$ in the upper stratosphere, At lower altitudes the production and loss processes slow down so that at altitudes below about $25 \mathrm{~km}$ the local concentration of ozone is determined primarily by transport. The production of ozone from $\mathrm{O}_{2}$ photolysis becomes negligible at altitudes below $20 \mathrm{~km}$ and destruction by gas-phase chemistry is very slow, except in regions where the chemistry is perturbed, e.g. by heterogeneous reactions in the polar vortex or following volcanic eruptions.

It has proved more difficult to describe adequately both the chemistry and the dynamics in the lower stratosphere. Here the chemistry is complicated by the involvement of temporary reservoir species such as $\mathrm{HCl}, \mathrm{HOCl}, \mathrm{H}_{2} \mathrm{O}_{2}, \mathrm{HNO}_{3}, \mathrm{HNO}_{4}, \mathrm{HO}_{2} \mathrm{NO}_{2}$ and $\mathrm{ClONO}_{2}$ which "store" active radicals and which strongly couple the $\mathrm{HO}_{x}, \mathrm{NO}_{x}$ and $\mathrm{ClO}_{x}$ families. Also heterogeneous reactions involving the reservoir species serve to release active species and add new cycles leading to production and loss of active species. The long photochemical and thermal lifetimes of ozone and the stable reservoir species in this region give rise to a strong interaction between chemistry and dynamics (transport) in the control of the distribution of ozone and other trace gases. Seasonal and latitudinal variability and natural perturbations due to volcanic injections of gases and aerosol particles further complicate the description and interpretation of atmospheric behaviour in this region. Finally, in 
the proximity to the tropopause, exchange of material between the stratosphere and the tropopause occurs, which affects the budgets of the chemical species in this region in a complex fashion. Most of the changes in the predicted effects of chlorofluoromethanes and other pollutants on ozone have resulted from changes in our view of the chemistry in the lower stratosphere, not least the novel chemical processes involved in the polar regions.

3.4.2. Odd hydrogen chemistry. The main reservoir species for $\mathrm{HO}_{x}$ in the stratosphere is water vapour. The main source of water in the middle and upper stratosphere is oxidation of methane which forms two water molecules for each $\mathrm{CH}_{4}$ oxidised. Methane is transported into the stratosphere from the troposphere. Some water vapour is also transported, but this is limited by the very cold temperatures near the tropopause in the upwelling regions. Thus, the driest part of the atmosphere is just above the tropical tropopause.

The active $\mathrm{HO}_{x}$ species are released by reaction of water with excited atomic oxygen:

$$
\mathrm{O}\left({ }^{1} \mathrm{D}\right)+\mathrm{H}_{2} \mathrm{O} \rightarrow 2 \mathrm{OH} .
$$

$\mathrm{O}\left({ }^{1} \mathrm{D}\right)$ is produced throughout the atmosphere by photodissociation of $\mathrm{O}_{3}$ at wavelengths less than $310 \mathrm{~nm}$. Two important $\mathrm{O}_{3}$ destruction cycles involving $\mathrm{HO}_{x}$ occur. In the upper stratosphere $\mathrm{O}_{3}$ removal is predominantly caused by

$$
\begin{aligned}
& \mathrm{OH}+\mathrm{O}_{3} \rightarrow \mathrm{HO}_{2}+\mathrm{O}_{2} \\
& \mathrm{HO}_{2}+\mathrm{O} \rightarrow \mathrm{OH}+\mathrm{O}_{2}
\end{aligned}
$$

Net: $\mathrm{O}+\mathrm{O}_{3} \rightarrow \mathrm{O}_{2}+\mathrm{O}_{2}$.

In the lower stratosphere, where $\mathrm{O}$ is not so abundant, reaction (3.29) is replaced by

$$
\mathrm{HO}_{2}+\mathrm{O}_{3} \rightarrow \mathrm{OH}+2 \mathrm{O}_{2} \text {. }
$$

Removal of $\mathrm{HO}_{x}$ occurs by the reactions

$$
\begin{gathered}
\mathrm{OH}+\mathrm{HO}_{2} \rightarrow \mathrm{H}_{2} \mathrm{O}+\mathrm{O}_{2} \\
\mathrm{HO}_{2}+\mathrm{HO}_{2} \rightarrow \mathrm{H}_{2} \mathrm{O}_{2}+\mathrm{O}_{2}
\end{gathered}
$$

reaction (3.31) being more important at higher altitudes and $\mathrm{H}_{2} \mathrm{O}_{2}$ formation is important in the troposphere.

3.4.3. Odd nitrogen chemistry. The main source of $\mathrm{NO}_{x}$ in the stratosphere is $\mathrm{N}_{2} \mathrm{O}$ and the reactive species are released by reaction with $\mathrm{O}\left({ }^{1} \mathrm{D}\right)$ :

$$
\mathrm{O}\left({ }^{1} \mathrm{D}\right)+\mathrm{N}_{2} \mathrm{O} \rightarrow 2 \mathrm{NO} .
$$

The following catalytic cycle is the dominant ozone loss process in the middle stratosphere $(25-35 \mathrm{~km})$.

$$
\begin{aligned}
& \mathrm{NO}+\mathrm{O}_{3} \rightarrow \mathrm{NO}_{2}+\mathrm{O}_{2} \\
& \mathrm{NO}_{2}+\mathrm{O} \rightarrow \mathrm{NO}+\mathrm{O}_{2}
\end{aligned}
$$

At lower altitudes, where [O] is lower, photodissociation of $\mathrm{NO}_{2}$ nullifies the odd oxygen removal effect, since ground-state oxygen atoms are produced:

$$
\mathrm{NO}_{2}+h v \rightarrow \mathrm{NO}+\mathrm{O}\left({ }^{3} \mathrm{P}\right) .
$$

In the lower stratosphere and the troposphere, coupling of the $\mathrm{NO}$ chemistry with $\mathrm{HO}_{x}$ chemistry and $\mathrm{CO}$ oxidation, gives rise to the net production of ozone:

$$
\begin{gathered}
\mathrm{HO}_{2}+\mathrm{NO} \rightarrow \mathrm{NO}+\mathrm{OH} \\
\mathrm{OH}+\mathrm{CO}\left(+\mathrm{O}_{2}\right) \rightarrow \mathrm{CO}_{2}+\mathrm{HO}_{2} \\
\mathrm{NO}_{2}+h v \rightarrow \mathrm{NO}+\mathrm{O} \\
\mathrm{O}+\mathrm{O}_{2}+\mathrm{M} \rightarrow \mathrm{O}_{3}+\mathrm{M}
\end{gathered}
$$

$\mathrm{Net}: \mathrm{CO}+2 \mathrm{O}_{2} \rightarrow \mathrm{CO}_{2}+\mathrm{O}_{3}$

The change from net $\mathrm{O}_{3}$ production to net ozone destruction resulting from $\mathrm{NO}_{x}$ chemistry, occurs in the lowermost region of the stratosphere. As with the tropopause height, the location of the changeover point depends on altitude and season. Clearly, this point is crucial in determining the direct influence of aircraft emissions of $\mathrm{NO}_{x}$ on local ozone concentration.

The main reservoir species for NO is nitric acid, which is formed in a reaction that couples the $\mathrm{HO}_{x}$ and $\mathrm{NO}_{x}$ families through the reaction:

$$
\mathrm{OH}+\mathrm{NO}_{2}+\mathrm{M} \rightarrow \mathrm{HNO}_{3}+\mathrm{M} .
$$

Active nitrogen species are only slowly regenerated from $\mathrm{HNO}_{3}$ by photolysis and by reaction with $\mathrm{OH}$ :

$$
\begin{gathered}
\mathrm{HNO}_{3}+h v \rightarrow \mathrm{OH}+\mathrm{NO}_{2} \\
\mathrm{OH}+\mathrm{HNO}_{3} \rightarrow \mathrm{H}_{2} \mathrm{O}+\mathrm{NO}_{3} .
\end{gathered}
$$

The coupled $\mathrm{NO}_{x}-\mathrm{HO}_{x}$ schemes also control the abundance of $\mathrm{OH}$ and $\mathrm{HO}_{2}$ in the lower stratosphere, through conversion of active species to $\mathrm{H}_{2} \mathrm{O}$. This is counterbalanced through heterogeneous reactions between $\mathrm{H}_{2} \mathrm{O}$ and $\mathrm{NO}_{x}, \mathrm{ClO}_{x}$ and $\mathrm{BrO}_{x}$ species which lead to photolytic production of $\mathrm{HO}_{x}$.

3.4.4. Odd chlorine chemistry The major source of stratospheric chlorine is the photodissociation of organic chlorine compounds such as methyl chloride, other chlorinated hydrocarbons and chlorofluorocarbons:

$$
\mathrm{RCl}+h v(\lambda<215 \mathrm{~nm}) \rightarrow \mathrm{R}+\mathrm{Cl} .
$$

The ozone destruction cycle involves $\mathrm{Cl}$ and $\mathrm{ClO}$ radicals:

$$
\begin{aligned}
& \mathrm{Cl}+\mathrm{O}_{3} \rightarrow \mathrm{ClO}+\mathrm{N}_{2} \\
& \mathrm{ClO}+\mathrm{O} \rightarrow \mathrm{Cl}+\mathrm{O}_{2}
\end{aligned}
$$

Net: $\mathrm{O}+\mathrm{O}_{3} \rightarrow \mathrm{O}_{2}+\mathrm{O}_{2}$. 
The effect is modified in the presence of $\mathrm{NO}_{x}$ by the reactions

$$
\begin{gathered}
\mathrm{ClO}+\mathrm{NO} \rightarrow \mathrm{Cl}+\mathrm{NO}_{2} \\
\mathrm{NO}_{2}+h v \rightarrow \mathrm{NO}+\mathrm{O}\left({ }^{3} \mathrm{P}\right)
\end{gathered}
$$

which offset the odd oxygen loss in reaction (3.43). Thus, the extent of ozone destruction at a particular altitude by $\mathrm{ClO}_{x}$ depends on the amount of $\mathrm{NO}_{x}$ present. A further important coupling between the chlorine and nitrogen oxides is the formation of chlorine nitrate:

$$
\mathrm{ClO}+\mathrm{NO}_{2}+\mathrm{M} \rightarrow \mathrm{ClONO}_{2}+\mathrm{M} .
$$

This is a typical "temporary reservoir species" (other examples are $\mathrm{N}_{2} \mathrm{O}_{5}, \mathrm{HO}_{2} \mathrm{NO}_{2}, \mathrm{HOCl}$ ) which do not directly participate in odd oxygen destruction catalytic cycles but which serve to tie up active species, thereby reducing the rate of ozone destruction.

The main removal of active chlorine species occurs via the reaction

$$
\mathrm{Cl}+\mathrm{CH}_{4} \rightarrow \mathrm{HCl}+\mathrm{CH}_{3} .
$$

$\mathrm{HCl}$ is the major reservoir species for stratospheric chlorine from which active $\mathrm{Cl}$ is released by reaction with $\mathrm{OH}$ :

$$
\mathrm{OH}+\mathrm{HCl} \rightarrow \mathrm{H}_{2} \mathrm{O}+\mathrm{Cl} .
$$

Some $\mathrm{HCl}$ is transported downwards into the troposphere from where it is removed by rain, thereby completing the atmospheric chlorine cycle.
3.4.5. Polar ozone depletion. The circulation in the winter stratosphere over the polar regions is dominated by the polar vortex, a region of very cold air surrounded by strong westerly winds. This leads to a confinement of the cold air within the vortex and it has been known for many years that the ozone climatology in this region differs from other parts of the atmosphere. However, Farman et al. (1985) showed that in the column ozone in this vortex region had changed in recent years with the development of a deep minimum in column ozone in the early spring. The ozone hole as it became to known has returned every spring with increasing intensity since the mid1980s and in recent years ozone depletion has been observed in the Arctic polar spring. Observations have shown clearly that the ozone loss is due to chemical destruction of ozone in the lower stratosphere, in the region where ozone is normally longlived and its distribution determined by transport processes. These seasonal depletions were completely unexpected and were not predicted or explained by the gas-phase chemical reactions discussed above. These were the first unequivocal changes in global climate brought about by man-made pollutants.

As a result of intensive studies over the past $10 \mathrm{yr}$, a picture is emerging of the sequence of physical and chemical processes which lead to polar ozone depletion.

This picture is illustrated in Fig. 4 and can be summarised briefly as follows: Air from the upper stratosphere is trapped in the polar vortex and sinks

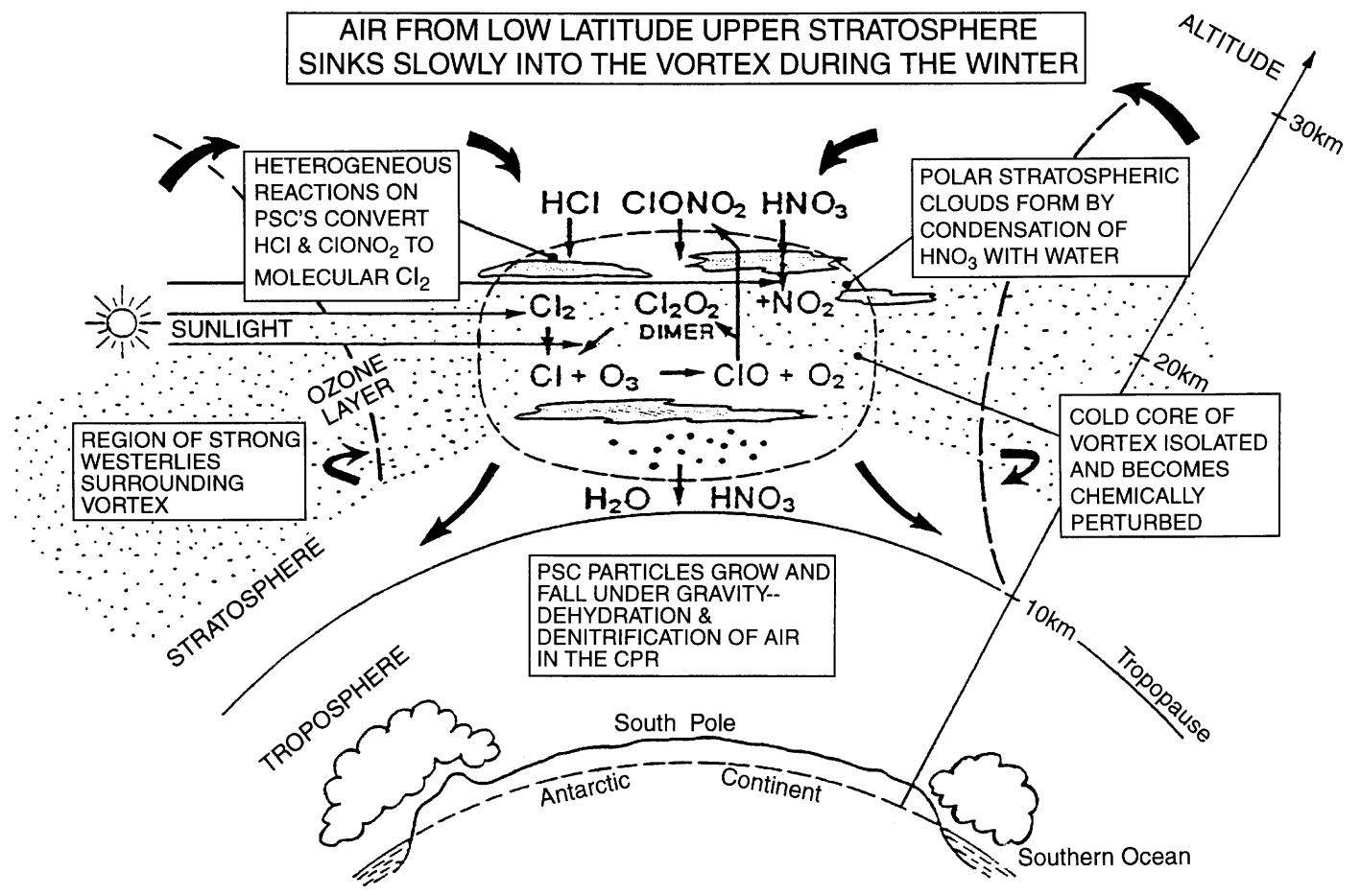

Fig. 4. Formation of the Antarctic "ozone hole". 
slowly during winter. In this air, most of the CFCs have been photochemically decomposed and chlorine is mainly in the form of the reservoir molecules $\mathrm{HCl}$ and $\mathrm{ClONO}_{2}$. As the air in the core of the vortex cools, condensation of water and nitric acid onto stratospheric sulphate particles occurs at about $-80^{\circ} \mathrm{C}$, leading to the formation of polar stratosphere clouds (PSCs), consisting of liquid and solid mixtures of these components. Then, at colder temperatures $\left(-90^{\circ} \mathrm{C}\right)$ when the frost point is reached, larger particles of water-ice are formed.

The surface of the PSCs provides sites for heterogeneous reactions between reservoir species which would otherwise be quite stable. This leads to the creation of new temporary reservoir molecules containing chlorine which are much more sensitive to photochemical decomposition. For example $\mathrm{ClONO}_{2}$ reacts with $\mathrm{HCl}$ on ice surfaces to give molecular chlorine $\left(\mathrm{Cl}_{2}\right)$ and nitric acid which remains in the condensed phase:

$$
\mathrm{ClONO}_{2}+\mathrm{HCl} \text { (surface) } \rightarrow \mathrm{Cl}_{2}+\mathrm{HNO}_{3} \text {. }
$$

When sunlight returns to the polar regions in early spring, photochemical reactions commence but, because of the low sun angles, only visible and near-UV light penetrates into the low stratosphere. Molecules which require higher-energy UV for rapid dissociation, such as $\mathrm{HNO}_{3}$ breaking up to form $\mathrm{NO}_{2}$, are photolysed very slowly but the new chlorine reservoirs (e.g. $\left.\mathrm{Cl}_{2}\right)$ are dissociated readily by visible radiation to give chlorine atoms:

$$
\mathrm{Cl}_{2}+h v \rightarrow \mathrm{Cl}+\mathrm{Cl} \text {. }
$$

The chlorine atoms react with ozone to yield $\mathrm{ClO}$ and, because the NO concentration is very low, the usual reservoir for active chlorine, $\mathrm{ClONO}_{2}$ generated by the fast reaction of $\mathrm{ClO}$ with $\mathrm{NO}_{2}$, is not formed. An excess concentration of $\mathrm{ClO}$ (over $\mathrm{NO}_{2}$ ) can build up, and the high concentrations of $\mathrm{ClO}$ lead to the formation of the dimer, $\mathrm{Cl}_{2} \mathrm{O}_{2}$ in the self-reaction of $\mathrm{ClO}$. Photolysis of the dimer by near UV light releases chlorine atoms again and the whole sequence leads to loss of ozone:

$$
\begin{gathered}
\mathrm{ClO}+\mathrm{ClO}(+\mathrm{M}) \rightarrow \mathrm{Cl}_{2} \mathrm{O}_{2}(+\mathrm{M}) \\
\mathrm{Cl}_{2} \mathrm{O}_{2}+h v(\text { visible }) \rightarrow 2 \mathrm{Cl}+\mathrm{O}_{2} \\
2\left(\mathrm{Cl}+\mathrm{O}_{3} \rightarrow \mathrm{ClO}+\mathrm{O}_{2}\right)
\end{gathered}
$$

$$
\text { Net: } 2 \mathrm{O}_{3} \rightarrow 3 \mathrm{O}_{2} \text {. }
$$

The rate-determining step is the self-reaction of $\mathrm{ClO}$ which is second order in $\mathrm{ClO}$ concentration. Thus, to a first approximation in this highly perturbed atmosphere, ozone loss is proportional to the square of the concentration of $\mathrm{ClO}$, i.e. is highly non-linear. This cycle is now known to be the major cause of ozone loss in the lower stratosphere in polar regions in spring. The time evolution of events is illustrated in Fig. 5.

Note that once the processing by PSCs is terminated as temperatures start to rise, partitioning of the active chlorine into the normal reservoir species begins. First the $\mathrm{ClO}$ is converted to chlorine nitrate via reaction of with $\mathrm{NO}_{2}$ released by the photolysis of nitric acid:

$$
\mathrm{HNO}_{3}+h v \rightarrow \mathrm{OH}+\mathrm{NO}_{2} .
$$

On a longer time scale, chlorine is converted back to the most stable reservoir, $\mathrm{HCl}$, by reaction of $\mathrm{Cl}$ with methane:

$$
\mathrm{Cl}+\mathrm{CH}_{4} \rightarrow \mathrm{HCl}+\mathrm{CH}_{3} .
$$

Other catalytic cycles also contribute to ozone loss in the polar stratosphere, and the most important of these is that involving the reaction of bromine monoxide radicals, $\mathrm{BrO}$, derived from stratospheric breakdown of man-made and natural bromine compounds, with $\mathrm{ClO}$. The key steps are

$$
\begin{gathered}
\mathrm{BrO}+\mathrm{ClO} \rightarrow \mathrm{Br}+\mathrm{Cl}+\mathrm{O}_{2} \\
\mathrm{Br}+\mathrm{O}_{3} \rightarrow \mathrm{BrO}+\mathrm{O}_{2} \\
\mathrm{Cl}+\mathrm{O}_{3} \rightarrow \mathrm{ClO}+\mathrm{O}_{2} \\
\hline \text { Net: } 2 \mathrm{O}_{3} \rightarrow 3 \mathrm{O}_{2} .
\end{gathered}
$$

Considering that $\mathrm{NO}_{2}$ prevents ozone destruction via the above reactions, emissions of $\mathrm{NO}_{x}$ from aircraft flying in the lower stratosphere in polar regions would act to decrease the efficiency of ozone loss by accelerating $\mathrm{ClONO}_{2}$ formation.

3.4.6. Polar stratospheric cloud processes. Polar stratospheric clouds (PSCs) are implicated in polar ozone loss in two distinct ways:

(a) They are thought to provide sites for chemical reactions which convert relatively inert chlorine compounds to highly reactive, ozone-destroying forms.

(b) Sedimentation of cloud particles containing nitric acid removes reactive nitrogen from the lower stratosphere (denitrification), slowing the rate of return of reactive chlorine to inert forms.

Laboratory studies have thrown further light on these processes. The rate of reaction on cloud surfaces is measured as a fraction of the collisions of the gas molecules with the surface of the particles, i.e. the "uptake coefficients" or "sticking coefficients". In the laboratory, sticking coefficients of chlorine nitrate $\left(\mathrm{ClONO}_{2}\right), \mathrm{HCl}$, nitric acid $\left(\mathrm{HNO}_{3}\right)$ and dinitrogen pentoxide $\left(\mathrm{N}_{2} \mathrm{O}_{5}\right)$ have been measured on surfaces of water ice, nitric acid trihydrate (NAT) and liquid sulphuric acid. The results show strong support for the occurrence of fast heterogeneous reactions on PSCs. Laboratory measurements show that $\mathrm{HCl}$ is sufficiently soluble in ice and NAT to enhance its rate of heterogeneous reaction with $\mathrm{ClONO}_{2}$ or $\mathrm{N}_{2} \mathrm{O}_{5}$. 


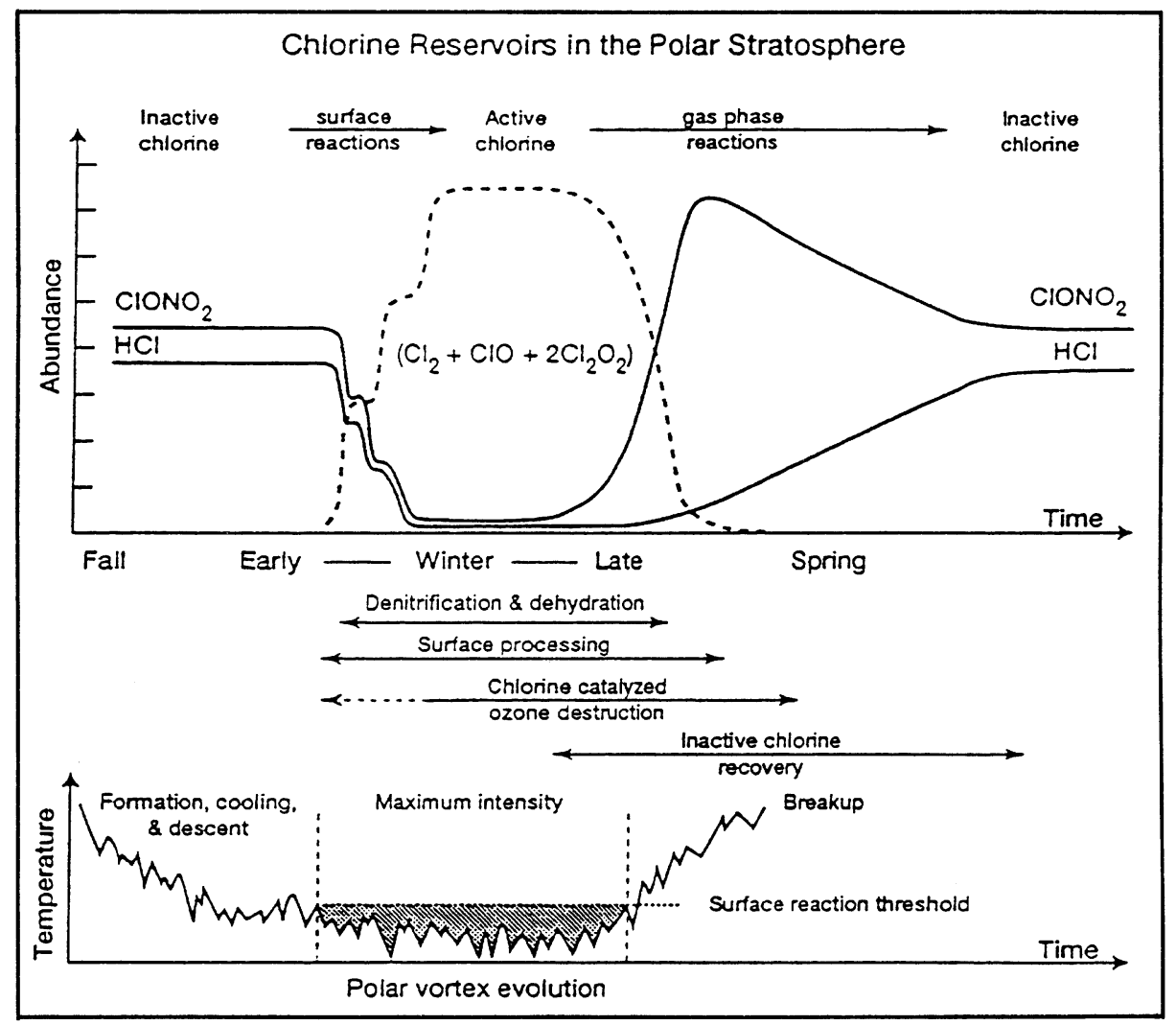

Fig. 5. Time evolution of chlorine activation-deactivation related to polar ozone depletion. The upper panel represented the conversion of chlorine from inactive to active form, and the reformation of inactive forms in spring. The partitioning between active chlorine species, $\mathrm{Cl}_{2}, \mathrm{Cl}_{2} \mathrm{O}_{2}$ and $\mathrm{ClO}$ depends on exposure to sunlight after PSC processing. The corresponding stages in the polar vortex are indicated in the lower panel, where the temperature scale represents changes in the minimum polar temperatures in the lower stratosphere (adapted from Webster et al., 1993).

Laboratory measurements of the vapour pressures of the nitric acid-water system confirm that condensation of NAT can occur at temperatures observed in the polar stratosphere. There is now evidence from stratospheric measurements that nitric acid can condense into cloud particles, but the phase and characteristic of these particles is not well defined. Gravitational settling of the larger ice particles formed at lower temperatures $(<185 \mathrm{~K})$ can occur, depleting air locally of reactive nitrogen and of water vapour. However, the understanding of the processes involved is not adequate to make reliable quantitative predictions of denitrification. A current picture for a PSC condensation/evaporation cycle is summarised in Table 5.

The larger PSC particles can fall under gravity leading to a reduction in the total amount of $\mathrm{HNO}_{3}$ (and water) in the stratosphere. This is important because in the spring, when photochemistry occurs, $\mathrm{NO}_{2}$ which is released by photodissociation of $\mathrm{HNO}_{3}$ inhibits the ozone-depletion reactions involving chlorine monoxide by $\mathrm{ClONO}_{2}$ formation.

Aircraft could influence the PSC processes in several ways. Emissions of $\mathrm{NO}_{x}$ and $\mathrm{H}_{2} \mathrm{O}$ could raise the local supersaturation temperature for condensation of PSCs (Peter et al., 1991). The occurrence of PSCs, and hence chlorine activation, is critically dependent on the frequency with which supersaturation temperatures are reached and even small changes could be significant in Arctic regions. Emission of aerosol particles from aircraft could enhance the number of condensation nuclei present for PSC particles to form. This could enhance the surface area of the PSCs and so accelerate the rate of heterogeneous reactions. This effect, however, has not been quantified and is likely to be more important for heterogeneous reactions at mid-latitudes.

3.4.7. Midlatitude ozone loss. In recent years it has become apparent that ozone loss has occurred in the lower stratosphere in the mid-latitudes in both hemispheres. This is illustrated in Fig. 6 which shows changes in stratospheric ozone levels as a function of altitude over the period 1979-1991. A large number of photochemical and dynamical processes can influence the stratospheric ozone in this region and catalytic chemical destruction is widely believed to be responsible for these changes. Elucidation of the exact cause of these changes has been the subject of a wide range 
Table 5. Condensation processes involving sulphuric acid, nitric acid, hydrogen chloride and water

Temperature

(K)

$<195$

190

185
Cooling/condensation

Warming/evaporation

\author{
Background aerosol $60-70 \% \mathrm{H}_{2} \mathrm{SO}_{4}$ \\ Water uptake on $\mathrm{H}_{2} \mathrm{SO}_{4}$ particles \\ Particles grow by condensation of $\mathrm{H}_{2} \mathrm{O}$ \\ and $\mathrm{HNO}_{3}$ on $\mathrm{H}_{2} \mathrm{SO}_{4} ; \mathrm{HCl}$ uptake \\ Droplets of supercooled ternary solution \\ removing essentially all gas-phase \\ $\mathrm{HNO}_{3}$ (Type Ib PSCs) \\ Ice point - condensation of pure water ice. \\ Growth to larger size; $\mathrm{HCl}$ and $\mathrm{HNO}_{3}$ \\ present in surface layers \\ (Type II PSCs)
}

\author{
SAT sublimation \\ Water evaporation; SAT stability region \\ $\mathrm{HNO}_{3}$ evaporation; NAT sublimation to \\ form SAT \\ Solid NAT removing essentially all \\ gas-phase $\mathrm{HNO}_{3}$ \\ (Type Ia PSCs) \\ Ice point-evaporation of pure water surface \\ reduction in size; $\mathrm{HCl}$ and $\mathrm{HNO}_{3}$ present \\ in surface layers \\ (Type II PSCs)
}

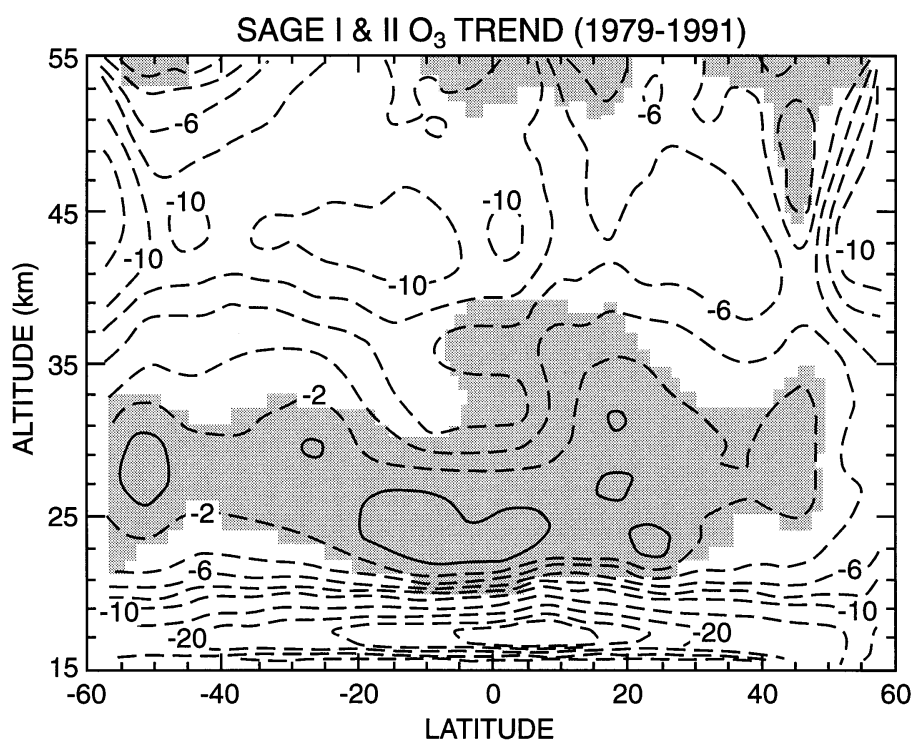

Fig. 6. Changes in stratospheric ozone levels (percent) as a function of altitude over the period 1979-1991. (from WMO, 1995).

of recent observational and modelling studies but is still controversial.

The main gas-phase reactions leading to ozone loss in the mid-latitude lower stratosphere involve the $\mathrm{HO}_{x}$ species. The simple cycle involving reactions (3.28) and (3.30) (see Section 3.4.2) is augmented by the following cycle involving $\mathrm{XO}(\mathrm{X}=\mathrm{Cl}$ or $\mathrm{Br})$ :

$$
\begin{gathered}
\mathrm{XO}+\mathrm{HO}_{2} \rightarrow \mathrm{HOX}+\mathrm{O}_{2} \\
\mathrm{HOX}+h v \rightarrow \mathrm{OH}+\mathrm{X} \\
\mathrm{X}+\mathrm{O}_{3} \rightarrow \mathrm{XO}+\mathrm{O}_{2} \\
\mathrm{OH}+\mathrm{O}_{3} \rightarrow \mathrm{HO}_{2}+\mathrm{O}_{2}
\end{gathered}
$$

$$
\text { Net: } 2 \mathrm{O}_{3} \rightarrow 3 \mathrm{O}_{2} \text {. }
$$

In the contemporary atmosphere the elevated halogen oxide concentration also make the $\mathrm{BrO}$ and $\mathrm{ClO}$ ozone loss cycle [Reactions (3.52), (3.53) and (3.42)] significant at mid-latitudes.

Although stratospheric bromine chemistry is formally similar to chlorine chemistry, the bromine reservoir species $\left(\mathrm{HBr}, \mathrm{BrONO}_{2}, \mathrm{HOBr}\right.$, etc.) are more reactive photo-chemically and in heterogeneous processes than chlorine reservoirs in several important aspects. As a result, $\mathrm{BrO}$ is expected to be the dominant form of bromine in the stratosphere and although there is much less bromine in the stratosphere compared to chlorine, the contribution of $\mathrm{BrO}$ to ozone loss through catalytic processes involving $\mathrm{BrO}+\mathrm{ClO}$ and $\mathrm{BrO}+\mathrm{HO}_{2}$ reactions take on particular importance in the lower stratosphere. Thus, an important contribution is suspected from bromine compounds to the mid-latitude ozone loss. However, these processes with purely gas-phase chemistry are too slow to account for either the observed ozone loss or recently measured concentration of the $\mathrm{NO}_{x}, \mathrm{HO}_{x}$ and $\mathrm{ClO}_{x}$ species in the stratosphere (WMO, 1994). 
Outside the polar regions, the stratospheric aerosol consists mainly of sulphuric acid droplets, which are distributed worldwide in the lower stratosphere. Reaction rates measured on sulphuric acid $\left(\mathrm{H}_{2} \mathrm{SO}_{4}\right)$ surfaces in the laboratory depend strongly on the temperature and the water content, implying more effective heterogeneous reactions when the stratosphere is very cold. These measurements suggest the possibility of heterogeneous reactions on the sulphate aerosol, at latitudes where PSCs are absent. These heterogeneous reactions can effect the chemistry of chlorine, bromine and nitrogen species in a significant way, particularly in periods of high aerosol density following major volcanic eruptions.

Better agreement with observations has been obtained using models in which heterogeneous reactions are included. The key reactions which can take place in sulphuric acid droplets are

$$
\begin{gathered}
\mathrm{N}_{2} \mathrm{O}_{5}+\mathrm{H}_{2} \mathrm{O} \rightarrow 2 \mathrm{HNO}_{3} \\
\mathrm{ClONO}_{2}+\mathrm{H}_{2} \mathrm{O} \rightarrow \mathrm{HOCl}+\mathrm{HNO}_{3} \\
\mathrm{BrONO}_{2}+\mathrm{H}_{2} \mathrm{O} \rightarrow \mathrm{HOBr}+\mathrm{HNO}_{3} .
\end{gathered}
$$

Reaction (3.57) leads indirectly to chlorine activation by conversion of $\mathrm{NO}_{x}$ to $\mathrm{HNO}_{3}$, thus inhibiting $\mathrm{ClONO}_{2}$ formation, which is the main sink for $\mathrm{ClO}$. Reaction 3.58 leads directly to chlorine activation through the photolysis of $\mathrm{HOCl}$ [reaction (3.55); $\mathrm{X}=\mathrm{Cl}]$. The analogous reaction of $\mathrm{BrONO}_{2}$ [reaction (3.59)] leads to rapid cycling through the $\mathrm{BrO}_{x}$ reservoirs and can significantly augment the production of $\mathrm{OH}$ through $\mathrm{HOBr}$ photolysis. Sulphate aerosol amounts are influenced dramatically by volcanic eruptions. The significance of heterogeneous chemistry at mid-latitudes became apparent after the eruption of Mt Pinatubo in June 1991, which caused a 20-fold increase in the stratospheric aerosol concentration. Following this injection of material into the stratosphere, the ratio of $\mathrm{NO}_{x} / \mathrm{NO}_{y}\left(\mathrm{NO}_{y}=\right.$ total reactive nitrogen) was observed to fall to $50 \%$ of prePinatubo level and the ratio $\mathrm{ClO} / \mathrm{ClO}_{y}$ increased by a factor of 2. These observations are consistent with enhanced rates of reactions (3.57) and (3.58), and this chemistry may have contributed to the depletion of ozone seen at mid-latitudes after the eruption of Mt. Pinatubo in 1991.

Winter and spring vortex erosion is an ongoing process leading to the ultimate break up of the vortex, that leads to eventual mixing of vortex air into midlatitudes. In the southern hemisphere, this constitutes a significant flux of ozone-depleted air but nevertheless this dilution is not sufficient to explain the observed mid-latitude loss.

PSC formation is not necessarily restricted to air masses confined to the polar vortices, but can occur in and equatorward of the core of the stratospheric jet stream. Persistent PSCs in such regions can lead to chemical perturbation of large volumes of air that as a result of jet stream meandering can be transported to lower latitudes. Ozone loss in this chemically processed air, by halogen-oxide-mediated catalysis, could lead to reductions in the ozone column in the mid-latitudes.

Nevertheless, attempts to explain quantitatively the trends in lower stratospheric ozone in recent years using models including the above heterogeneous chemistry have not been successful. Ozone loss appears to have been greater than predicted. Several speculative suggestions have been made such as involvement of iodine catalysed ozone loss (Solomon, 1996), reactions on soot particles and on cirrus clouds. The degree to which air processed and/or depleted in ozone in polar regions could influence ozone in the mid-latitude lower stratosphere has also been considered. There remains substantial uncertainty concerning the process and the future evolution of ozone amounts in this region cannot be predicted with confidence.

The region of greatest uncertainly coincides with that where there is a growing extent of aviation activity, which is predicted to increase in the future. The central issue of aircraft emission can potentially influence the level of $\mathrm{NO}_{x}$ and atmospheric particles. Section 6 describes in more detail the results of recent attempts to define the magnitude of these influences and the resultant effects on stratospheric ozone.

\subsection{Radiation, dynamics and transport in the atmosphere}

3.5.1. Radiative properties. The sun emits approximately the electromagnetic spectrum of radiation characteristic of a black-body at a temperature of $5800 \mathrm{~K}$, while the Earth emits at a mean atmospheric temperature of about $245 \mathrm{~K}$. The peak radiative fluxes from these two sources thus occur at well-separated wavelengths in the visible $(400-600 \mathrm{~nm})$ and infrared $(10,000-15,000 \mathrm{~nm}$ or $10-15 \mu \mathrm{m})$. Solar and terrestrial fluxes may thus be treated separately in calculating the heat balance. Accurate calculations of solar heating rates in the atmosphere require knowledge of the incident radiation and the absorption cross-sections of various gases. Knowledge of the spectral irradiance, especially in the solar ultraviolet, has improved in recent years from satellite measurements. There has also been a marked improvement in the accuracy and completeness of the gaseous absorption cross-sections as a function of temperature, based on laboratory measurements.

Uncertainties are greater in the calculation of longwave radiation. In this region, gases have complicated absorption spectra, spectroscopic data is sometimes inaccurate or incomplete and the so-called band spectra, used to circumvent the laborious calculations for individual spectral lines, may be unsatisfactory, especially at higher pressure. Studies of radiative transfer are making rapid advances by the availability of satellite data on ozone, temperature, solar irradiance and terrestrial radiation. These studies are 
a necessary part of the development of predictive capability of models for climate and climate-atmospheric chemistry interactions.

3.5.2. Dynamical processes in the troposphere. The dynamics of the atmosphere is governed by latitudinal differences in incoming solar radiation, leading to redistribution of heat and trace components. Largescale atmospheric motions cause latitudinal exchange by transporting warm air poleward and cold air equatorward. The Earth's rotation causes the Coriolis force which deflects meridional motions in the zonal direction. Together, these forces drive the global Hadley circulation, in which the large-scale mean flow forms distinct cells, i.e. the Hadley, Ferrel and polar cells. Characteristically, easterly surface winds occur near the equator and calm weather in the subtropical high-pressure regions, the latter in the downward branch of the tropical Hadley cells. The trade winds carry moisture to the tropics where a zonal band with deep convective clouds is formed in the intertropical convergence zone (ITCZ).

The action of the Coriolis force increases with latitude, so that the zonal wind component becomes stronger, leading to the mid-latitude westerlies. While in low latitudes atmospheric motions are quite persistent, in mid-to-high latitudes transient synoptic systems dominate, causing highly variable weather. These systems, cyclones and anticyclones, act to reduce the strong latitudinal temperature contrasts and are thus particularly prominent during the winter season. Their appearance near the surface reflects closed-cell-like systems and associated cloudiness. In the middle and upper troposphere, the intermittent cyclones and anticyclones form planetary waves in which air motions are eastward. Near the tropopause, at altitudes between 9 and $15 \mathrm{~km}$, persistent and high wind speeds reach a maximum of $40 \mathrm{~m} \mathrm{~s}^{-1}$ or more in the subtropical jet stream (Salby, 1996). This is a narrow band at about $30^{\circ}$ latitude, associated with a strongly sloping or even breaking tropopause, coinciding with a maximum meridional temperature gradient and energy transfer. A second jet stream occurs at the polar front, at about $60^{\circ}$ latitude, due to interaction of polar and tropical air. The polar front jet stream is much weaker and less persistent, and sometimes it is discontinuous.

Transport processes in the troposphere are thus determined by temperature contrasts, and additionally by energy transfer through evaporation and condensation of water. The incoming solar radiation is much more effectively absorbed by the surface than by the atmosphere. As a consequence, upwelling infrared radiation heats the atmosphere from below, while radiative cooling at higher altitudes destabilises the troposphere by increasing the temperature lapse rate. The lapse rate is reduced and the troposphere stabilised by convection, which causes vertical mixing. Convection is enhanced by condensation of water vapour, which releases latent heat and causes precipitation. The global mean result of convective overturn- ing is that the troposphere is mixed vertically in roughly one month. This implies that, in the global mean, short-lived species such as $\mathrm{NO}_{x}$, with lifetimes less than a week, emitted either at the surface by industrial sources or near the tropopause by aircraft, influence the ozone chemistry predominantly at the altitude of their release. On the other hand, trace gases with longer lifetimes, such as $\mathrm{CO}$ and alkanes, can build-up throughout the troposphere.

On shorter time scales, i.e. of hours, deep thunderstorm convection can cause vertical exchange between the lower and upper troposphere so that also short-lived species can be effectively redistributed (Dickerson et al., 1987). The associated cumulonimbus clouds cause rain showers that remove soluble species from the atmosphere. However, some of the condensed water evaporates again and releases its solutes. In the cold upper troposphere most of the water is deposited as ice. The melting and evaporation of ice cools the air, and in addition to cirrus radiative cooling this leads to mesoscale subsidence in the cloud environment. The mesoscale descent occurs during the subsequent $1-2 \mathrm{~d}$ over a much larger area compared to the convective ascent. These overturning motions carry $\mathrm{NO}_{x}$ and other short-lived pollutants from the boundary layer upward and perturb the upper troposphere (Ehhalt et al., 1992). On the other hand, aircraft exhausts and trace gases of stratospheric origin are transported towards the surface where their lifetimes are considerably shorter (Lelieveld and Crutzen, 1994).

Whereas deep cumulonimbus clouds are prominent in the tropics, extratropical cyclones often cause vertical exchange in higher latitudes. Middle latitudes are characterised by strong temperature gradients, which are particularly steep in frontal zones. These zones can become unstable in wave-like patterns so that cyclones develop, transporting warm air poleward and cold air equatorward. Organised vertical motions carry warm, moist air upward and cold, dry air downward. Deep convection ahead of the frontal zone also contributes to vertical exchange of trace species. In addition to these cyclonic systems, particularly violent vertical motions are caused by mesoscale convective systems that occur in the tropics, subtropics and midlatitudes. These systems can develop into heavy storms and, in extreme cases, into tornadoes. They produce large amounts of precipitation, sometimes as hail, and furnish strong vertical motions and effective overturning of the troposphere. Sometimes these systems can penetrate the stratosphere (Poulida et al., 1996). Effective vertical transport of sulphur dioxide and acetone in correlation with carbon dioxide, nitric acid and condensation nuclei was observed by in situ measurements near the tropopause west of Ireland over the North Atlantic by Arnold et al. (1997). Backward trajectory analyses showed that the measured pollution originated from surface sources in the boundary layer over the northern continental United States. In two more cases, upward transport of 
polluted air from Texas and Florida to the upper troposphere was observable just below the tropopause west of Europe over the North Atlantic (see Schumann, 1996c). It appears that the synoptic scale upward transport of pollution from continental sources towards the upper troposphere with long-range transport across the oceans occurs more often than expected before.

An important chemical effect of convection is that surface emitted $\mathrm{NO}_{x}$ reaches the upper troposphere, which enhances photochemical $\mathrm{O}_{3}$ formation (Pickering et al., 1992). Evaluation of aircraft emissions therefore requires quantification of such transports to distinguish them from local emissions. This is particularly significant since the "effective lifetime" of $\mathrm{NO}_{x}$ is higher in the upper troposphere compared to the boundary layer. $\mathrm{NO}_{x}$ is converted to nitric acid, which has a sufficiently long dynamical residence time so that $\mathrm{NO}_{x}$ can be regenerated from $\mathrm{HNO}_{3}$ by photolysis or, to a lesser extent, by reaction with $\mathrm{OH}$; removal of soluble gases is much slower compared to lower altitudes. Further, convective upward transports are likely to introduce pollutants into a region of the atmosphere where background $\mathrm{NO}_{x}$ levels are lower, so that addition of $\mathrm{NO}_{x}$ relatively efficiently contributes to $\mathrm{O}_{3}$ formation. Hence, in polluted parts of the troposphere convection adds to the tropospheric $\mathrm{O}_{3}$ column. On the other hand, associated downward motions carry some of these pollutants and local emissions downward, in addition to ozone that has been mixed down from the stratosphere. Hence, in remote parts of the troposphere, where surface emissions are low or absent, convection reduces the $\mathrm{O}_{3}$ column. In Section 6 the results from global chemistry-transport models that quantify these three-dimensional motions and their large-scale chemical effects will be discussed.

3.5.3. Dynamical processes in the middle atmosphere. There have been significant advances recently in our understanding of dynamics and transport in the stratosphere. This has resulted from measurements from satellites of the large-scale circulation of the middle atmosphere, measurements of gravity waves from the ground-based lidars and radars, and the great success in the capability of general circulation models in reproducing the characteristics of the global atmospheric circulation.

The zonally averaged transport in the troposphere, stratosphere and mesosphere may be summarised by reference to Fig. 7. In the troposphere, there is advection by the Hadley circulation (the cell near the equator); quasi-horizontal dispersion by planetary and smaller-scale eddies (thick horizontal arrows); and vertical mixing by convection (vertical arrows). Time scales for transport are mostly short (about a week to a few months). In the winter stratosphere, transport is

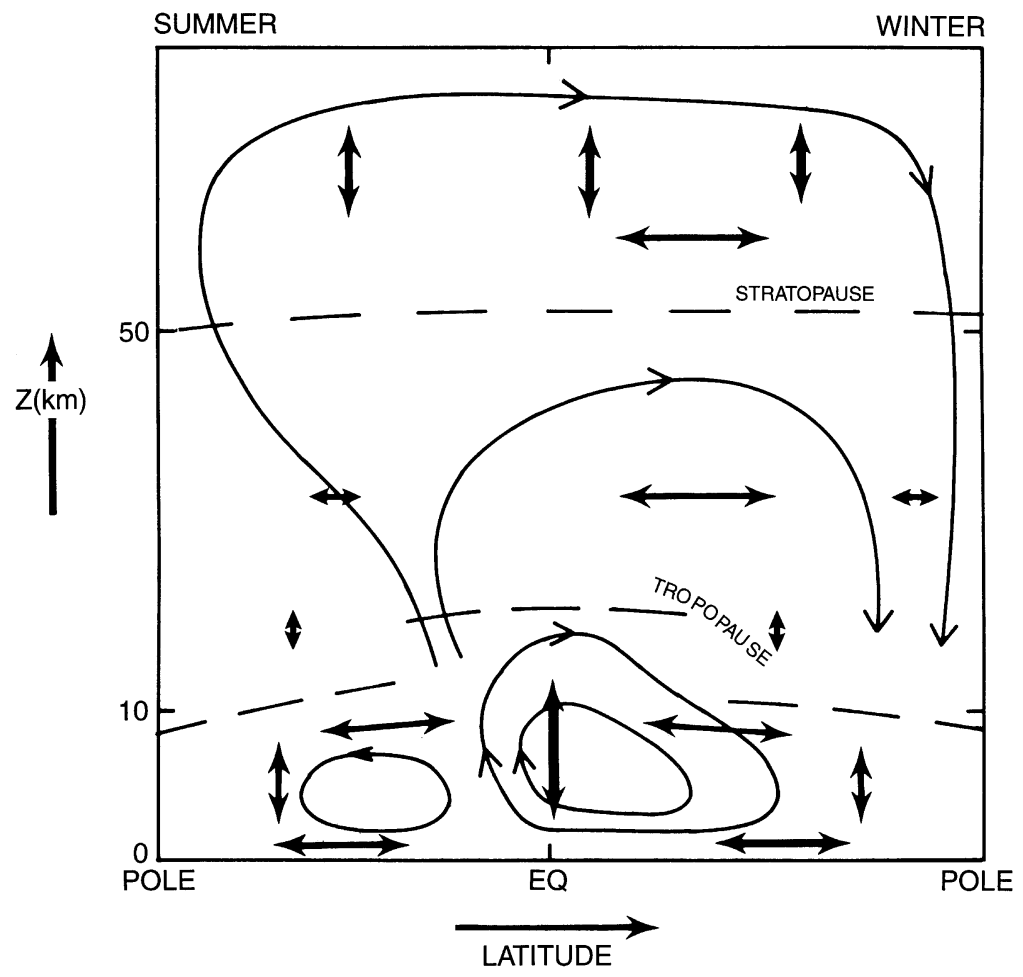

Fig. 7. Schematic illustration of zonally averaged transport up to the mesopause in latitude-altitude domain. Single arrows denote mean circulation; double arrows denote quasi-horizontal and vertical diffusion. Pecked lines denote the tropopause (lower) and stratopause (upper) (SORG, 1988). 
largely dictated by planetary-scale eddies, both indirectly in a wave-driven meridional circulation and directly by quasi-horizontal dispersion or "mixing". In the mesosphere, planetary-scale eddies decrease in amplitude and transport processes appear to be dominated by gravity waves. They reach large amplitudes as they propagate upwards from the troposphere (because density decreases with height) and they may "break". The turbulence, generated as light and heavy fluid elements overturn, mixes trace species in the vertical, and also leads to advection in a strong pole-to-pole circulation.

In the stratosphere time scales for transport are generally quite long compared to the upper troposphere, especially in the vertical direction. The importance of this for the issue of aircraft emissions is that material injected at altitudes above $20 \mathrm{~km}$ or so will have a relatively long residence time in the stratosphere and hence will have a more severe impact, for example, on ozone chemistry.

The dynamics of the middle atmosphere has historically been interpreted using the theory of wave mean flow interaction. Planetary scale waves, defined as departures from mean zonal flow, are taken to propagate on that flow, forcing changes in it. Such separation into waves and mean flow may not be appropriate when the circulation is more disturbed. Instead, the dynamical features are currently treated in terms of potential vorticity, a fundamental quantity in dynamical meteorology. Potential vorticity does not change along an air parcels trajectory for as long as friction and radiation can be neglected, nor does potential temperature. So contours of potential vor- ticity plotted on surfaces of potential temperature define material lines, allowing the movement of strings of air parcels to be followed. Such maps are useful therefore in studying how material is transported. Figure 8 provides an example of such maps. Contours of potential vorticity are highly and irreversibly deformed as pools of air from low latitudes, having low values of potential vorticity, are drawn eastward and poleward around the westerly vortex.

Many aspects of the circulation of the middle atmosphere have been reproduced by general circulation models (GCMs) - comprehensive three-dimensional numerical models of the atmosphere, with the main physical processes represented in some way. They are now regularly used in climatological and short-term (forecast) simulations, in studies of transport and in numerical experiments in which a perturbation is applied to the system (for example, changing the concentration of carbon dioxide).

At present, computer time is too expensive to include a full description of atmospheric photochemistry in GCMs. Much progress has been made recently using analysed wind and temperature fields from forecast GCMs together with "off-line" calculations of photochemistry. This type of model is termed a Chemical Transport Model and has started to be used to good effect for case studies of observational campaigns and for assessment studies. Much effort has also been directed to ways in which dynamical and transport processes might be parameterized in a two-dimensional model, which are much cheaper and more flexible for perturbation studies.

180

NORTHERN HEMISPHERE

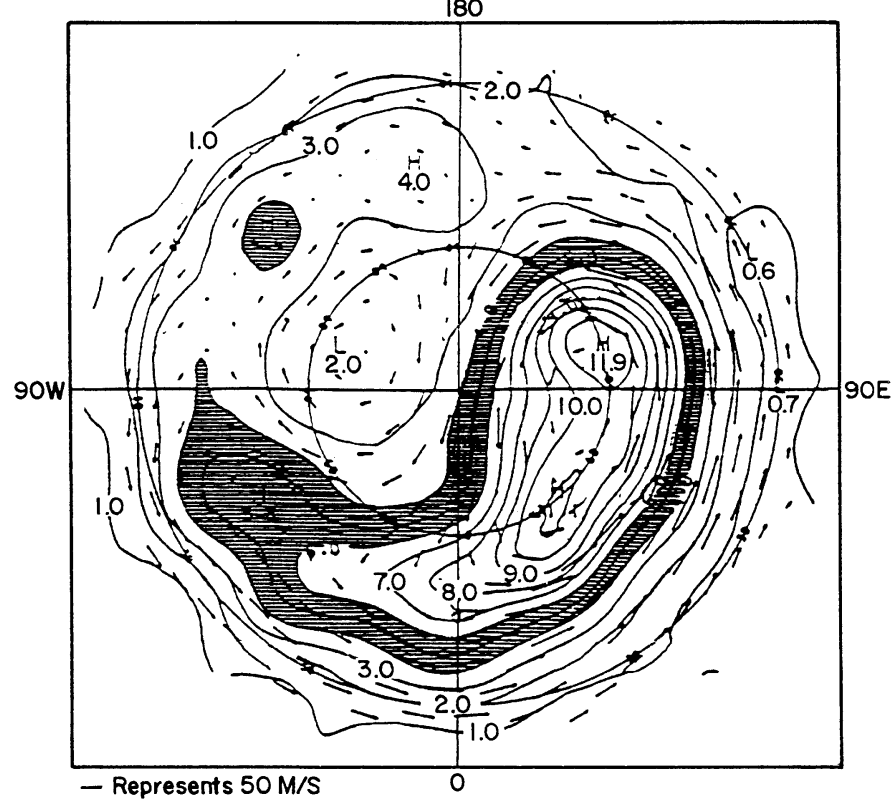

Fig. 8. Potential vorticity and geostrophic winds on the $850 \mathrm{~K}$ isentropic surface (near 10 mbar pressure, $30 \mathrm{~km}$ altitude) for the Northern Hemisphere, 4 December 1981. 


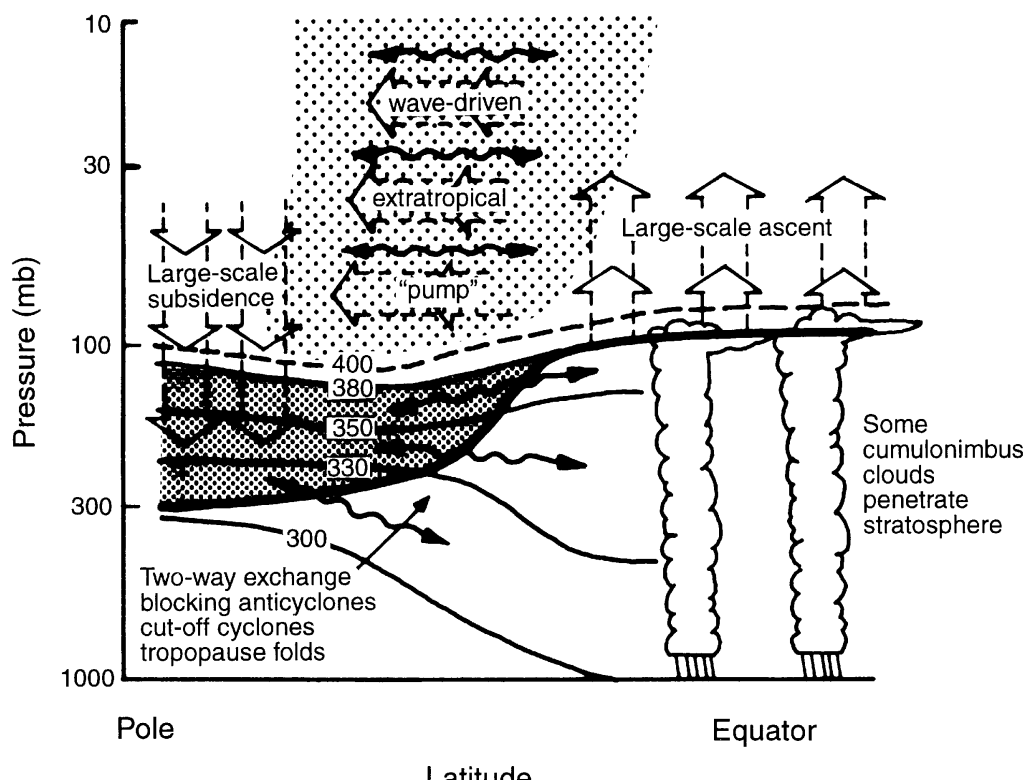

Latitude

Fig. 9. Schematic representation of the dynamical coupling between the stratosphere and troposphere (Holton et al., 1995). Upward motion prevails at the equator while net downward motion occurs in the extratropics. The shaded area between the extratropical tropopause (thick solid line) and the $380 \mathrm{~K}$ isentropic surface $(\sim 100 \mathrm{mb})$ is the "lowermost stratosphere". Two-way exchange between this area and the upper troposphere occurs along isentropic surfaces $(320-350 \mathrm{~K}$ ) that cross the tropopause (curved arrows).

3.5.4. Stratosphere-troposphere exchange. The stratosphere and troposphere are coupled dynamically, chemically and radiatively (Fig. 9). A particular important coupling process is the exchange of mass and trace species between the stratosphere and troposphere (Mahlman, 1997). Upward mass transport from the troposphere into the stratosphere is concentrated in the tropics, mainly through the convective ITCZ. This provides the mechanism to deposit anthropogenic chlorine gases into the stratosphere, which leads to destruction of the ozone layer. Downward transport into the troposphere occurs in the subtropics through the subtropical tropopause breaks, and in the extratropics through tropopause foldings associated with cyclones and cut-off lows (Holton et al., 1995). This downward transport is a sink for the products of chlorine chemistry involved in stratospheric ozone depletion, and it also supplies ozone to the troposphere. Although isentropic mixing, tropopause folds and cut-off lows strongly affect the tropopause dynamics, and thus the time and location of exchanges, the total amplitude of downward mass transport is constrained by the strength of the stratospheric circulation which, in turn, is determined by the wave forcing in the stratosphere and mesosphere (Holton et al., 1995).

Recent studies of dynamical processes have provided estimates of the seasonal and hemispheric dependence of stratosphere-troposphere exchange (Holton et al., 1995). Downward transport in the lower mid-latitude stratosphere appears to be up to twice as large in the northern hemisphere compared to the southern hemisphere, and has a maximum during the northern hemispheric winter, while ozone concentrations in the lower stratosphere are highest during spring. Further, the tropopause height increases during spring, which is particularly significant in the northern hemisphere (Appenzeller et al., 1996). Therefore, stratosphere-troposphere exchange of ozone has a maximum between late winter and spring.

The tropopause is traditionally defined thermally as the altitude at which the temperature lapse rate decreases to $2 \mathrm{~K} \mathrm{~km}^{-1}$ for at least $2 \mathrm{~km}$. From a dynamical viewpoint, however, a better tropopause definition is given by a specified value of a long-lived tracer such as ozone, which has distinctly different stratospheric and tropospheric values. In the extratropics the dynamical tracer potential vorticity $(\mathrm{PV})$, which is highly correlated with ozone, is a particularly suitable tracer to define the tropopause. PV increases strongly from troposphere to stratosphere, and it can be calculated from conventional meteorological data. Here, the extratropical tropopause is defined at the 3.5 PVU level ( $\left.\mathrm{PVU}=\mathrm{K} \mathrm{m}^{2} \mathrm{~kg}^{-1} \mathrm{~s}^{-1}\right)$.

The "lowermost" stratosphere in the extratropics (Fig. 9) is thus defined as the region between the tropopause at $3.5 \mathrm{PVU}$ and the $380 \mathrm{~K}$ isentropic surface, the latter at $12-14 \mathrm{~km}$ altitude. Cross-tropopause exchange can thus occur up to approximately 12-14 km altitude (Holton et al., 1995). In addition to isentropic transports between the lowermost stratosphere and the troposphere, which may be 
particularly important in the sub-tropics (Chen, 1995), diabatic cross-tropopause exchange can occur in mid-latitudes (Lamarque and Hess, 1994). Sometimes, violent storms can penetrate the lowermost stratosphere (Poulida et al., 1996). This is particularly significant because a large part of the subsonic air traffic takes place in this region. The cross tropopause transports dilute the aircraft exhausts and introduce tropospheric pollutants into the lowermost stratosphere (Lelieveld et al., 1997).

The downward transport of ozone through stratosphere-troposphere exchange (STE) contributes significantly to the tropospheric ozone budget. The use of general circulation models, in addition to tracer correlation studies, have constrained the total amount of ozone that is transported downward to about $500 \mathrm{Tg} \mathrm{yr}^{-1}$, with an uncertainty range of about $50 \%$ (WMO, 1995). Nevertheless, observations are best explained by assuming a strong in situ photochemical component, which dominates tropospheric $\mathrm{O}_{3}$ in the anthropogenically influenced boundary layer as well as the free troposphere, particularly in northern midlatitudes (Crutzen et al., 1994). However, STE considerably affects the seasonality of $\mathrm{O}_{3}$ in the free troposphere and even in the boundary layer, especially in remote marine locations and at high latitudes. During mid-latitude winter the $\mathrm{O}_{3}$ lifetime is relatively long (months) so that stratospheric $\mathrm{O}_{3}$ can reach the surface (Roelofs and Lelieveld, 1997). In the tropics, however, where STE is upward and the $\mathrm{O}_{3}$ lifetime is short (weeks or less), little stratospheric ozone reaches the troposphere. Therefore, tropospheric ozone in the tropics is largely controlled by photochemistry. Model results of the tropospheric ozone budget are presented in Section 6 .

\section{AIR TRAFFIC, ENGINE COMBUSTION AND AIRCRAFT EMISSIONS}

\subsection{Introduction}

The concerns about emissions from aircraft were originally focused on their contribution to local air quality in the vicinity of airports and led to the introduction of legislation in the U.S.A. (Clean Air Act) and subsequently to International Standards for control of fuel venting and emissions of carbon monoxide (CO), unburned fuel $(\mathrm{HC})$, oxides of nitrogen $\left(\mathrm{NO}_{x}\right)$ and smoke from aircraft engines below $915 \mathrm{~m}(3000 \mathrm{ft})$ (ICAO, 1981).

The transition during the 1960s and 1970s from turbojet to high bypass ratio turbofan engines, for powering subsonic aircraft, resulted in improved fuel efficiency, lower noise levels and substantially reduced emissions of $\mathrm{CO}$ and $\mathrm{HC}$ through improved combustion efficiencies. $\mathrm{NO}_{x}$ levels increased because of the higher engine internal temperatures and pressures. However, this increase has been minimised by the incorporation of advanced combustor technology designed to reduce $\mathrm{NO}_{x}$ emissions. Improvements in engine design and combustor technology are continuing, under increasingly stringent regulatory requirements (ICAO, 1993).

In the 1960s, the first civil supersonic aircraft was developed. Their $\mathrm{NO}_{x}$ emissions were viewed as a threat to the stratospheric ozone layer and substantial research was undertaken in the 1970s (CIAP, COMESA, COVOS), to try to quantify the impact. In the event, only 16 production Concorde aircraft were built, of which 13 remain in commercial operation. A proposed second generation civil supersonic aircraft-high speed civil transport (HSCT) - has again stimulated research into (Prather et al., 1992; Stolarski and Wesoky, 1993, 1995) and assessments of (Albritton et al., 1993; NRC, 1994) the atmospheric effects of such a plane. Alongside this scientific investigation, there is substantial research and testing aimed at developing the appropriate technology. A fleet size of at least 500 is likely to be required for economic viability.

The emphasis has now shifted to addressing the role and contribution of aviation emissions to the global issues of ozone loss and potential climate change through research initiatives such as the European AERONOX (Schumann, 1995) and the US Subsonic Assessment (SASS) (Thompson et al., 1996) programmes and the consequent impact on future aircraft design and operation. Emissions of $\mathrm{CO}_{2}, \mathrm{H}_{2} \mathrm{O}, \mathrm{NO}_{x}$, $\mathrm{CO}$, hydrocarbons, particulates, aerosols and other trace species are dependent on engine cycle designs, combustor technology and fuel composition. There may be potential for reducing, or altering the balance between, these various emissions by technology design and/or changed operational practices. Currently, there are no regulations controlling the emissions from aircraft at cruise altitudes.

Although aviation may be a relatively small user of fossil fuel at this time, it is important to make a proper assessment of the future potential emissions burden, in view of the historic rapid expansion and forecast high growth rates of aviation.

The assessment of the impact of aviation emissions on the atmosphere is through the use of models. These require a knowledge of the nature and scale of the emissions, where they are emitted and their likely changes over time. Several global three-dimensional (3-D) emissions databases (inventories) of civil scheduled, charter, cargo, non-scheduled and military aviation have been compiled and are in widespread use by atmospheric scientists. In addition, 50-100 yr scenarios have been developed in an attempt to assess the longer-term impacts.

Many of the issues have been examined and reported recently (WMO, 1995). This section of the current review provides an update and extension of the earlier information.

\subsection{Traffic and fuel use}

The historic rapid expansion of civil aviation traffic over the past decades is forecast to continue into the 


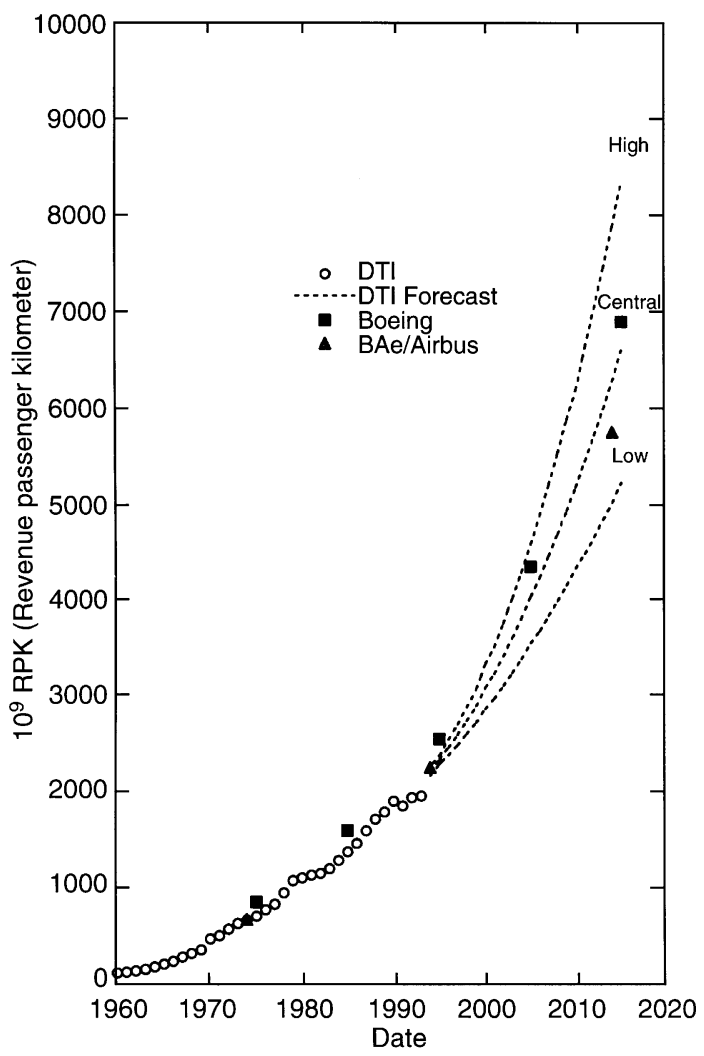

Fig. 10. Civil Aviation Traffic Growth and Forecast, 1960 to 2015. DTI historic data are derived from analysis of IATA World Traffic Statistics, 1993 and ICAO Civil Aviation Statistics of the World, ICAO Statistical Year Book, 1993. DTI forecasts use an initial load factor of $65 \%$ in 1993 and assume $0.4 \%$ increase per year. The central, high and low forecasts use 4.8, 5.9 and $3.6 \%$ per year increase in traffic.

future (Fig. 10) (BAe/Airbus, 1995; Boeing, 1997; DTI, 1996) although the rates of growth are slowing with time $(15 \%$ in the 1970 s, $9 \%$ in the 1980 s to around $5 \%$ from 2000 to 2015). Growth rates are predicted to vary significantly for the different regions of the world. Table 6 compares growth rates between 1996 and 2016.

The differences in the average growth rates between the two forecasts result in a traffic difference of about $5 \%$ over the $20 \mathrm{yr}$ period. This is small compared with the actual growth during this period: $270 \%$ (Airbus) or $255 \%$ (Boeing).

Aviation currently consumes $2-3 \%$ of the fossil fuels used worldwide, of which the vast majority $(>80 \%)$ is used by civil aviation. Fuel usage growth trends are shown in Fig. 11 (DTI). Increases are typically only $70-80 \%$ of the traffic increase figures. This is a consequence of the improvements in both engine and aircraft fuel efficiencies (see Section 4.4).

Military aircraft have traditionally been a substantial user $(\sim 20 \%)$ of aviation fuel. The ending of the Cold War has resulted in a decline of activity, which will probably settle out at a new, lower level. The fuel usage is difficult to estimate accurately due to lack of fixed operational practices and flight patterns and also because of national security issues. Further information is given in Section 4.8.

\subsection{Engine design}

The modern, high-performance gas turbine "jet" engine that is used to power typical commercial and military aircraft is essentially a continuous-flow heat engine operating at constant pressure. It uses air as its working fluid to generate the thrust to propel the aircraft through the atmosphere. The aerothermodynamic and mechanical design principles are well established and documented in standard texts (e.g. Rolls-Royce, 1986). A helpful, brief introduction to the engine performance cycle, the different efficiency terms and the parameters which control the fuel economy and emissions production was given at a recent Symposium (Albritton et al., 1997).

Since the earliest days of the jet engine, the design concept has advanced from the simple turbojet through the low bypass ratio engines (Spey, JT8D) of the 1960s to the large, high bypass ratio engines (RB211, JT9D and CF6 families) of the 1970s and 1980s. These improved engine cycles result in higher internal engine temperatures and pressures with the concurrent improvements in thermal and propulsive efficiencies and fuel economy (Fig. 12). It is the engine cycle design that determines the overall engine fuel efficiency and therefore the quantity of $\mathrm{CO}_{2}$ and $\mathrm{H}_{2} \mathrm{O}$ emitted per unit of productive output of the engine. Further increases in bypass ratio, offer the potential for additional fuel economy.

In the combustion process, the fuel-aviation kerosene-is sprayed at high pressure into the combustion chamber where it mixes with the hot, high-pressure air supplied by the compressor and is ignited. The principles of combustion are well explained in standard textbooks (e.g. Kuo, 1986). The primary products of the combustion of aviation fuel are $\mathrm{CO}_{2}$ and water; the exact proportions depend on the specific fuel carbon-hydrogen ratio. The secondary products

Table 6. World traffic growth forecasts (percent per year)

\begin{tabular}{lcccc}
\hline & $\begin{array}{c}\text { 1996-2006 } \\
\text { World average }\end{array}$ & $\begin{array}{c}\text { 2006-2016 } \\
\text { World average }\end{array}$ & $\begin{array}{c}\text { 1996-2016 } \\
\text { World average }\end{array}$ & $\begin{array}{c}\text { 1996-2016 } \\
\text { Regional range }\end{array}$ \\
\hline Airbus & 5.9 & 4.6 & 5.2 & $1.9-9.6$ \\
Boeing & 5.5 & 4.4 & 4.9 & $3.1-10.3$ \\
\hline
\end{tabular}




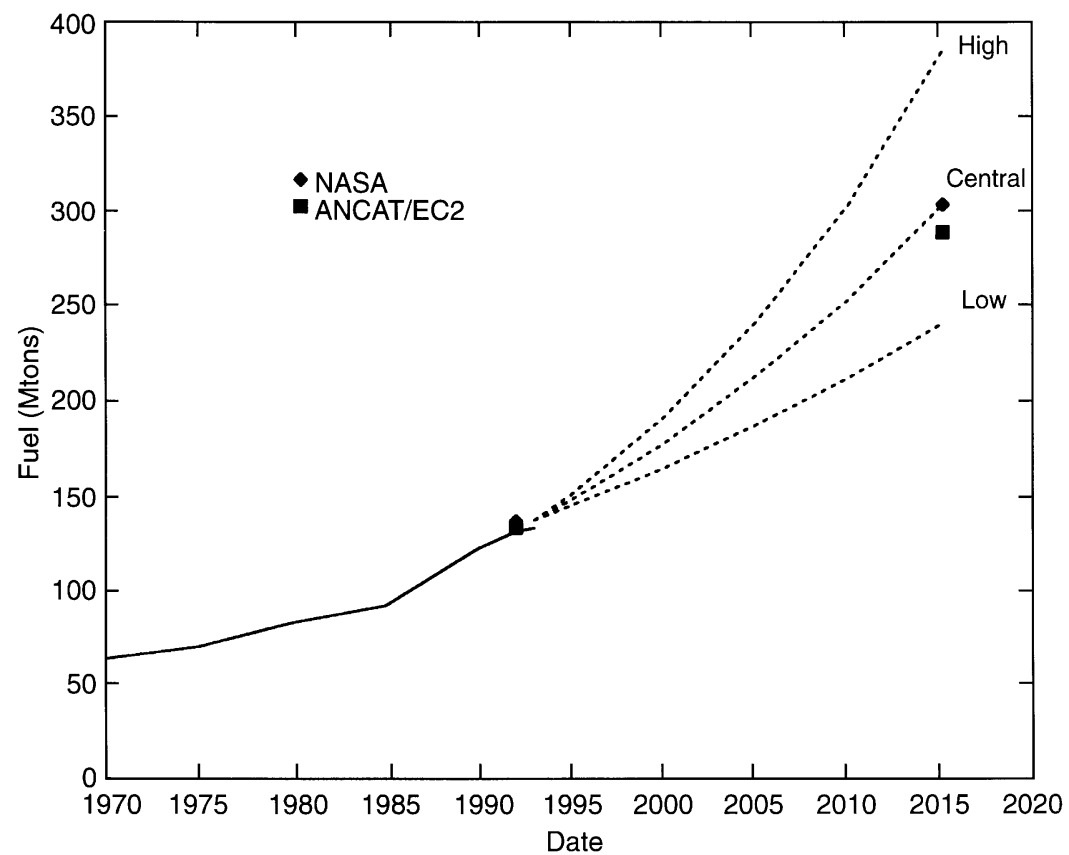

Fig. 11. Civil Aviation Fuel Trends with Time, 1970-2015. Data source, DTI analysis of International Energy Agency Annual data, 1993 and Aviation Fuels Business, World-wide, (Jenkins, 1996). The central, low and high forecasts use 3.7, 2.6 and 4.8\% per year increase in fuel used. ANCAT/EC and NASA data are

from the inventory studies (Gardner, 1997b; Baughcum et al., 1996; Metwally et al., 1995).

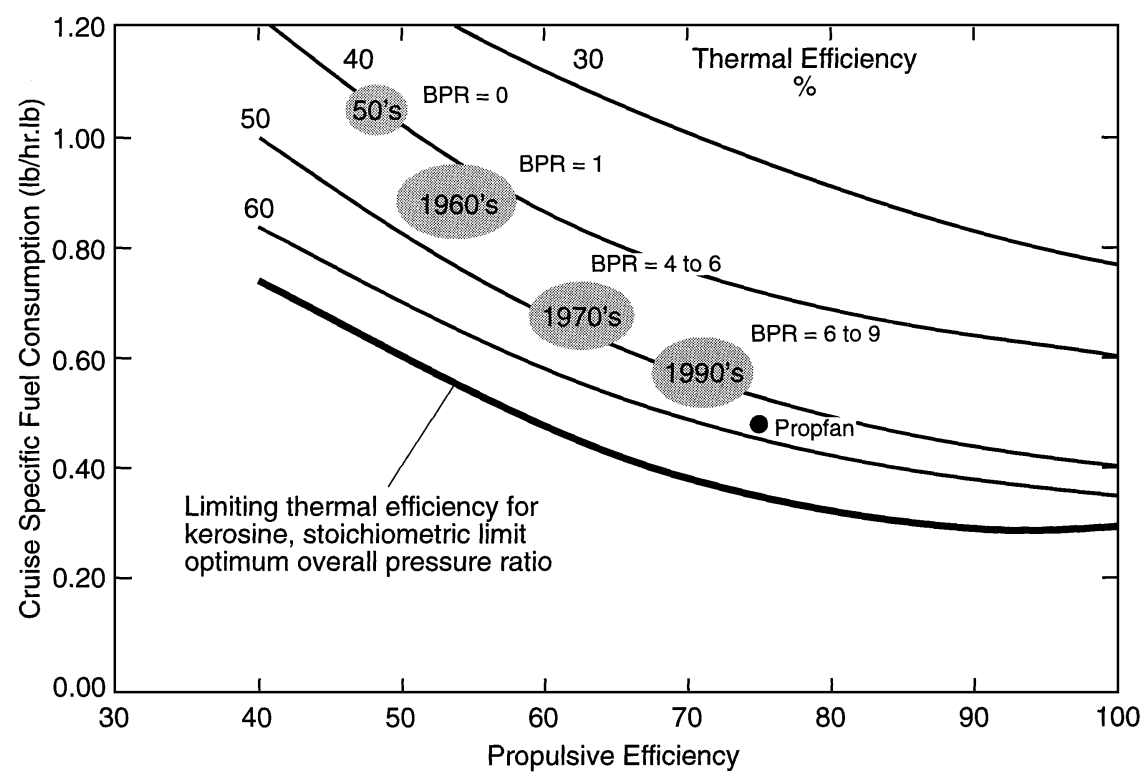

Fig. 12. Engine performance cycle fuel efficiency trends. Engine bypass ratio (BPR) is the ratio of the airflow through the engine bypass duct to the airflow through the core of the engine.

include $\mathrm{CO}$, hydrocarbons, $\mathrm{NO}_{x}\left(=\mathrm{NO}+\mathrm{NO}_{2}\right)$ and soot/particulates which vary according to combustor design, and operating pressures and temperatures. It is the design of the combustion chamber, not the engine cycle, which mainly determines the level of these secondary products (emissions), some of which are regulated. This is discussed further in Section 4.7.

\subsection{Fuel composition}

Aviation kerosene is a hydrocarbon fuel refined from crude oil. While there are variations depending 
on the oil source and refining process, the bulk physical and chemical properties are controlled by specification, e.g. DERD 4294, ASTM D 1655 for aviation jet fuel. A more limited specification is defined for aircraft engine emissions certification testing (ICAO, 1993a). Within this specification, the hydrogen content of the fuel must be between 13.4 and $14.1 \%$ by mass, while the total sulphur content must be no more than $0.3 \%$ by mass. A number of large-scale surveys of actual fuel quality have been carried out (Hadaller and Momenthy, 1989; Rickard, 1996), which show consistent results (Table 7).

In addition, the work of Rickard is part of longterm, continuing annual surveys of United Kingdom aviation fuel quality. This indicates that the average hydrogen content has remained between 13.80 and $13.90 \%$ over the last decade, although the variation between batches within any one year (1 standard deviation) may be up to $0.2 \%$. At present, typical sulphur levels in aviation kerosene are in the range $0.04-0.05 \%$ by weight, with a slight downward trend over the last decade compared with the allowed speci- fication limit of $0.3 \%$ (ICAO, 1981, 1993). Figures 13 and 14 show the trend and the statistical distribution within the specification limits.

Fuel samples taken from various European test facilities and from a range of airports worldwide were analysed as part of the European AEROTRACE programme (Cottington et al., 1997) and support these other survey results. Sulphur levels were in the range $0.003-0.06 \%$ and hydrogen content $13.54-13.96 \%$.

\subsection{Pollutant formation in combustion}

The primary products of the combustion of aviation fuel are $\mathrm{CO}_{2}$ and water; the exact proportions depend on the specific fuel carbon-hydrogen ratio. The secondary products include $\mathrm{CO}$, hydrocarbons, $\mathrm{NO}_{x}\left(=\mathrm{NO}+\mathrm{NO}_{2}\right)$ and soot/particulates which vary according to combustor design, and operating pressures and temperatures. $\mathrm{CO}$ and hydrocarbons (HC) are primarily products of low-power engine operating conditions, whereas $\mathrm{NO}_{x}$ and soot are dominant at the high temperatures and pressures corresponding to high power operation.

Table 7. Hydrogen and sulphur content of aviation fuel

\begin{tabular}{lcccc}
\hline & $\begin{array}{c}\text { Hydrogen } \\
\text { \% by mass } \\
\text { (mean value) }\end{array}$ & $\begin{array}{c}\text { Sulphur } \\
\% \text { by mass } \\
\text { (mean value) }\end{array}$ & $\begin{array}{c}\text { Sulphur fraction } \\
<0.1 \% \text { by mass }\end{array}$ & Comments \\
\hline Hadaller \& Momethy & 13.8 & 0.042 & 0.90 & $\begin{array}{c}\text { Samples taken from airports around the } \\
\text { world } \\
\text { Rickard }\end{array}$ \\
ICAO Fuel specification & 13.83 & 0.045 & 0.86 & $\begin{array}{c}\text { Samples from aviation fuel supplied in } \\
\text { U.K. }\end{array}$ \\
\hline
\end{tabular}

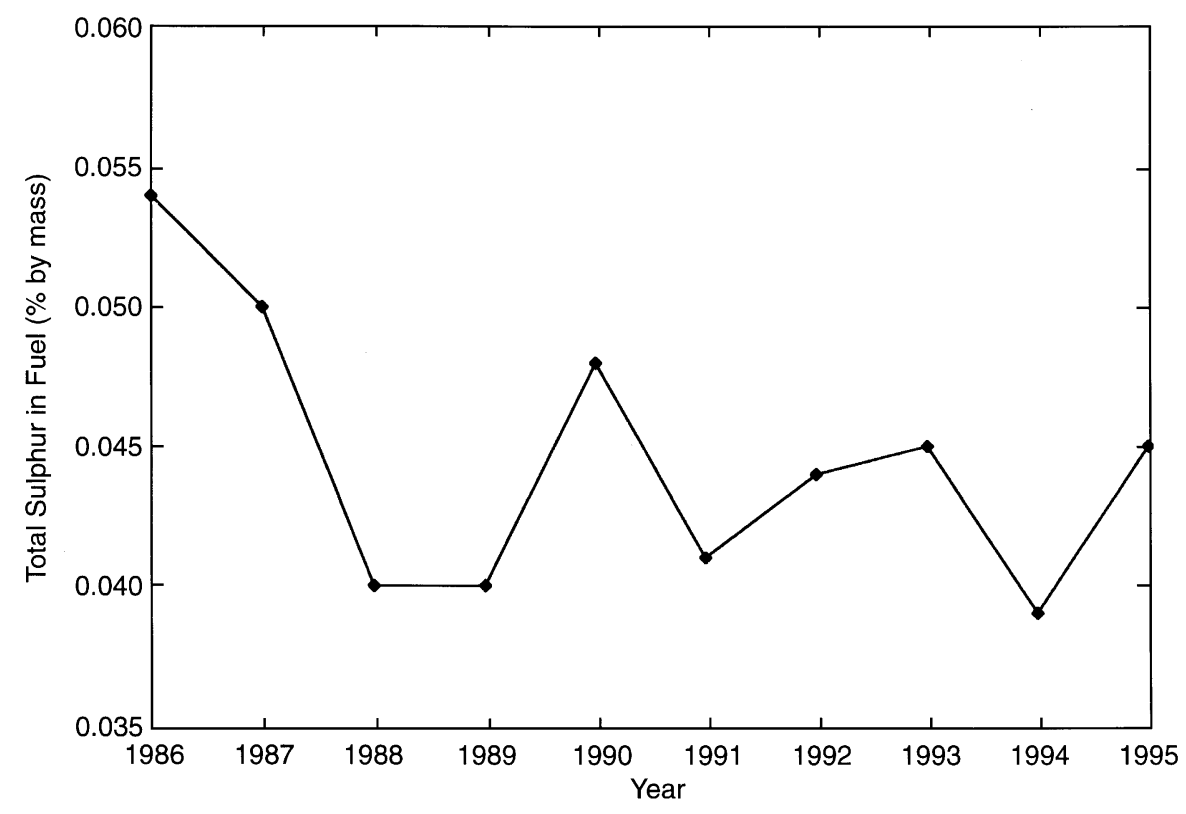

Fig. 13. Trends of the annual mean total sulphur in fuel (1986-1995). 


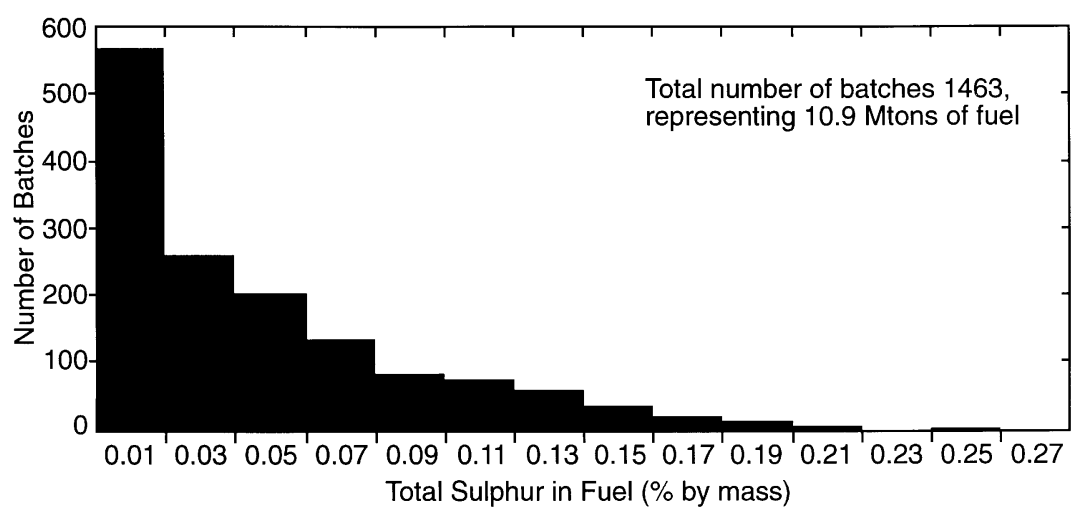

Fig. 14. Total sulphur in aviation fuel. Data are for aviation fuel supplied in the U.K. in 1995 (Rickard) and is representative of $10.9 \mathrm{Mt}$ of fuel, i.e. about $7-8 \%$ of total world civil aviation annual usage.

$\mathrm{CO}$ formation generally occurs in combustion under fuel-rich conditions, i.e. if the concentration of the oxidiser is too low. However, under high pressure and temperature, small amounts of $\mathrm{CO}$ are always present in the exhaust.

Unburned, or partially burnt hydrocarbons arise either directly from the fuel or are generated during the combustion process. In general, unburnt hydrocarbons are a consequence of local flame extinction, e.g. at walls. These flame extinctions are caused by the interaction of the flame with the walls of the reaction system, i.e. heat transfer (cooling of the reaction zone) and/or the removal of radical species by surface reactions.

The formation of $\mathrm{NO}_{x}$ during combustion occurs via four different routes which have been studied in great detail. These are the thermal route (thermal $\mathrm{NO}$ ), the prompt route (prompt $\mathrm{NO}$ ), the $\mathrm{N}_{2} \mathrm{O}$ route and the fuel-bound nitrogen route. Depending on the combustion conditions one of the routes can dominate over the others, e.g. under fuel-rich conditions, prompt NO is favoured in rich flames, whereas in lean premixed combustion in turbines the $\mathrm{N}_{2} \mathrm{O}$ route is the major source of NO. The different mechanisms have been reviewed and described in detail (Bowman, 1992).

If no extinction occurs in the combustor the fuel is completely cracked to $\mathrm{C}_{1}$ and $\mathrm{C}_{2}$ hydrocarbons. Under fuel-rich conditions, acetylene $\left(\mathrm{C}_{2} \mathrm{H}_{2}\right)$ is formed in large amounts. $\mathrm{C}_{2} \mathrm{H}_{2}$ is the most important precursor of higher hydrocarbons such as polycyclic aromatic hydrocarbons (PAH), which are important precursors in soot formation. It is commonly accepted that aromatic rings are formed by the reaction of either $\mathrm{CH}$ or $\mathrm{CH}_{2}$ radicals with $\mathrm{C}_{2} \mathrm{H}_{2}$ to form $\mathrm{C}_{3} \mathrm{H}_{3}$ which can form benzene after recombination and rearrangement. Further addition of $\mathrm{C}_{2} \mathrm{H}_{2}$ to the ring leads to the growth of the molecule finally leading to soot. Higher temperatures and pressures in the combustion system may lead to increased soot formation. Soot maybe carcinogenic itself or absorb other carcinogenic PAH. The structure of soot is difficult to charac- terise. An excellent overview on soot formation in combustion processes has been published recently (Bockhorn, 1994).

\subsection{Aircraft emissions}

4.6.1. Landing/take-off cycle emissions. Table 8 gives typical emission levels for various operating regimes. The emission values are quoted as an Emissions Index (EI) with units of grams per kilogram of fuel burnt. Traditionally, $\mathrm{NO}_{x}$ is considered as if it were $\mathrm{NO}_{2}$. Similarly, $\mathrm{HC}$ is treated as if it were methane. Soot (for regulatory purposes) has been related to visual obscuration and defined as a Smoke Number. Correlations exist (Hurley, 1993) which enable this to be converted to an equivalent mass of carbon and hence to derive an Emissions Index.

$\mathrm{CO}, \mathrm{HC}, \mathrm{NO}_{x}$ and smoke have been regulated on the basis of a landing-take/off (LTO) cycle up to $915 \mathrm{~m}$ at and around airports (ICAO, 1981, 1993). As such these data are available for a very wide range of commercial aircraft engines (ICAO, 1995b). Table 9 shows an example for one modern engine (the RollsRoyce Trent 772 engine), which is fitted to the Airbus A330 aircraft.

The regulatory parameter $\left(D p / F_{\text {oo }}\right)$ for a species is the mass of the species emitted over the LTO cycle divided by the rated power output of the engine and has units of $\mathrm{g} \mathrm{kN}^{-1}$. Figure 15 shows $\mathrm{NO}_{x}$ certification levels for late model engines. It includes the original 1986, the revised 1996 ICAO regulatory standards for comparison purposes and the latest recommendation for a further reduction. Similar data are available for $\mathrm{CO}, \mathrm{HC}$ and smoke.

The spread of emission values for these species (all meeting the LTO cycle regulatory standards) is a consequence of conflicting design requirements, which manufacturers have resolved with different compromises.

Historical trends in emissions show that very substantial decreases in $\mathrm{HC}$ and $\mathrm{CO}$ emissions have been achieved due to improvements in engine design to achieve greater fuel efficiency. Along with this has 
Table 8. Typical emission index levels for engine-operating regimes. Units are grams of pollutant per kilogram of fuel burnt $\left(\mathrm{g} \mathrm{kg}^{-1}\right)$

\begin{tabular}{lcccc}
\hline & \multicolumn{3}{c}{ Operating condition } & \\
\cline { 2 - 4 } Species & Idle & Take-off & Cruise & Comments \\
\hline $\mathrm{CO}_{2}$ & 3160 & 3160 & 3160 & \\
$\mathrm{H}_{2} \mathrm{O}$ & 1230 & 1230 & 1230 & \\
$\mathrm{CO}$ & $25(10-65)$ & $<1$ & $1-3.5$ & \\
$\mathrm{HC}$ (as methane) & $4(0-12)$ & $<0.5$ & $0.2-1.3$ & \\
$\mathrm{NO}_{x}$ (as NO & $4.5(3-6)$ & $32(20-65)$ & $7.9-11.9$ & (Short haul) \\
$\mathrm{SO}_{x}$ (as $\left.\mathrm{SO}_{2}\right)$ & $4.5(3-6)$ & $27(10-53)$ & $11.1-15.4$ & (Long haul) \\
\hline
\end{tabular}

Note: Idle and take-off data are derived from ICAO Engine exhaust emissions databank (ICAO, 1995b). Cruise data are taken from the global 3-D inventories of ANCAT/EC (Gardner, 1997b) and NASA (Baughcum et al., 1996); $\mathrm{NO}_{x}$ data are averages of data from the two inventories; $\mathrm{CO}$ and $\mathrm{HC}$ are from the NASA work.

Table 9. Emissions certification data for Trent 772 Engine

\begin{tabular}{lccccccc}
\hline & \multirow{2}{*}{$\begin{array}{c}\text { Power } \\
\text { Metting } \\
\left(\% / F_{\text {oo }}\right)\end{array}$} & $\begin{array}{c}\text { Time } \\
(\mathrm{mins})\end{array}$ & $\begin{array}{c}\text { Fuel flow } \\
\left(\mathrm{kg} \mathrm{s}^{-1}\right)\end{array}$ & & $\mathrm{HC}$ & $\mathrm{CO}$ & $\mathrm{NO}_{x}$ \\
\cline { 5 - 8 } & 100 & 0.7 & 3.20 & 0.00 & 0.20 & 34.38 \\
Take-off & 85 & 2.2 & 2.58 & 0.00 & 0.16 & 26.44 \\
Climb out & 30 & 4.0 & 0.85 & 0.01 & 0.89 & 10.30 \\
Approach & 7 & 26.0 & 0.28 & 1.46 & 17.94 & 4.71 \\
Idle & & & & 2.06 & 26.0 & 56.3 \\
Regulatory parameter $\left(\mathrm{g} \mathrm{kN}^{-1}\right)$ & & & & & \\
\hline
\end{tabular}

Note: The power settings for each mode are expressed as a percentage of the rated output $\left(F_{\text {oo }}\right)$ of the engine. For emissions purposes, the rated output is the maximum power available for take-off under normal operating conditions at ISA (International Standard Atmosphere) sea level static conditions (ICAO, 1993a).
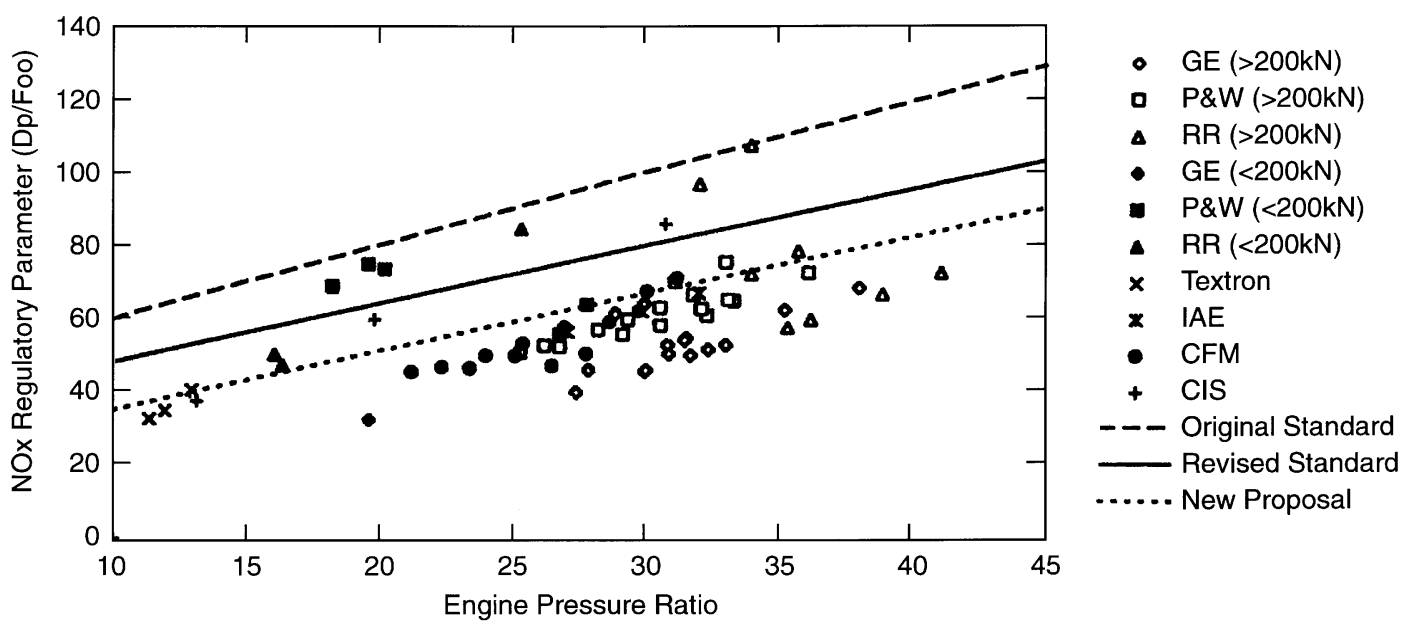

Fig. 15. Oxides of nitrogen emissions from late model engines.

been only a relatively small increase in $\mathrm{NO}_{x}$ emissions due to improvements in combustor technology, rather than the much larger increase which would be predicted due to the much higher combustion temperatures and pressures associated with the more fuelefficient engine cycles. Actual fleet trend data, relevant to atmospheric research, cannot be directly deter- mined from the certification information, but is available from the most recent 3-D global emissions distribution studies (Section 4.8).

Currently, there are no regulations covering flight phases such as cruise. However, ICAO (1995c), taking note of scientific concerns about the impact of inflight emissions, has begun to consider the need and 
feasibility of introducing standards for cruise and climb phases of flight. This is also addressing the issue of whether certification should be applied to aircraft rather than to engines.

In addition to the currently regulated products, emissions of particulates, aerosols, speciated hydrocarbons, other nitrogen and sulphur compounds are of concern to the atmospheric science community because of their potential effects on global ozone and climate change.

4.6.2. Cruise emissions. As noted earlier, engines are currently only regulated for some species over an LTO cycle. The LTO part of a flight mission is a very small proportion as shown for typical short haul and long haul missions (Tables 10 and 11). Whilst LTO emissions data are available, it is clearly necessary to be able to generate accurate data for other flight phases.

It is not possible to achieve flight operating conditions on the test facilities used for certification testing, since the environmental temperature and pressure regimes corresponding to the flight altitudes differ very significantly. If such data are required, they have to be obtained using an altitude simulation test cell, in-flight measurement on an aircraft or by using mathematical prediction procedures.

Determination of emissions at other flight phases. Currently, controlled measurements of emissions from a very limited number of engines operating at flight conditions have been made in altitude simulation test facilities (Howard, 1996; Lister et al., 1995). Such facilities are highly instrumented and can produce all the necessary engine performance data to a very high quality. However, there are only a few facilities in the world available for such tests and these are complex and extremely expensive to operate. While it is impracticable to use these facilities for routine determination of engine emissions, such measurements provide the "gold standard" reference against which other measurement methods and prediction techniques should be judged. In-flight measurements have been performed, both by remote optical measurements of engine exhausts (Haschberger and Lindermeir, 1996) and by using a chase plane to sample the exhaust from another aircraft (Fahey et al., 1995a, b; Schulte and Schlager, 1996; Schulte et al., 1997). Again, however, these are impractical for determination of emissions from all aircraft and engine types.

Flight emissions prediction. Recognising these limitations, engine manufacturers have developed methods for calculation of in-flight emissions from the ground-level certification data, based on, amongst other parameters, the pressure $\left(P_{3}\right)$ and temperature $\left(T_{3}\right)$ conditions at the inlet to the combustor. In practice, these methods rely on detailed computer simulations of the internal engine performance, which have been extensively validated against ground level and flight performance test data by each individual engine manufacturer. These $P_{3}, T_{3}$ methods are considered to be the most accurate for calculation of in-flight emissions. A typical example is shown in Fig. 16. Agreement is better than 5\%.

Unfortunately, engine manufacturers regard combustor inlet parameters as commercially sensitive and consequently they are not normally available.

Table 10. Short-haul route emissions: London-Glasgow (distance $555 \mathrm{~km}$ ); Boeing 757 aircraft

\begin{tabular}{lrrrrrrr}
\hline & $\begin{array}{r}\mathrm{Fuel} \\
(\mathrm{kg})\end{array}$ & $\begin{array}{c}\mathrm{CO}_{2} \\
(\mathrm{~kg})\end{array}$ & $\begin{array}{r}\mathrm{H}_{2} \mathrm{O} \\
(\mathrm{kg})\end{array}$ & $\begin{array}{r}\mathrm{SO}_{x} \\
(\mathrm{~kg})\end{array}$ & $\begin{array}{r}\mathrm{HC} \\
(\mathrm{kg})\end{array}$ & $\begin{array}{r}\mathrm{CO} \\
(\mathrm{kg})\end{array}$ & $\begin{array}{c}\mathrm{NO}_{x} \\
(\mathrm{~kg})\end{array}$ \\
\hline Taxi-take/off-climb out & 1000 & 3130 & 1220 & 1.0 & 0.9 & 8 & 17 \\
Climb-cruise-descent & 2400 & 7560 & 2950 & 2.4 & 1.4 & 13 & 40 \\
Approach-landing-taxi & 430 & 1350 & 530 & 0.4 & 0.4 & 3 & 2 \\
Total flight & 3830 & 12,040 & 4700 & 3.8 & 2.7 & 24 & 59 \\
LTO/total flight (\%) & 37 & 37 & 37 & 37 & 48 & 46 & 32 \\
\hline
\end{tabular}

Note: For this comparison, the climb out segment is up to $915 \mathrm{~m}$ and the approach segment is down from $915 \mathrm{~m}$, i.e. the LTO cycle. The remaining climb-cruise-descent is between $915 \mathrm{~m}$ and the cruise altitude.

Table 11. Long-Haul route emissions: Los Angeles-Tokyo (distance 8750 km); DC10-30 aircraft

\begin{tabular}{lrrrrrrr}
\hline & $\begin{array}{c}\text { Fuel } \\
(\mathrm{kg})\end{array}$ & $\begin{array}{c}\mathrm{CO}_{2} \\
(\mathrm{~kg})\end{array}$ & $\begin{array}{c}\mathrm{H}_{2} \mathrm{O} \\
(\mathrm{kg})\end{array}$ & $\begin{array}{r}\mathrm{SO}_{x} \\
(\mathrm{~kg})\end{array}$ & $\begin{array}{r}\mathrm{HC} \\
(\mathrm{kg})\end{array}$ & $\begin{array}{c}\mathrm{CO} \\
(\mathrm{kg})\end{array}$ & $\begin{array}{c}\mathrm{NO}_{x} \\
(\mathrm{~kg})\end{array}$ \\
\hline Taxi-take/off-climb out & 1680 & 5280 & 2060 & 1.7 & 16 & 43 & 35 \\
Climb-cruise-descent & 82,060 & 258,500 & 100,930 & 82.0 & 87 & 340 & 1620 \\
Approach-landing-taxi & 660 & 2070 & 810 & 0.7 & 6 & 18 & 5 \\
Total flight & 84,400 & 265,850 & 103,800 & 84.4 & 109 & 401 & 1660 \\
LTO/total flight (\%) & 3 & 3 & 3 & 3 & 20 & 15 & 2 \\
\hline
\end{tabular}

Note: For this comparison, the climb out segment is up to $915 \mathrm{~m}$ and the approach segment is down from $915 \mathrm{~m}$, i.e. the LTO cycle. The remaining climb-cruise-descent is between $915 \mathrm{~m}$ and the cruise altitude. 


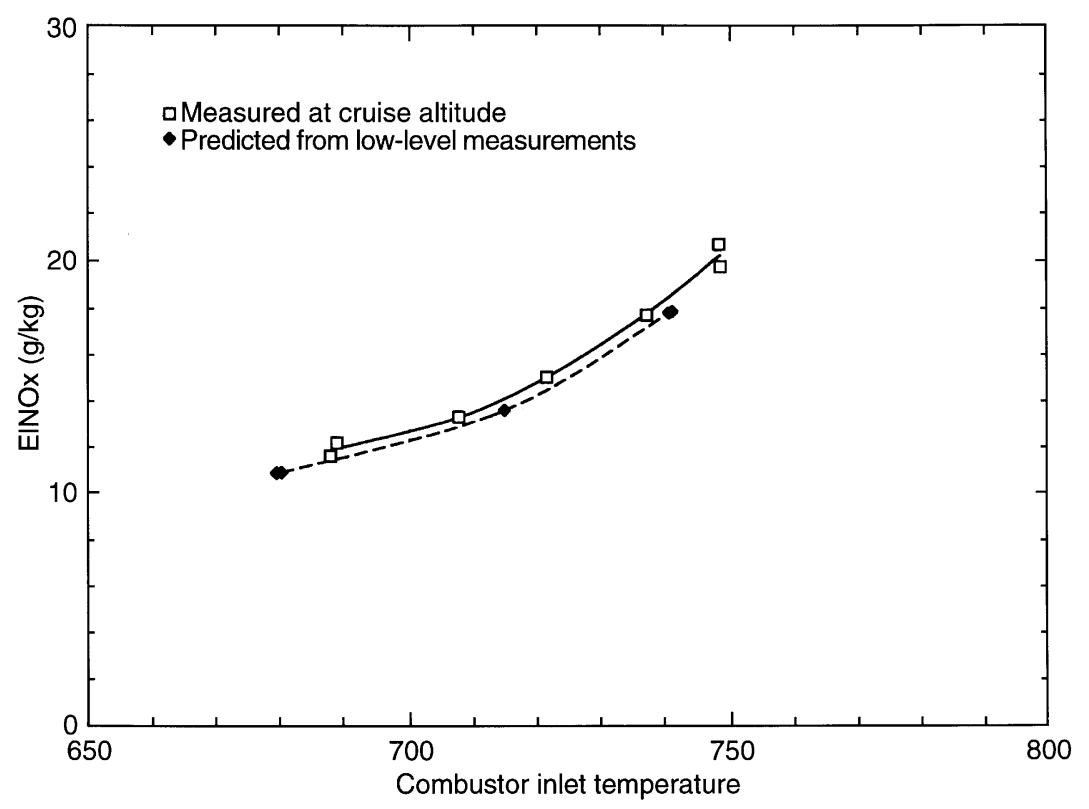

Fig. 16. Rolls-Royce RB211 engine: Comparison of measured and predicted EINOX, based on combustor inlet parameters (Lister et al., 1995). The prediction equation was developed from parametric tests on the combustor, varying combustor inlet temperature, pressure, air and fuel flow. The prediction equation is: predicted EINOX = measured EINOX $\left(\mathrm{P}_{\text {ref }} / \mathrm{P}_{\text {measured }}\right)^{0.3}\left(\mathrm{AFR}_{\text {ref }} / \mathrm{AFR}_{\text {measured }}\right)^{-0.91}$, where AFR is air to fuel ratio.

Therefore, alternative methods based only on a knowledge of engine fuel flow, ambient conditions and emissions certification data have been developed for use in development of inventories (Section 4.8) and environmental impact studies (AERONOX, AESA, SASS). Validation of these have been performed, mainly by engine manufacturers, against $P_{3}, T_{3^{-}}$based predictions.

Further confirmation has come from specific research programmes. In the AERONOX programme, both a RB211 and a PW305 engine were tested over a range of flight altitudes and operating conditions in altitude simulation test facilities (Lister et al., 1995). Figure 17 indicates that for the RB211 engine, $\mathrm{NO}_{x}$ prediction and measurement is within $10 \%$.

Comparison of measurements and predictions of cruise altitude $\mathrm{NO}_{x}$ (Fig. 18) from commercial jet aircraft by chase planes (Fahey et al., 1995a; Schulte and Schlager, 1996; Schulte et al., 1997), show a larger scatter, but good agreement with the prediction method. Recent measurements of a Concorde supersonic aircraft exhaust (Fahey et al., 1995b) also shows good agreement between measurements in-flight, prediction and altitude simulation test facility measurements (EINOX $=23.3,19.5-21.7$ and 18.9-26.4, respectively). Overall, there is a high degree of confidence in the use of these alternative fuel-flow-based methods for environmental assessment purposes and they have been the basis of all the recent major inventory developments.

4.6.3. Unregulated emissions. Whereas the formation and emission of nitrogen oxides $\mathrm{NO}_{x}(\mathrm{NO}$ and
$\mathrm{NO}_{2}$ ) has been the object of numerous investigations (Schumann, 1995) there is only limited information available on the emission of other reactive nitrogen species $\left(\mathrm{NO}_{y}\right)$ such as HONO, the exact composition of the hydrocarbons emitted and their partially oxidised products (ketones, aldehydes, acids) and particles (Stolarski and Wesoky, 1993; Lazano et al., 1968; Katzman and Libby, 1975; Spicer et al., 1992, 1994; Wiesen et al., 1996a).

A better knowledge of direct $\mathrm{NO}_{y}$ emissions from aircraft and the formation of $\mathrm{NO}_{y}$ species in the aircraft plume is needed because of the potential influence of these species on stratospheric and tropospheric ozone. A detailed knowledge of the emission of non-methane hydrocarbons and partially oxidised hydrocarbons is of particular importance because of the reactivity of these species which may lead to chemical reactions forming, e.g. organic nitrates and peroxynitrates in the immediate wake of aircraft. A substantially better understanding of particulate emission is required since these species may contribute directly to climate change due to their scattering and absorption properties and also because of the heterogeneous reactions that may occur. Finally, knowledge of emission indices for these trace species are, at least in part, essential for the correct modelling of the engine exhaust and the plume chemistry.

Volatile organic compound measurements. The chemical composition of the exhaust from aircraft turbine engines with respect to the hydrocarbons has been studied at high-altitude supersonic flight conditions (Katzman and Libby, 1975). The authors who 


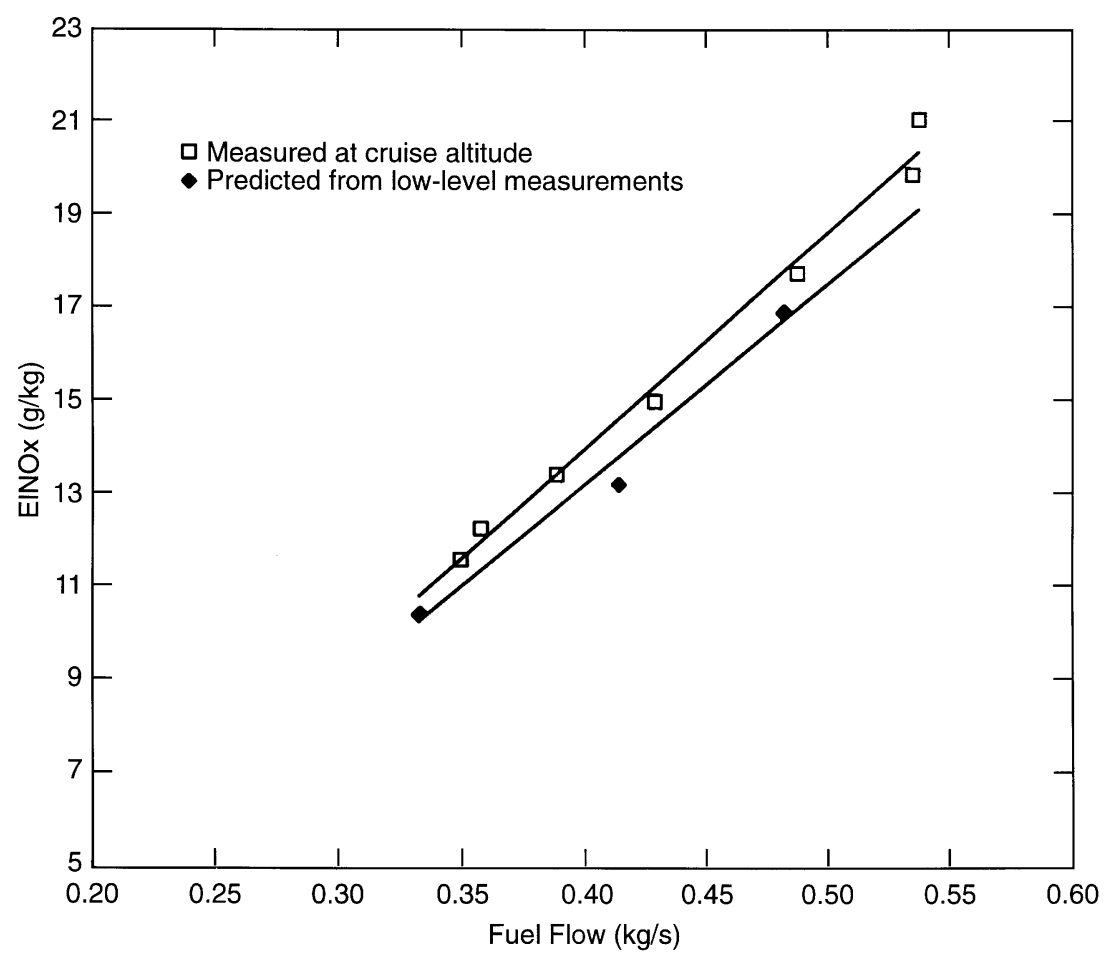

Fig. 17. Rolls Royce RB 211 engine: Comparison of measured and predicted EINOX, based on engine fuel flow (Lister et al., 1995). The prediction equation used, which was developed by DLR, Germany, takes account of the altitude and flight speed (Mach number) and is given in Appendix B of Part II of the report of the AERONOX programme (Schumann, 1995).

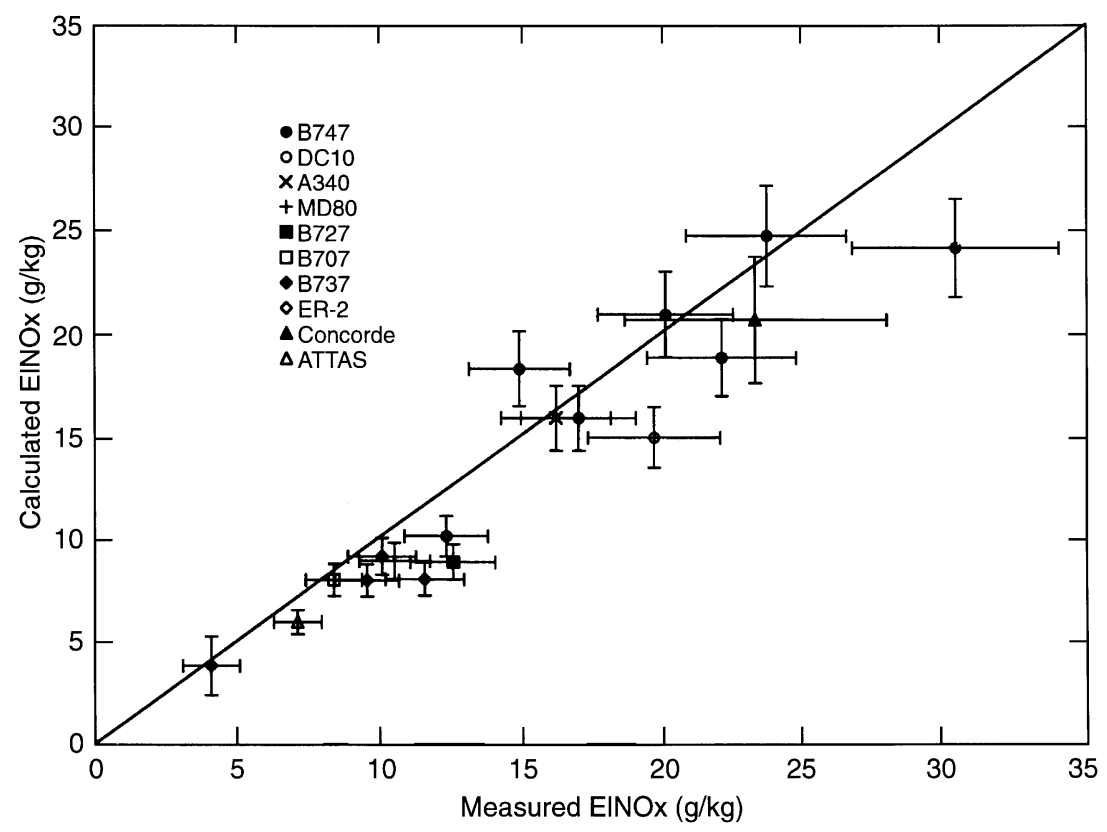

Fig. 18. Cruise altitude $\mathrm{NO}_{x}$ emission indices of Commercial Jet Aircraft. Composite plot of data; Concorde and ER-2 (Fahey et al., 1995a, b), B747, DC10, and A340 (Schulte et al., 1997), others (Schulte and Schlager, 1996).

studied the emissions as part of the U.S. Climatic Impact Assessment Program in the mid-1970s investigated a YJ93GE-3 and a J85-GE-5B engine running under two power settings. The experimental tech- nique used was gas chromatography (GC) in combination with an adsorption/desorption technique. It should be pointed out that the authors found that olefins accounted for up to $75 \mathrm{~mol} \%$ carbon of the 
hydrocarbons observed in the exhaust, which is, at least in part, caused by the high efficiency of the turbine aircraft engines. Surprisingly, the authors did not find identifiable oxygenated hydrocarbons such as aldehydes, ketones, alcohols, esters, etc., in the exhaust. However, this finding was probably an artefact caused by interaction of these species with the column packing material used for the GC analysis.

Further investigations on the chemical composition of the exhaust from military engines were carried out by Spicer et al. (1992). These authors investigated a F101 and a F110 engine in a sea-level test bed as a function of engine power by using cryogenic pre-concentration and capillary column gas chromatography for detecting volatile organic compounds (VOC). Carbonyl compounds were measured by a special derivatisation technique using dinitrophenylhydrazine in combination with HPLC/UV detection. The authors reported a significant reduction of the organic emissions as the engine power was increased above idle running conditions. Methane was found to be the dominant organic compound in the exhaust at all power levels investigated. Other than methane, four species ethane, formaldehyde, acetylene and propene accounted for $20-40 \%$ of the VOC emissions at idle running conditions. Alkanes were the most significant class of organic chemicals by concentration at all power levels. Alkenes, aldehydes and ketones which were observed to be products of incomplete combustion were present in the exhaust at much higher concentrations at low-power settings.

In continuation of this work, Spicer et al. (1994) studied the emissions from a GE TF-39 and a CFM56 engine which were both operated with JP-5 fuel. The CFM-56 engine represents an engine type designed for low emissions. Table 12 summarises the main results from this study. The measurements included $\mathrm{C}_{1}-\mathrm{C}_{17}$ hydrocarbons, polycyclic aromatic hydrocarbons, aldehydes, ketones, alcohols and dicarbonyl compounds. A carbon mass balance on the organic emissions showed that $99 \pm 13 \%$ of the organic carbon was accounted for by the measure- ments. Five substances (ethene, propene, acetylene, methane and formaldehyde) accounted for $30-40 \%$ of the organic emissions at idle running conditions, whereas at $80 \%$ power methane was the dominant organic constituent in the exhaust. Carbonyl compounds were found to be very significant contributors to the organic composition of the exhaust, especially at idle power setting. In addition, the authors studied the photochemical reactivity of the emissions at idle running conditions using two large outdoor smog chambers from which it was concluded that the emissions from the CFM-56 engine are about $40 \%$ more reactive with respect to ozone formation than the GE TF-39 emissions. Alkenes were estimated to contribute about $70 \%$ of the reactivity and aldehydes $17-24 \%$.

More recently, the emission of a large variety of trace species from two engine combustors were studied under various operating conditions within the AEROTRACE project which was funded by the European Commission. Preliminary results which were obtained in a modified reverse annular flow combustor were recently presented at an international colloquium in Paris (Wiesen et al., 1996a). In agreement with previous findings, the concentration of the different hydrocarbons and oxygenated hydrocarbons were found to be strongly dependent on the operating conditions of the combustor. The concentration of unsaturated hydrocarbons such as alkenes and alkynes was always much greater than the concentration of the saturated hydrocarbons. Although a large number of different species were detected in the exhaust, it was observed that under specific conditions only a small number, $8-10$ species, contribute up to $80 \%$ of the total emission of organic species (Table 13).

From the different experiments described above it can be concluded that the emissions of the species investigated are strongly dependent on the operating conditions of the engines. However, the implications of the present results for atmospheric chemistry, in particular, ozone formation have still to be evaluated.

Table 12. Emission of selected VOC from jet engines operated at sea-level flight conditions (Spicer et al., 1994); values are given in ppmC; ND = below detection

\begin{tabular}{lcccccc}
\hline & \multicolumn{3}{c}{ TF-39 Engine } & \multicolumn{3}{c}{ CFM-56 Engine } \\
\hline Thrust & Idle & $30 \%$ & $80 \%$ & Idle & $30 \%$ & $80 \%$ \\
Methane & 9.42 & 1.63 & 1.09 & 5.58 & 0.58 & 0.44 \\
Ethane & 2.04 & 0.05 & 0.11 & 1.11 & 0.04 & ND \\
Ethene & 62.28 & 3.03 & 0.04 & 35.25 & ND & 0.05 \\
Propane & 0.89 & 0.01 & ND & 0.17 & 0.01 & ND \\
Acetylene & 16.85 & 1.23 & ND & 9.67 & ND & ND \\
Propene & 21.33 & 0.42 & 0.02 & 10.34 & 0.01 & ND \\
1,3-Butadiene & 8.28 & 0.29 & ND & 3.99 & ND & 0.01 \\
Benzene & 7.45 & 0.49 & 0.03 & 4.13 & 0.02 & 0.02 \\
Toluene & 2.71 & 0.11 & 0.01 & 1.56 & 0.01 & ND \\
Formaldehyde & 14.6 & 1.2 & 0.34 & 13.1 & 0.77 & 0.17 \\
Acetaldehyde & 7.5 & 0.51 & 0.09 & 6.2 & 0.03 & 0.041 \\
Acrolein & 6.17 & 0.35 & 0.03 & 4.2 & $<0.01$ & $<0.01$ \\
\hline
\end{tabular}


Table 13. Emission of selected VOC from a reverse annular flow combustor as a function of operating conditions (Wiesen et al., 1996a); values are given in ppmV; to obtain emissions in ppmC multiply the given values with the respective number of carbon atoms of the species selected

\begin{tabular}{lcccc}
\hline \multicolumn{4}{c}{ Reverse annular flow combustor } \\
\hline Thrust & $18.5 \%$ & $30 \%$ & $85 \%$ & $100 \%$ \\
Methane & $0.47-1.22$ & $1.09-1.58$ & 0.23 & 0.15 \\
Propane & $0.010-0.005$ & $0.004-0.006$ & $<0.001$ & 0.002 \\
iso-Butane & $0.020-0.026$ & $0.023-0.035$ & $<0.011$ & 0.017 \\
$n$-Butane & $0.028-0.032$ & $0.026-0.045$ & $<0.011$ & 0.022 \\
Ethene & $0.196-1.06$ & $0.006-0.187$ & $<0.005$ & $<0.005$ \\
Propene & $0.290-1.32$ & $0.293-0.901$ & $<0.014$ & $<0.016$ \\
1-Butene & $0.237-0.867$ & 0.211 & 0.043 & 0.061 \\
iso-Butene & $0.167-0.312$ & $0.132-0.211$ & 0.045 & 0.175 \\
Benzene & $0.021-0.122$ & $0.010-0.030$ & $<0.002$ & $<0.002$ \\
Toluene & $0.013-0.021$ & $0.010-0.012$ & $<0.002$ & 0.004 \\
$m / p$-Xylene & $<0.001$ & $<0.001$ & 0.010 & 0.025 \\
$o$-Xylene & $<0.001$ & $<0.001$ & $<0.001$ & 0.002 \\
Carbonyl compounds & $1.76-1.94$ & $2.7-4.56$ & $0.19-0.28$ & 0.18 \\
\hline
\end{tabular}

More experiments with different types of combustors or engines such as low- $\mathrm{NO}_{x}$ combustors are still necessary to set up a reliable database for the emission of trace species from aeroengines.

$\mathrm{NO}_{y}$ species measurements. The chemical composition of the exhaust from aircraft turbine engines with respect to $\mathrm{NO}_{y}$ species has been studied in only a very limited number of experiments most of which were carried out at real flight conditions. With respect to $\mathrm{NO}_{y}$ species, other than $\mathrm{NO}$ and $\mathrm{NO}_{2}$, most experiments have dealt with the detection of HONO and $\mathrm{HNO}_{3}$. From global three-dimensional model studies on $\mathrm{NO}_{y}$ emissions from aircraft it was concluded that aircraft sources appear to have only a minimal impact on lower tropospheric $\mathrm{NO}_{y}$ mixing ratios in the Northern Hemisphere and in much of the Southern Hemisphere (Kasibhatla, 1993).

Arnold et al. (1992) studied the emission of HONO and $\mathrm{HNO}_{3}$ at cruise altitude by using a AAMAS instrument which is essentially comprised of a quadrupole mass spectrometer, a liquid neon-cooled cryopump, a flow-tube reactor and an ion source. The instrument was flown aboard the DLR research aircraft FALCON. The authors investigated the plume of a DC-9 airliner at a flight altitude of $9.5 \mathrm{~km}$ at a distance of $2 \mathrm{~km}$ which corresponds to a plume age of $9 \mathrm{~s}$. The authors observed an increase of the HONO concentration from a background value of about $5 \mathrm{pptV}$ to maximum values of about $520 \mathrm{pptV}$ when the FALCON flew within the plume of the DC-9 airliner. In addition, the results from the $\mathrm{HNO}_{3}$ measurements imply that only about $0.05 \%$ of the emitted reactive nitrogen oxides undergoes conversion into $\mathrm{HNO}_{3}$ in the "young" exhaust plume. This result is of particular interest since $\mathrm{HNO}_{3}$ contributes to the formation of aerosols. However, from this study it was not possible to answer the question whether $\mathrm{HONO}$ was directly formed in the engine or by reac- tion of $\mathrm{NO}$ and $\mathrm{NO}_{2}$ with $\mathrm{OH}$ radicals in the "young" plume.

Fahey et al. (1995a) studied the total reactive nitrogen emissions from a J75 turbine engine by using a chemiluminescence detector aboard the NASA ER-2 high-altitude aircraft. From the measurement of the $\mathrm{NO}_{x}$ and $\mathrm{NO}_{y}$ concentration it was concluded that $\mathrm{NO}_{x}$ is the predominant reactive nitrogen species up to $10 \mathrm{~min}$ after emission. In continuation of their work Fahey et al. (1995b) investigated the $\mathrm{NO}_{y}$ emission from the Concorde supersonic aircraft with the same research aircraft. The high $\mathrm{NO}_{x} / \mathrm{NO}_{y}$ ratios observed in the Concorde plume indicate that $\mathrm{HNO}_{3}$ was not abundant in the plume in the first minutes to hours after emission. $\mathrm{HNO}_{3}$ formation is probably controlled by the reaction of $\mathrm{OH}$ with $\mathrm{NO}_{2}$. The observed $\mathrm{OH}$ peak in the plume was attributed to the rapid photolysis of $\mathrm{HONO}$ which is probably formed in the reaction of $\mathrm{OH}+\mathrm{NO}$ within seconds of their emission from the engine.

More recently, the emission of $\mathrm{NO}_{y}$ species from engine combustors were studied under various operating conditions within the AEROTRACE project. Preliminary results which were obtained in an aircraft engine combustor were recently presented at an international colloquium in Paris (Ristori and Baudoin, 1996). The authors reported high HONO concentrations up to $5 \mathrm{ppmV}$ which were measured directly at the exit of the combustor. However, it is not yet clear whether HONO emitted from the combustor will reach the exit of the engine without further chemical reactions, e.g. with $\mathrm{OH}$ radicals.

From the different experiments described above, it can be concluded that only very limited data are available on the emissions of $\mathrm{NO}_{y}$ species from aeroengines. Further experiments with different types of combustors or engines such as low- $\mathrm{NO}_{x}$ combustors are strongly encouraged in order to set up a reliable database for the emission of $\mathrm{NO}_{y}$ species from aeroengines. 
Particulates. Traditionally, particulates from jet engines have been considered as essentially carbon (soot) particles, with some fuel or fuel breakdown products absorbed onto them. The original environmental concern was the visibility of aircraft engine exhaust plumes and the certification method developed to control this was based around a filter method of smoke measurement (SAE, 1991). The measurement index (Smoke Number) was originally correlated against plume obscuration (i.e. visibility) (Champagne, 1971) and certification data for the LTO cycle are available for most engines currently in operation (ICAO, 1995b). This method provides an indication of the mass of the particle emissions, but not of mean particle size or size distributions. Until recently, there has been a scarcity of published size data. However, indications were that the peak of the particle size distribution was in the region of 50-100 nm. Some work has been performed to evaluate the relationships between particle size distributions and smoke number (Girling et al., 1990; Paladino, 1997) using simulation sources of smoke that were reasonably representative of engine smoke. These indicate that the smoke number, and therefore the SAE method, only reflects the number density of the relatively insignificant numbers of large particles, while not accurately accounting for the total number of particles emitted.

More recently, particle size measurements at the engine exhaust have become available (Howard, 1996; Rickey, 1995; Spicer et al., 1990, Whitefield et al., 1996), which confirm that the distribution peaks between 30 and $100 \mathrm{~nm}$. In addition, a number of flight campaigns have sampled the plumes of aircraft and determined number densities and size distributions of particulates. These are summarised and discussed in Section 5.

One of the most comprehensive investigations is that on a J85-GE-5L turbojet engine. Particles were measured at the engine exhaust over a range of engine speeds at simulated altitude conditions ranging from near sea level up to $45,000 \mathrm{ft}$ and at two flight Mach numbers (0.5 and 0.8) (Rickey, 1995). The total number, volume and surface area of particles decreased as the altitude increased, which resulted in a decrease in the Sauter mean diameter from 70 to $40 \mathrm{~nm}$ with altitude. Comparison of the particle data measured at near-sea-level conditions with other data from a similar engine (GE-J85-4A) operating at sea-level static conditions showed very good agreement for total particle count and mean diameter, i.e. within a factor of 2 . Further comparisons of the engine altitude results with data from a J85 combustor at three different simulated altitudes gave poorer agreement, both in absolute levels and trends with altitude and power setting; for a given altitude and engine power, the combustor produced fewer, larger particles than the engine. The results of other well controlled tests in altitude simulation facilities (Hagen et al., 1996) are consistent with these earlier data.
These results would indicate that sea-level static engine test measurements should not be used to represent the altitude particle emissions from an engine. While there are prediction equations for calculation of gaseous emissions at altitude conditions from sea-level data, such relationships have not yet been established for particulates.

Recently, the emissions of particulates from a range of engine combustors were studied under a parametric carpet of operating conditions including sea-level static and typical cruise conditions. Preliminary results from one of the combustors (Hurley et al., 1996) indicated that the total number of particles increased linearly with pressure, and decreased with combustor inlet temperature. It is not yet certain whether these conclusions hold for all types of combustor. Further tests are being undertaken with the corresponding engine to attempt to establish the relationships between combustor and engine exhaust particulates, at least at ground level.

For atmospheric issues, sulphur compounds, arising from the fuel sulphur, are also important as precursors of atmospheric aerosols and contrails. It had been thought that the fuel sulphur was only converted to $\mathrm{SO}_{2}$ between the combustor and engine exhaust. However, explanation of plume observations (Fahey et al., 1995b) is not consistent with this. Kinetic studies, measurements and modelling (Brown et al., 1996; Hunter, 1982; Kärcher and Fahey, 1997) would now appear to indicate that substantial conversion to $\mathrm{SO}_{3}(>10 \%)$ and possibly to $\mathrm{H}_{2} \mathrm{SO}_{4}$ occurs in the engine exhaust. More work is required to establish the controlling parameters and whether it is possible to predict their formation under all operating conditions.

$\mathrm{CH}_{4}$ and $\mathrm{N}_{2} \mathrm{O}$ measurements. The chemical composition of the exhaust from aircraft turbine engines with respect to $\mathrm{CH}_{4}$ and $\mathrm{N}_{2} \mathrm{O}$ has been studied in only a very limited number of experiments. Within the European AERONOX project, Wiesen et al. (1994, 1996b) studied the $\mathrm{CH}_{4}$ and $\mathrm{N}_{2} \mathrm{O}$ emissions from a Rolls Royce RB 211 and a Pratt \& Whitney PW 305 engine under various engine operating conditions in sea-level tests as well as under simulated flight conditions. The authors reported that methane contributes to the combustion products only under idle/taxi running conditions and, possibly, also during the descend mode, when the engine is also in idle conditions. At higher thrust levels, much of the methane in the exhaust is probably due to atmospheric $\mathrm{CH}_{4}$ that was present in the ambient air used for combustion.

For $\mathrm{N}_{2} \mathrm{O}$ the situation was found to be quite similar. It was concluded that direct $\mathrm{CH}_{4}$ and $\mathrm{N}_{2} \mathrm{O}$ emissions from aircraft engines do not contribute significantly to the global $\mathrm{N}_{2} \mathrm{O}$ and $\mathrm{CH}_{4}$ budgets at present. Further work by Fahey et al. (1995) and within the European AEROTRACE project confirmed the results from this study. 
$\mathrm{OH}$ radical measurements. The hydroxyl radicals which leave the combustor exit, and possibly the engine exit, drive the oxidative processing of $\mathrm{NO}_{y}$ and $\mathrm{SO}_{x}$ in the engine plume. The exhaust hydroxyl levels are expected to be very small. Although $\mathrm{OH}$ radicals emitted from aero engines possibly do not affect the stratosphere because of their short life-time, engine plume and wake levels of $\mathrm{NO}_{2}, \mathrm{HNO}_{3}, \mathrm{SO}_{3}$ and $\mathrm{H}_{2} \mathrm{SO}_{4}$ are determined by $\mathrm{OH}$-induced chemistry. Despite its importance in engine combustion processes up to now no direct measurements of $\mathrm{OH}$ radicals in engine exhaust have been reported.

\subsection{Technology development}

The emissions from aircraft are important from the point of atmospheric chemistry and the potential impacts on ozone and climate. However, engine/aircraft performance, fuel efficiency, technical reliability and durability are of high priority to airlines and therefore to manufacturers. Technology advances are also sought as the means of improving emissions performance. These issues have been dealt with in detail elsewhere (ICAO, 1995a), but a brief summary is provided in the following section.

4.7.1. Importance of fuel efficiency in engine design. Fuel efficiency has always been one of the key aspects of engine design, since fuel costs are a large proportion of the direct operating costs (DOC) of airlines. Improvements in fuel efficiency provide airlines with the potential for extending the flight range, increasing the payload or a combination of both of these. Thus, this is a highly competitive commercial issue, which will continue to remain a very high priority with operators and manufacturers.
Since the early 1960s, significant improvements ( $>40 \%$ ) in the specific fuel consumption (SFC) of jet engines have been achieved as engine designs have moved from the early turbojets through the first generation low bypass ratio turbofan engines to the current high bypass ratio turbofan engines (Fig. 12). These have required concurrent significant advances in high-temperature materials and cooling technology to cope with the higher internal pressures and temperatures generated by the advanced engine cycles of modern high bypass ratio (6:1) engines. The GE90 engine, certificated in 1995, was designed with a bypass ratio of $>9$, aiming to achieve further improvements in SFC (about 10\% lower) and associated emission benefits.

Further increases in bypass ratio (up to 15 or 20:1 may be feasible, with a consequent further $15-20 \%$ SFC (and hence $\mathrm{CO}_{2}$ ) benefit and improvements in all emissions levels. However, major new technology breakthroughs are needed before such bypass ratios can become a reality. Some concepts, e.g. intercooled-recuperated systems, would be inapplicable to aircraft due to increased weight, bulk and complexity. Nevertheless, there is a theoretical limit, based on thermodynamic considerations, which is likely to be equivalent to a reduction of around $65-70 \%$ from the 1960s level (Fig. 19).

From the emissions viewpoint, the major products from the combustion of aviation fuel, i.e. $\mathrm{CO}_{2}$ and water vapour, are effectively controlled by these ongoing commercial and operational pressures on the manufacturers to reduce fuel consumption. Therefore, there is a common benefit to both the commercial and environmental interests.

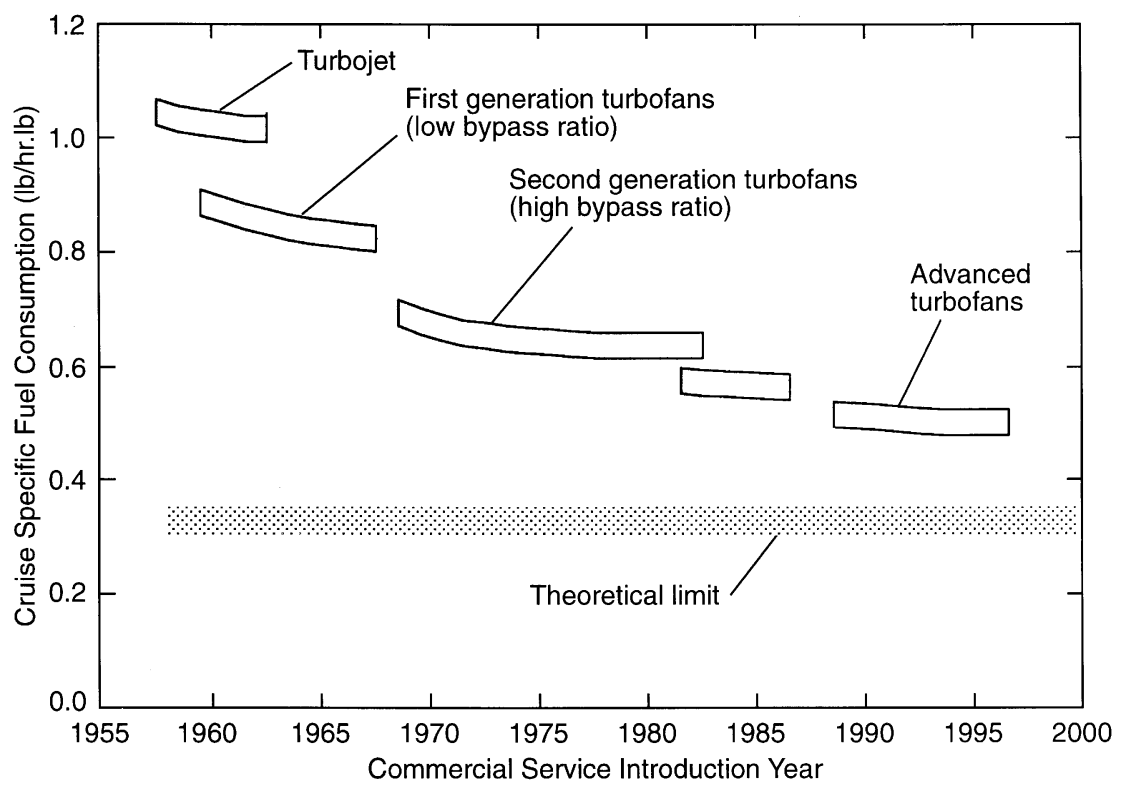

Fig. 19. Fuel consumption improvements as engine technology has advanced from straight turbojets to turbofan engines with increasing bypass ratio. 
4.7.2. $\mathrm{CO}_{2}-\mathrm{NO}_{\mathrm{x}}$ reduction conflicts. While the continuing trend to higher temperatures and pressures in the advanced engine cycles will lead to improved SFC and reduced $\mathrm{CO}_{2}$ and water vapour, it would, without further technological improvements, result in higher $\mathrm{NO}_{x}$ levels, which would more than offset any emissions reductions arising from the improved SFC. This conflict is well recognised and is part of the trade-off considerations in engine designs. Some considerable limitation of $\mathrm{NO}_{x}$ has been achieved by optimisation of fuel-air mixing and distribution within the combustor as well as by the shortening of the combustor, with consequent reductions in residence time for the formation of $\mathrm{NO}_{x}$. The pressures for further large reductions in $\mathrm{NO}_{x}$ have been addressed by radically different combustor technology as indicated below.

4.7.3. $\mathrm{NO}_{x}$ reduction technology. Conventional combustor technology. Improved combustors are still being developed, both for the existing engine types, such as the JT8D-200 and CF6-80 series, and also for new engine models such as the Trent, PW4084, BR700. 10-20\% $\mathrm{NO}_{x}$ reductions are the goals for the older engines, although only smaller reductions can be anticipated for newer engine types since they already incorporate many of the available technical improvements and optimisations.

$\mathrm{HC}$ and $\mathrm{CO}$ have been reduced considerably without significant adverse effects on $\mathrm{NO}_{x}$. Typically, current production engines have large margins when compared to the relevant ICAO standard.

Historically, there has been concern over the possible trade-offs between $\mathrm{HC}$ and $\mathrm{CO}$ on the one side and $\mathrm{NO}_{x}$ on the other; also between smoke and $\mathrm{NO}_{x}$. However, while there is consistency in the trade-off trends, the available data indicate that the actual trade-offs are not unique and can vary significantly between different combustor designs. If $\mathrm{NO}_{x}$ is reduced through a change to the fuel-air ratio then smoke may not increase, but the low power emissions of $\mathrm{HC}$ and $\mathrm{CO}$ will tend to do so.

Low $\mathrm{NO}_{x}$ combustor technology. Research to develop combustion systems producing significantly lower $\mathrm{NO}_{x}$ levels occurred in the NASA Experimental Clean Combustor Program of the mid-1970s (CIAP, 1975). These fuel-staged systems offered the potential of about a $30 \% \mathrm{NO}_{x}$ reduction and have now been developed into airworthy systems for incorporation into medium and high thrust engines.

The first of these, a CFM56-5B, was certificated in July 1994 with a $>30 \%$ reduction in $\mathrm{NO}_{x}$ emissions compared to those of a single conventional combustor in the same engine. Additionally, a greater reduction was realised for the whole flight mission than for the ICAO LTO cycle (approximately 45\% compared to just over $30 \%$ ). The reason for this difference is that reduced $\mathrm{NO}_{x}$ levels are obtained at all higher power conditions including cruise, but not at the two low power conditions of the LTO cycle.
For the larger, higher pressure ratio GE90 engine a smaller improvement has been achieved at present, because of the demands for increased cooling requirements. Because of such factors, the attainment of similar $\mathrm{NO}_{x}$ reductions in higher pressure ratio engines can be expected to be more difficult, if not compromised.

In smaller, lower power engines, there are substantial difficulties (physical size, manufacturing tolerances, etc.) which limit the incorporation of the same $\mathrm{NO}_{x}$ combustor technology.

Similarly, such technology can only be applied to modern engine types which are fitted with FADEC (Full Authority Digital Electronic Control) systems. This severely limits any prospects of retrofitting older engines with this technology. Additionally, even for those engines which are fitted with FADEC, the need to replace most of the midsection engine components would make this an expensive and probably uneconomic proposition.

Ultra-low $\mathrm{NO}_{x}$ combustor technology. Other, more radical, fuel-staged combustor technologies [lean-burn-premixed-prevapourised (LPP) and richburn-quick mix-lean burn (RQL)] are being investigated. In principle, these have the potential to achieve reductions of at least $80 \%$. Initially, the application is to a second generation civil supersonic transport aircraft. Target values of EINOX $=5$ have been achieved in the laboratory. Many technology issues remain to be resolved and assuming success, engines incorporating these combustion concepts are not anticipated to enter service much before 2010.

Other research programmes are underway in Europe and U.S.A. to evaluate the potential of these concepts for future high-pressure ratio commercial subsonic aircraft engines.

\subsection{Inventories and scenarios}

4.8.1. Inventories. Two comprehensive inventories (ANCAT/EC and NASA) have been developed in recent years and are widely used by atmospheric modellers. Both incorporate an extensive air traffic movements database, idealised flight operations assumptions and a methodology for prediction of emissions over the entire flight mission. Comparisons of the fuel and $\mathrm{NO}_{x}$ data, from the initial inventories of the two groups (ANCAT, 1995; Wuebbles et al., 1993), showed significant differences which have been reported elsewhere (WMO/UNEP, 1995). Both groups have continued work on their products and have now generated revised versions (Gardner, 1997b; Baughcum et al., 1996a; Metwally, 1996) which result in considerably closer agreement (Table 14). The global distributions of $\mathrm{NO}_{x}$ for the ANCAT/EC2 inventory are shown in Figs. 20 and 21. Numerous areas of uncertainty still exist (e.g. traffic, fuel burn) within both inventories and they therefore provide a range of results for global $\mathrm{NO}_{x}$. 
Table 14. Comparisons of annual fuel use and $\mathrm{NO}_{x}$ mass produced by aviation: ANCAT/EC and NASA inventories

\begin{tabular}{|c|c|c|c|c|}
\hline & $\begin{array}{l}\text { ANCAT/EC } \\
\text { 1A (1992) }\end{array}$ & $\begin{array}{l}\text { ANCAT/EC } \\
2(1992)\end{array}$ & $\begin{array}{c}\text { NASA } \\
1990\end{array}$ & $\begin{array}{c}\text { NASA } \\
1992\end{array}$ \\
\hline & $\begin{array}{l}\text { (ANCAT, 1995; } \\
\text { Gardner et al., } \\
\text { 1997a) }\end{array}$ & (Gardner, 1997b) & $\begin{array}{l}\text { (Wuebbles et al., } \\
\text { 1993) }\end{array}$ & $\begin{array}{l}\text { (Baughcum et al., 1996a; } \\
\text { Metwally, 1995) }\end{array}$ \\
\hline Grid size and spacing & $2.8 \times 2.8 \times 1 \mathrm{~km}$ & $1 \times 1 \times 1 \mathrm{~km}$ & $1 \times 1 \times 1 \mathrm{~km}$ & $1 \times 1 \times 1 \mathrm{~km}$ \\
\hline Fuel use $\left(\mathrm{Tg} \mathrm{yr}^{-1}\right)$ & 165.3 & 132.3 & 133.7 & 135.7 \\
\hline $\begin{array}{l}\mathrm{NO}_{x} \text { mass }\left(\mathrm{Tg} \mathrm{yr}^{-1}\right) \\
\left(\text { as } \mathrm{NO}_{2}\right)\end{array}$ & 2.78 & 1.81 & 1.46 & 1.51 \\
\hline $\operatorname{Tg}(\mathrm{N}) / \mathrm{yr}$ & & 0.55 & & \\
\hline $\mathrm{EI} \mathrm{NO}_{x} \mathrm{~g} \mathrm{~kg}^{-1}$ & 16.8 & 13.7 & 10.9 & 11.1 \\
\hline
\end{tabular}

Note: $\mathrm{NO}_{x}$ is considered as if it were $\mathrm{NO}_{2}$. Values of $\mathrm{Tg} \mathrm{NO}_{x}$ can be converted to $\mathrm{Tg} \mathrm{N}$ by multiplying by $14 / 46=0.30$.

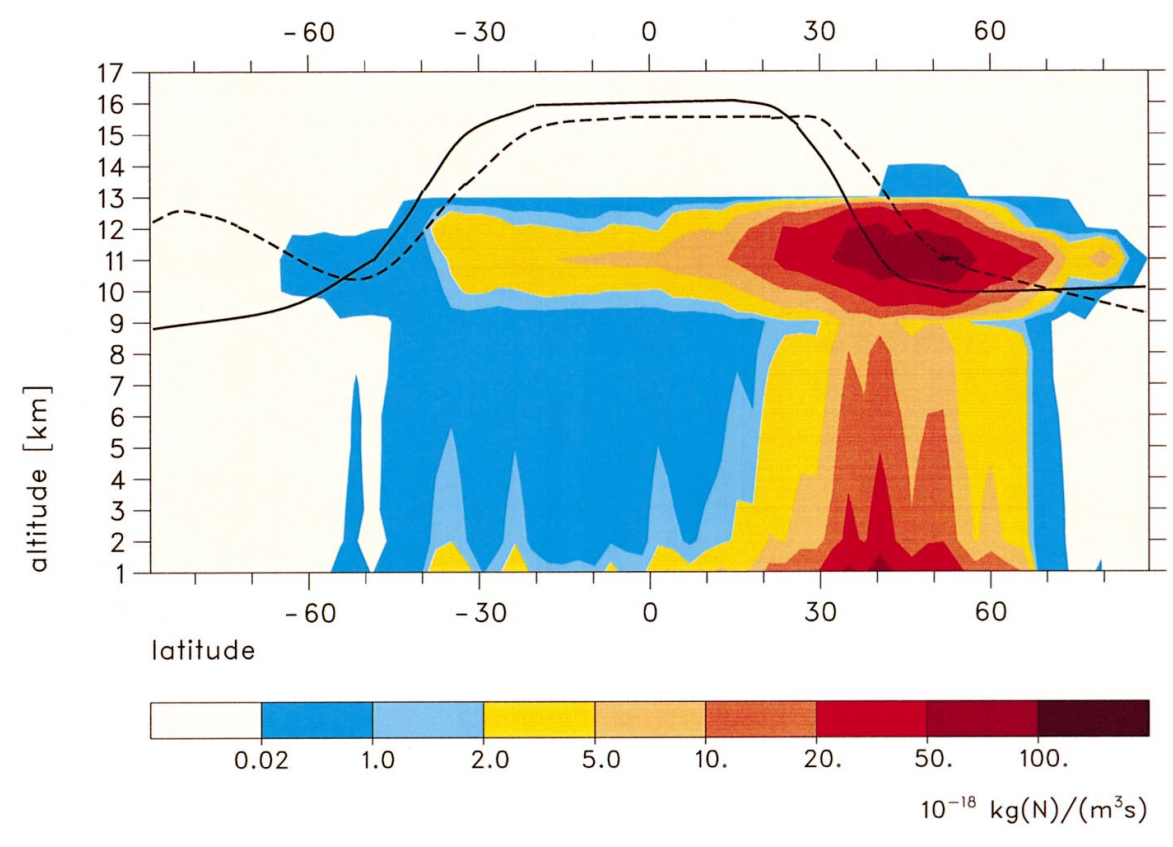

Fig. 20. $\mathrm{NO}_{x}$ emissions by air traffic from ANCAT/EC2 inventory (annual mean; zonal mean).

Historic databases have also been developed for 1976 and 1984 (Baughcum et al., 1996b). Currently, these only incorporate scheduled air traffic. However, they do provide an important indication of fuel and emissions trends for the aggregated world civil aviation fleet (Tables 15 and 16). Fuel and $\mathrm{NO}_{x}$ have increased broadly in line, though EINOX shows an annual average increase of $1 \%$ over the time period of 1976-1992. CO and HC both remain relatively constant over the same time period. For 2015, the prospective size of a supersonic aircraft fleet, displacing part of the subsonic fleet, has a noticeable impact on the fuel and emissions.

It is also clear from the fuel data of the inventories that there is a significant shortfall $(>20 \%)$ between the total aggregate of the inventories and the figures published for world production of refined jet fuel
(IEA, 1993). Figure 22 compares the IEA data with the results from the revised inventories.

These inventories assume optimum flight profiles, great circle (i.e. minimum distance) flight routing, no Air Traffic Control (ATC) delays, etc. The fuel use and emissions may therefore be considered as lower limits and incorporation of real operational practices can only increase the fuel quantity towards the IEA value. The experience of some airlines suggests that real consumption may be up to $10 \%$ higher than the minimum needed for a flight. In addition, it is known that not all fuel declared to be aviation jet fuel is actually sold or used as such; substantial amounts can be blended with diesel type fuels to improve their low temperature properties and be used as heating fuel. These discrepancies are currently being reviewed. 

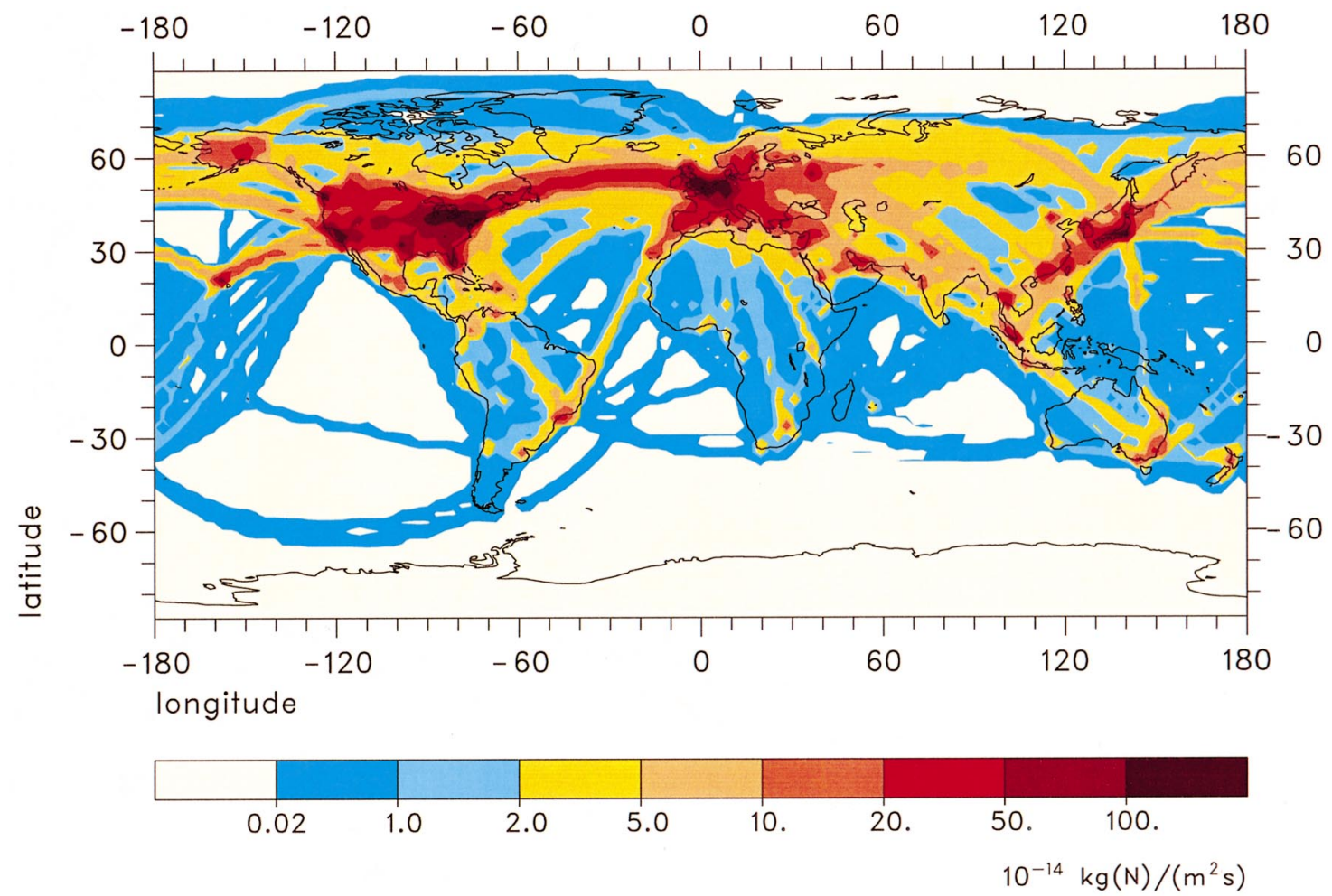

Fig. 21. $\mathrm{NO}_{x}$ emissions by air traffic from ANCAT/EC2 inventory (annual mean).

Table 15. Historic and forecast inventory trends. Annual fuel use and emissions mass output: Civil scheduled air traffic only. 1976, 1984 data from Baughcum (1996b); 1992 data from Baughcum (1996a); 2015 data with Mach 2.4 supersonic aircraft having EINOX $=5$ at cruise condition, from Baughcum and Henderson (1995)

\begin{tabular}{|c|c|c|c|c|c|c|}
\hline & \multirow[b]{2}{*}{1976} & \multirow[b]{2}{*}{1984} & \multirow[b]{2}{*}{1992} & \multicolumn{3}{|c|}{2015} \\
\hline & & & & $\begin{array}{l}\text { Subsonic } \\
\text { only }\end{array}$ & $\begin{array}{c}\text { With } 500 \\
\text { super-sonic }\end{array}$ & $\begin{array}{l}\text { With } 1000 \\
\text { super-sonic }\end{array}$ \\
\hline Fuel use (Tg) & 45.7 & 63.9 & 94.8 & 256 & 310 & 359 \\
\hline $\mathrm{NO}_{x}$ mass $(\mathrm{Tg})$ & 0.50 & 0.79 & 1.23 & 2.37 & 2.63 & 2.89 \\
\hline $\mathrm{CO}$ mass $(\mathrm{Tg})$ & 0.41 & 0.41 & 0.50 & 1.14 & 1.32 & 1.48 \\
\hline $\mathrm{HC}$ mass (Tg) & 0.28 & 0.20 & 0.20 & 0.10 & 0.13 & 0.15 \\
\hline EI NO ${ }_{x}\left(\mathrm{~g} \mathrm{~kg}^{-1}\right)$ & 10.7 & 12.3 & 13.0 & 9.3 & 8.5 & 7.8 \\
\hline EI CO $\left(\mathrm{g} \mathrm{kg}^{-1}\right)$ & 8.9 & 6.3 & 5.3 & 4.5 & 4.3 & 4.1 \\
\hline EI $\mathrm{HC}\left(\mathrm{g} \mathrm{kg}^{-1}\right)$ & 6.0 & 3.2 & 2.1 & 0.4 & 0.4 & 0.4 \\
\hline
\end{tabular}

Note: $\mathrm{NO}_{x}$ is treated as if it were $\mathrm{NO}_{2}$. Values of $\mathrm{NO}_{x}$ mass $(\mathrm{Tg})$ can be converted to mass of nitrogen $(\mathrm{N})$ (Tg) by multiplying by 0.30 .

The inventories described above have forecast elements in them for the year 2015, which were developed on the basis of traffic growth and knowledge of realistic advances in specific engine and aircraft technologies. Given that aircraft have a lifetime of 25-30 yr, this timescale of 2015 has reasonably definable, though substantial, uncertainties (Figs 10 and 11).

4.8.2. Scenarios. Attempts have been made to make longer timescale assessments of aviations' future fuel demands and emissions output. These are generally considered as scenarios. The UK Department of Trade and Industry (DTI) has developed a $\mathrm{NO}_{x}$ estimation model, based on generic aircraft types and seat size bands, regional and intra-regional traffic flows and the traffic efficiency of the aircraft types. This is primarily a policy tool and has been applied to estimate future global fuel use and $\mathrm{NO}_{x}$ burdens over a $50 \mathrm{yr}$ timescale, for use within the ICAO/CAEP 
Table 16. Historic inventory trends: Annual rate of increase 1976-1992 for different altitude bands: Civil scheduled air traffic only. 1976, 1984 data from Baughcum et al. (1996b), 1992 data from Baughcum et al. (1996a)

\begin{tabular}{lcrc}
\hline & & \multicolumn{1}{c}{ All } \\
& \multicolumn{1}{c}{$1976-1992$} & altitudes & \multicolumn{1}{c}{$9-13 \mathrm{~km}$} \\
\hline Fuel mass & (Annual change) & $4.6 \%$ & $5.5 \%$ \\
NO $_{x}$ mass & (Annual change) & $5.7 \%$ & $6.9 \%$ \\
$\mathrm{CO}$ mass & (Annual change) & $1.5 \%$ & $2.6 \%$ \\
$\mathrm{HC}$ mass & (Annual change) & $-1.7 \%$ & $-0.03 \%$ \\
EI NO & (Annual change) & $1.0 \%$ & $1.4 \%$ \\
EI CO & (Annual change) & $-3.2 \%$ & $-3.0 \%$ \\
EI HC & (Annual change) & $-6.1 \%$ & $-5.9 \%$ \\
\hline
\end{tabular}

process (ICAO, 1995d). Using this model, the results for 2015 agree well with those from the inventories. For 2040, the results fall well within the range of data from other longer-term studies, e.g. U.S. Environmental Defense Fund (Vedantham and Oppenheimer, 1994).

The latter study adopts a different approach, having a long-term dynamical model for aviation demand that draws upon market history in industrial nations and attempts to capture the eventual slowdown in demand growth rates as markets mature and approach saturation. It takes note of manufacturers expectations of efficiency improvements and projections of technology change. In particular, it relies strongly on the IPCC long-term estimates for regional gross national product (GNP) and population growth (Pepper et al., 1992). It has provided a range of estimates of fuel demand, $\mathrm{CO}_{2}$ and $\mathrm{NO}_{x}$ emissions out to the year 2100, which show large increases in comparison with a base year of 1990, but also a wide variation (up to a factor of 3-4, depending on scenario). A shortcoming is that the growth in GNP may not be a reliable indicator of the growth in aviation, since in many industrial nations aviation is a relatively mature market. ICAO/CAEP, in its current work programme, is addressing this issue with the aim of providing a more relevant, aviation specific, set of scenarios for inclusion into future Assessments.

\subsection{Conclusions}

The historic rapid growth of civil aviation traffic is forecast to continue in the future, leading to an expected increase of $260 \%$ by the year 2015 . However, fuel usage growth is slower (only $70-80 \%$ of the traffic increase) due to anticipated improvements in both engine and aircraft fuel efficiencies.

Over the last two to three decades, improvements in engine design have resulted in significant reductions in specific fuel consumption, largely through increases in engine bypass ratio, with its concurrent increases in core temperatures and pressures. This has led to substantial reductions of hydrocarbons and carbon monoxide emissions. Despite the increased core temperatures and pressures, which would be expected to result in significant increases in $\mathrm{NO}_{x}$ emissions, the introduction of improved combustor technology has limited the increase to modest levels.

Some future improvements in fuel efficiency may be anticipated with further increases in engine

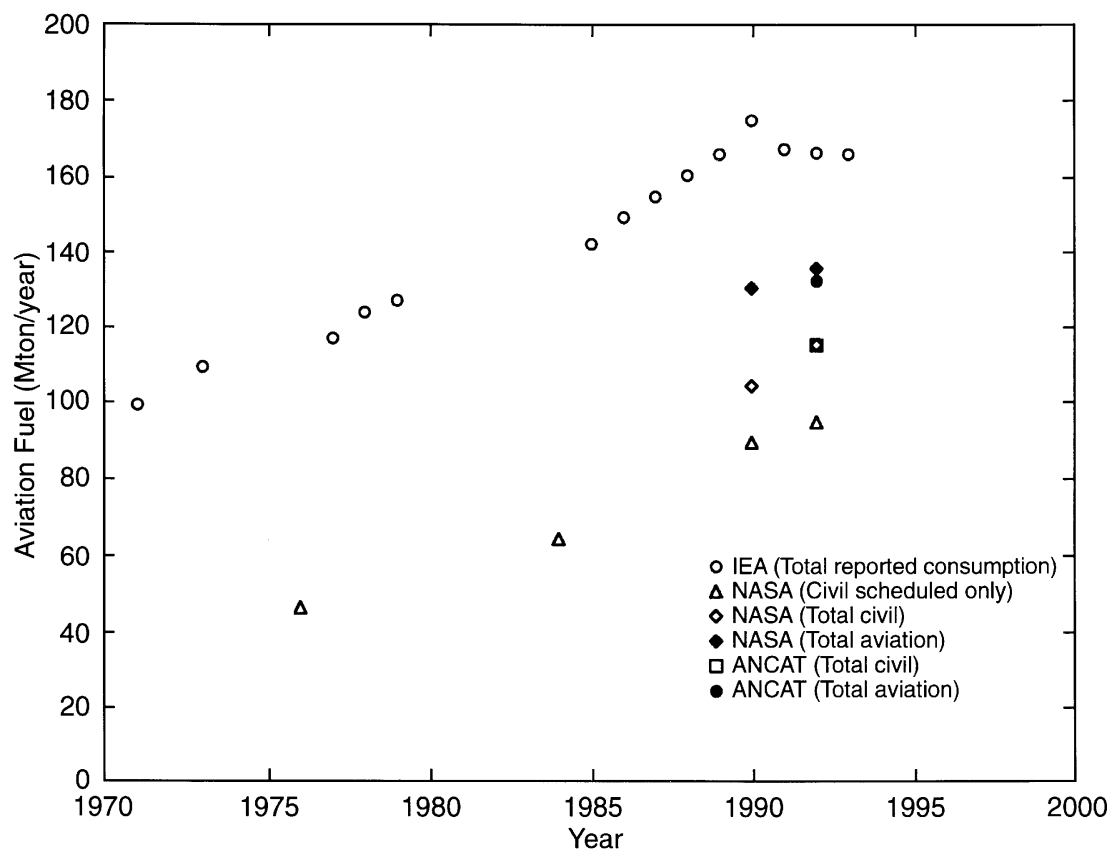

Fig. 22. Comparison of total annual production of refined jet fuel with fuel use data from ANCAT/EC and NASA inventories. 
bypass ratio, improvements in airframe aerodynamic efficiency and traffic efficiency. The development and introduction of very advanced combustor technologies may offer the potential for further significant reduction in $\mathrm{NO}_{x}$ emissions, while maintaining the current low hydrocarbon and carbon monoxide levels.

Engine emissions of $\mathrm{NO}_{x}$ at in-flight, especially cruise, conditions can be calculated with sufficient accuracy for atmospheric science purposes using well established prediction methods. However, for unregulated emissions, only limited experimental investigations have been carried out and much more work is needed to establish reliable prediction methods to estimate in-flight emission levels. In particular, the formation of particulates and particulate precursors should be studied because of the particular concerns about their influence on the global climate.

Currently, there are two comprehensive 3-D global inventories of fuel use and aviation emissions, both for a base year (1992) and with a future forecast (2015). Initial discrepancies between these have largely been resolved for civil aviation, but differences still remain for the military portion of these inventories. Historic data sets $(1976,1984)$ have also been developed for one of these inventories. All of these assume optimised operating conditions and therefore generate minimum fuel use and emissions. The difference, on an annual basis, between the calculated inventory fuel use and the reported refined fuel production is significant. While some of this is due to the difference between the optimised flight operations assumed in the inventories and the actual airline operations, further work is required to establish the causes and magnitudes.

\section{ATMOSPHERIC IMPACT OF AIRCRAFT EMISSIONS} AT PLUME SCALES

\subsection{Introduction}

5.1.1. The issues. Aircraft emissions are formed in the combuster zone of jet engines and get emitted in the form of a plume of exhaust gases and particles from the engine exit. The exhaust gases and particles experience conversions on their way from the combuster to the regional scales after which larger-scale models can describe their impact on air chemistry and cloudiness. This section deals with the fate of the emissions from the sources to the regional scales, i.e. on time scales from milliseconds to a day, and space scales from decimetres to several $10 \mathrm{~km}$.

The basic questions are:

How quickly does the exhaust plume become diluted with ambient air and what is the vertical and horizontal distribution of the emissions after a time scale of several hours or one day?

How are the emitted species chemically transformed and what is the impact of the emissions on ozone within the plumes?
What particles are formed in the exhaust plume and what is their impact on chemistry and cloud formation?

5.1.2. The scales. The scales of the plume regime are usually separated according to physical processes: The flow period from the combuster to the jet tail pipe is characterised by temperatures ranging from about $1500 \mathrm{~K}$ (after the combuster at entry to high power engine) to about $600 \mathrm{~K}$ (at core engine tail pipe). The exhaust from the core engine mixes with the bypass air from the fan to a temperature of about $300 \mathrm{~K}$ and then gets dispersed in the jet regime behind the engines. At the end of the jet regime, the temperature has essentially dropped to ambient conditions with a temperature excess of a few Kelvin. At a distance of a few wing spans after the engines, the jets interact with the vortex flow generated aerodynamically due to circulation around the wing (Donaldson and Bilanin, 1975), see Fig. 23. Part of the exhaust gets captured in the sinking vortex pair, another part is left above in a curtain of exhaust. The vortex regime ends when the initially formed vortex system breaks up into turbulent motion. Thereafter, the dispersion regime follows in which aircraft and vortex induced turbulence are controlling further mixing. After 3-5 min, the aircraftinduced turbulence has ceased and ambient air motions control the further spreading. Finally, plumes of individual aircraft in dense traffic areas or flight corridors interact with each other and form a highly variable concentration field at regional scales.

5.1.3. Previous studies. Plume processes have been investigated mainly with respect to $\mathrm{NO}_{x} / \mathrm{HO}_{x}$ emissions, first within the CIAP study, concentrating on supersonic aircraft emissions and their impact on stratospheric ozone chemistry (Poppoff et al., 1974; Galinas and Walton, 1974; Turco et al., 1980). The

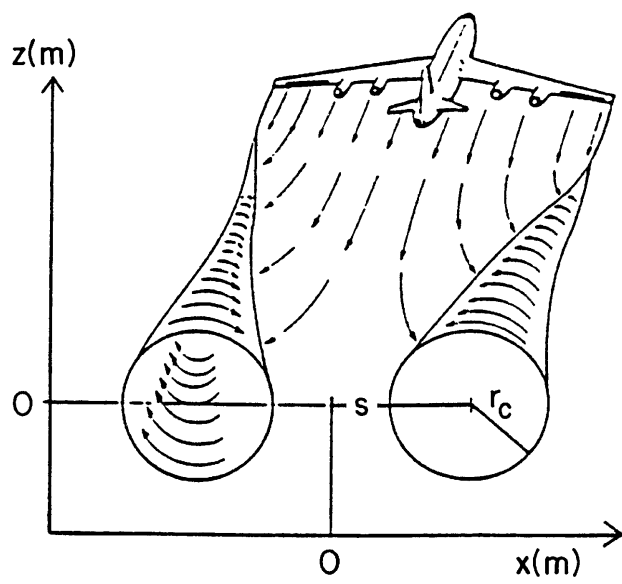

Fig. 23. The roll-up of the vortex sheet into a trailing vortex pair within the first $2 \mathrm{~s}$ behind a wide-body aircraft (Schilling et al., 1996). The arrows indicate the streamlines. The engine exhaust enters the vortex cores at some distance from the engines. 
topic became of renewed interest since about 1990 with increasing attention to aerosol formation, impact on contrail and cirrus formation, and subsonic aircraft (Schumann, 1994; WMO, 1995).

Most studies performed so far have been based on model calculations, mainly with chemistry for given aerosol properties (e.g. Miake-Lye et al., 1993; Danilin et al., 1992, 1994; Karol and Ozolin, 1994; Rodriguez et al., 1994; Weibrink and Zellner, 1994; Beier and Schreier, 1994; Kärcher, 1994, 1995; Kärcher et al., 1996a; Anderson et al., 1996; Garnier et al., 1997). More recent studies also simulate the aerosol formation process (Kärcher et al., 1995; Zhao and Turco, 1995; Kärcher, 1996; Brown et al., 1996a). Rather fewer models yet treat the dynamics of contrails (Gierens, 1996). The interaction of the ice particles in contrails with chemistry has not yet been studied in detail (Kärcher and Peter, 1995; Kärcher, 1997) but more detailed work is needed.

In recent years, several experiments have been performed to measure the exhaust properties in situ within aircraft plumes at cruise (see Table 17). The measurements include relevant subsonic aircraft and also the Concorde. Moreover, aircraft plume properties were measured under incidental flights through plumes without identifying the source aircraft (Ridley et al., 1994; Zheng et al., 1995, 1996).

Particle and contrail properties have been measured in situ (Knollenberg, 1972; Pitchford et al., 1991; Hagen et al., 1992; Baumgardner and Cooper, 1994; Busen, 1995, 1996; Gayet et al., 1996; Schumann et al., 1996; Schumann, 1996c, Petzold et al., 1997), by Lidar methods (Schumann, 1994; Freudenthaler et al., 1995), and by satellite data (Carleton and Lamb, 1986; Schumann and Wendling, 1990; Betancor-Gothe and Graß1, 1993; Bakan et al., 1994). Recent results were presented at the International Colloquium on the Impact of Aircraft Emissions upon the Atmosphere in Paris in October 1996 (proceedings available from ONERA, F-92320 Chatillon).

\subsection{Plume dilution}

The concentration of exhaust gases and their temperature depends on the amount of fuel mass burned in the engine and the amount of air mass mixed with the exhaust gases. The details of the mixing process are complex and result in a three-dimensional and time-dependent exhaust plume field. The bulk mean values can be estimated, however, if one knows the dilution factor $N$, i.e. the mass of exhaust gases in the plume per mass of fuel burned.

The bulk mean properties of the plume differ from ambient values by differences in temperature,

$$
\Delta T=\frac{Q(1-\eta)}{c_{p} N}
$$

mass concentration and volume mixing ratio of gaseous species $i$

$$
\Delta c_{i}=\frac{\mathrm{EI}_{i}}{N}, \quad \Delta n_{i}=\frac{\mathrm{EI}_{i} M_{\mathrm{air}}}{M_{i} N}
$$

volume specific concentration of particles such as condensation nuclei $(\mathrm{CN})$,

$$
\Delta \mathrm{CN}=\frac{\mathrm{EI}_{\mathrm{CN}} \rho}{N}
$$

and the jet velocity relative to the frame of aircraft

$$
\Delta V=\frac{F}{m_{\mathrm{F}} N} .
$$

The area of the plume cross-section of the exhaust

\begin{tabular}{|c|c|c|c|}
\hline Reference & Aircraft & Plume age & Measurements \\
\hline Pitchford et al. (1991) & Sabreliner & $1-2 \mathrm{~s}$ & $\mathrm{CN}, \mathrm{CCN}$, aerosol, $\mathrm{T}$ \\
\hline $\begin{array}{l}\text { Arnold et al. }(1992,1994), \\
\text { Busen et al. }(1994)\end{array}$ & DC-9 & $9 \mathrm{~s}$ & $\begin{array}{l}\text { CIMS: } \mathrm{NO}, \mathrm{NO}_{2}, \mathrm{HNO}_{2} \\
\mathrm{HNO}_{3}, \mathrm{SO}_{2}, \mathrm{~T}, \mathrm{H}_{2} \mathrm{O} \text {, wind }\end{array}$ \\
\hline Fahey et al. (1995a) & ER-2 & $470-630 \mathrm{~s}$ & $\begin{array}{l}\mathrm{NO}, \mathrm{NO}_{2}, \mathrm{NO}_{\mathrm{y}}, \mathrm{CO}_{2}, \\
\mathrm{CO}, \mathrm{H}_{2} \mathrm{O}, \mathrm{CN}, \mathrm{N}_{2} \mathrm{O}, \mathrm{O}_{3}, \mathrm{~T}, \text { wind }\end{array}$ \\
\hline Schumann et al. (1995) & $\begin{array}{l}\text { B747, B767 } \\
\text { B727, L1011 }\end{array}$ & $4.5-95 \mathrm{~min}$ & NO, turbulence \\
\hline Fahey et al. (1995b) & Concorde & $16-58 \mathrm{~min}$ & $\begin{array}{l}\mathrm{NO}, \mathrm{NO}_{2}, \mathrm{NO}_{\mathrm{y}}, \mathrm{CO}_{2}, \\
\mathrm{CO}, \mathrm{H}_{2} \mathrm{O}, \mathrm{OH}, \mathrm{HO}_{2}, \\
\mathrm{CN}, \mathrm{N}_{2} \mathrm{O}, \mathrm{O}_{3}\end{array}$ \\
\hline Schumann et al. (1996) & $\begin{array}{l}\text { ATTAS } \\
\text { (VFW-614) }\end{array}$ & $\begin{array}{c}(0.07-1 \mathrm{~s}) \\
19-27 \mathrm{~s}\end{array}$ & $\begin{array}{l}\text { Contrail diameter, } \mathrm{CN} \\
\mathrm{H}_{2} \mathrm{O} \text {, T, wind }\end{array}$ \\
\hline Schulte and Schlager (1996) & $\begin{array}{l}\text { MD80, B727, } \\
\text { B707, B737 }\end{array}$ & $40-130 \mathrm{~s}$ & $\mathrm{NO}, \mathrm{CO}_{2}$ \\
\hline $\begin{array}{l}\text { POLINAT (Schumann, 1996c, } \\
\text { Schulte et al., 1996) }\end{array}$ & $\begin{array}{l}\text { B747, DC-10, } \\
\quad \text { A340 }\end{array}$ & $40-130 \mathrm{~s}$ & $\begin{array}{l}\mathrm{NO}, \mathrm{NO}_{2}, \mathrm{CO}_{2}, \mathrm{H}_{2} \mathrm{O}, \mathrm{HNO}_{3}, \mathrm{HNO}_{2}, \mathrm{SO}_{2}, \mathrm{O}_{3} \text {, } \\
\quad \mathrm{CN} \text {, T, wind }\end{array}$ \\
\hline
\end{tabular}
plume is

$$
A=\frac{m_{\mathrm{F}} N}{\rho V} .
$$

Table 17. In situ measurements of plume properties 
In the above equation $Q$ is the specific heat of combustion (about $43 \mathrm{MJ} \mathrm{kg}^{-1}$ for kerosene), $c_{p}$ the specific heat capacity of the plume gases at constant pressure (about $1004 \mathrm{~J} \mathrm{~kg}^{-1} \mathrm{~K}^{-1}$ ), $F$ the engine's thrust in $N, m_{\mathrm{F}}$ the fuel flow rate in $\mathrm{kg} \mathrm{s}^{-1}$ (typically the specific fuel consumption of modern engines at cruise is $\left.\mathrm{SFC}=m_{\mathrm{F}} / F=20 \mathrm{mg} \mathrm{N}^{-1} \mathrm{~s}^{-1}\right), \mathrm{EI}_{i}$ the emission mass of species $i$ per unit mass of fuel, $M_{i}$ the molar mass of species $i, \rho$ the plume gas density, and $\eta=F V /\left(Q m_{\mathrm{F}}\right)$ the overall propulsion efficiency (typically between 0.15 and 0.35 ). The fraction $\eta$ accounts for the amount of combustion heat used to produce forward motion against the aircraft's drag. This work causes heating of the air by dissipating turbulent motions in the far wake of the aircraft. Hence, the effective-decreases with growing plume age. The emission indices for $\mathrm{CO}_{2}, \mathrm{H}_{2} \mathrm{O}$, and $\mathrm{SO}_{2}$ (assuming complete combustion), depend on $m_{\mathrm{C}}, m_{\mathrm{H}}$, and $m_{\mathrm{S}}$, the carbon, hydrogen, and sulphur mass contents of the fuel; typically $m_{\mathrm{H}}=0.138 \pm 0.02, m_{\mathrm{S}}=450 \mathrm{ppm}$ $\left(1 \mathrm{ppm}=10^{-6}\right)$ and $m_{\mathrm{C}}=1-m_{\mathrm{H}}-m_{\mathrm{s}} ; \quad \mathrm{EI}_{\mathrm{CO}_{2}}=$ $m_{\mathrm{C}} M_{\mathrm{CO}_{2}} / M_{\mathrm{C}}-3.15, \quad \mathrm{EI}_{\mathrm{H}_{2} \mathrm{O}}=m_{\mathrm{H}} M_{\mathrm{H}_{2} \mathrm{O}} / M_{\mathrm{H}_{2}} \cong 1.24$, $\mathrm{EI}_{\mathrm{SO}_{2}}=m_{\mathrm{s}} M_{\mathrm{SO}_{2}} / M_{\mathrm{s}} \cong 0.8 \mathrm{~g} \mathrm{~kg}^{-1}$.

Stoichiometric combustion of kerosene with air requires a dilution factor of about 16 (Schumann, 1996a). The exhaust gases leave the core engine with engine specific dilution factors ("air/fuel ratio of the engine") of about 50-70 (see Schumann, 1995). The combustion occurs at time scales of 1-4 ms. Part of the combustion heat is given by the work of the engine fans to the bypass air. For modern engines, the ratio of bypass air mass flux to core air mass flux is 4 to 6 . Hence, after mixing of the exhaust gases from the core engine with the bypass air, the dilution factor is between 200 and 420. Thereafter, the exhaust gases form a jet which mixes with ambient air.

The jet mixing can be described as being axisymmetric and related models are given, e.g. in Kärcher et al. (1996a). For constant turbulent diffusivities, the plume cross-section $A$ and the dilution factor $N$ would grow about linearly with time. However, the diffusivities depend on the plume scale and the velocity difference so that details are more complex (Anderson et al., 1996; Garnier et al., 1997). After a time scale of about $1 \mathrm{~s}$, the jet temperature has approached the ambient temperature to a few degree $\mathrm{K}$ and the jet velocity has become comparable to the velocity of the vortex flow induced by the aircraft (Miake-Lye et al., 1993).

In order to keep constant altitude, the aircraft's lift must equal its weight $g M$. The lift is produced by circulation around the wings (span width $B$ ) leaving downward moving air behind the aircraft. This motion induces a double vortex system, (see Fig. 23) with vortex axis parallel to the flight direction and vortex axis separation of about $\pi B / 4$. The vortex system forms after a time of about $1.5 \rho V B^{3} /(g M)$, i.e. typically within 2-10 s. The vortex moves downward as a whole at a speed of about $w_{\mathrm{s}}=8 \mathrm{gM} /\left(\pi^{3} \rho B^{2} V\right)$ of about $1.5-2.5 \mathrm{~m} \mathrm{~s}^{-1}$ (experimentally verified, see Schumann, 1994). Depending on the location of the engines relative to the vortex axis (Miake-Lye et al., 1993) and possibly the buoyancy of the exhaust (Quackenbush et al., 1996; Gerz and Ehret, 1996), part of the exhaust gases get captured by the vortex system and move downwards with the vortex system, while the rest is left in a curtain of exhaust gases between the flight path and the sinking vortex. The vortex system moves downward until its motion is limited by the stable stratification of the ambient atmosphere and then tends to return and oscillate around the flight level with the Brunt-Väisälä frequency $N_{\mathrm{BV}}$, i.e. at time scales $2 \pi / N_{\mathrm{BV}}$ of about $100-600 \mathrm{~s}$. The amplitude of this oscillation is $w_{\mathrm{s}} / N_{\mathrm{BV}}$, of order $100-200 \mathrm{~m}$.

The vortex motion is unstable (Crow, 1970) and experiences disturbances from non-uniform atmospheric motions. The transition to turbulence has been simulated numerically by Gerz and Palma (1994), Lewellen and Lewellen (1996) and Gerz and Ehret (1997), see Fig. 24. In most cases, the vortex motion breaks down into turbulence before reaching the minimum altitude and the pollutants get spread over the altitude range between flight level and about 100-200 m below that level. This has been observed in terms of $\mathrm{NO}_{x}$ measurements within the POLINAT project (Schumann, 1996c).

When the vortex motions have ceased, the mixing is controlled by ambient turbulent or random wavy air motions and, in particular, by shear (Schumann et al., 1995). In general, the atmosphere near the tropopause exhibits weakly interacting nonlinear random wavy motions. Fully turbulent (scalar mixing and energy dissipating) motions occur intermittently near sources of mesoscale variability (such as strong jet streams, convection, and fronts or by strong flows over mountains) (Fritts and Nastrom, 1992) and within cirrus clouds (Gultepe and Starr, 1995). The prevailing wavy conditions cause nearly zero vertical mixing but some horizontal mixing of the exhaust gases. Even weak shear strongly enhances lateral mixing while strong shear (larger than the Brunt-Väisälä frequency) is required to cause turbulence and enhanced vertical mixing. Typical values of vertical and horizontal diffusivities, as deduced from measurements (Schumann et al., 1995) and large-eddy simulations (Dürbeck and Gerz, 1995, 1996), are $D_{\mathrm{V}}=0-0.3 \mathrm{~m}^{2} \mathrm{~s}^{-1}$, and $D_{\mathrm{H}}=$ $5-20 \mathrm{~m}^{2} \mathrm{~s}^{-1}$. The impact of shear is also visible from contrails observed by Lidar (Freudenthaler et al., 1995) reaching more than $3 \mathrm{~km}$ width within 20 mins, while remaining contained within a narrow vertical range of less than $350 \mathrm{~m}$.

Hence, the dilution factor $N$ is a complex function of many parameters depending on the specific aircraft and atmospheric conditions. Measurements and complex models are needed to determine $N$ as a function of plume age. In Fig. 25, most of the data available so far are compiled (Schumann et al., 1998). The data follow one interpolating curve

$$
N=7000\left(t / t_{0}\right)^{0.8}, \quad t_{0}=1 \mathrm{~s}
$$

within a factor of about 5 . 

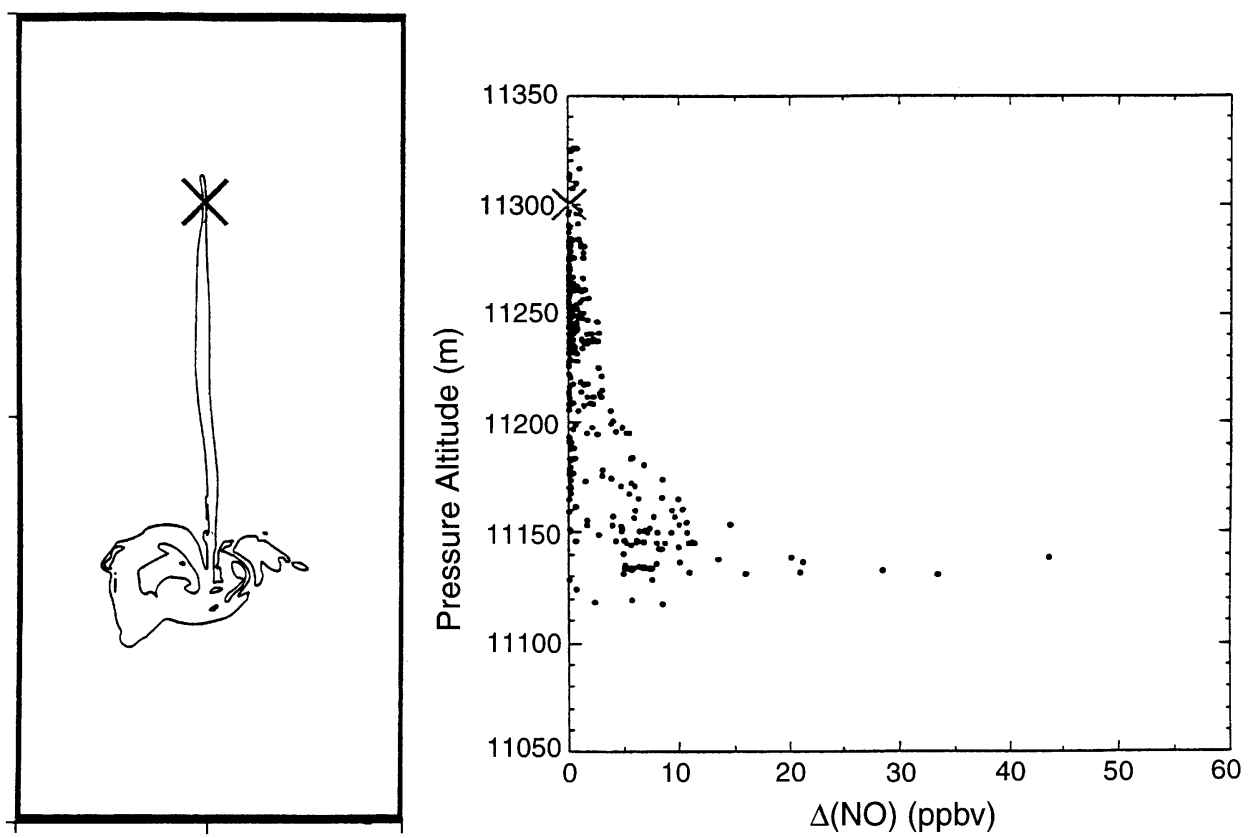

Fig. 24. Comparison of computed and measured exhaust concentration field in a sinking vortex pair about $150 \mathrm{~s}$ after passage of a B747. Left: Contour lines of the computed tracer field in a sinking vortex pair in a vertical plane perpendicular to the flight track (Gerz and Ehret, 1996). Right: Measured NO concentration increase above background as measured in situ (Schlager et al., 1996).

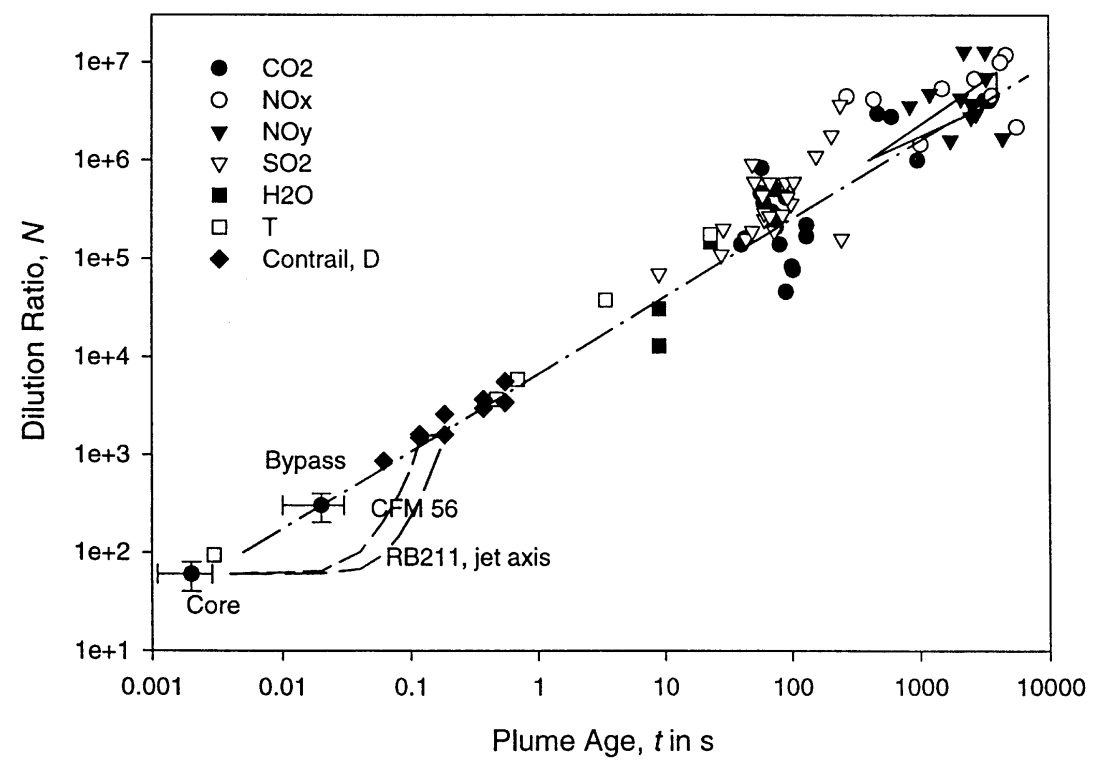

Fig. 25. Dilution factor vs plume age based on measurements of various trace gases, temperature and contrail diameters for subsonic aircraft and for the ER-2 and Concorde (for details see, Schumann et al., 1998). The full curves for the two engines CFM56 and RB211 describe the dilution on the jet axis based on computations within AERONOX. The triangle at large plume ages encloses the range of large-eddy simulation results. The core and bypass conditions represent the range of modern jet engines.

Table 18 lists typical plume bulk properties for given dilution factors. The cross-section given depends on the fuel flow rate which was taken as being typical for the four engines of a B747 aircraft $\left(\dot{m}_{\mathrm{F}} \cong 2.4 \mathrm{~kg} \mathrm{~s}^{-1}\right)$.
The identity of individual plumes depends on the deviation of the plume properties from ambient values compared to the natural variability of the specific property in the ambient air. Hence, the plume loses identity quickly in terms of velocity, temperature, and 
Table 18. Plume bulk property changes for given mass dilution factors

\begin{tabular}{|c|c|c|c|c|}
\hline Property & Symbol & $\begin{array}{c}\text { Engine exit } \\
N=100\end{array}$ & $\begin{array}{c}0.5-2 \mathrm{~s} \\
N=10,000\end{array}$ & $\begin{array}{c}1-4 \mathrm{~h} \\
N=10^{7}\end{array}$ \\
\hline Temperature & $\Delta T$ & $400 \mathrm{~K}$ & $4 \mathrm{~K}$ & $0.04 \mathrm{~K}$ \\
\hline Velocity & $\Delta V$ & $500 \mathrm{~m} \mathrm{~s}^{-1}$ & $5 \mathrm{~m} \mathrm{~s}^{-1}$ & $5 \mathrm{~mm} \mathrm{~s}^{-1}$ \\
\hline \multirow[t]{4}{*}{ Mixing ratio } & $\Delta \mathrm{CO}_{2}$ & $2 \%$ & $200 \mu \mathrm{mol} \mathrm{mol}^{-1}$ & $0.2 \mu \mathrm{mol} \mathrm{mol}^{-1}$ \\
\hline & $\Delta \mathrm{H}_{2} \mathrm{O}$ & $2 \%$ & $200 \mu \mathrm{mol} \mathrm{mol}^{-1}$ & $0.2 \mu \mathrm{mol} \mathrm{mol}^{-1}$ \\
\hline & $\Delta \mathrm{NO}_{x}$ & $100 \mu \mathrm{mol} \mathrm{mol}^{-1}$ & $1 \mu \mathrm{mol} \mathrm{mol}^{-1}$ & $1 \mathrm{nmol} \mathrm{mol}^{-1}$ \\
\hline & $\Delta \mathrm{SO}_{2}$ & $3 \mu \mathrm{mol} \mathrm{mol}^{-1}$ & $30 \mathrm{nmol} \mathrm{mol}^{-1}$ & $30 \mathrm{pmol} \mathrm{mol}^{-1}$ \\
\hline Particle concentration & $\mathrm{CN}$ & $10^{7} \mathrm{~cm}^{-3}$ & $10^{5} \mathrm{~cm}^{-3}$ & $100 \mathrm{~cm}^{-3}$ \\
\hline Plume cross-section & A & $3 \mathrm{~m}^{2}$ & $300 \mathrm{~m}^{2}$ & $300,000 \mathrm{~m}^{2}$ \\
\hline
\end{tabular}

humidity, remains measurable longer in terms of the concentration increase of $\mathrm{CO}_{2}$, and longest in terms of $\mathrm{NO}_{x}$ and small particles (CN) (cf. Table 18). In terms of $\mathrm{NO}_{x}$ and particles, the concentration increase remains measurable up to time scales of the order $5-10 \mathrm{~h}$.

\subsection{Gas-phase chemistry}

5.3.1. Chemical conversions of emissions in the jet phase. Gas-phase chemistry emissions include the nitrogen oxide components $\mathrm{NO}_{x}$ composed of $\mathrm{NO}$ and $\mathrm{NO}_{2}$. At cruise, most of the $\mathrm{NO}_{x}$ is emitted in the form of NO. Ratios $\mathrm{NO}_{2} / \mathrm{NO}$ of less than 0.05 have been measured for the RB211 engine (Lister et al., 1995), but this ratio is engine-dependent.

In the early jet phase, the air chemistry is essentially unaffected by photolysis (the time scale of $\mathrm{NO}_{2}$ photolysis is of order $100 \mathrm{~s}$ ). The emitted NO reacts quickly with $\mathrm{O}_{3}$ to produce $\mathrm{NO}_{2}$ and $\mathrm{O}_{2}$. During nighttime, essentially all NO gets oxidised this way. During daytime, photolysis causes a non-zero $\mathrm{NO} / \mathrm{NO}_{2}$ ratio after some time (see below). The titration reaction of $\mathrm{NO}$ with $\mathrm{O}_{3}$ causes a slight local reduction of $\mathrm{O}_{3}$ in the young plume which is irrelevant on global scales. The depleted $\mathrm{O}_{3}$ levels quickly get restored by mixing with ambient air. At plume ages of an hour, the $\mathrm{NO}_{x}$ concentration is typically below 1 ppbv, i.e. 100 times less than the $\mathrm{O}_{3}$ concentration, so that only $1 \%$ of the $\mathrm{O}_{3}$ may get titrated in plumes under such conditions. If all $\mathrm{NO}_{x}$ emissions from aircraft $[0.6 \mathrm{Tg}(\mathrm{N})$ per year $]$ would cause titration of $\mathrm{O}_{3}$, then this would imply $2.7 \mathrm{Tg}\left(\mathrm{O}_{3}\right)$ loss per year, or less than $0.1 \%$ of the ozone flux from the stratosphere to the troposphere in the northern hemisphere [the ozone flux amounts to $320-950 \mathrm{Tg} \mathrm{yr}^{-1}$, see Ebel et al., (1996)]. Measurements which clearly show that $\mathrm{O}_{3}$ has been depleted in aircraft plumes do not exist.

At the engine exit, the exhaust contains relatively large concentrations of hydroxyl radicals and other radicals which oxidise parts of the emitted $\mathrm{NO}, \mathrm{NO}_{2}$, and $\mathrm{SO}_{2}$ to nitrous acid $\left(\mathrm{HNO}_{2}\right)$, nitric acid $\left(\mathrm{HNO}_{3}\right)$, and sulphuric acid $\left(\mathrm{H}_{2} \mathrm{SO}_{4}\right)$. The conversion depends strongly on the amount of $\mathrm{OH}$ and other radicals which are available at the engine exit and get consumed by these reactions. Figure 26 shows model

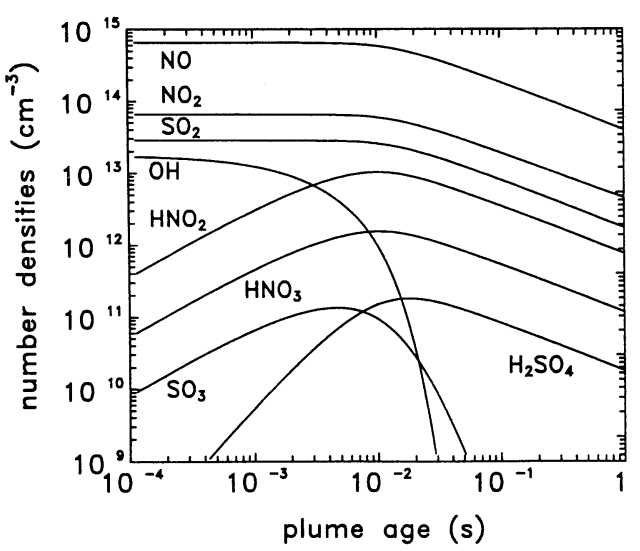

Fig. 26. Gas-phase chemistry of nitrogen and sulphur species in an early B747 plume according to a simplified chemical reaction sequence (from Kärcher et al., 1996a).

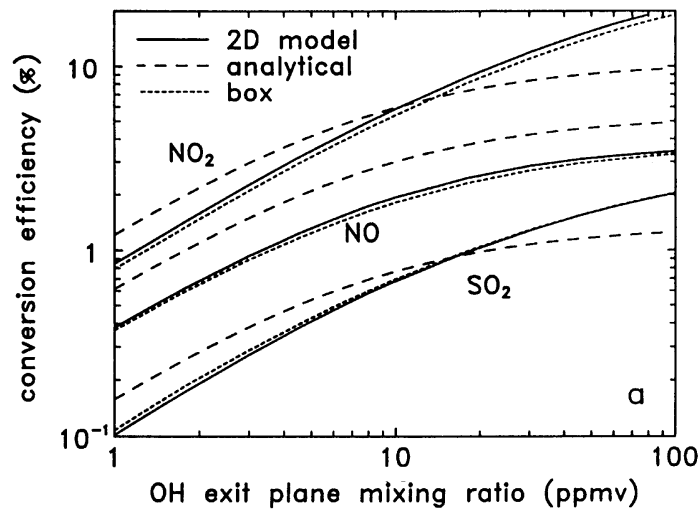

Fig. 27. Conversion efficiencies for $\mathrm{NO}$ into $\mathrm{HNO}_{2}, \mathrm{NO}_{2}$ into $\mathrm{HNO}_{3}$, and $\mathrm{SO}_{2}$ into $\mathrm{H}_{2} \mathrm{SO}_{4}$ (via $\mathrm{SO}_{3}$ ) for a $\mathrm{B} 747$ as a function of $\mathrm{OH}$ exit plane mixing ratio from calculations with a two-dimensional model (solid curves), from an analytical model (long-dashed curves), and from a box model (short-dashed curves) according to Kärcher et al. (1996a).

results for the gas-phase chemistry of some of these components (Kärcher et al., 1996a). As shown in Fig. 27, the reactions cause $0.1-10 \%$ conversion of emitted $\mathrm{NO}, \mathrm{NO}_{2}, \mathrm{SO}_{2}$ to $\mathrm{HNO}_{2}, \mathrm{HNO}_{3}, \mathrm{H}_{2} \mathrm{SO}_{4}$, strongly depending on the $\mathrm{OH}$ concentrations at the 
exit plane. The results are also very sensitive to the self-reaction between $\mathrm{OH}$ radicals, hence on the dilution, and are also sensitive to the temperature in the jet and the $\mathrm{NO} / \mathrm{NO}_{2}$ ratio at engine exit. The model used to generate Fig. 27 assumed zero $\mathrm{H}_{2} \mathrm{SO}_{4}$ and $\mathrm{SO}_{3}$ emissions from the engines, and did not account for the chemistry within the engine, from the combustor to the core engine exit plane (Fahey et al., 1995a; Anderson et al., 1996). Part of the oxidation processes, in particular the formation of $\mathrm{SO}_{3}$, occurs already inside the engine by reactions between $\mathrm{SO}_{2}$ and atomic and molecular oxygen (Hunter, 1982; Harris, 1990). Calculations (Brown et al., 1996b) indicate that the amount of $\mathrm{SO}_{2}$ which reacts with $\mathrm{O}$ to $\mathrm{SO}_{3}$ inside the engine or in the very young plume is limited by the amount of $\mathrm{O}$ available. Hence the conversion fraction $\left(\mathrm{SO}_{3}+\mathrm{H}_{2} \mathrm{SO}_{4}\right) / \mathrm{SO}_{2}$ is greater at lower fuel sulphur content. The computations show that $2-12 \%$ of $\mathrm{SO}_{2}$ molecules may be oxidised to $\mathrm{SO}_{3}$ and $\mathrm{H}_{2} \mathrm{SO}_{4}$, in agreement with measured data for conventional gas turbines (Harris, 1990; Farago, 1991). However, the model does not yet account for heterogeneous reactions of, e.g. activated oxygen with soot.

The conversion rates are important because the resultant gases $\mathrm{HNO}_{3}, \mathrm{H}_{2} \mathrm{SO}_{4}$, together with $\mathrm{H}_{2} \mathrm{O}$, are important precursor gases for particle formation (Arnold et al., 1992; Kärcher, 1996). The impact of emitted $\mathrm{NO}_{x}$ on the chemistry at large scales is reduced for large conversion rates.

Up to now only very few measurements exist which can be used to determine the fraction of acids emitted or generated from the primary exhaust gases. Measurements in young exhaust plumes (i.e. in plumes which experienced little photochemistry), have been performed by Arnold et al. $(1992,1994)$ using aircraft-based chemical ionisation mass spectrometry (CIMS). Figure 28 depicts an example of $\mathrm{SO}_{2}, \mathrm{HNO}_{2}$, and $\mathrm{HNO}_{3}$ number concentrations measured behind
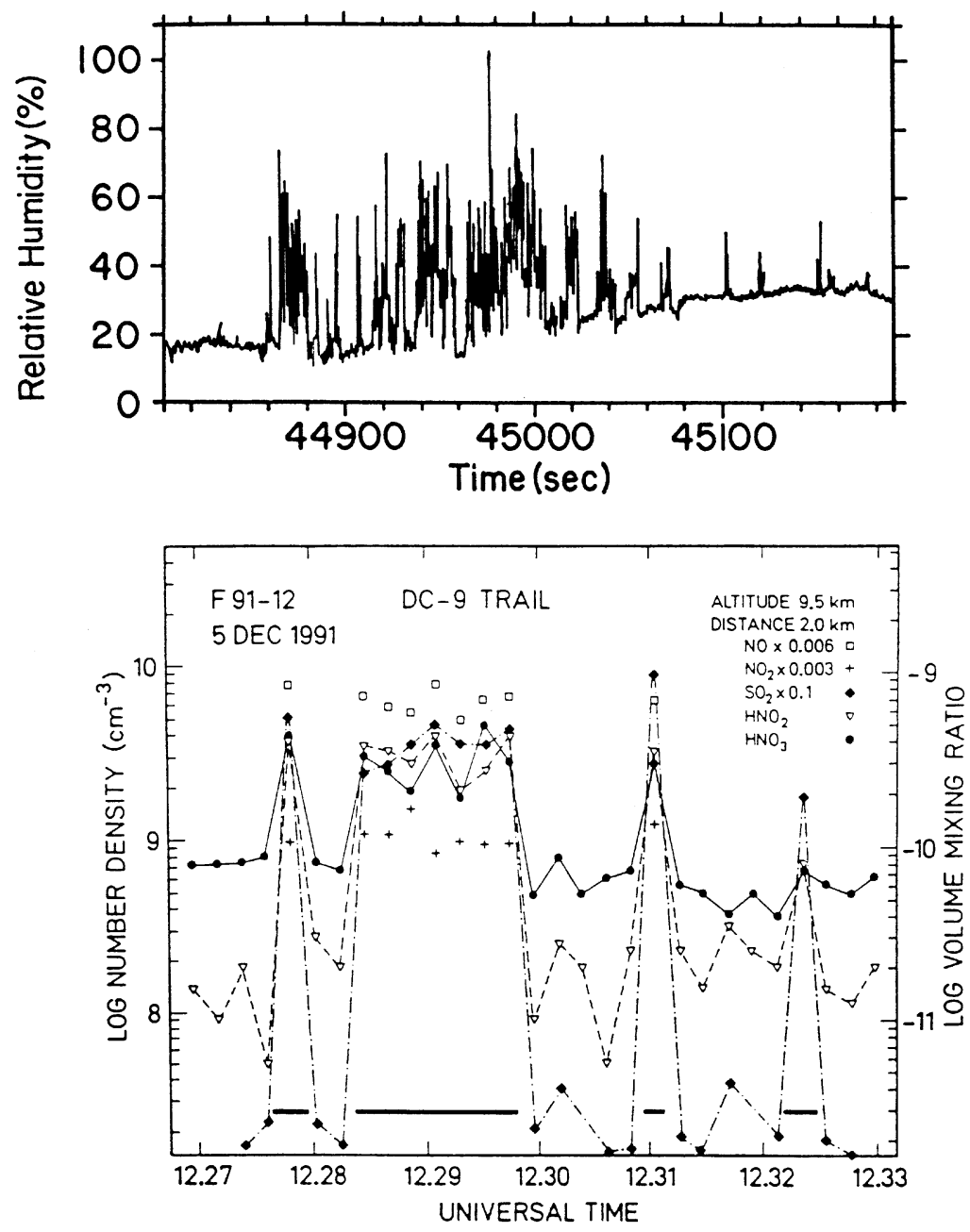

Fig. 28. Measured concentrations of various trace gases and water vapour in the plume of a DC-9 aircraft, bottom form Arnold et al. (1994), top form Busen et al. (1994). Both figures cover the same time interval. The thick lines in the lower diagram indicate the times when the measuring aircraft was within the plume of the 
a DC-9 aircraft at a plume age of $9 \mathrm{~s}$. Signatures of $\mathrm{NO}$ and $\mathrm{NO}_{2}$ gases were also detected by the same instrument although indirectly. The data show a ratio $\mathrm{NO}_{2} / \mathrm{NO}$ of about $0.2-0.3$. This value is larger than what is found by chemiluminescence instruments in other occasions (Schulte et al., 1997). Inside the exhaust plume, the concentrations of $\mathrm{HNO}_{3}$, and even more $\mathrm{HNO}_{2}$ and $\mathrm{SO}_{2}$ are well above the background values. The data indicate that about $0.6 \%$ of the $\mathrm{NO}_{x}$ is converted to $\mathrm{HNO}_{2}$ and $\mathrm{HNO}_{3}$. The measured $\mathrm{HNO}_{2} / \mathrm{HNO}_{3}$ fraction is about 1 and is smaller than to be expected for large $\mathrm{NO} / \mathrm{NO}_{2}$ ratios. The measured $\mathrm{HNO}_{2}$ and $\mathrm{HNO}_{3}$ concentrations imply an emission index of order $0.03 \mathrm{~g} \mathrm{~kg}^{-1}$ for $\mathrm{OH}$ (Arnold et al., 1994), causing typical concentrations of $1 \mathrm{ppmv}$ at the engine exit (for a dilution factor of $N=60)$.

Other measurements (Fahey et al., 1995a, b) have been performed in plumes at plume ages of 10-60 min using instruments which measure $\mathrm{NO}_{y}$ and $\mathrm{NO}_{x}$ but not specifically $\mathrm{HNO}_{3}$ and $\mathrm{HNO}_{2}$. Within the range of measurement uncertainty these data indicate that about $10 \pm 10 \%$ of $\mathrm{NO}_{x}$ is converted into $\mathrm{NO}_{y}$ within $1 \mathrm{hr}$.

Recently, Arnold and coworkers have performed further measurements of $\mathrm{HNO}_{2}$ and $\mathrm{HNO}_{3}$ in plumes of various ages within the POLINAT project (Schumann, 1996c). Based on the results for six aircraft plumes (five B747, one DC10) with simultaneous $\mathrm{CO}_{2}$ measurements, it is found that the emission index varies between 0.1 and $0.4 \mathrm{~g} \mathrm{~kg}^{-1}$ for $\mathrm{HNO}_{2}$ and between 0.06 and $0.3 \mathrm{~g} \mathrm{~kg}^{-1}$ for $\mathrm{HNO}_{3}$, which implies that $1-5 \%$ of the $\mathrm{NO}_{x}$ is converted into $\mathrm{NO}_{y}$. The measurements took place at plume ages of $40-130 \mathrm{~s}$, mostly during daytime. By means of a plume model one may deduce the amount of $\mathrm{OH}$ and the $\mathrm{NO}_{2} / \mathrm{NO}_{x}$ fraction required to explain the observed concentrations of $\mathrm{HNO}_{2}$ and $\mathrm{HNO}_{3}$ and the observed $\mathrm{NO}_{2} / \mathrm{NO}_{x}$ ratio in the plumes. The model results suggest emission indices of $\mathrm{OH}$ between 0.1 and $0.4 \mathrm{~g} \mathrm{~kg}^{-1}(\mathrm{OH}$ concentration of $3-12 \mathrm{ppmv}$ at the engine exit) and values of $\mathrm{NO}_{2} / \mathrm{NO}_{x}$ between 0 and 0.2 .

With respect to $\mathrm{SO}_{3}$ and $\mathrm{H}_{2} \mathrm{SO}_{4}$, only preliminary results exists (Harris, 1990; Frenzel and Arnold, 1994). The results so far reported by Arnold et al. (1996a), indicate that between 1 and $5 \%$ of the $\mathrm{SO}_{2}$ may get converted to $\mathrm{SO}_{3}+\mathrm{H}_{2} \mathrm{SO}_{4}$ gases. These components are very difficult to measure because of possible losses by wall reactions and uncertain reaction rates between ions and sulphuric acid-water clusters. Recent measurements at very short distances behind an A310 aircraft and the ATTAS aircraft (80-200 m distance) indicate very small $\mathrm{H}_{2} \mathrm{SO}_{4}$ concentrations in the gas phase (Arnold et al., 1996). It appears that a large fraction of the gaseous $\mathrm{H}_{2} \mathrm{SO}_{4}$ goes into particles very quickly (Kärcher, 1996). Fahey et al. (1995b) measured the number density of condensation nuclei (diameters above $10 \mathrm{~nm}$ ) within the plume of the Concorde aircraft, and assumed that the volatile fraction of the particles were composed only of sulphuric acid with water in thermodynamical equilibrium with the ambient air. For two measured plume encounters they deduced that more than either $12 \%$ or $45 \%$ of all fuel sulphur entered aerosol within 10-30 min. They did not consider the possibility of other particle constituents or possible thermodynamical non-equilibrium effects. Their result, however, would be consistent with large sulphuric acid aerosol particle concentrations reported by Hofmann and Rosen (1978) (who estimated that about $100 \%$ of all fuel sulphur ended in aerosol after $18 \mathrm{~h}$ at $23 \mathrm{~km}$ altitude presumably behind a Russian SR-71 spy aircraft). During POLINAT, $\mathrm{H}_{2} \mathrm{SO}_{4}$ was measured during the night in a plume of about $70 \mathrm{~s}$ age using mass spectrometry of natural ions. The measurement was limited by a time resolution of about $10 \mathrm{~s}$ and, hence, may underestimate the $\mathrm{H}_{2} \mathrm{SO}_{4}$ increase in the plume. However, the result (Arnold et al., 1996b) shows no significant difference between $\mathrm{H}_{2} \mathrm{SO}_{4}$ within the plume and ambient air and suggests again that very little $\mathrm{H}_{2} \mathrm{SO}_{4}$ remains in the gas phase.

5.3.2. Photochemical equilibrium after several minutes. During daytime, photolysis of $\mathrm{NO}_{2}$ causes regeneration of NO. Moreover, photolysis of $\mathrm{HNO}_{2}$ is a source of $\mathrm{OH}$ radicals (Arnold et al., 1992) which, together with $\mathrm{OH}$ from other sources (Hanisco et al., 1997), causes further conversion of $\mathrm{NO}_{x}$ to $\mathrm{HNO}_{3}$ and of $\mathrm{SO}_{2}$ to $\mathrm{H}_{2} \mathrm{SO}_{4}$. Moreover photolysis of $\mathrm{HNO}_{3}$ limits the conversion of $\mathrm{NO}_{x}$ to $\mathrm{HNO}_{3}$, see Section 3 .

The photolysis of $\mathrm{NO}_{2}$ and the reaction of $\mathrm{NO}$ with $\mathrm{O}_{3}$ cause a rapid establishment of a photochemical equilibrium ratio between $\mathrm{NO}_{2}$ and NO. Figure 29 shows measured values of $\mathrm{NO}_{2} / \mathrm{NO}$ compared with calculated ratios assuming a photochemical steadystate according to

$$
\frac{\left[\mathrm{NO}_{2}\right]}{[\mathrm{NO}]}=\frac{k\left[\mathrm{O}_{3}\right]}{j_{\mathrm{NO}_{2}}}
$$

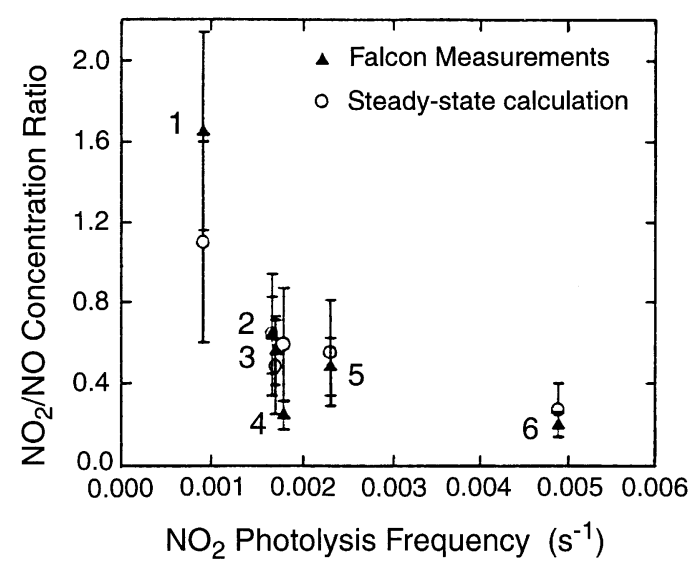

Fig. 29. $\mathrm{NO}_{2} / \mathrm{NO}$ ratios vs calculated photodissociation coefficients based on in situ measurements (full triangles) and steady-state calculations (open circles) (from Schlager et al., 1997). 
where brackets denote concentrations, $k$ is the temperature-dependent reaction rate of $\mathrm{O}_{3}$ with $\mathrm{NO}$, and $j_{\mathrm{NO}_{2}}$ is the photodissociation coefficient for $\mathrm{NO}_{2}$. The time required to reach the steady-state ratio depends on $1 /\left(j+k\left[\mathrm{O}_{3}\right]\right)$. It amounts to $9 \mathrm{~min}$ for the case with smallest $j$-value at sunrise, and $3 \mathrm{~min}$ for the case with largest $j$-value for these cases. The model results agree generally with the measured ratios, except for the lowest $j$-value, for which steady-state conditions might not yet have been reached at the time of measurement (Schlager et al., 1997).

5.3.3. Photochemical changes from hours to days. Within several hours, most of the emitted $\mathrm{NO}_{x}$ gets converted to $\mathrm{HNO}_{3}$, with a smaller fraction forming $\mathrm{HNO}_{4}, \mathrm{PAN}$, and other organic nitrates (Möllhoff et al., 1996; Meijer et al., 1996). Model studies of Lippert (1996) and Möllhoff et al. (1996) illustrate the steady conversion of $\mathrm{NO}_{x}$ to $\mathrm{NO}_{y}$ during the first days. Figure 30 shows the percentage split of emitted $\mathrm{NO}_{x}$ on various $\mathrm{NO}_{y}$ components for emissions of a B747 at $236 \mathrm{hPa}$ and $218 \mathrm{~K}$ during the first days after emission at 8 local time. The model assumes either continuous or sudden mixing of the exhaust over a mesoscale grid cell of $50 \mathrm{~km}$ width and $1 \mathrm{~km}$ height. About $30 \%$ of the $\mathrm{NO}_{x}$ gets converted to $\mathrm{HNO}_{3}$ and $\mathrm{HNO}_{4}$ within one day in this model. During night, some $\mathrm{N}_{2} \mathrm{O}_{5}$ is formed, which photolyses during daytime. Other $\mathrm{NO}_{y}$ components (including PAN and chlorine nitrate) remain very small. The conversion rate of $\mathrm{HNO}_{4}$ in the plume is smaller than for background concentrations because of reduced $\mathrm{HO}_{x}$ concentrations at high $\mathrm{NO}_{x}$ abundances. For the same reason, the conversion is even smaller when one uses a more realistic narrow and slowly growing plume cross-section. The ozone increase for this example is $0.04 \mathrm{ppbv}$ within the first $18 \mathrm{~h}$ in the model for sudden mixing over a mesoscale grid cell, and half that value for a slowly increasing plume cross-section. Besides mixing, the model depends strongly on the photolysis rates which may be much larger over clouds or within thin cirrus clouds (including contrails) than for clear sky (Ruggaber et al., 1994). An increase in the actinic flux increases the $\mathrm{HO}_{x}$ content, the $\mathrm{OH} / \mathrm{HO}_{2}$ ratio, enhances the conversion to $\mathrm{HNO}_{3}$, reduces conversion to $\mathrm{HNO}_{4}$, and increases the $\mathrm{O}_{3}$ generation. As a consequence, the chemical changes depend strongly on season (Möllhoff et al., 1996; Meijer et al., 1996).

The hydrocarbons and $\mathrm{CO}$ emissions appear to be unimportant for these issues, because the emissions cause only small changes in the rather large background concentrations of these components. It is conceivable, however, that more hydrocarbons in the exhaust may cause more photolytic formation of $\mathrm{OH}$ in the young plumes, hence more $\mathrm{HNO}_{3}$ and $\mathrm{H}_{2} \mathrm{SO}_{4}$, and thus enhanced particle formation.

The increase in $\mathrm{NO}_{x}$ enhances photochemical generation of $\mathrm{O}_{3}$ by photosmog reactions with $\mathrm{CO}$ and hydrocarbons in the background atmosphere or may contribute to photocatalytic destruction of $\mathrm{O}_{3}$ as discussed in Section 3. These reactions are slow and cause ozone changes which amount to a few ppbv per day. Photochemical ozone changes at plume scales (i.e. at time scales of hours to a day) have not yet been measured and will be difficult to measure because the plume-induced variations are small compared to background variability.

Recent measurements within a stagnant anticyclone through which air traffic passed for several days showed measurable increases in $\mathrm{NO}_{x}$, particles, and ozone. The increase in $\mathrm{NO}_{x}$ and particles, with lifetimes of order of several days, may be attributed to the emitted $\mathrm{NO}_{x}$ and particles or particle precursors. However, the increase in ozone, with a much larger lifetime, is presumably caused by different origins of spontaneous expansion $\mathrm{T}[\mathrm{K}]: 218 \quad \mathrm{p}[\mathrm{hPa}]: 236$

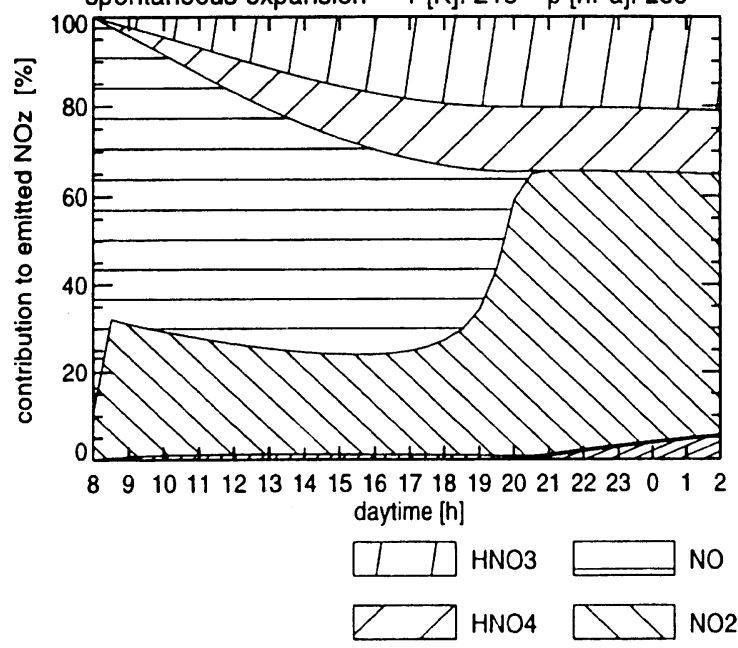

continuous expansion $\mathrm{T}[\mathrm{K}]: 218 \mathrm{p}[\mathrm{hPa}]: 236$

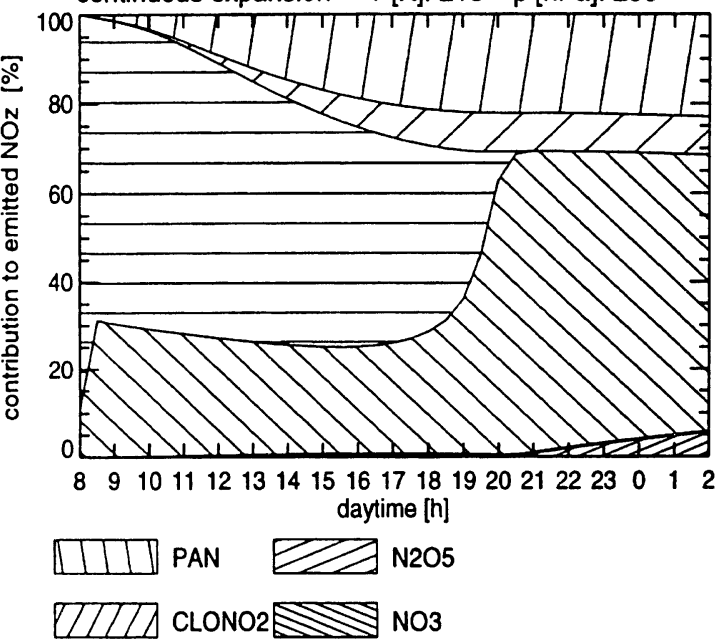

Fig. 30. Conversion of emitted $\mathrm{NO}_{x}$ into various $\mathrm{NO}_{y}$ compounds during 2.5 days, as computed with a box model which either expanded slowly and continuously from the plume scale to the mesoscale box (left) or which is assumed to expand suddenly over the mesoscale box (right) (Möllhoff et al., 1996). 
the air masses encountered. This is supported also by model calculations (Schlager et al., 1996).

\subsection{Contrail formation}

The clouds often seen to be formed in the wake of aircraft are called condensation trails (Brewer, 1946) or contrails (Appleman, 1953).

5.4.1. Thermodynamical conditions for contrail formation. As reviewed in Schumann (1996a) and as first explained by Schmidt (1941) and Appleman (1953) using a thermodynamical equilibrium theory, contrails are expected to form in the engine exhaust plumes when isobaric mixing between the hot and humid exhaust gases and cold ambient air leads to a mixture reaching saturation with respect to water (see Fig. 31) so that cloud droplets form which then might freeze to form ice particles. For ambient humidity sufficiently below ice saturation, the contrails evaporate and remain short-lived while persistent contrails may form otherwise. In order to reach water saturation in the plume, the ambient air temperature must be below a certain threshold temperature which depends on pressure, ambient humidity, and the ratio of water vapour and heat emissions from the engines, typically colder than $-40^{\circ} \mathrm{C}$, see (Fig. 32). Small changes in the threshold temperature can cause considerable changes in the altitude range where contrails form (Miake-Lye et al., 1993). The threshold temperature is larger than predicted by Appleman (1953) because only part of the combustion heat is emitted with the exhaust while the fraction $\eta$ is converted into work to propel the aircraft, where $\eta$ is the overall propulsion efficiency of the engine/aircraft combination (Busen and Schumann, 1995), as defined earlier. In order to form droplets for small liquid supersaturation, the exhaust must contain sufficient cloud condensation nuclei (CCN). The general thermodynamical theories are roughly confirmed by Lidar observations correlated with radiosonde data for temperature (Freudenthaler et al., 1995), by in situ measurements (Busen and Schumann, 1995; Schumann et al., 1996), and several older observations (see Schumann, 1996a).

The mechanism by which the condensation nuclei are formed has been investigated in several recent studies (e.g. Kärcher et al., 1996b). Particle measurements in contrails (Knollenberg, 1972; Gayet et al., 1996; Schumann et al., 1996) show very large concentrations of particles which cannot be explained by background aerosol. Possible alternative sources are soot (Pitchford et al., 1991; Hagen et al., 1992) and sulphur emissions (Hofmann and Rosen, 1978) from the engine exhaust, or combinations of both (Schumann et al., 1996). These emissions lead to an invisible aerosol trail (Arnold et al., 1994).

Moreover, observations of contrails forming very quickly behind aircraft under conditions where the maximum relative humidity just reaches saturation with respect to liquid water (Busen and Schumann, 1995), raised the question whether contrail particles

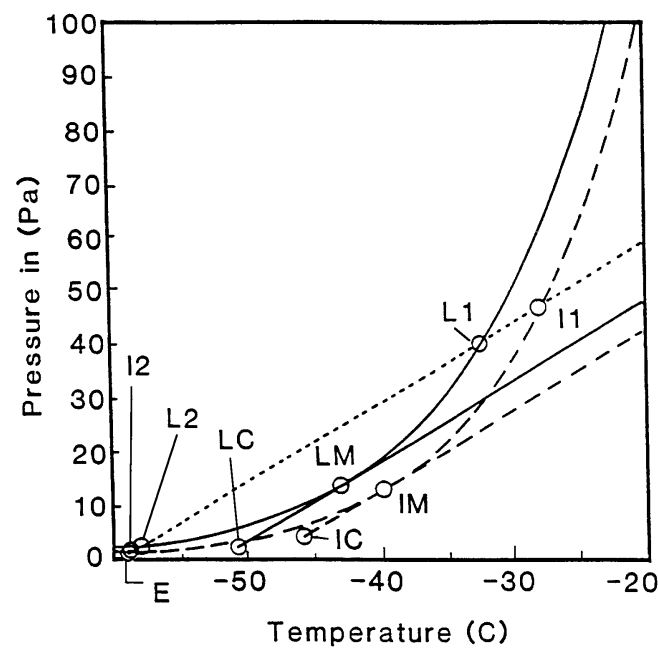

Fig. 31. Water vapour partial pressure vs temperature with saturation for liquid water (full curve) and ice (dashed), and lines of isobaric mixing for contrail onset at liquid saturation (full), ice saturation (long-dashed) and ambient temperature (short dashed). The various points denote: E, environmental state, LC, liquid critical threshold, IC, ice critical threshold, L1, L2, first and last state with liquid saturation, I1, I2, first and last state with ice saturation, LM, IM, state with maximum liquid or ice saturation (from Schumann, 1996a).

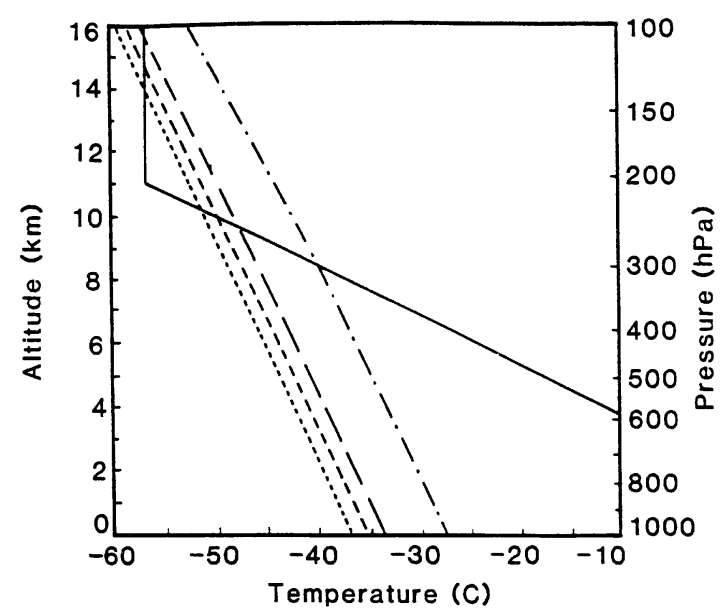

Fig. 32. Schmidt-Appleman diagram with threshold temperature $T_{\mathrm{LC}}$ vs altitude for relative humidity of 0 (short dashed curve), 30\% (medium dashed), 60\% (long dashed) and $100 \%$ (dash-dotted line), and the temperature profile of the international standard atmosphere (full) (from Schumann, 1996a).

may form also by as yet identified mechanisms under slightly subsaturated conditions. Freezing of solution droplets (Heymsfield and Sabin, 1989), or homogeneous nucleation and ice freezing are too slow processes to explain visible contrail formation as early as observed (Kärcher et al., 1995). However, these processes become important at temperatures much below $-40^{\circ} \mathrm{C}$ and in jet plumes causing large water supersaturation (Kärcher, 1995). Freudenthaler et al. (1996) 
investigated contrails by means of a scanning backscatter and depolarisation lidar. They find depolarisation values of 0.5 , indicating ice particles, except for young contrails at temperatures below $-50^{\circ} \mathrm{C}$, where the depolarisation is much smaller initially, typical for liquid droplets or very small ice particles. This indicates different particle and ice forming processes as a function of ambient temperature.

The most likely candidate for heterogeneous ice formation is soot (Kärcher et al., 1996b; Schumann, 1996b). Also, turbulent inhomogeneities produced from the different emissions of heat and moisture from the core and bypass parts of jet engines (Kärcher, 1995) may cause local supersaturation even when the mean field is slightly subsaturated (Schumann et al., 1997).

Very little information is available on the lifetime of contrail particles. Measurements show that contrails are still visible when the humidity has dropped below ice saturation (Busen et al., 1994; Schumann et al., 1996). The contrail ice particles may acquire a $\mathrm{HNO}_{3}-3 \mathrm{H}_{2} \mathrm{O}$ (NAT) coating which can potentially lead to a lengthening of their lifetime (Diehl et al., 1995; Kärcher, 1996).

5.4.2. Formation of spreading contrails and cirrus clouds. It is assumed that persistent and spreading contrails form when the ambient air is supersaturated with respect to ice. In this case the particles formed do not evaporate until the ambient air has become dried. Only a few measurements exist to confirm that the humidity is above ice saturation when persistent contrails are visible (Brewer, 1946; Ovarlez et al., 1996).

Persistent contrails in the form of line clouds are often visible in satellite data (Carleton and Lamb, 1986; Schumann and Wendling, 1990), and such line clouds cover on average less than $0.4 \%$ of the area over mid Europe and about $1 \%$ of the area over the eastern North Atlantic (Bakan et al., 1994). However, the actual coverage by aircraft-induced clouds may be larger because not all contrails may have the shape of line clouds. Moreover, the aerosol emitted by aircraft may impact cloud formation at places and times much different from those of emission.
For a local observer, the sky may be covered completely at times. On average, satellite data reveal that contrails occur in clusters within patches of obviously humid air masses which cover about 5-20\% of the sky over Europe (Mannstein, 1996). Hence, it can be expected that the average cloud coverage by contrails in main traffic regions at northern midlatitudes may reach order $10 \%$ when air traffic grows very large. However, more work is required for more definite conclusion.

Persistent contrails form mainly in the upper troposphere. The stratosphere is usually too dry for persistent contrails. In this respect, subsonic aviation in the upper troposphere may cause larger climate impact than aircraft flying in the lower stratosphere.

\subsection{Particle formation and heterogeneous chemistry}

The particles formed within contrails are of relevance not only for cloud formation but also with respect to heterogeneous chemistry. Hence, it is important to understand how particles may get formed in the plume of aircraft. Reported particle emission indices (for volatile or for non-volatile particles) vary over at least two orders of magnitude (see Table 19).

5.5.1. Nitric acid and sulphuric acid aerosol. The upper troposphere and lower stratosphere may be cold and humid enough to allow for the existence of nitric acid-water particles (Hanson and Mauersberg, 1988) and the emissions of aircraft may increase the $\mathrm{H}_{2} \mathrm{O}$ and $\mathrm{HNO}_{3}$ concentration such that more such particles may be generated in the plume of aircraft (Peter et al., 1991; Arnold et al., 1992). The upper troposphere is also generally supersaturated with respect to $\mathrm{H}_{2} \mathrm{SO}_{4}$, so that additional $\mathrm{H}_{2} \mathrm{SO}_{4}$ which gets formed in the plume of aircraft causes high supersaturations (factors 100 are possible). Under these conditions, sulphuric acid aerosol particles may be formed by binary nucleation of sulphuric acid with water (Mirabel and Katz, 1974; Hofmann and Rosen, 1978; McGraw, 1995). Particles may also form by heterogeneous nucleation of sulphuric acid with water on the surface of soot particles emitted from jet engines (Turco et al., 1980).

Table 19. Particle emission indices for total and non-volatile particles per fuel mass as measured with condensation nucleus counters in units of $10^{15} \mathrm{~kg}^{-1}$

\begin{tabular}{lccl}
\hline Aircraft & Total & Non-volatile & \multicolumn{1}{c}{ Reference } \\
\hline Sabreliner & 2 & - & Pitchford et al. (1991) \\
ER-2 & $0.1-1.3$ & - & Fahey et al. (1995a) \\
Concorde at cruise & $170-650$ & $43-87$ & Fahey et al. (1995b) \\
Concorde at ground & 10,000 & 500 & Lilenfeld et al. (1996) \\
ATTAS & 0.4 (idle) to 2 (cruise) & - & Schumann et al. (1996), Petzold and \\
B747 & $0.8-9.9$ & $0.27-0.57$ & Schröder (1997) \\
DC10 & 4.5 & 0.46 & POLINAT, Schumann et al. (1996d) \\
A340 & 2.9 & 1.6 & POLINAT, Schumann et al. (1996d) \\
B747, B757, B767, A310, MD80 & 10 & - & POLINAT, Schumann et al. (1996d) \\
\hline
\end{tabular}


5.5.2. Soot. Soot usually consists of more than $90 \%$ carbon by mass, with properties depending strongly on the combustion process (Haynes and Wagner, 1981). Typically, modern jet engines emit $0.01-0.1 \mathrm{~g}$ of soot per kilogram of fuel, with peak diameters of 30-100 nm (Hagen et al., 1992), though much larger emission indices have been measured for older engines (Rosen and Greegor, 1974). Pure carbon particles are hydrophobic and form condensation nuclei only for large supersaturation. Soot differs in many respects from black carbon particles. Hallett et al. (1990) investigated the $\mathrm{CCN} / \mathrm{CN}$ ratio for the aerosol resulting from combustion of aviation fuel from burning kerosene pools (under conditions different from engines flying at cruise altitude). They found a low fraction of CCN. Pitchford et al. (1991) measured also a very small $\mathrm{CCN} / \mathrm{CN}$ ratio of order $1 / 1000$, but the aircraft flew at ambient temperature of about $11^{\circ} \mathrm{C}$. The ambient temperature is much lower for cruising commercial aircraft, where the $\mathrm{CCN} / \mathrm{CN}$ ratio may be larger. Also, supersaturations in exhaust plumes may exceed $100 \%$ and soot particles coated with sulphuric acid provide a source for $\mathrm{CCN}$ (Parungo et al., 1992) and carbon particles exposed to $\mathrm{OH}$ become slightly more hydrophilic (Kärcher et al., 1996b). Filter analysis of soot behind engines suggest that an order $1 \%$ of the fuel sulphur enters the soot particles already during the combustion process (Petzold and Schröder, 1998). Droplets formed from soot may undergo immersion freezing at temperatures between -24 and $-34^{\circ} \mathrm{C}$, and homogeneous freezing at lower temperatures (DeMott, 1990), and soot from automobiles was found to act as ice nuclei at temperatures below $-25^{\circ} \mathrm{C}$ (Grant and Corrin, 1974). Recent model studies showed that a substantial fraction of soot particles in exhaust plumes may get converted into acid aerosols by heterogeneous nucleation (Zhao and Turco, 1995; Brown et al., 1996a; Kärcher et al., 1996a, b). Hence, soot is likely to be very important in controlling the particle spectrum of contrails.

In a recent experiment, the impact of sulphur oxides on particle formation and contrails was investigated in the exhaust plumes of the twin-engine jet research aircraft ATTAS. Different fuels were used with sulphur mass fractions of 170 and $5500 \mathrm{ppm}(1 \mathrm{ppm}$ $=10^{-6}$ ) in the fuel, one lower than average, the other above the specification limit of standard Jet-A1 fuel (Schumann et al., 1996). During the same flight, different high- and low-sulphur fuels were burned at the same time on the two engines. The observations showed visible and measurable differences between contrails caused by the different sulphur levels. The contrail became visible about $10 \mathrm{~m}$ after the engine exit for high sulphur content, but $15 \mathrm{~m}$ after the engine exit for low sulphur content. The higher sulphur emission caused a larger optical thickness of the contrail shortly after onset, with slightly brown-coloured contrail when the Sun was behind the observer, and more contrast when viewed against the Sun. This has been explained by more but smaller droplets in the high-sulphur plume (Gierens and Schumann, 1996). At plume ages of about $20 \mathrm{~s}$, the plumes contained many subvisible particles. Peak number densities were $30,000 \mathrm{~cm}^{-3}$ for particles of diameter above $7 \mathrm{~nm}$ and $15,000 \mathrm{~cm}^{-3}$ above $18 \mathrm{~nm}$. The high-sulphur plume showed more particles than the low-sulphur plume, see (Fig. 33). The differences were about $25 \%$ for particles above $7 \mathrm{~nm}$ and about $50 \%$ above $18 \mathrm{~nm}$. The results indicated that part of the fuel sulphur is converted to sulphuric acid which nucleates with water vapour heterogeneously on soot or nucleates acid droplets homogeneously which then coagulate partly with soot.

In an earlier, related experiment, Busen and Schumann (1995) found no visible contrail differences when using fuels with sulphur contents of 2 and

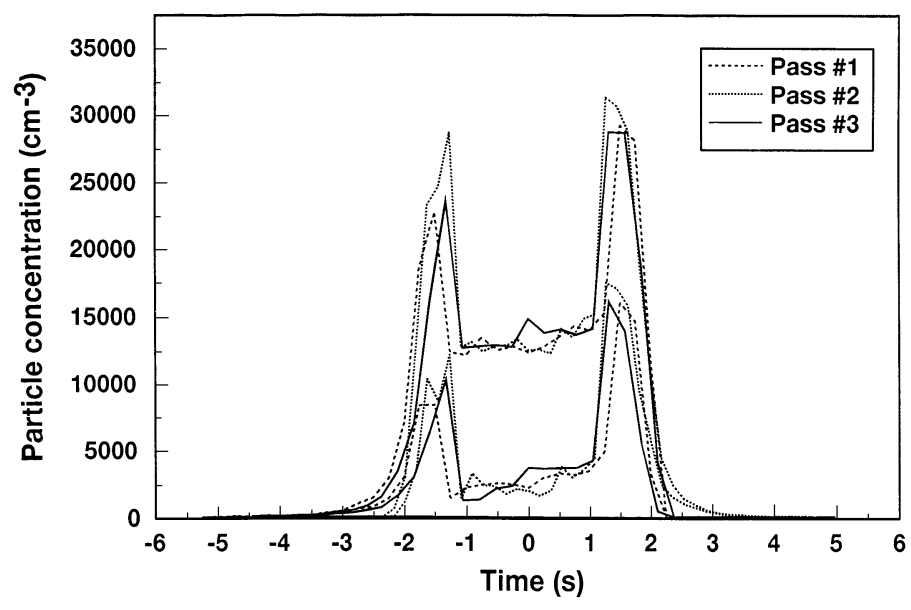

Fig. 33. Aerosol number concentration vs time for particles larger than $7 \mathrm{~nm}$ (top curves) and larger than $18 \mathrm{~nm}$ (bottom curves) in diameter from three passes through the plumes, while using fuel with elevated sulphur content in the right engine (from Schumann et al., 1996). 
$250 \mathrm{ppm}$, respectively. It is not yet fully understood for which sulphur levels measurable effects are to be expected. Some recent studies suggest that even the small sulphur levels in this experiment may be high enough to get changes in the particle spectrum, but these changes may be too small to become visible to an observer (Kärcher et al., 1996; Brown et al., 1997). However, these model simulations need to be verified by comparison to experimental data (such as presented by Petzold et al., 1997).

Recently, such experiments were repeated by providing fuels with 800 and $2700 \mathrm{ppm}$ sulphur mass content to different engines of one Airbus A310 (Busen et al., 1996; Petzold et al., 1997). The experiments were performed under dry and humid conditions, without and with a visible contrail. The particle measurements show that the particle density in the plume depends strongly on the type of engine (the CF6-80C2A2 engine of the Airbus produces less soot by mass but more particles by number than the older ATTAS engines), sulphur causes a strong source of small particles, and ice particles in contrails are slightly more (perhaps a factor of two) numerous but smaller when the fuel sulphur content is high.

Hence, sulphur contributes to form particles both by homogeneous nucleation and by activating soot particles. The sulphur impact might increase when the engine emits soot with smaller specific surface.

5.5.3. Heterogeneous chemical effects. Though important in principle, computations performed so far (Danilin et al., 1994; Karol and Ozolin, 1994; Louisnard et al., 1995) indicate that heterogeneous chemistry on the surface of aerosol or contrail particles in aircraft plumes has little impact on air chemistry in aircraft plumes. However, these simulations were performed with assumptions on the specific aerosol surface per unit volume, which are perhaps underestimating the actual surface values. Moreover, it is not yet known how important chemical reactions on the much larger surface of natural cirrus clouds are, although such reactions have a high potential to be important (Borrmann et al., 1996; Reichardt et al., 1996). Typical values for the specific surface per volume are of order $10,000 \mu \mathrm{m}^{2} \mathrm{~cm}^{-3}$ in fresh contrails (Petzold et al., 1997), of same order with very large scatter in natural cirrus clouds (Dowling and Radke, 1990), and of order $1 \mu \mathrm{m}^{2} \mathrm{~cm}^{-3}$ for stratospheric background aerosol (Pueschel, 1996). However, the lifetime of the young contrail is of order minutes while individual cirrus clouds may exist for hours.

Finally, a recent study suggests that $\mathrm{HNO}_{3}$ and $\mathrm{NO}_{2}$ may get heterogeneously reduced on soot surfaces and these reactions form a sink for $\mathrm{O}_{3}$ (Lary et al., 1997). This study lead Bekki (1997) to conclude that soot from aviation may be responsible for a large fraction of the observed ozone loss at mid-latitudes of the lower stratosphere in the last decades. However, Bekki's model assumed that the soot surface was increasing by $5 \%$ per year over the last $20 \mathrm{yr}$, and that the reactions of ozone on soot surfaces are purely catalytic. If the reactions are non-catalytic then the amount of soot mass available would not be large enough to explain any substantial amount of ozone mass reduction. Moreover, the postulated increase in soot surface is not yet supported by emission analysis.

\subsection{Corridor effects}

Over Europe, North America and over the North Atlantic, air traffic occurs in heavily loaded and rather narrow flight corridors. For example, about 300-500 aircraft pass daily in either of both directions over the North Atlantic (Hoinka et al., 1993) within a corridor of about $1000 \mathrm{~km}$ width and $2 \mathrm{~km}$ altitude (Schumann, 1994). The traffic over the ocean is organised along rather few discrete flight tracks with $2000 \mathrm{ft}$ vertical and $1^{\circ}$ latitude separation on which individual aircraft fly with typically $20 \mathrm{~min}$ time separation and with small lateral variations. Model calculations (Franzkowiak et al., 1996) show that the small-scale spatial variation of the emissions cause a smaller ozone production than a smooth emission of the same amount of $\mathrm{NO}_{x}$; the temporal variation is also important.

Measurements performed in the North Atlantic flight traffic corridor have shown aircraft traces in terms of $\mathrm{NO}_{x}, \mathrm{CO}_{2}$, aerosols, $\mathrm{H}_{2} \mathrm{O}, \mathrm{SO}_{2}, \mathrm{HNO}_{2}$, and $\mathrm{HNO}_{3}$. The largest signals were found in young exhaust plumes of wide body aircraft with maximum values of more than $200 \mathrm{ppbv} \mathrm{NO}_{x}$. The exhaust plumes were still highly turbulent in these cases. When flying perpendicular to the main traffic route, the data show $\mathrm{NO}_{x}$ and particle increases caused by aircraft in plumes at ages of typically $15 \mathrm{~min}$ to $3 \mathrm{~h}$, (see Fig. 34). Measured peak values are about $3 \mathrm{nmol}$ $\mathrm{mol}^{-1}$ for $\mathrm{NO}_{x}$ and $500 \mathrm{~cm}^{-3}$ for particles, being 30 and 3 times larger than the background values, respectively. Turbulence was rarely notable in these crossings. Often, the measured plumes result from a superposition of the exhausts from several aircraft flying the same track (Schlager et al., 1997).

As expected from precalculations (Schumann and Konopka, 1994), the measurements show that air traffic emissions cause a very spotty distribution of the concentration field in the flight corridor, in particular for $\mathrm{NO}_{x}$ and particles. Individual aircraft plumes have been identified at plume ages up to $3 \mathrm{~h}$. At this time, individual plumes get dispersed to typically $200 \mathrm{~m}$ vertically and $15 \mathrm{~km}$ horizontally. Concentration peaks which are significantly above the background values are concentrated in a small fraction of the corridor volume (order of a few percent).

Mean concentration changes at the outer scales of corridors (order $1000 \mathrm{~km}$ ) are difficult to identify in general. However, as mentioned before, under special meteorological conditions, within a stationary anticyclone, measured data showed accumulation of $\mathrm{NO}_{x}$ and particles (Schlager et al., 1996).

Within a flight corridor, the strongest change in background values are to be expected for $\mathrm{NO}_{x}$ (order 50-150 pptv, see Section 6), and for CN particles. The 


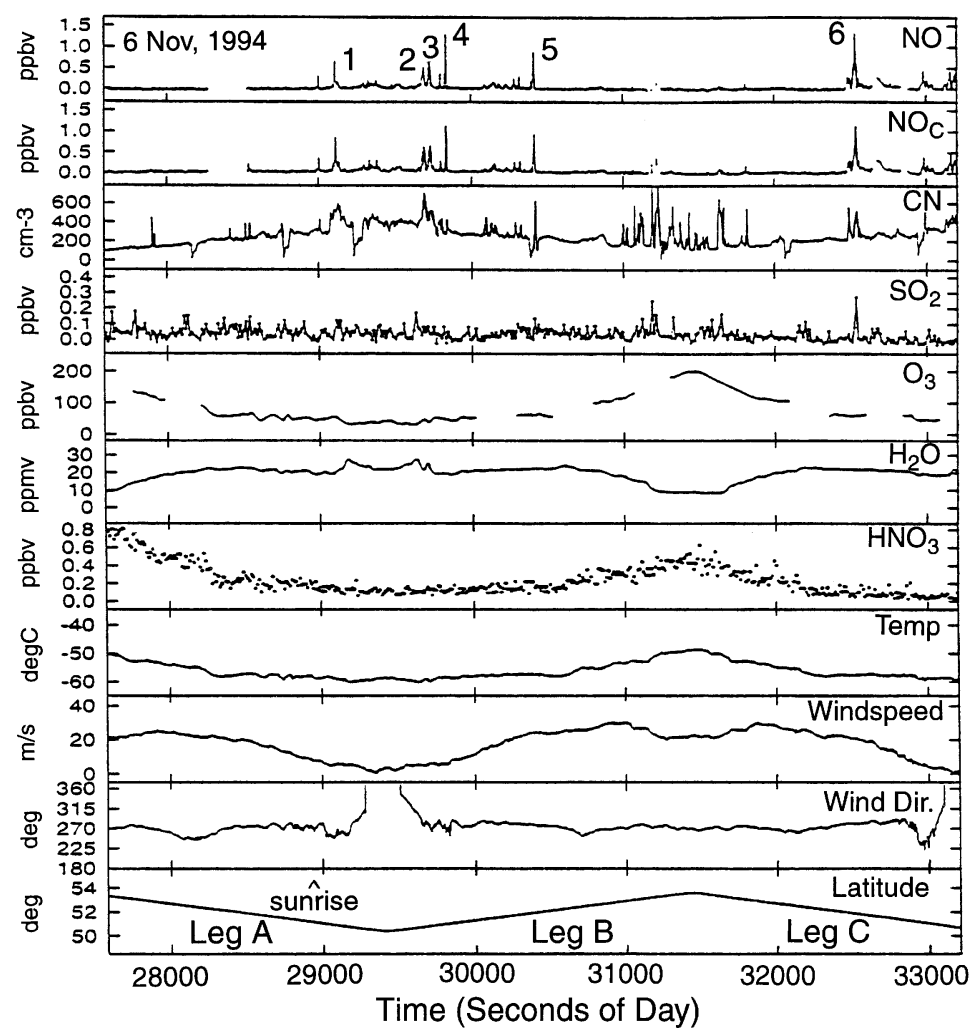

Fig. 34. In situ observations of aircraft emission signatures when flying forth and back at constant altitude $(11.3 \mathrm{~km})$ and constant longitude $\left(12^{\circ} \mathrm{W}\right)$ through aircraft plumes in the North Atlantic flight corridor (Schlager et al., 1997). Time series of $\mathrm{NO}, \mathrm{NO}_{\mathrm{c}}=\mathrm{NO}+0.35 \mathrm{~N}_{2}$, condensation nuclei $\mathrm{CN}, \mathrm{SO}_{2}, \mathrm{O}_{3}, \mathrm{H}_{2} \mathrm{O}$, $\mathrm{HNO}_{3}$, temperature, wind speed and direction, and northern latitude vs time of day (total duration about $1.6 \mathrm{~h})$.

expected mean increase in particle concentration may be estimated for the North Atlantic flight traffic corridor: Under assumptions as given by Schumann (1994) (500 aircraft daily, consuming $60 \mathrm{Mg}$ of fuel each within a corridor volume of $5000 \mathrm{~km} \times 1000 \mathrm{~km} \times$ $2 \mathrm{~km}$ ) and for an emission index of $10^{16}$ particles per kilogram of fuel, one computes a mean increase in $\mathrm{CN}$ of $30 \mathrm{~cm}^{-3}$ within one day. The same value follows from the measured ratio of $\mathrm{CN} / \mathrm{NO}_{x}=300 \mathrm{~cm}^{-3}$ $\mathrm{ppbv}^{-1}$ in airliner plumes within the North Atlantic Flight corridor (Schlager et al., 1997), if the $\mathrm{NO}_{x}$ increase is of order 100 pptv. This change in $\mathrm{CN}$ is significant compared to typical background values of $300 \mathrm{~cm}^{-3}$. However, the impact of these additional $\mathrm{CN}$ on cloud properties is still unknown.

\subsection{Conclusions}

Aircraft plumes get diluted by mixing over 5 orders of magnitude (relative to the concentration at the engine exit plane) within a few hours and can be detected in terms of $\mathrm{NO}_{x}$ and $\mathrm{CN}$ particles at time scales of up to one day. Aircraft cause a very spotty concentration field in the regions of heavy air traffic.

Measurements and plume models indicate that an order $10 \%$ of the emitted $\mathrm{NO}_{x}$ gets converted within hours into less reactive $\mathrm{NO}_{y}$, such as $\mathrm{HNO}_{2}, \mathrm{HNO}_{3}$. and $\mathrm{HNO}_{4}$. Most of this conversion takes place in the first milliseconds after engine exit, and is controlled by the amount of emitted $\mathrm{OH}$. The plume processes are relatively slow. However, after a day, about $50 \%$ of the $\mathrm{NO}_{x}$ might have been converted. The change in $\mathrm{O}_{3}$ in the plumes is too small to become measurable during one day.

Aircraft also emit soot and the soot interacts with $\mathrm{HNO}_{3}, \mathrm{H}_{2} \mathrm{SO}_{4}$, and $\mathrm{H}_{2} \mathrm{O}$ to form contrail particles which later may serve as ice nuclei for cirrus clouds. The measurements show that typically $10^{16}$ particles are formed in the plume per unit kilogram of burned fuel. This causes a substantial increase of background aerosol (about 30\% with respect to $\mathrm{CN}$ ). However, it is unknown which fraction of these $\mathrm{CN}$ are suited to form ice particles. The knowledge on the details of $\mathrm{SO}_{2}$ to particle conversion is presently changing rapidly. Recent studies suggest that roughly $10 \%$ (possibly 1-50\%) gets converted to gaseous $\mathrm{H}_{2} \mathrm{SO}_{4}$ which gets quickly converted into aerosol or condenses on soot particles. The few model studies performed so far indicate small impact of the particles on air chemistry, but with uncertain estimates of the specific surface of the aerosol available. However, the 
emitted or generated aerosol is very likely to change the occurrence and the particle properties of natural cirrus. Changes in natural cirrus cloud properties and cloud cover are to be expected in the neighbourhood of major traffic routes, but clear evidence for such effects is still rare. Much more research is required to clarify the processes which lead to particle formation and their impact on air chemistry and even more on cloudiness and climate. Since persistent contrails and cirrus clouds form mainly in the upper troposphere, this region may be more sensitive to aircraft emissions than the lower stratosphere, in this respect.

The plume processes for subsonic and supersonic aircraft are similar except for different background conditions, and vertical mixing properties. Hence, contrails form mainly behind subsonic aircraft. Vertical plume mixing is weaker for stratospheric conditions, but the measured plume dilution values indicate no major difference compared to flights in the tropopause region. Heterogeneous particle processes activating chlorine compounds are more likely for stratospheric plumes, and ozone production decreases with altitude.

In conclusion, plume processes control the conversion of $\mathrm{NO}_{x}$ to $\mathrm{NO}_{y}$ during the first day, and control the particle formation process. The conversion of $\mathrm{NO}_{x}$ to $\mathrm{NO}_{y}$ reduces the impact of the emitted $\mathrm{NO}_{x}$ on ozone at global scales. Also, the slow dispersion of the exhaust gases with the plumes causes smaller ozone impact than if the same emissions are spread immediately over a global model box. On the other hand, the particle formation process is strongest for slow plume dispersion. The impact of the particles formed on cloudiness and chemistry is potentially large, but not yet assessable in detail. One needs to know more about the fate of the particles formed at time scales of days to weeks for this purpose.

\section{EFFECTS OF AIRCRAFT EMISSIONS ON THE CHEMICAL} COMPOSITION OF THE ATMOSPHERE AT LARGE SCALE

\subsection{Introduction}

Studies of how a projected future fleet of supersonic aircraft affect stratospheric ozone have been done since the early 1970s, when it was demonstrated that $\mathrm{NO}_{x}$ emissions could have a significant impact on stratospheric ozone (Crutzen, 1971; Johnston, 1971), thereby leading to enhanced penetration of UV radiation to the Earth's surface.

Changes in lower stratospheric ozone is of importance not only from a chemical point of view, but also for climate considerations, since ozone changes in the tropopause region will have much stronger impact on surface temperatures than ozone changes in lower parts of the troposphere (Lacis et al., 1990). Due to the strong height dependence of the climate effect it is important to be able to model the height variation of the ozone perturbations from aircraft emissions.
Recent model studies, which take into account the strong interactions between the $\mathrm{NO}_{x}$ and chlorine chemistry and the role of particles for the ozone depletion chemistry, indicate that $\mathrm{NO}_{x}$ emission from supersonic aircraft in the lower stratosphere is less significant than earlier estimates indicated. However, an open question is to assess how aircraft impact is affected by the possible particle formation due to emissions of sulphur, nitrogen oxides and water vapour.

The tropopause region (ranging from a few $\mathrm{km}$ below the tropopause to a few $\mathrm{km}$ above) is particularly difficult to model due to large variations in the concentration of key chemical compounds and large spatial variations in the transport pattern. There are also large uncertainties in our understanding of key chemical processes, primarily due to limited knowledge of the $\mathrm{NO}_{x}$ distribution and of key transport processes (tropospheric-stratospheric exchange and deep convection).

The impact on the upper tropospheric $\mathrm{NO}_{x}$ emitted from currently flying aeroplanes in the upper troposphere is found to be significant. For instance, model studies performed through the AERONOX project, using a simplified $\mathrm{NO}_{x}$ chemistry, give large enhancements of upper tropospheric $\mathrm{NO}_{x}$ in areas with heavy traffic (Sausen et al., 1995). $\mathrm{NO}_{x}$ enhancements are characterised by large temporal and spatial variations (van Velthoven et al., 1997). Regional increases in $\mathrm{NO}_{x}$ up to $50-100 \%$ are obtained (Köhler et al., 1997).

Two-dimensional (2-D) chemistry/transport model simulations have strong limitations when it comes to transport formulation and description of the complex chemical processes which take place in the height regions below and above the tropopause. Our knowledge of these processes and the distribution of key compounds like $\mathrm{NO}_{x}$, ozone and water vapour is also limited. These problems can only be adequately addressed in three-dimensional (3-D) models which have sufficient resolution to handle the spatial variations expected to occur. It is only during the last few years that 3-D models with sufficient chemistry have been developed to study the distribution and perturbations of ozone in the upper troposphere/lower stratosphere. More studies of the impact of chemical and dynamical processes have to be performed before reliable estimates of aeroplane-generated ozone perturbations are obtained.

The estimated ozone perturbations from aircraft emissions depend on the emission scenarios used for $\mathrm{NO}_{x}$ emissions. Early model studies have used both the NASA and the first ANCAT data basis which were significantly different. The differences in emissions: $0.44 \mathrm{Tg}(\mathrm{N}) \mathrm{yr}^{-1}$ for the NASA emissions and $0.89 \mathrm{Tg}(\mathrm{N}) \mathrm{yr}^{-1}$ for the ANCAT emission (Wuebbles et al., 1993; Gardner et al., 1995), were reflected in the calculated perturbations.

Large gaps exist in the current understanding of basic processes in the lower stratosphere and upper troposphere regions. Model studies will therefore reduce uncertainties in the key processes for ozone distribution and changes, and will therefore 
improve the basis for predictions of present and future ozone perturbations by aircraft emissions.

The modelling should contribute to a better understanding of the processes controlling ozone in height regions where ozone change could contribute significantly to climate change and increases in the penetration of harmful UV-radiation to the Earth's surface. It will provide important inputs to international assessments on ozone and climate in areas (role of aircraft emissions) where knowledge is limited. It will thus provide advice for decisions on future aircraft development and air traffic regulations.

Two main points are of interest in connection with modelling ozone perturbations by aircraft: (a) Although the total emission from aircraft is small compared with emission from surface sources, the emission takes place in a region where the contribution from other sources to the $\mathrm{NO}_{x}$ distribution (lightning, transport from the stratosphere, transport from the surface) is limited; therefore the impact could be large. (b) Aircraft emissions are growing rapidly in certain regions, and are expected to do so over at least the next couple of decades. We can therefore expect significant changes in the contribution from aircraft over the next decades, but the effect will be highly different in the different regions.

Several projects with $3-\mathrm{D}$ chemical transport model (CTM) studies with focus on ozone chemistry in the upper troposphere and lower stratosphere are under way as part of the Environment and Climate Research Programme of the European Commission. One aim of these projects is to improve modelling capability in the lower stratosphere and upper troposphere through extensive tests of chemical and dynamical processes and improvement of these processes in the context of 3-D modelling. This will lead to more reliable modelling of the impact of past, present and future emissions from aircraft.

The emphasis is on processes affecting transport and chemistry in the lower stratosphere and upper troposphere. The models have different formulations of chemistry and transport, and represent state-ofthe-art 3-D modelling. A model study using updated $\mathrm{NO}_{x}$ emission data from aircraft, where several of the current 3-D models participate, will be performed as part of the present assessment.

In this section we will discuss ozone distribution and changes in the upper troposphere and lower stratosphere, and also the upper tropospheric $\mathrm{NO}_{x}$ distribution since $\mathrm{NO}_{x}$ levels are critical for ozone generation in this region. The emphasis will be on recent threedimensional model studies of upper tropospheric ozone perturbations caused by $\mathrm{NO}_{x}$ perturbations from current (1991/1992) aircraft emissions. We will also summarise model studies regarding the impact of supersonic aircraft emissions on stratospheric ozone.

\section{2. $\mathrm{NO}_{x}$ distribution in the upper troposphere}

Ozone production in the upper troposphere is determined by the presence of $\mathrm{NO}_{x}$ in the region. The large-scale $\mathrm{NO}_{x}$ distribution has been extensively measured during the STRATOZ III in 1984 and the TROPOZ II missions in 1991 (Drummond et al., 1988; Ehhalt et al., 1992; Wahner et al., 1994; Rohrer et al., 1996) and during the AASE I and AASE II missions in 1990 and 1992 (Carroll et al., 1990; Weinheimer et al., 1994). Several other observations of the free tropospheric $\mathrm{NO}_{x}$ distribution have also been performed during the last few years (Emmons et al., 1997; Ziereis et al., 1997). The observations show that there are large spatial variations in the $\mathrm{NO}_{x}$ distribution with substantial higher $\mathrm{NO}_{x}$ levels at northern latitudes than at southern latitudes. The high $\mathrm{NO}_{x}$ mixing ratios at northern mid-latitudes are likely a result of several processes: stratospheric input, aircraft emissions, convective transport from the polluted boundary layer (Ehhalt et al., 1992; WMO, 1995). Using the IMAGES model (Müller and Brasseur, 1995), Lamarque et al. (1996) have estimated the relative contribution of the various $\mathrm{NO}_{x}$ sources on the atmospheric abundance of nitrogen oxides. Figure 35 suggests that, during January near $10-12 \mathrm{~km}$ altitude at mid-latitudes in the Northern Hemisphere, the relative contributions of stratospheric injection of fossil-fuel emissions at the surface, of lightning production, and of aircraft injection are similar in magnitude if the global lightning source is assumed to be $5 \mathrm{Tg} \mathrm{N} \mathrm{yr}{ }^{-1}$. This highlights the fact that an accurate prediction of $\mathrm{NO}_{x}$ and ozone changes caused by aircraft requires a reliable estimate of all natural and anthropogenic sources and sinks of nitrogen compounds in the atmosphere. It also requires that complex dynamical processes such as stratosphere/ troposphere exchanges and convective transport be accurately parameterized in the models. A similar calculation performed with IMAGES for July (not shown) suggests that during summertime, the contribution of the lightning source $(5 \mathrm{Tg} \mathrm{N})$ to upper tropospheric $\mathrm{NO}_{x}$ concentrations is close to $40-50 \%$, while that of the stratospheric source is of the order of $10 \%$, and that of fossil fuel $\mathrm{NO}_{x}$ released at the surface amounts to $20 \%$. Aircraft $\mathrm{NO}_{x}$ represents about $25 \%$ of the total burden near $10 \mathrm{~km}$ altitude. Note, however, that these calculations were performed with the NASA emission data $(0.44 \mathrm{Tg}$ $\mathrm{N} \mathrm{yr}^{-1}$ ). Other models, using other formulations (e.g. the early ANCAT emissions of $0.89 \mathrm{Tg} \mathrm{N} \mathrm{yr}^{-1}$ ) and parameterizations, could provide somewhat different quantitative results (in this case, a higher contribution of aircraft). Model validations are difficult to perform due to the lack of global observations of free tropospheric $\mathrm{NO}_{x}$.

Modelling studies of the free tropospheric $\mathrm{NO}_{x}$ distribution and the variation in time and space with a 3-D CTM where an extensive photochemical scheme is included (Jaffe et al., 1997; Berntsen et al., 1996) give $\mathrm{NO}_{x}$ levels in the upper troposphere which show strong seasonal and latitudinal variations. The $\mathrm{NO}_{x}$ levels are significantly higher at northern midlatitudes than at southern latitudes (almost a factor 


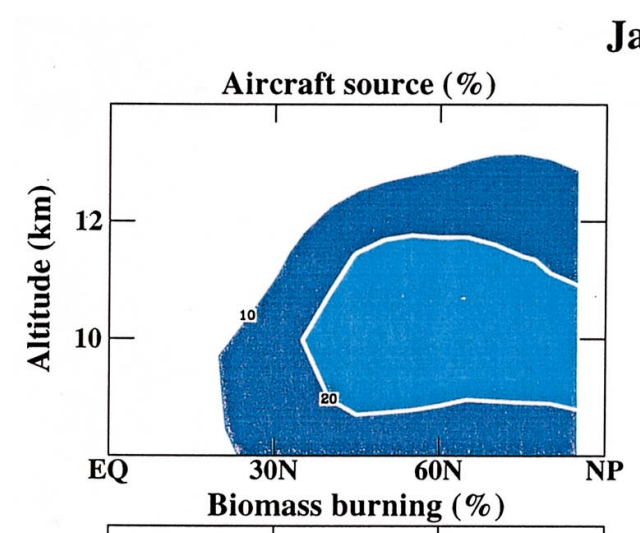

January
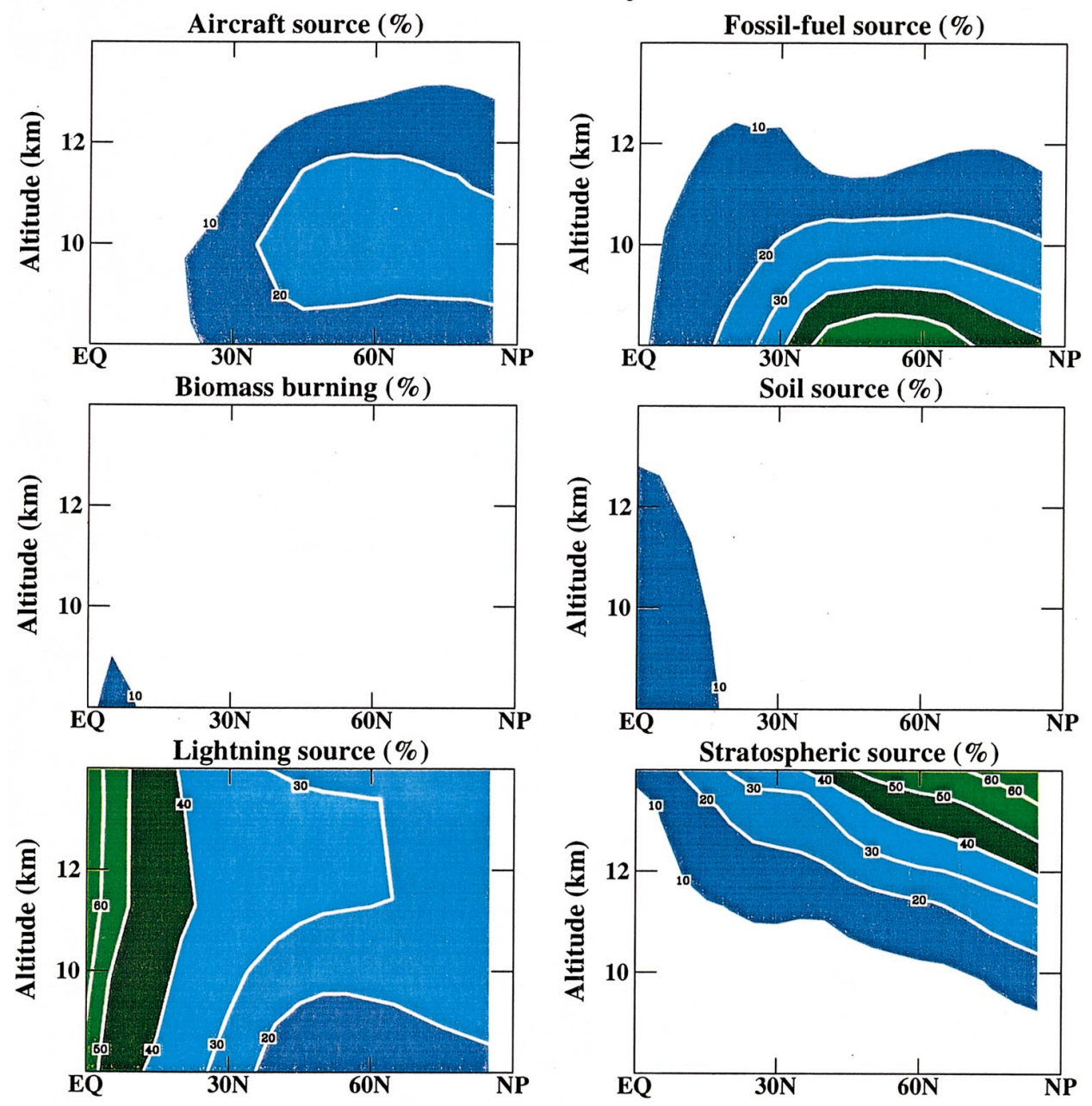

Fig. 35. Relative contribution (percent) of different sources in the concentration of $\mathrm{NO}_{x}$ calculated by the IMAGES model in the northern hemisphere (zonal mean, January).

10), suggesting the importance of transport of $\mathrm{NO}_{x}$ emitted from polluted sources from the surface to the upper troposphere. Comparisons with observations show calculated distributions that are somewhat lower than the observed values (Jaffe et al., 1997). In a study, using the same 3-D CTM, Berntsen et al. (1996) showed that surface emissions of $\mathrm{NO}_{x}$ and other pollutants contribute to the upper-tropospheric ozone distribution through efficient convective transport. In particular, the rapid growth of surface emissions in SouthEast Asia during the last two decades have most likely enhanced $\mathrm{NO}_{x}$ levels significantly (in excess of $50 \%$ above $8 \mathrm{~km}$ ) and enhanced ozone production over the region where emissions occur. It was, however, shown that this impact is strongly dependent on the representation in the model of convective process.

IPCC (1992) and WMO (1995) report several 2-D model studies where the impact of aircraft emissions on the $\mathrm{NO}_{x}$ levels in the upper troposphere is esti- mated. These studies suggest a significant enhancement of $\mathrm{NO}_{x}$ due to aircraft emissions at northern mid-latitudes where most of the traffic is concentrated. More realistic studies of enhanced $\mathrm{NO}_{x}$ distribution from aircraft emissions have recently been performed with 3-D models, for instance, as part of the AERONOX project (Sausen et al., 1995; van Velthoven et al., 1995; Köhler et al., 1997; Kasibhatla, 1993; Brasseur et al., 1996; Kraus et al., 1996).

Velders et al. (1994) have used an off-line 3-D CTM coupled to the analysis provided by the European Centre for Middle-Range Weather Forecast (ECMWF) to simulate the transport of $\mathrm{NO}_{x}$ in the upper troposphere in the region where the aircraft emissions occur. A decay constant corresponding to a half-life of 4-20 d were used as parameterized loss for $\mathrm{NO}_{x}$ emitted at this height. They found large zonal as well as seasonal variations in the $\mathrm{NO}_{x}$ distribution. Furthermore, they found that some $\mathrm{NO}_{x}$ was transported into the stratosphere, depending on the 
altitude of the corridor where emissions occurred. They also found that the distributions in the lower stratosphere were sensitive to the numerical grid size used in the model. Using a finer mesh increased the concentrations in the lower stratosphere, thereby affecting the impact of aircraft emissions at these heights.

In a recent 3-D model intercomparison performed under the IGAC Global Interpretation and Modelling (GIM) activity of the International Global Atmospheric Chemistry (IGAC) project of IGBP, calculated distributions of $\mathrm{NO}_{x}$ and ozone were presented for eight of the current CTMs used for tropospheric chemical studies. The comparison revealed that there are large differences in the calculated distribution of $\mathrm{NO}_{x}$ between the models, particularly in the upper troposphere. Calculated $\mathrm{NO}_{x}$ distribution for the month of July at $200 \mathrm{hPa}$ for ten of the models are shown in Fig. 36. Both the magnitude and the location of maximum values vary substantially, probably reflecting differences in transport formulation and in source strengths between the different models.
BISA

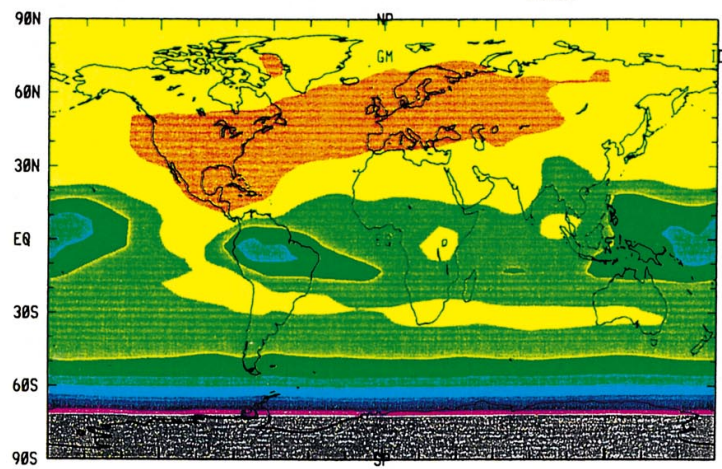

IMAU2

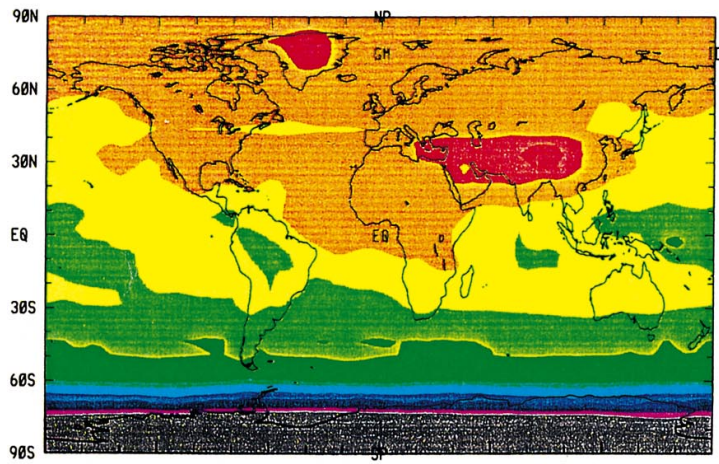

KNMI

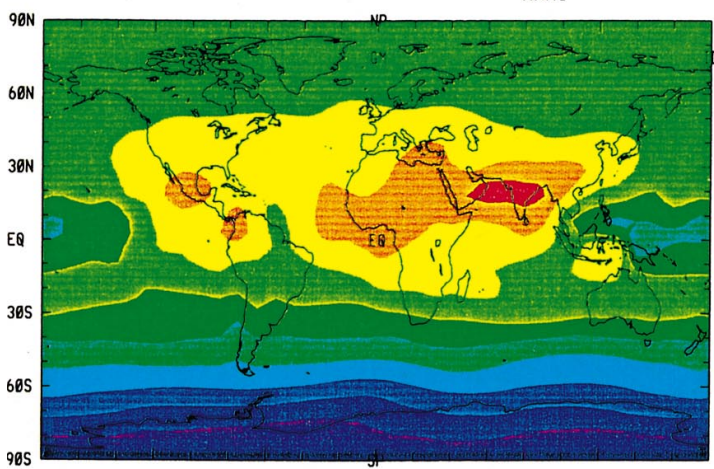

UIO

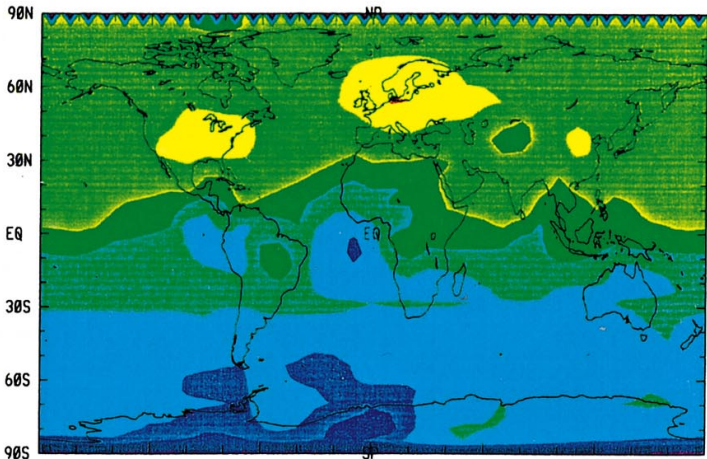

IMAU3
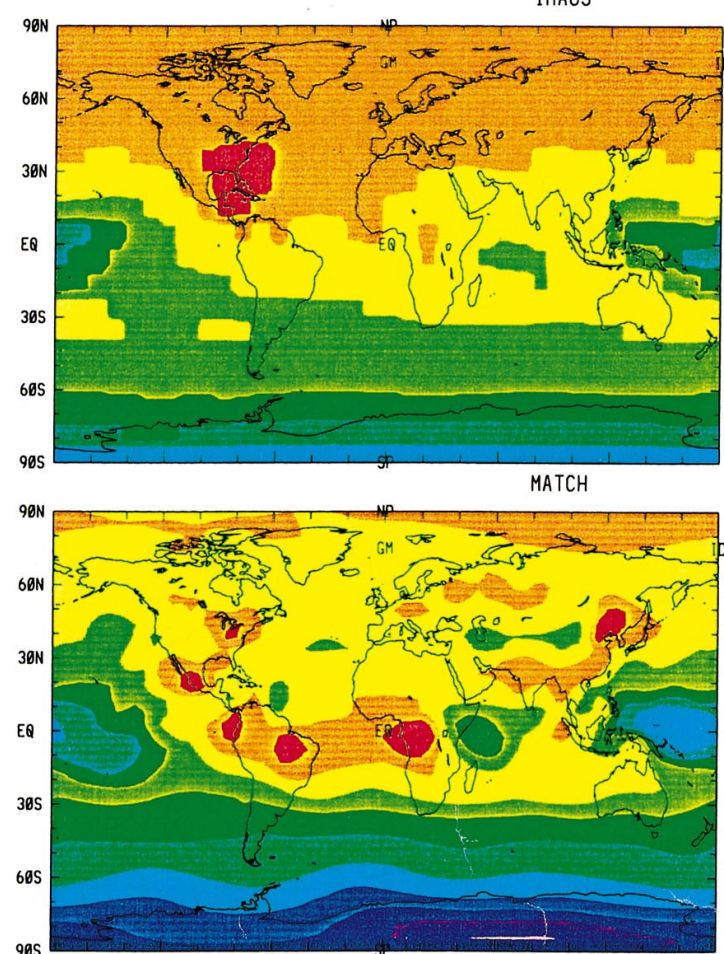

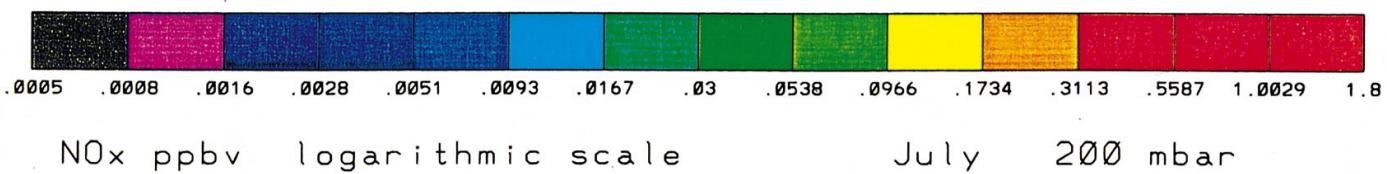

Fig. 36. (Caption opposite). 

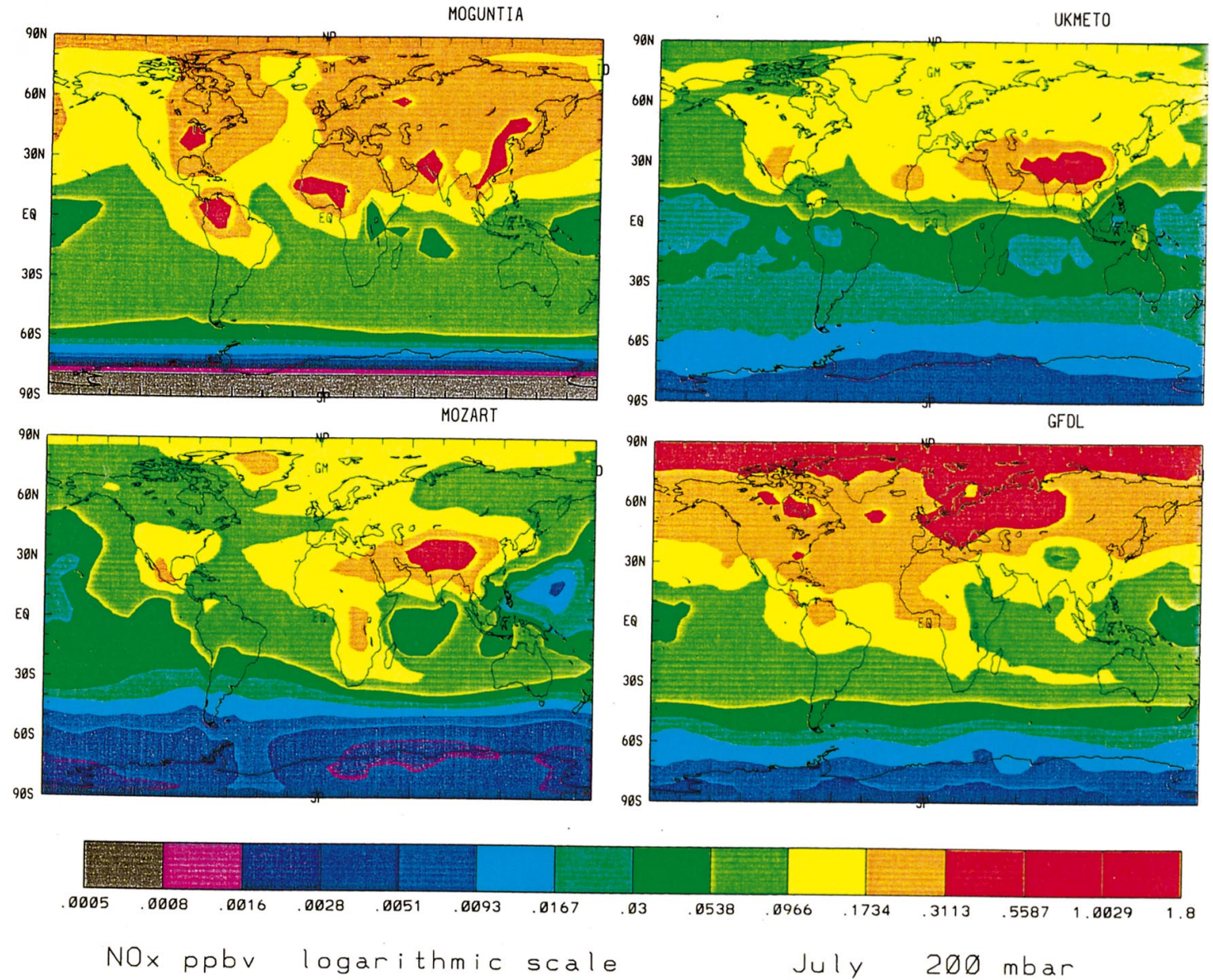

Fig. 36. (Continued). Calculated $\mathrm{NO}_{x}$ distribution from 10 different three-dimensional CTMs at $200 \mathrm{hPa}$ for the month of July (from the GIM intercomparison project of IGAC).

Van Velthoven et al. (1997) report studies of the aircraft emissions of $\mathrm{NO}_{x}$ with a hierarchy of models ranging from 2-D CTMs to 3-D general circulation models, using a simplified parameterization for the $\mathrm{NO}_{x}$ sink (assuming exponential decay with a half-life of 10 d). Two other studies (Köhler et al., 1997; Kraus et al., 1996) assumed $\mathrm{NO}_{x}$ and $\mathrm{HNO}_{3}$ to be tracers with a specified loss rate. These three studies showed large temporal and spatial variations in the $\mathrm{NO}_{x}$ distribution, suggesting that the strong nonlinearity in the ozone production needs to be taken into account in 3-D models. Surface emissions, lightning and aircraft emissions all contribute to the free tropospheric $\mathrm{NO}_{x}$ levels. However, the spatial distributions of these contributions are quite different. $\mathrm{NO}_{x}$ perturbations from aircraft emissions are particular large at high altitudes and high latitudes of the Northern Hemisphere, with marked variations in the perturbations.

Most numerical models underestimate the abundance of $\mathrm{NO}_{x}$ and overestimate the $\mathrm{HNO}_{3} / \mathrm{NO}_{x}$ concentration ratio in most regions where observations are available [see the discussion of the $\mathrm{NO}_{x}$ modelling above (Jaffe et al., 1997)]. This suggests that there might be a mechanism, perhaps related to the presence of aerosol particles, that recycles $\mathrm{HNO}_{3}$ back to $\mathrm{NO}_{x}$ faster that currently assumed (Hauglustaine et al., 1996). The recent data of Arnold and Schlager during the POLINAT campaigns show, however, $\mathrm{HNO}_{3} / \mathrm{NO}_{x}$ concentration ratios that are consistent with model calculations performed without inclusion of aerosol processing (see Schumann, 1996c).

Table 20 shows a comparison between some observed and modelled $\mathrm{HNO}_{3}$ levels at $200 \mathrm{hPa}$ for the month of July. The limited number of observations available for comparisons suggests that models underestimate the atmospheric abundance of $\mathrm{HNO}_{3}$. The calculated $\mathrm{HNO}_{3}$ distribution in the upper troposphere will depend strongly on how the loss processes (heterogeneous removal) are treated in the model.

The limited knowledge of the $\mathrm{NO}_{x}$ distribution in the free troposphere puts some limitations on our ability to accurately estimate ozone production in the upper troposphere. However, it is clear that free tropospheric ozone production, as a result of the large variation in $\mathrm{NO}_{x}$, undergoes large spatial and temporal variations. Calculations in 3-D models of the ozone production from aircraft emissions need to be 
Table 20. Observed and model calculated $\mathrm{HNO}_{3}$ distribution at the $200 \mathrm{hPa}$ level for the month of July (Northern Hemisphere)

\begin{tabular}{lll}
\hline & \multicolumn{1}{c}{ References } & $\begin{array}{c}\mathrm{HNO}_{3} \\
\text { (in ppbv) }\end{array}$ \\
\hline Measurements & $\begin{array}{l}\text { Arnold } \text { et al. (1997) and } \\
\text { Bregman } \text { et al. (1997) }\end{array}$ & $0.7-1.6$ \\
& Keim et al. (1996) & $1.2-2^{\mathrm{a}}$ \\
Model results & Kasibhatla et al. (1991, 1993) & $0.5-0.7$ \\
& Velders et al. (1994) & 0.6 \\
& Ehhalt et al. (1992) & 0.4 \\
& Hough (1991) & $0.4-0.5$ \\
& Wauben et al. (1994, 1997) & 0.6 \\
& Müller and Brasseur (1995) & 0.3 \\
\hline
\end{tabular}

${ }^{\text {a }}$ Assuming that $80 \%$ of the $\mathrm{NO}_{y}$ measured was present as $\mathrm{HNO}_{3}$.

performed with sufficient spatial resolution to describe spatial variations.

\subsection{Ozone distribution and changes}

6.3.1. The role of $\mathrm{NO}_{x}$ for ozone production in the free troposphere and in the tropopause region. Ozone production in the troposphere (see Section 3) appears to be controlled nonlinearly by the amount of nitrogen oxides $\left(\mathrm{NO}_{x}\right)$ present (Ehhalt and Rohrer, 1995). A key point here is that the atmospheric lifetime of $\mathrm{NO}_{x}$ is short [weeks to months in the upper troposphere/lower stratosphere (UT/LS)]. In a recent 3-D model study of the impact of aircraft $\mathrm{NO}_{x}$ emissions on the upper-tropospheric chemistry, Brasseur et al. (1996), demonstrated that net ozone production in the upper troposphere is affected by several factors including the amount of $\mathrm{NO}_{x}$, water vapour, and hydrocarbons present, and the solar flux available, all factors that can vary substantially. This is shown in Fig. 37. Because the spatial variability of $\mathrm{NO}_{x}$ is large, a very good global coverage in observations of $\mathrm{NO}_{x}$ is needed to estimate the impact of this chemical compound on the ozone budget. Since only limited observations of the $\mathrm{NO}_{x}$ distribution in the free troposphere are available, large uncertainties exist in the estimates of upper-tropospheric ozone production.

An important unknown in the budget of the $\mathrm{NO}_{x}$ is the rate at which it is recycled from nitrogen reservoirs such as $\mathrm{HNO}_{3}$ and PAN. Modelling studies indicate that a large fraction of $\mathrm{NO}_{x}$ could be stored as PAN, in the remote troposphere and later relieved as $\mathrm{NO}_{x}$.

Three-dimensional model calculations of the free tropospheric ozone production confirm that the production is crucially dependent on the $\mathrm{NO}_{x}$ levels (Berntsen and Isaksen, 1996). Figure 38 shows an example of the calculated ozone production at approximately $10.5 \mathrm{~km}$ altitude over Europe and the North Atlantic calculated with a regional model including full chemistry (Flatøy and Hov, 1996). The large variations in ozone production is first of all

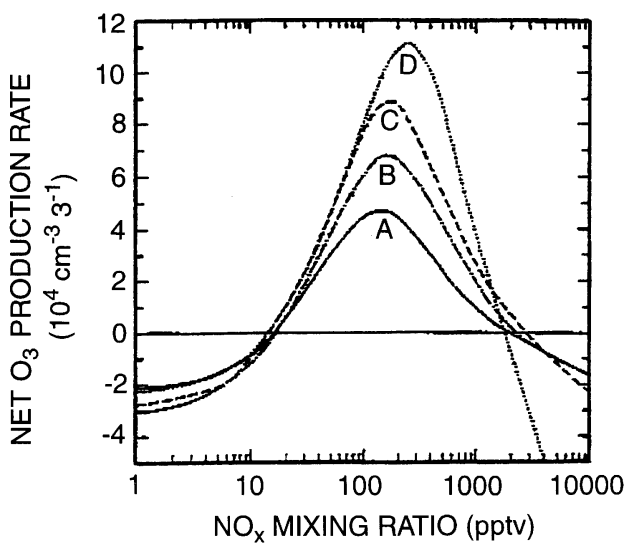

Fig. 37. Net ozone production rate in cubic centimetres per second calculated as a function of the atmospheric $\mathrm{NO}_{x}$ mixing ratio (in parts per billion by volume) at $50^{\circ} \mathrm{N}$ at $10 \mathrm{~km}$ in July for clear-sky conditions.

a result of large variations in the $\mathrm{NO}_{x}$ levels (see also the discussion of this study under Section 3.3.1). Maximum ozone production is usually found at surface levels where emissions of pollutants occur and where the $\mathrm{NO}_{x}$ levels are high. In the middle troposphere where minimum $\mathrm{NO}_{x}$ levels are obtained, ozone loss exceeds the production leading to a net ozone loss. In the upper troposphere, where $\mathrm{NO}_{x}$ levels are higher, a net ozone production is predicted in global models. However, there are large spatial variations in the ozone production, reflecting first of all the variation in the $\mathrm{NO}_{x}$ distribution. Results from a model comparisons of tropospheric ozone budgets performed with 2-D and one 3-D model in connection with the last ozone assessment (WMO, 1995) underline the nonlinear nature of the ozone chemistry in the troposphere. The different terms in the ozone budget (transport from the stratosphere, net tropospheric chemical production, surface deposition) differed strongly between the models. Only small changes in the ozone level will, for instance, change the net ozone production substantially.

6.3.2. Ozone loss in the lower stratosphere. Process studies are needed to understand stratospheric ozone depletion in the polar regions and at mid-latitudes in the Northern Hemisphere. Recent measurements campaigns, such as the European SESAME, suggests in the Arctic loss rates that are close to those observed in the Antarctica during the cold period of late winter and early spring.

Although the stratospheric chemistry leading to ozone loss (see Section 3 ) is most active in the Antarctic and Arctic regions in winter and early spring, the role of halogens at mid-latitudes, particularly the reactions involving bromine compounds, could also be significant, especially after large volcanic eruptions (e.g. after the Mt Pinatubo eruption in 1991) when the particle loading of the lower stratosphere can be enhanced by more than a factor 10 (e.g., after the El Chichón and Mt Pinatubo eruptions in 1982 and 


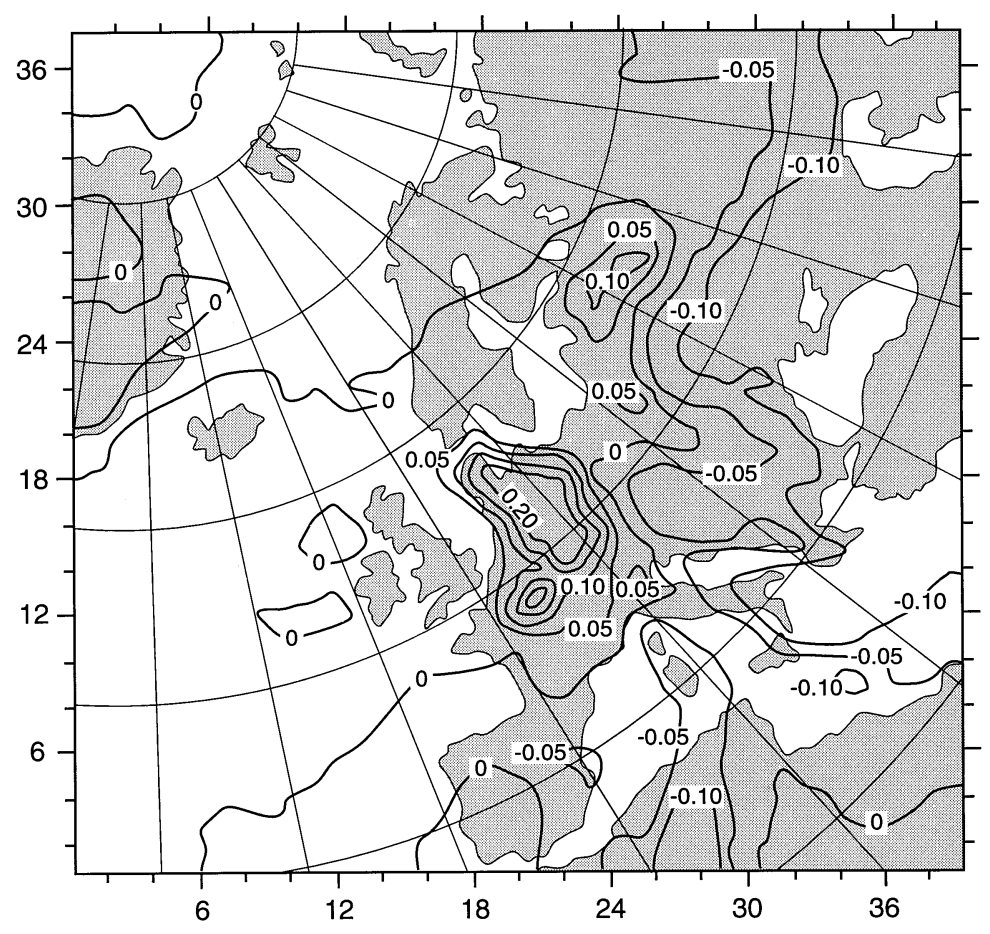

Fig. 38. $\mathrm{O}_{3}$ net chemical tendency in ppbv $\mathrm{h}^{-1}$ at $\approx 10.5 \mathrm{~km}$ (sigma-level 2) on 8 July, 1991, $1200 \mathrm{UT}$ (from Flatøy and Hov, 1996).

1991, respectively) above the particle loading during quiescent periods (WMO, 1995).

The presence of polar stratospheric clouds (PSCs) and volcanic particles which are limited in space and which show large variations in time (PSCs varies strongly from year to year; the volcanic particle loading is enhanced a few years after major volcanic eruptions) leads to chemical activity and ozone loss in the lower stratosphere which undergo large variations. To understand these processes, and their impact on the chemistry, a good global coverage of the key chemical compounds involved is required.

The measurement of the $\mathrm{ClO}$ concentration in the lower stratosphere is crucial for the estimation of the ozone loss in this region of the atmosphere. Several airborne campaigns (e.g. from the NASA ER-2) have shown that, in air masses processed by PSCs, the mixing ratio of $\mathrm{ClO}$ can be larger than $1 \mathrm{ppbv}$ inside the polar vortex, where large amounts of ozone are destroyed. Large-scale distributions of $\mathrm{ClO}$, with mixing ratios consistent with the airborne observations, have been provided by the MLS instrument on board UARS. A thorough study of the mechanisms involved in the ozone destruction in the lower stratosphere requires that the global distribution of chlorine reservoirs (such as $\mathrm{ClONO}_{2}$ ) as well as that of the nitrogen oxides (which closely interact with chlorine compounds) be accurately measured above the tropopause. In order to quantify the total amount of inorganic chlorine present in the stratosphere, it would also be useful to obtain information on the abundance of $\mathrm{HCl}$ in the stratosphere. Such information will be particularly important beyond year 2000 , at a period when the level of chlorine is expected to decrease as a result of the implementation of the Montreal Protocol and its amendments. At the present time, little is known about the global distribution and the temporal variability of $\mathrm{NO}_{x}$ in the lower stratosphere. The measurement of $\mathrm{ClONO}_{2}$ by UARS/CLAES has been shown to be an excellent complement to the measurement of $\mathrm{ClO}$ by MLS.

\subsection{Distribution and changes in upper tropospheric/ lower stratospheric ozone}

Different methods have been used to measure the vertical distribution of ozone in the tropopause region. Ozone measurements performed with different methods are thoroughly discussed in several international ozone assessments, for instance in the latest WMO assessment (WMO, 1995). However, most of the existing models are connected with large uncertainties, and there are large areas (for instance, in the upper troposphere) where ozone observations are lacking. Significant uncertainties exist with regards to ozone losses in the lower stratosphere, particularly during the 1980s at mid-northern latitudes. There seems to be an important ozone loss in the lower stratosphere which most likely is connected to the increases in stratospheric chlorine loading. However, there are large discrepancies in the derived losses from satellites (SAGE) data and ozone sonde observations. 


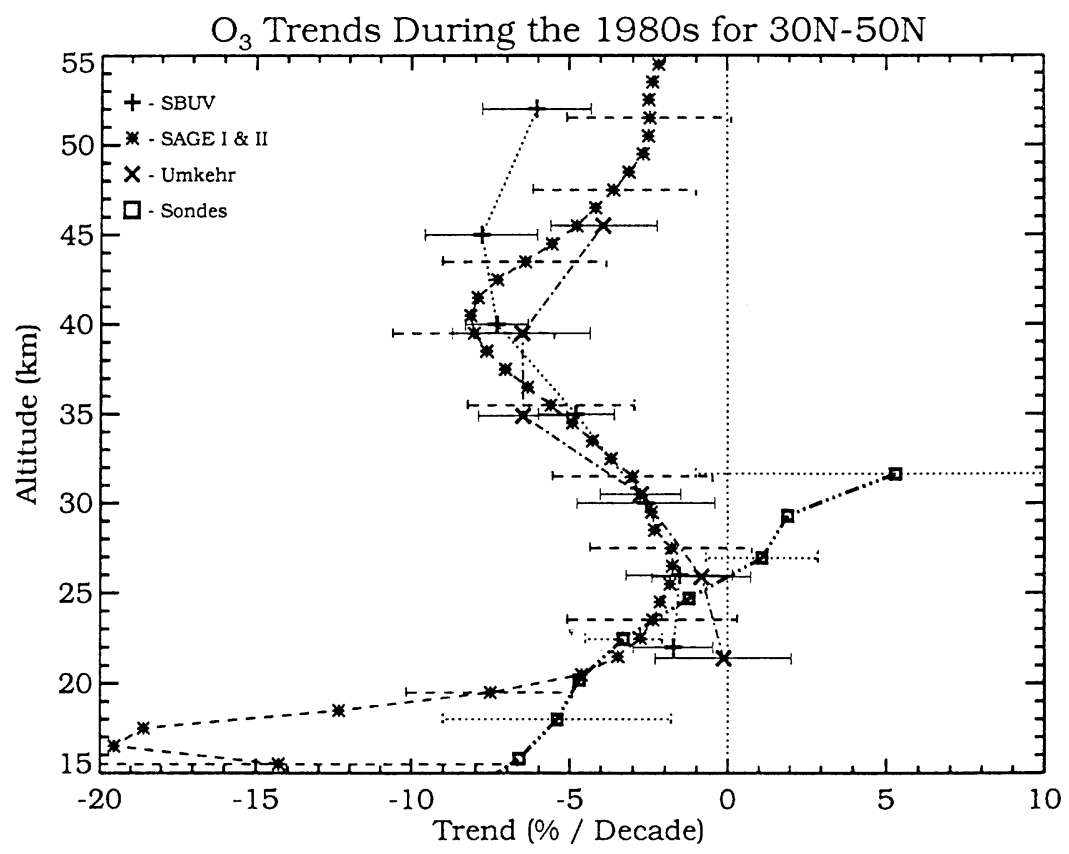

Fig. 39. Zonally averaged derived ozone trends for the 1980 s in the latitude band $30^{\circ}-50^{\circ} \mathrm{N}$ from SBUV (plus signs), SAGE I and II (stars), Umkehr (crosses), sondes (squares), and the GSFC 2-D model (solid line). The measurement values were all taken from WMO (1995, Fig. 1-14).

There are also discrepancies between observed and modelled long-term ozone changes in the stratosphere, particularly in the lower stratosphere as shown in Fig. 39 (Jackman et al., 1996). The satellite analyses give much larger ozone losses than what is derived from the ozone sonde measurements. Unfortunately, very few ozone sonde data available for trend analysis exists for other latitudes. Extensive campaigns, e.g. EASOE and SESAME, have shown that there have been significant ozone losses within the Arctic vortex in the winter months during the last few years (von der Gathen, 1995).

The ozone distribution in the upper troposphere is very poorly known. Except for campaigns like the EASOE and SESAME when frequent sonde launches were performed at high northern latitudes only a few sonde sites are operated regularly, mostly in Europe and in North America. Aircraft measurements from the STRATOZ and TROPOZ and from the more recent EU funded project MOZAIC are available.

The distribution of ozone for four seasons in 1995 for the height range $10-11 \mathrm{~km}$ obtained in the MOZAIC programme is shown in Fig. 40. A maximum is observed at the mid- and high-northern latitudes in winter and spring, and a minimum at the tropics and in the Southern Hemisphere in autumn and winter. This is in agreement with the latitudinal variation of the tropopause altitude and the position of the polar front; at these heights no stratospheric air is found south of $30^{\circ} \mathrm{N}$ but is found more and more frequently when moving northward to become pre- dominant north of $65^{\circ} \mathrm{N}$. The North and Central Atlantic and North and South America are obviously the most documented regions, due to the more frequent location of the routes followed by MOZAIC aircraft.

The trends in the upper-tropospheric ozone is less well documented and understood than the trends in lower stratospheric ozone. Only limited data are available for trend analysis, and they are all from a limited number of ozone sonde measurements. While there was a clear upward trend in ozone concentrations during the 1970s and most of the 1980s over Europe, only a small trend has been observed over North America and Japan during the same period. Since the end of the 1980s, the free tropospheric ozone increases seems to have stopped over Europe also (WMO, 1995) although ozone in the upper troposphere seems to be increasing again over Hohenpeissenberg since 1995. The causes for the trend and changes in the trend are not known. Surface ozone measurements show significant increases since the 1950s over Europe. Concentrations have probably doubled over this time period, and it is likely there have been even larger changes in surface ozone since pre-industrial time.

Several models are now available for studies of ozone distribution and changes associated with the emission of pollutants. Roelofs and Lelieveld (1995), for example, have studied the tropospheric ozone distribution using a coupled chemistry/atmospheric GCM. Their calculated monthly average $\mathrm{O}_{3}$ mixing 


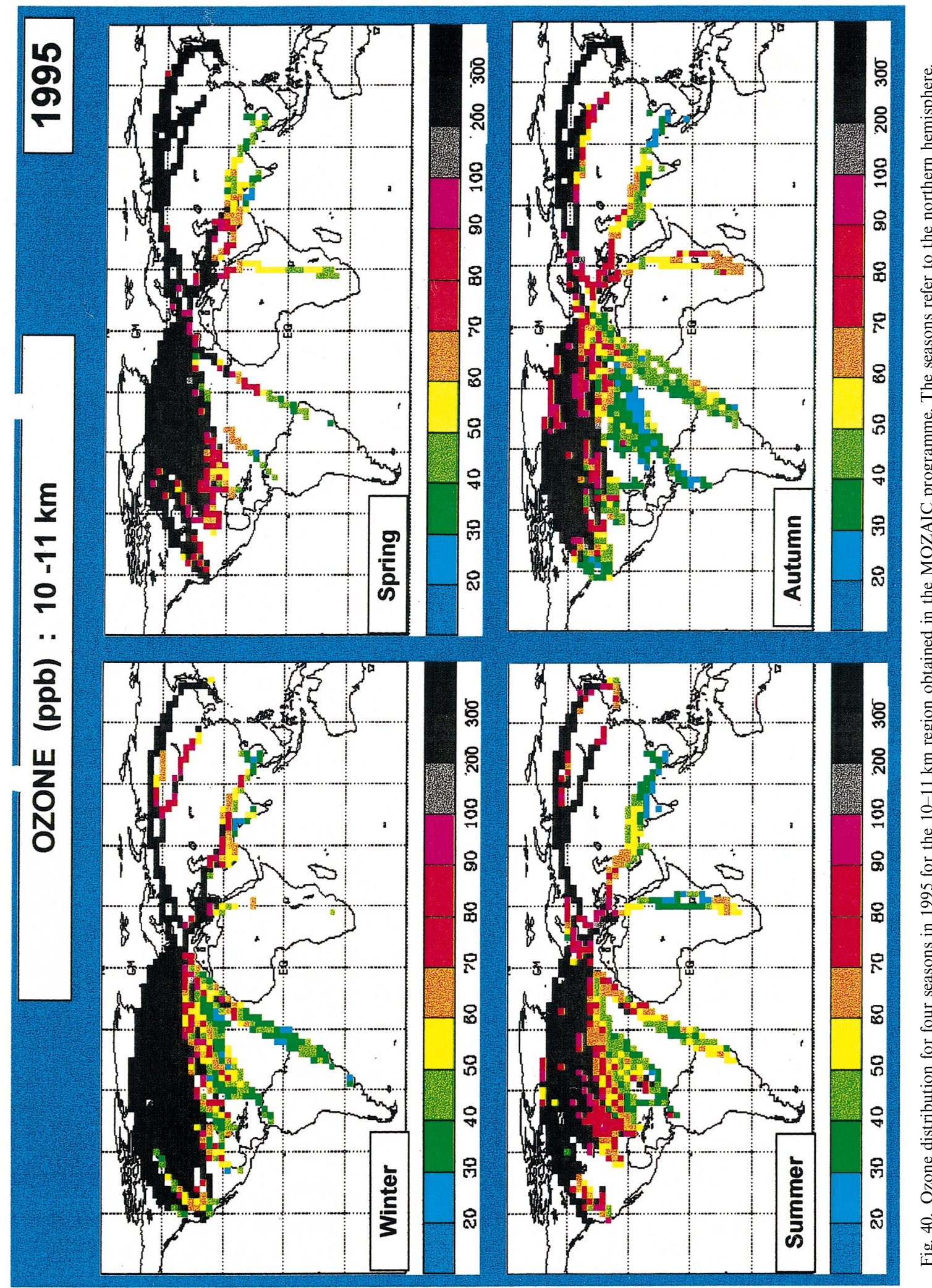



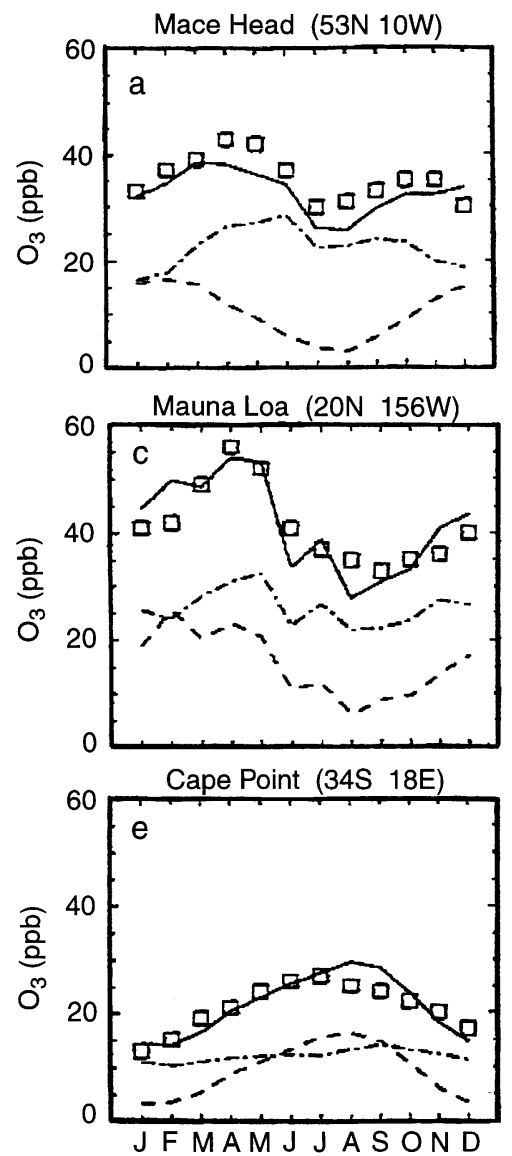

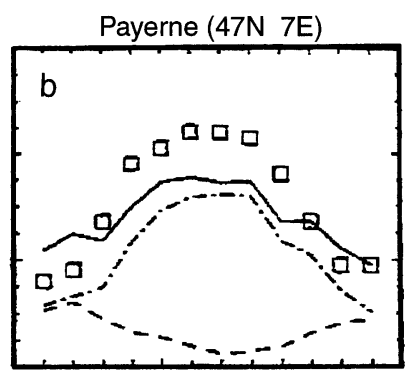

Samoa (14S 171W)

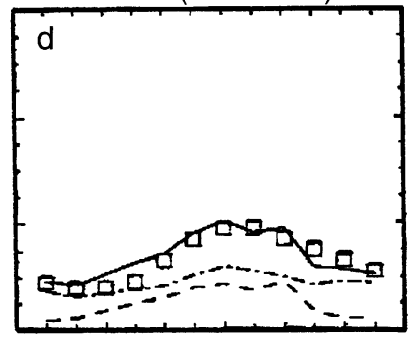

Cape Grim (41S 145E)

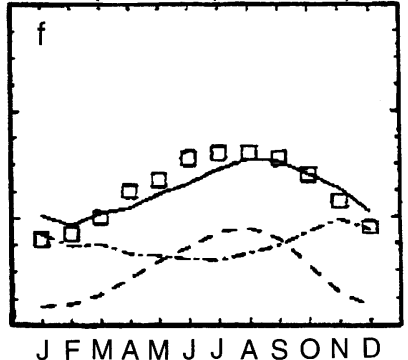

Fig. 41. Monthly patterns of calculated surface concentrations (ppbv) for $\mathrm{O}_{3}$ (solid line), for ozone of stratospheric origin $\mathrm{O}_{3} \mathrm{~s}$ (dashed line), and for photochemically produced tropospheric ozone $\mathrm{O}_{3} \mathrm{t}$ (dasheddotted line) at grid cells representing (a) Western Ireland (Mace Head), (b) Central Europe (Payerne), (c) and (d) the tropical Pacific (Mauna Loa, Samoa), (e) Southern Africa (Cape Point), and (f) Tasmania (Cape Grim). Measurement values (squares) have been obtained from Oltmans and Levy (1994) and the World Ozone Data Centre.

ratios at the surface is given in Fig. 41. Measured ozone values are also included in the figure. They found the seasonal variations in ozone production and the input from the stratosphere to provide a realistic representation of the ozone distribution in remote tropical and mid-latitude regions. Ozone distributions were underestimated in other regions partly due to poor representation of tropospheric/ stratospheric exchange. They have also compared ozone height profiles in the troposphere with ozone sonde measurements at two locations (Boulder, Colorado and at Hilo, Hawaii in the tropical Pacific) for different seasons and find good agreement (Roelofs and Lelieveld, 1997) (Fig. 42).

Several model studies have been performed to calculate tropospheric changes in the distribution of ozone and other pollutants between 1850 and 1990 . These calculations have been used to calculate the changes in radiative forcing due to ozone changes (see Section 7). The calculated surface distributions for January and July for 1850 and 1990, respectively, are given in Figs 43 and 44 (Lelieveld and van Dorland, 1995). Between 1850 and 1990, surface ozone concentrations are calculated to have increase from 10-15 to 30 to $50 \mathrm{ppb}$ in regions which are directly affected by the emission of pollutants.

In a study of increased emission of pollutants in the Asian region during the last two decades, Berntsen et al. (1996) estimate significant ozone increases in the free troposphere. This study also shows a rather large variation in the ozone distribution which is likely to be a combination of transport and chemical processes. This study points to the importance of surface emissions for the free tropospheric ozone formation in regions affected by convective transport. Due to the efficient convective transport of ozone precursors during the summer months ozone production increases significantly with large impacts on the abundance of upper troposphere ozone. The significance of this process is illustrated in Fig. 45 where increases in $\mathrm{NO}_{x}$ and ozone for a doubling in surface emissions are shown as a north-south cross-section over Southeast 

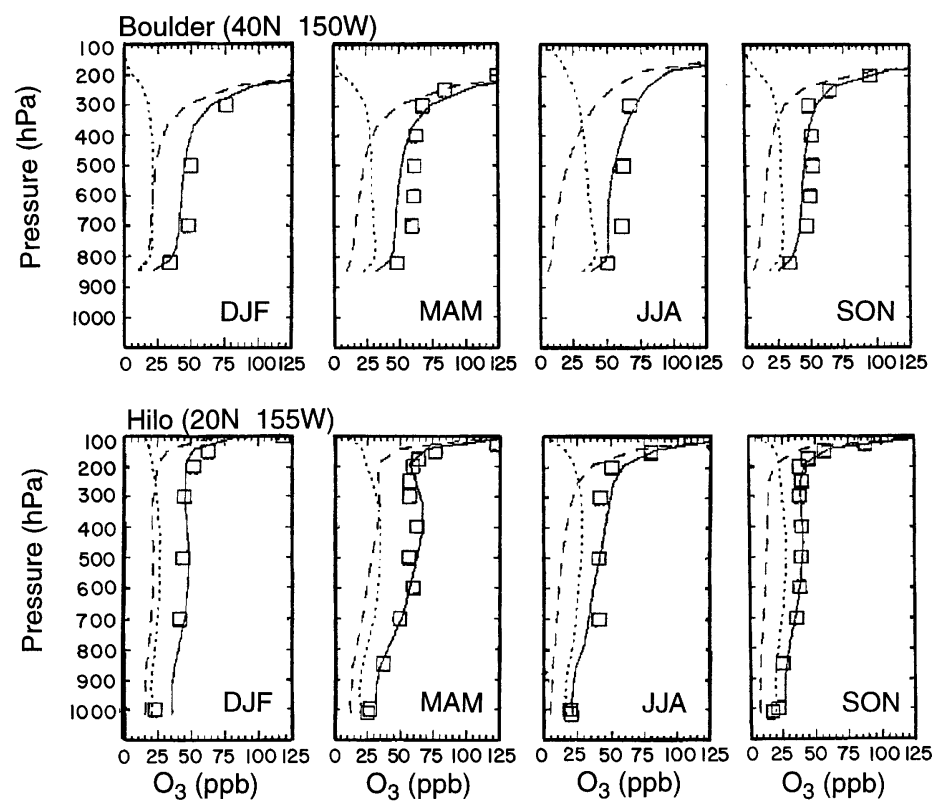

Fig. 42. Calculated seasonally varying vertical concentration profiles (ppbv) of tropospheric $\mathrm{O}_{3}$ (solid line), subdivided into $\mathrm{O}_{3}$ from stratospheric origin $\left(\mathrm{O}_{3} \mathrm{~s}\right.$, dashed line), and $\mathrm{O}_{3}$ from photochemical production $\left(\mathrm{O}_{3} \mathrm{t}\right.$, dotted line) for model grid cells in North America (Boulder) and the tropical Pacific (Hilo) (Roelofs and Lelieveld, 1997). Measurements from ozone sondes, indicated by squares, have been obtained from Oltmans et al. (1989) and Komhyr et al. (1989).

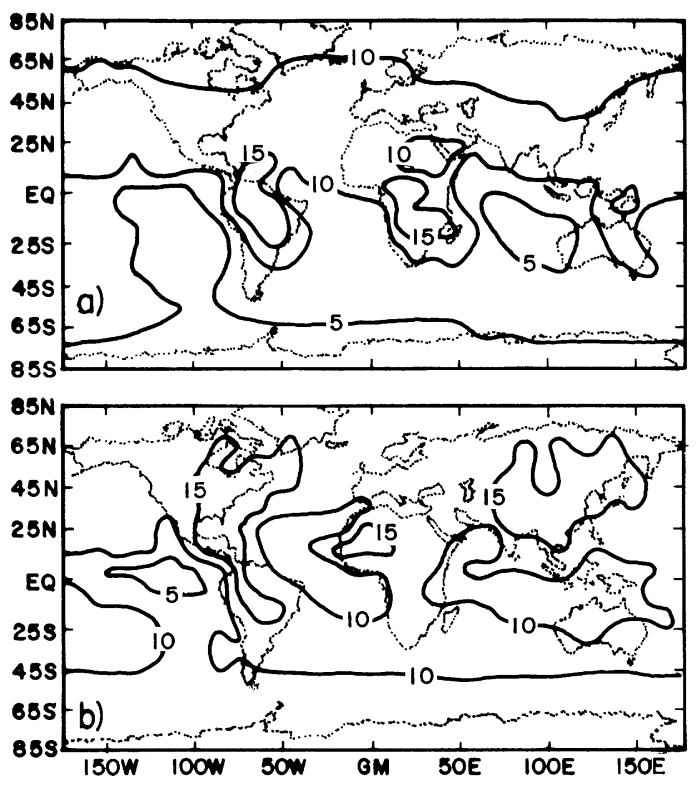

Fig. 43. Calculated $\mathrm{O}_{3}$ mixing ratios in ppbv near the Earth's surface for January (a) and July (b) of 1850.

Asia. With the rapid growth in the emissions in the region, the calculations refer to a situation expected to occur in approximately $15 \mathrm{yr}$.

\subsection{Modelling of ozone perturbations by aircraft emissions}

6.5.1. Ozone perturbations caused by $\mathrm{NO}_{x}$ emissions from supersonic transport. The chemical impact of

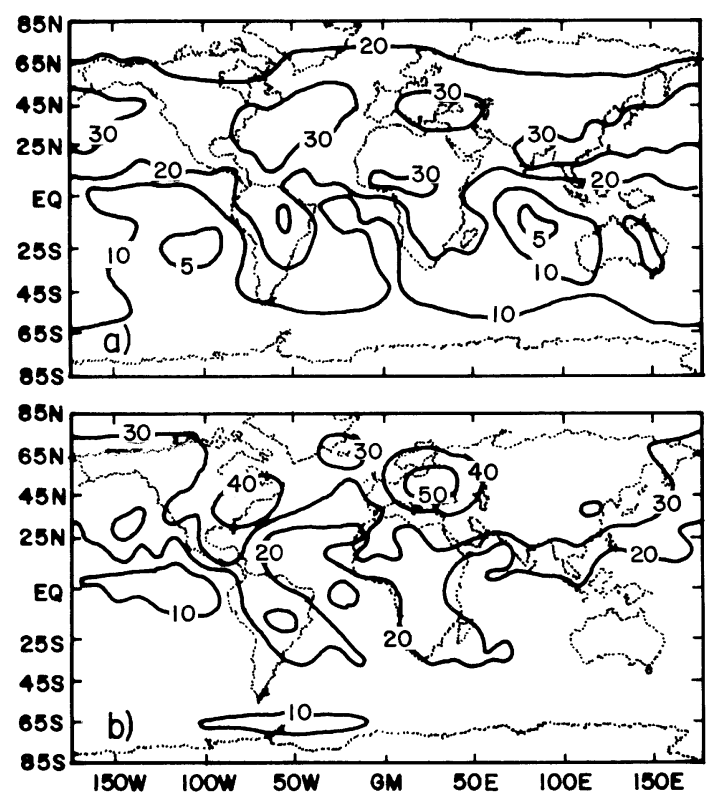

Fig. 44. Calculated $\mathrm{O}_{3}$ mixing ratios in ppbv near the Earth's surface for January (a) and July (b) of 1990.

$\mathrm{NO}_{x}$ emissions in the stratosphere depends on the height level of emission since $\mathrm{NO}_{x}$ catalytically destroys ozone as well as inhibits the ozone destruction by the $\mathrm{HO}_{x}$ cycle and halogen radical catalytical cycles through the formation of "temporary reservoir species" (see Section 3). The effect of adding $\mathrm{NO}_{x}$ from aircraft flying in the stratosphere is a balance between 

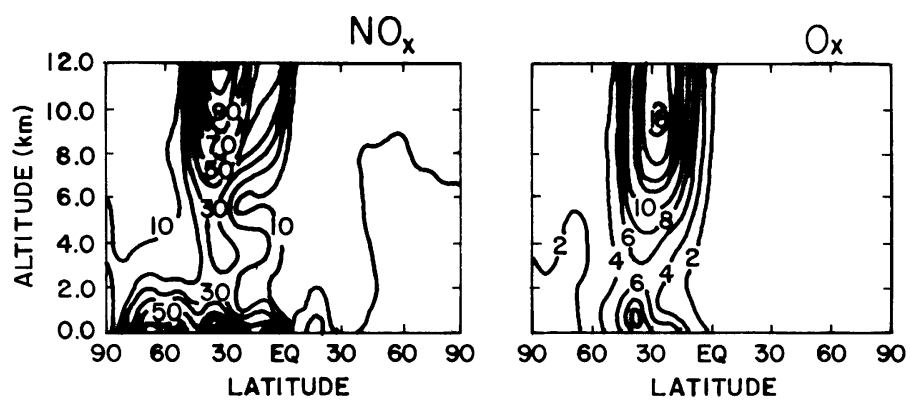

Fig. 45. Altitude vs latitude cross-sections at $112.5^{\circ} \mathrm{E}$ of calculated change (A2 vs R) in monthly averaged concentrations of $\mathrm{NO}_{x}(\%)$ and ozone (ppbv) for August (northern latitudes are on the left-hand side of the figure).

these two processes. In the stratosphere above approximately $26 \mathrm{~km}, \mathrm{NO}_{x}$ catalysis is the most efficient ozone loss process. Increased $\mathrm{NO}_{x}$ will therefore lead to ozone loss at these altitudes. In the lower stratosphere, emitted $\mathrm{NO}_{x}$ interferes with the efficient $\mathrm{HO}_{x}$ and halogen catalysis cycles of ozone destruction, making the sign of the ozone perturbation dependent on other factors like the background levels of trace gases and particle surfaces (sulphate aerosols and PSCs). Since emissions of sulphur, soot and water vapour from high flying aircraft will change the surface area of the particles, composition and number of particles in the lower stratosphere emissions from aircraft indirectly influence the ozone loss rate.

Extensive model studies of the impact of aircraft on lower stratospheric ozone levels have been performed during several years using 2-D chemical/transport models. Most of these studies have been on the impact on ozone from $\mathrm{NO}_{x}$ emissions. In several model studies such as those performed through the NASA HighSpeed Research Program (HSRP) (NASA, 1995; WMO, 1995), where U.S. and European research groups participated, small ozone changes were calculated in response to a baseline fleet of 500 civil supersonic aircraft. The total ozone column losses were less than $1 \%$. Changes in the cruising altitude of $1-2 \mathrm{~km}$ did not provide any large changes in the ozone perturbations. However, these studies did not include the effect of PSCs. Model studies of the particle formation from sulphur emissions from highspeed aircraft have shown that increases in the surface area of sulphate particles will occur in the lower stratosphere. Test cases where such effects were included indicate that the impact on ozone becomes somewhat larger. However, there are large variations in the effects on ozone calculated in the different model studies.

In a recent study, Dameris et al. (1998) performed 3-D model calculations of the impact of a projected future fleet (2015) of aircraft using the dynamicalchemical model ECHAM3/CHEM (Steil et al., 1998). In the case of subsonic plus supersonic aircraft emissions, ozone reductions in the lower stratosphere ranged from 3 to $4 \%$ in the high latitude northern hemisphere during January to $2-2.5 \%$ in July, and ozone increases in the upper troposphere. The pronounced effect during winter was attributed to the impact of PSCs which is included in the GCM calculations. In a similar 2-D model with heterogeneous chemistry on PSCs included, Grooss et al. (1997) obtained total ozone column reductions of $2 \%$ during winter and $1 \%$ during summer. In the winter hemisphere, this yielded a total ozone column reduction of 0.3 and $0.7 \%$ for southern latitudes, respectively, and a total increase of $1 \%$ in the northern summer hemisphere.

6.5.2. Ozone perturbations caused by subsonic aircraft emissions. A large number of 2-D model studies of the impact on ozone of $\mathrm{NO}_{x}$ emitted from aeroplane flying in the upper troposphere have been performed since the first studies in the late 1970s and early 1980s (Hidalgo and Crutzen, 1977; Isaksen, 1981; Ehhalt et al., 1992; Johnson et al., 1992; Fuglestvedt et al., 1993; Rohrer et al., 1993; see also WMO, 1995). $\mathrm{NO}_{x}$ emitted from aeroplane in the upper troposphere will enhance ozone levels, from a few percent up to $10 \%$ at mid-northern latitudes.

Several studies of the impact of $\mathrm{NO}_{x}$ emissions from aircraft have recently been performed using global 3-D atmospheric chemistry models (Brasseur et al., 1996; Stevenson et al., 1997; Wauben et al., 1997; Dameris et al., 1998; AEROCHEM project). The two first studies gave maximum ozone increases from $\mathrm{NO}_{x}$ emissions in the range $10-15$ ppbv. The increases were largest in the upper troposphere (at approximately $200 \mathrm{hPa}$ ) restricted to mid- and high-latitudes in the northern hemisphere, although the studies of Brasseur et al. (1996) and Dameris et al. (1998) show ozone increases over a larger height and latitude range. Wauben et al. (1996) and Brasseur et al. (1996) found marked seasonal variations in the ozone increases with the largest enhancement during the summer months, while Stevenson et al. (1997) and Dameris et al. (1998) found little seasonal variations.

Figure 46 gives a summary of previous 2-D and some 3-D estimates of ozone perturbations from different $\mathrm{NO}_{x}$ emissions. 


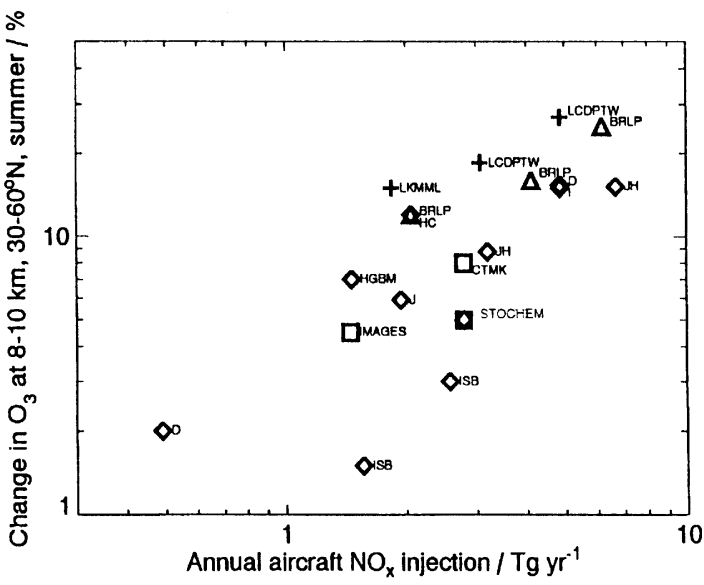

Fig. 46. Summary of previous model results for the percentage increase in summer, mid-latitude ozone concentration at $8-1-\mathrm{km}$ altitude, against aircraft $\mathrm{NO}_{x}$ injection rate. Different symbols refer to different types of models: 1-D $(+), 2-\mathrm{D}$ altitude-latitude $(\diamond), 2$-D altitude-longitude $(\triangle)$, 3-D altitude-latitude-longitude $(\square)$. Labels correspond to model results reported by HC (Hidalgo and Crutzen, 1977); LCDPTW (Luther et al., 1979); I (Isaksen, 1980); LKMML (Liu et al., 1980); D (Derwent, 1982); ISB (Isaksen et al., 1989); BRLP (Beck et al., 1992); J (Johnson et al., 1992); JH (Johnson and Henshaw, 1991); HGBM (Hauglustaine et al., 1994); ONERA (Ramaroson, 1995a); TROPOS (Johnson and Kingdon, 1995); UiB (Strand, 1995); CTMK (van Velthoven and Wauben, 1995); IMAGES (Brasseur et al., 1996). From Stevenson et al. (1997).

In a recent study by Flatøy and Hov (1996), using a mesoscale chemistry transport model, ozone production from aircraft $\mathrm{NO}_{x}$ emission in the upper troposphere over a $10 \mathrm{~d}$ time period over Europe and the North Atlantic was estimated. The ozone production was compared to the ozone production in the upper troposphere from other $\mathrm{NO}_{x}$ sources. In particular, it was shown that during days with high convective activities when air rich in ozone precursors (e.g. $\mathrm{NO}_{x}$ ) is transported to the upper troposphere ozone formation is highly efficient (up to $1.8 \mathrm{ppbv}$ $\mathrm{h}^{-1}$ ). However, the high production rates are only sustained for a few hours. The average ozone production in the upper troposphere is only $1 / 50$ th of this production. The continuos emissions from aircraft is found to give an ozone production (0.03-0.05 ppbv $\left.\mathrm{h}^{-1}\right)$. It is concluded in the study that as a longterm source it contributes significantly to the $\mathrm{NO}_{x}$ distribution and the ozone production in the upper troposphere.

A particular task in connection with this assessment has been to use existing global atmospheric 3-D models to calculate the impact of the current fleet of aircraft on the ozone distribution from $\mathrm{NO}_{x}$ emission using the recently updated ANCAT $\mathrm{NO}_{x}$ emissions (see Section 4; Gardner, (1997b).

The models involved in this differ in the formulation of transport (CTMs and GCMs), and in the chemistry used (simple to extensive chemical schemes). All models adopted the aircraft $\mathrm{NO}_{x}$ emis- sions provided by the new ANCAT II database. $\mathrm{NO}_{x}$ emissions are significantly lower than the previous emission estimates in ANCAT I [0.56 Tg (N) $\mathrm{yr}^{-1}$ compared to $0.85 \mathrm{Tg}(\mathrm{N}) \mathrm{yr}^{-1}$ as global emission]. The distribution of the emissions between the two sets of data for the aircraft emissions is also somewhat different. As $\mathrm{NO}_{x}$ production from lightning in the free upper troposphere is a key source for background $\mathrm{NO}_{x}$ levels, the same source strength of $5 \mathrm{Tg}(\mathrm{N}) \mathrm{yr}^{-1}$ was used in all models. For the other sources (e.g. surface sources) the modellers best estimates were used. The differences in modelled $\mathrm{NO}_{x}$ distribution shown in Fig. 46 reflect the differences in source distribution and in transport parameterization in previous models.

Calculated $\mathrm{NO}_{x}$ increases for July at the $200 \mathrm{hPa}$ level from a 1990 fleet of subsonic aircraft is shown in Fig. 47 for four of the models that participated in the intercomparison. The calculated impact on $\mathrm{NO}_{x}$ shows a similar pattern in the four models with maximum absolute increase corresponding to the area of the heaviest traffic (Europe, U.S. and the flight corridor between the two continents). Maximum $\mathrm{NO}_{x}$ increases ranges between 50 and 90 ppt between the models. The differences most likely result from differences in the transport formulations in the models. The seasonal variations in the $\mathrm{NO}_{x}$ perturbations are rather similar in each model.

Figures $48 \mathrm{a}-\mathrm{d}$ depict the calculated ozone perturbation at the $200 \mathrm{hPa}$ level for the four seasons. Maximum ozone perturbations are within the range of 5-9 ppt between the models. The models calculate significant seasonal variations in the ozone perturbations (in ppbv) of a factor of 2-3. The three chemical transport models show maximum ozone perturbations during the summer months, and minimum during winter months in the northern hemisphere, while the fourth model which is a GCM, run in the off-line mode, gives seasonal ozone variations which is maximum during winter and spring seasons. The maximum perturbations are found at high northern latitudes. The ozone enhancements are not restricted to the regions of aircraft emissions. This is a result of the long lifetime of ozone in the upper troposphere which allows for an efficient transport.

The calculated total mass of $\mathrm{NO}_{x}, \mathrm{O}_{3}, \mathrm{OH}$ and $\mathrm{HNO}_{3}$ and changes due to aircraft emissions are summarised in Table 21 for the four models that participated in the model experiment. The values are average for the latitude band 30 to $60^{\circ} \mathrm{N}$ and for pressure levels between 300 and $175 \mathrm{hPa}$ for the months of January and July.

The figures and the table depicted above illustrate the differences in the calculated upper-tropospheric distribution and perturbation by aircraft $\mathrm{NO}_{x}$ emissions of chemical compounds obtained in the four models participating in the model experiment. The differences are particularly large for the estimated distributions, but there are also significant differences in the calculated perturbations. This probably reflects 

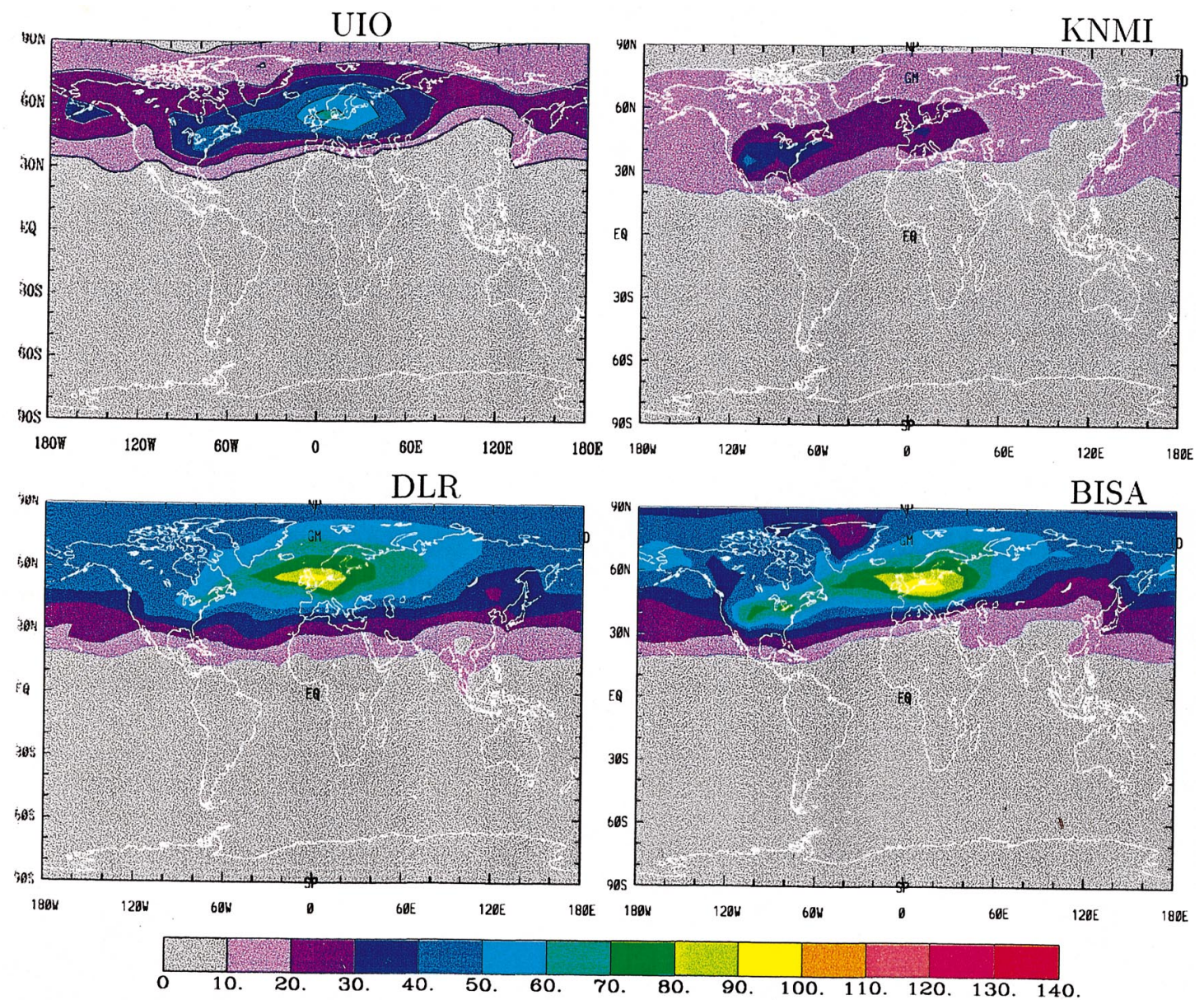

Fig. 47. Calculated increase from four three-dimensional CTMs in monthly mean $\mathrm{NO}_{x}$ mixing ratio (pptv) for July at approximately $200 \mathrm{hPa}$ due to aircraft emissions of $\mathrm{NO}_{x}$.

the limitations in the current 3-D models to represent chemical distributions in the upper troposphere.

When the results of this study are compared with other recent model studies it should be taken into account that the adopted emissions from aircraft used in the different studies (Stevenson et al., 1995; Wauben et al., 1997; Brasseur et al., 1996) are significantly different.

A recent GCM study (the ECHAM/CHEM model) of the ozone perturbation caused by a future fleet (2015) of subsonic aircraft (Dameris et al., 1998) gives significant ozone increases in the upper troposphere of $10-15 \%$. Brasseur et al. (1996) in a similar study obtained somewhat less ozone increases, 2-7\%. Parts of the differences in the calculated ozone perturbations in the two studies is due to different source strengths of the $\mathrm{NO}_{x}$ emissions.

\subsection{Conclusions}

3-D model studies of the $\mathrm{NO}_{x}$ perturbations by the current fleet of aircraft indicate significant increases in the upper troposphere (up to $50 \%$ in the latitude band 30 to $60^{\circ} \mathrm{N}$ ), and ozone increases in the upper troposphere at northern-mid latitudes from a few to
10 pptv compared to background results. However, there are significant differences in the calculated ozone perturbations between the different models, both in magnitude and in seasonal variations.

A common feature in all the 3-D model calculations of ozone perturbations from aircraft emissions (Figs 48a-d) is that, although the ozone production is largest near the flight corridors where the $\mathrm{NO}_{x}$ emissions take place, the changes in the ozone distribution seem to be relatively zonally uniform. This is a result of the long chemical lifetime of ozone in the upper troposphere which allows for zonal mixing.

Part of the discrepancy in calculated ozone perturbations is likely to be a result of the nonlinear nature of the ozone chemistry, which, combined with the large variations in the background distribution of chemical compounds of importance for the ozone perturbation studies $\left(\mathrm{NO}_{x}, \mathrm{O}_{3}, \mathrm{HNO}_{3}\right.$ and $\left.\mathrm{OH}\right)$, could lead to significant differences in the net ozone production rate in the upper troposphere.

The ozone production is particularly sensitive to the background distribution of $\mathrm{NO}_{x}$ as shown in Fig. 37. The $\mathrm{NO}_{x}$ concentrations are determined, as 

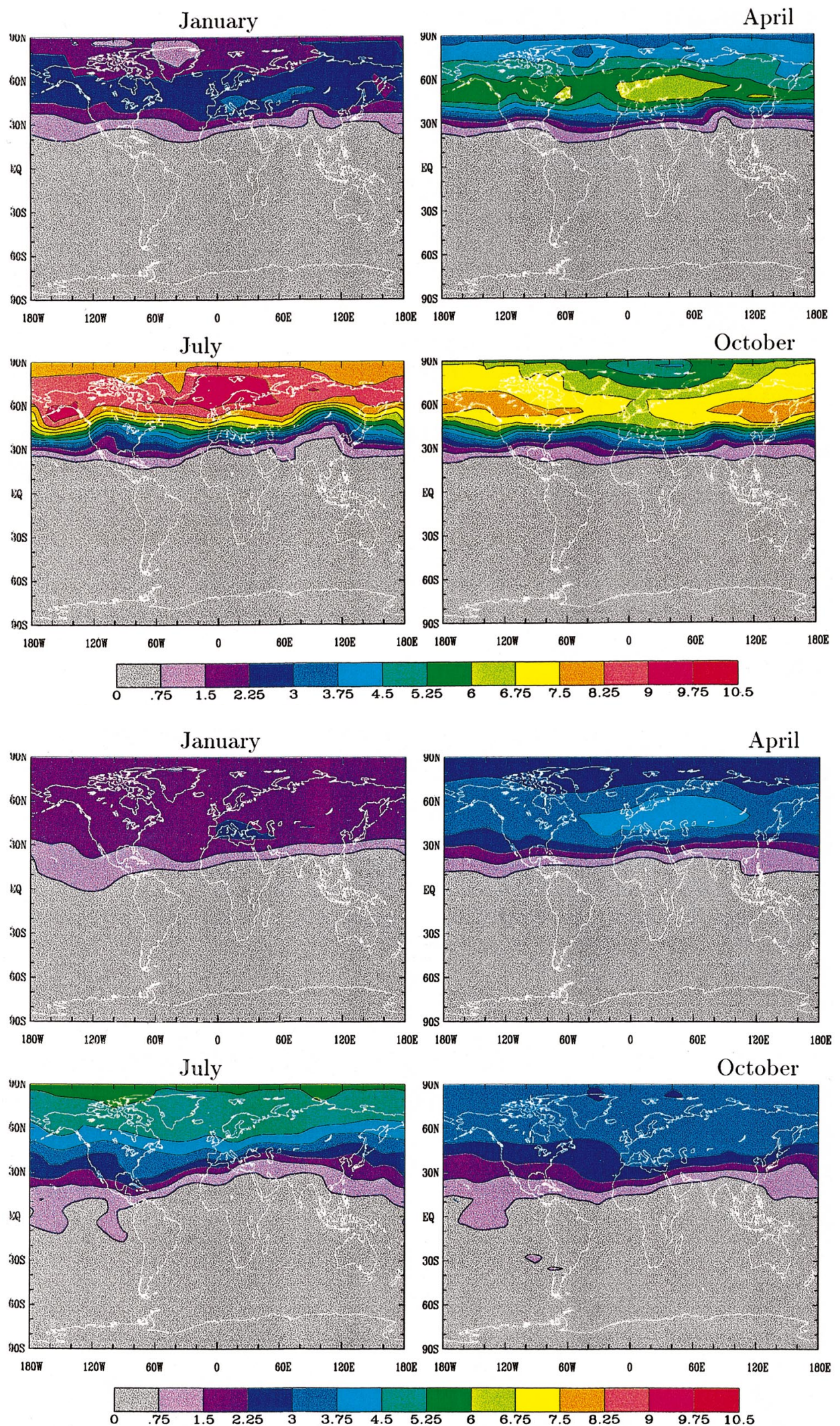

Fig. 48. (Continued overleaf) (a) Calculated increase in monthly mean ozone mixing ratio (ppbv) at approximately $200 \mathrm{hPa}$ due to aircraft emissions of $\mathrm{NO}_{x}$ in the Oslo CTM-1 model. (b) Calculated increase in monthly mean ozone mixing ratio (ppbv) at approximately $200 \mathrm{hPa}$ due to aircraft emissions of $\mathrm{NO}_{x}$ in the KNMI model. (c) Calculated increase in monthly mean ozone mixing ratio (ppbv) at approximately $200 \mathrm{hPa}$ due to aircraft emissions of $\mathrm{NO}_{x}$ in the BISA model. (d) Calculated increase in monthly mean ozone mixing ratio (ppbv) at approximately $200 \mathrm{hPa}$ due to aircraft emissions of $\mathrm{NO}_{x}$ in the DLR model. 

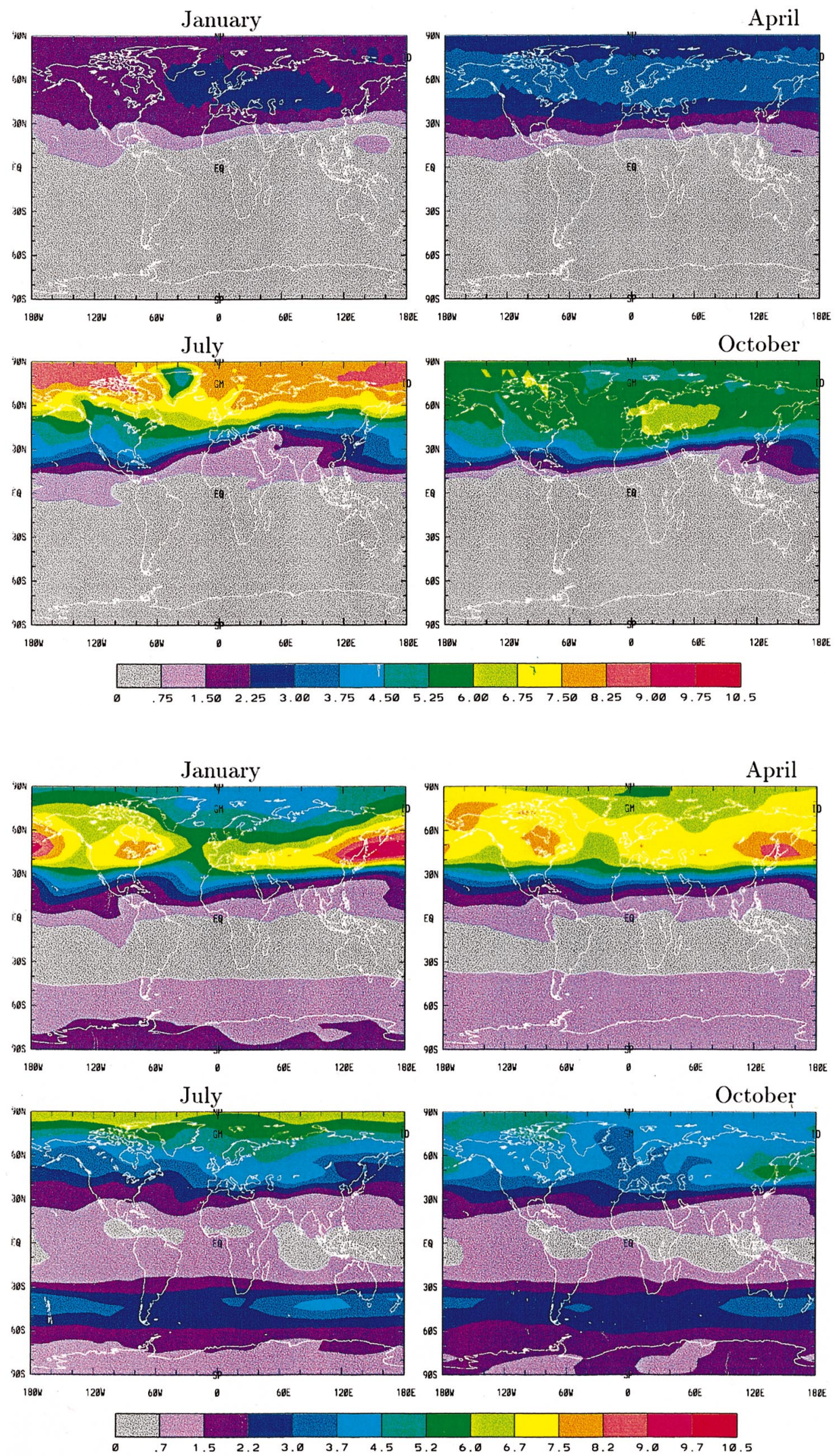

Fig. 48c and d. (Continued) Caption on p. 2393. 
Table 21. The calculated total mass of $\mathrm{NO}_{x}, \mathrm{O}_{3}, \mathrm{OH}$ and $\mathrm{HNO}_{3}$, and perturbation in total mass $(\%)$ due to current aircraft $\mathrm{NO}_{x}$ emissions for the latitude band 30 to $60^{\circ} \mathrm{N}$ and for pressure levels between 300 and $175 \mathrm{hPa}$ for the months of July and January respectively. The numbers are in $10^{6} \mathrm{~kg}(\mathrm{~N})$ for $\mathrm{NO}_{x}$ and $\mathrm{HNO}_{3}, 10^{9} \mathrm{~kg}$ for $\mathrm{O}_{3}$ and $10^{3} \mathrm{~kg}$ for $\mathrm{OH}$

\begin{tabular}{|c|c|c|c|c|c|c|c|c|}
\hline & \multicolumn{4}{|c|}{ Total mass } & \multicolumn{4}{|c|}{ Increase $(\%)$} \\
\hline & $\mathrm{NO}_{x}$ & $\mathrm{O}_{3}$ & $\mathrm{OH}$ & $\mathrm{HNO}_{3}$ & $\mathrm{NO}_{x}$ & $\mathrm{O}_{3}$ & $\mathrm{OH}$ & $\mathrm{HNO}_{3}$ \\
\hline \multicolumn{9}{|l|}{ July } \\
\hline KNMI & 7.7 & 69 & 41 & 191 & 15 & 1.3 & 5.8 & 13.1 \\
\hline BISA & 2.9 & 14.0 & 7.2 & 73 & 29 & 3.6 & 9.8 & 21.0 \\
\hline DLR & 13.0 & 11.1 & 16 & 88 & 15 & 3.2 & 2.3 & 10.7 \\
\hline $\mathrm{UiO}$ & 9.5 & 15 & 10.5 & 100 & 36 & 3.9 & 9.4 & 12.7 \\
\hline \multicolumn{9}{|l|}{ January } \\
\hline KNMI & 3.1 & 96 & 10.9 & 127 & 45 & 0.6 & 13.8 & 17.3 \\
\hline BISA & 1.8 & 18.8 & 1.4 & 121 & 50 & 1.5 & 14.2 & 12.5 \\
\hline DLR & 8.3 & 30 & 3.0 & 35 & 45 & 2.4 & 9.4 & 9.4 \\
\hline $\mathrm{UiO}$ & 6.0 & 22 & 2.1 & 72 & 48 & 1.6 & 16.2 & 13.5 \\
\hline
\end{tabular}

we have discussed above, by several processes: transport from the stratosphere through tropospheric/ stratospheric exchange, transport from the surface by convective processes, and in situ production by lightning and by aircraft emissions. The source strength of the emissions from these processes used in the different models differs substantially, hence the large differences in the $\mathrm{NO}_{x}$ concentrations (Fig. 36). This could explain some of the seasonal differences seen in the calculated ozone perturbations depicted in Figs $48 \mathrm{a}-\mathrm{d}$ for the four models participating in the model experiment. Dameris et al. (1998) explain that the seasonal behaviour with minimum ozone perturbations during summer and fall obtained in the ECHAM3 model calculations, which is opposite to what is obtained in the other models, is a result of the nonlinearity in the ozone production. They obtain large $\mathrm{NO}_{x}$ concentrations in the upper troposphere at northern latitudes during summer months when convective activity brings anthropogenically and naturally produced $\mathrm{NO}_{x}$ to the upper troposphere. This results in high $\mathrm{NO}_{x}$ levels which reduce the efficiency of the ozone production. Other possible sources of discrepancies between model calculated ozone production are the differences in the treatment of the hydrocarbon chemistry. This could effect the efficiency of the ozone production (see Fig. 37).

The calculated perturbations of $\mathrm{NO}_{x}$ and ozone obtained in the models that participated in the comparison referred to above do not differ significantly from previous 2-D and 3-D model estimates.

The uncertainties connected to the model estimates reflect the stage of 3-D model development which puts limitations of current models ability to estimate chemical distributions and changes in the tropopause region.

\section{EFFECTS ON RADIATIVE FORCING AND CLIMATE}

\subsection{Introduction}

Aircraft emissions are expected to modify the Earth's radiative forcing as a result of several processes: (1) the emission of radiatively active gases (e.g. $\mathrm{CO}_{2}$ or water vapour); (2) the emission of chemical species which produce radiatively active substances (like $\mathrm{NO}_{x}$ which modifies the $\mathrm{O}_{3}$ concentration); and (3) the emission of substances which trigger the generation of additional clouds (e.g. contrails). From the total amount of aircraft emissions, which is small relative to many other emissions, one might anticipate that the change in radiative forcing and consequently in climate will be small (relative to natural variability) for present-day air traffic. (An exception may be the contrail formation.) Similar arguments could be made for any other anthropogenic source of greenhouse gases of similar magnitude, e.g. the $\mathrm{CO}_{2}$ emissions of surface traffic. However, most aircraft emissions are taking place close to the tropopause where radiative effects are large (Lacis et al., 1990).

The climate response (e.g. changes in surface temperature and precipitation) depends on several internal feedback processes, which remain poorly quantified, even in the most advanced climate models. In addition, only a few estimates of the radiative forcing caused by aircraft emissions currently exist, so that the present analysis remains limited. Most of the recent studies have focused on the $\mathrm{NO}_{x}$-induced climatic perturbations. The direct and indirect climatic effects of particles produced by current and future aircraft operations were estimated by Fortuin et al. (1995), but remain uncertain, although potentially significant.

In the following sections, radiative and climatic effects of aircraft emissions, in particular those of $\mathrm{CO}_{2}, \mathrm{H}_{2} \mathrm{O}, \mathrm{NO}_{x}$, sulphur, and soot, will be discussed.

\subsection{Climatic impact of $\mathrm{CO}_{2}$}

Currently, aircraft contribute about $2-3 \%$ to the total emission of anthropogenic $\mathrm{CO}_{2}$. This represents about $10 \%$ of the $\mathrm{CO}_{2}$ emissions by all existing traffic. Due to its rather long adjustment time (more than $50 \mathrm{yr}), \mathrm{CO}_{2}$ from aircraft becomes rather homogeneously distributed in the atmosphere and, hence, in 
climate assessments, cannot be distinguished from other $\mathrm{CO}_{2}$ sources. Therefore, $\mathrm{CO}_{2}$ from aircraft requires no special treatment, and can rather be included in the traditional climate change studies (IPCC, 1996).

Of particular interest is the annual increase rate of $\mathrm{CO}_{2}$ emissions from aircraft [3-4\%], which is substantially larger than the corresponding rate for total anthropogenic $\mathrm{CO}_{2}$ emissions $(0.4 \%$ per year during the period from 1990 to 1994 (IPCC, 1996, Vol. II)]. As a consequence, the relative contribution of aircraft to $\mathrm{CO}_{2}$-induced climate changes will increase in the future.

The $\mathrm{CO}_{2}$ concentration change and the related climate change in terms of globally averaged surface temperature can be estimated using the simple response model of Hasselmann et al. $(1993,1997)$. In this model, the response functions describing the storage of carbon have been tuned to fit a comprehensive carbon cycle model. The climate sensitivity of the model is chosen such that the equilibrium response to a $\mathrm{CO}_{2}$ doubling is $2.5 \mathrm{~K}$, with a linear relation between the atmospheric $\mathrm{CO}_{2}$ concentration and the surface temperature. The model is applied assuming a linear increase of the $\mathrm{CO}_{2}$ emissions of aviation from zero in the year 1940 to the present value $0.13 \mathrm{GtC} \mathrm{yr}^{-1}$. Moreover, we assume that the emissions increase in the time period from 1995 to 2100 by a constant annual rate of either $1 \%, 2 \%$, or $3 \%$ per year. The linear increase in the past is used for simplicity but overestimates the actual aviation fuel consumption. For the trends in the future, Vedantham and Oppenheimer (1994) estimated an increase of less than $2 \%$ per year on average over the next 100 yr even for the scenarios representative of the most prosperous economies. However, the increase rate may be larger during smaller time periods. A 3\% annual increase rate for the whole century is very unlikely.

Table 22 lists the resulting emission rates, $\mathrm{CO}_{2}$ concentrations, and transient surface temperature changes for selected years. It can be seen that aviation contributed about $1.7 \%$ (which is an upper bound due to the assumed linear increase in the past decades) to the global $\mathrm{CO}_{2}$ concentration increase $(80 \mathrm{ppmv})$ since 1800 . This causes at present a global surface temperature increase of less than $0.01 \mathrm{~K}$. By the year 2050 (2100), a steady $2 \%$ annual fuel consumption increase per year causes an increase in $\mathrm{CO}_{2}$ concentration of about 6 ppmv (17 ppmv), and a temperature increase of about $0.04 \mathrm{~K}(0.11 \mathrm{~K})$. These changes vary nonlinearly with the increased rate of fuel consumption.

\subsection{Climatic impact of ozone changes}

The direct radiative effects of the aircraft $\mathrm{NO}_{x}$ emissions (and of $\mathrm{N}_{2} \mathrm{O}$ emissions) are negligible (Fortuin et al., 1995). However, the aircraft $\mathrm{NO}_{x}$ emissions have the potential to alter upper-tropospheric and lower-stratospheric ozone (see Section 6). Since ozone absorbs both solar and infrared radiation and plays a major role in determining the energy balance of the stratosphere and troposphere, these changes in ozone concentrations may have an impact on climate. The perturbation of the planetary radiation budget, referred to as radiative forcing, is strongly governed by the shape of the vertical profile of the ozone changes, particularly in the vicinity of the tropopause (Wang et al., 1980; Lacis et al., 1990; Hauglustaine and Granier, 1995; Chalita et al., 1996; Forster and Shine, 1997). Figure 49 illustrates the sensitivity of the net (solar + infrared) radiative forcing calculated at the tropopause level to the altitude of a constant 10 Dobson unit (Fig. 49a) and 10\% (Fig. 49b) increment in ozone over a $1 \mathrm{~km}$ thick layer for mid-latitude summer and clear-sky conditions. As a consequence of long-wave radiation trapping (greenhouse effect), a positive forcing (warming) is obtained when ozone is increased in the troposphere and lower stratosphere. Ozone added near the ground, provides little warming, while ozone increments added near the tropopause produces the largest positive forcing. Because ozone absorbs solar radiation in the stratosphere, a negative direct forcing (cooling) is predicted for $\mathrm{O}_{3}$ increment above about $20 \mathrm{~km}$. As discussed by Forster and Shine (1997), a fixed 10 DU increase in

Table 22. Climatic response to aviation $\mathrm{CO}_{2}$ emissions scenarios. The radiative forcing is calculated using a linearized relation between the $\mathrm{CO}_{2}$ change and the radiative forcing. This represents an overestimation of the radiative forcing

\begin{tabular}{|c|c|c|c|}
\hline Fuel consumption increase rate $\left(\% \mathrm{yr}^{-1}\right)$ & 1 & 2 & 3 \\
\hline $\mathrm{CO}_{2}$ emissions in year $1995\left(\mathrm{GtC} \mathrm{yr}^{-1}\right)$ & 0.13 & 0.13 & 0.13 \\
\hline $\mathrm{CO}_{2}$ emissions in year $2050\left(\mathrm{GtC} \mathrm{yr}^{-1}\right)$ & 0.22 & 0.38 & 0.66 \\
\hline $\mathrm{CO}_{2}$ emissions in year $2100\left(\mathrm{GtC} \mathrm{yr}^{-1}\right)$ & 0.37 & 1.0 & 2.9 \\
\hline $\mathrm{CO}_{2}$ concentration change in 1995 (ppmv) & 1.3 & 1.3 & 1.3 \\
\hline $\mathrm{CO}_{2}$ concentration change in 2050 (ppmv) & 4.4 & 5.8 & 7.7 \\
\hline $\mathrm{CO}_{2}$ concentration change in $2100(\mathrm{ppmv})$ & 8.8 & 16.7 & 34.4 \\
\hline Radiative forcing in $1995\left(\mathrm{~W} \mathrm{~m}^{-2}\right)$ & 0.03 & 0.03 & 0.03 \\
\hline Radiative forcing in $2050\left(\mathrm{~W} \mathrm{~m}^{-2}\right)$ & 0.09 & 0.12 & 0.15 \\
\hline Radiative forcing in $2100\left(\mathrm{~W} \mathrm{~m}^{-2}\right)$ & 0.18 & 0.33 & 0.69 \\
\hline Surface temperature change in $1995(\mathrm{~K})$ & 0.008 & 0.008 & 0.008 \\
\hline Surface temperature change in 2050 (K) & 0.030 & 0.038 & 0.048 \\
\hline Surface temperature change in $2100(\mathrm{~K})$ & 0.06 & 0.11 & 0.22 \\
\hline
\end{tabular}



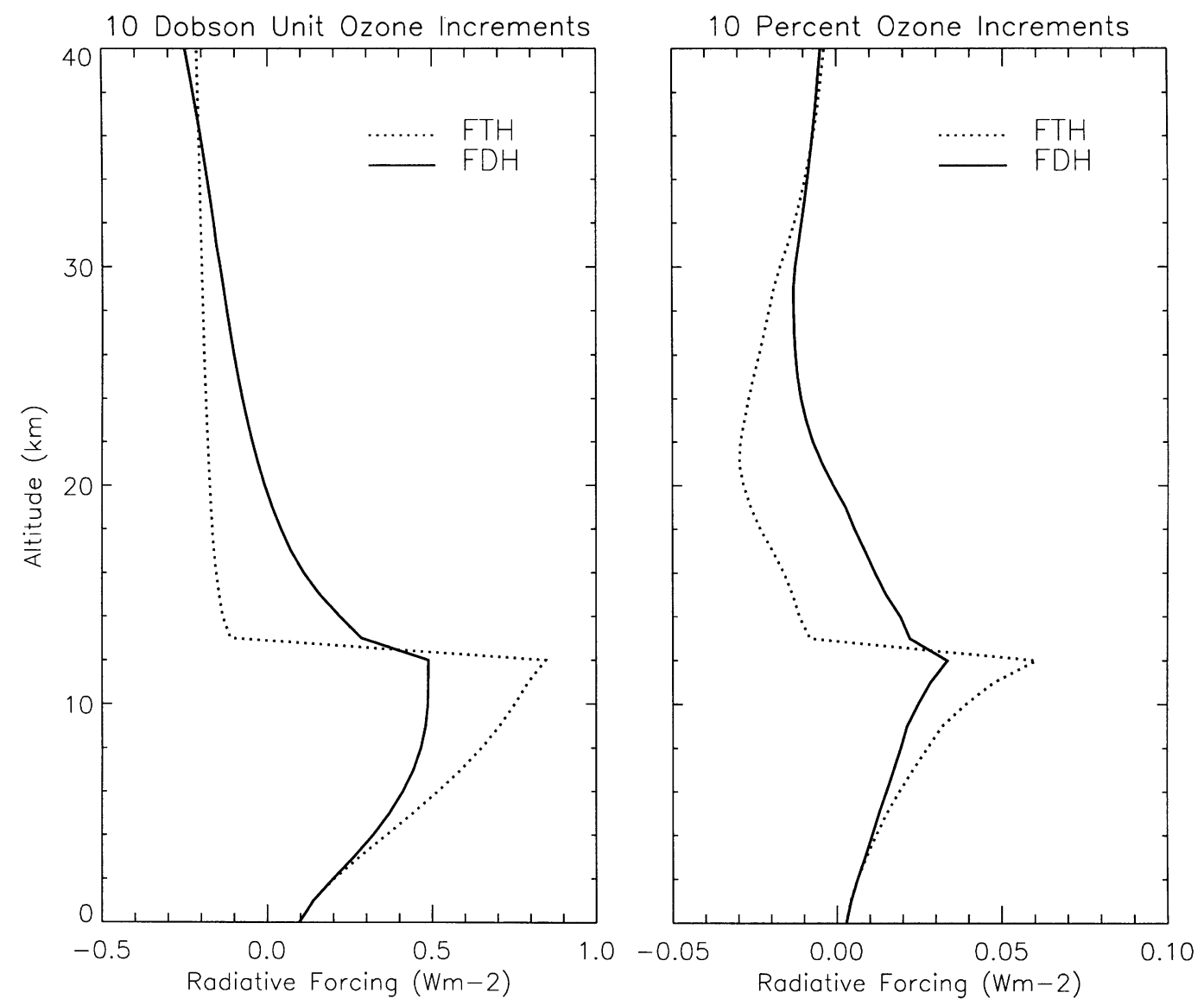

Fig. 49. Radiative forcing at the tropopause as a function of the altitude where the ozone perturbation is applied (mid-latitude summer conditions). In (a), a 10 Dobson unit (where $1 \mathrm{DU}=2.69 \times 10^{16} \mathrm{~mol} \mathrm{~cm}^{-2}$ in the vertical column) increment is successively added over a $1 \mathrm{~km}$ thick layer and in (b) a $10 \%$ increment over a $1 \mathrm{~km}$ thick layer is considered. These forcings have been calculated for the fixed dynamical heating $(\mathrm{FDH})$ approximation with the model of Hauglustaine and Granier (1995) modified as described in Shine $e t$ al. (1995) [see IPCC (1995) for a description of the fixed dynamical heating concept].

ozone is a $400 \%$ increment at the tropopause, but only a $60 \%$ increase at $25 \mathrm{~km}$. Therefore, this approach emphasises the ozone change at the tropopause. Forster and Shine (1997) recommend the use of a constant percentage change rather than a constant DU change. The high sensitivity of the forcing to the vertical distribution of changes in ozone concentrations is a key feature regarding the climate impact of aircraft emissions. The radiative forcing is most sensitive to changes in ozone at altitudes of about $8-12 \mathrm{~km}$, where aircraft emissions are maximum and the resulting changes in the ozone abundance are expected to be large.

7.3.1. Changes in tropospheric ozone. The ozonegenerated climate forcing associated with the actual aircraft fleet has been investigated on the basis of one-, two- and three-dimensional models. The largest uncertainty on the radiative forcing arises from the calculated tropospheric ozone increases, which differ among various models in both its absolute value and vertical/seasonal distributions. It should be noted, in particular, that the aircraft $\mathrm{NO}_{x}$ emissions vary con- siderably from model to model, which is an important cause for discrepancies between published results. Most European model calculations presented in this section are based on the earlier (European) ANCAT inventory for $\mathrm{NO}_{x}$ (ANCAT, 1995; Gardner et al., 1997a) which provided values significantly higher (a factor 1.5) than the NASA and more recent European inventories. Since nitrogen oxides released in the upper troposphere are more efficient in terms of ozone production than $\mathrm{NO}_{x}$ released at the surface, and since the radiative forcing is more sensitive to ozone increments around the tropopause, $\mathrm{NO}_{x}$ aircraft emissions are about 10-20 times more efficient in terms of $\mathrm{O}_{3}$ radiative perturbation than $\mathrm{NO}_{x}$ emissions at the surface (Johnson et al., 1992; Hauglustaine et al., 1994a; Fuglestvedt et al., 1996).

Table 23 summarises the globally averaged radiative forcing associated with ozone changes due to aircraft $\mathrm{NO}_{x}$ emissions calculated by different onedimensional (1-D), two-dimensional (2-D) and threedimensional (3-D) models. Using a 2-D chemical model in conjunction with the height-dependent sensitivity 
Table 23. Maximum ozone change in the upper troposphere at mid-latitude associated with present aircraft emissions and corresponding annual radiative forcing calculated with different models

\begin{tabular}{lcc}
\hline Reference & $\begin{array}{c}\text { Ozone } \\
\text { change } \\
(\%)\end{array}$ & $\begin{array}{c}\text { Radiative } \\
\text { forcing } \\
\left(\mathrm{W} \mathrm{m}^{-2}\right)\end{array}$ \\
\hline Johnson et al. $(1992)$ & 15 & 0.047 \\
Hauglustaine et al. $(1994 \mathrm{a})$ & 7 & 0.05 \\
Fortuin et al. $(1995)$ & $10-15$ & 0.023 \\
Brasseur et al. $(1996)$ & 4 & 0.015 \\
Stevenson et al. $(1997)$ & 9 & 0.05 \\
\hline
\end{tabular}

of the radiative forcing to changes in the ozone profile given by Lacis et al. (1990), Johnson et al. (1992) calculated a globally averaged forcing of about $0.047 \mathrm{~W} \mathrm{~m}^{-2}$, for an ozone increase reaching about $15 \%$ in January at $12 \mathrm{~km}$ at high northern latitudes. One-dimensional radiative transfer calculations by Fortuin et al. (1995) indicate a radiative forcing due to a $10-15 \%$ increase in ozone of about 0.03 and $0.012 \mathrm{~W} \mathrm{~m}^{-2}$ for, respectively, mid-latitude summer and winter conditions. With a coupled climate-chemistry 2-D model, Hauglustaine et al. (1994a) calculated a radiative forcing of $0.015 \mathrm{~W} \mathrm{~m}^{-2}$ on a global and annual mean basis, and reaching locally a maximum of about $0.8 \mathrm{~W} \mathrm{~m}^{-2}$ in July in northern mid-latitudes, for an ozone increase reaching up 7\% in summer at about $10 \mathrm{~km}$. Using the IMAGES model, Brasseur et al. (1996) calculated a tropospheric ozone increase reaching $4 \%$ in July $\left(10 \mathrm{~km}\right.$, north of $\left.50^{\circ} \mathrm{N}\right)$, and derived an $\mathrm{O}_{3}$ radiative forcing of the order of 0.02 $\mathrm{W} \mathrm{m}^{-2}$ in summer and $0.01 \mathrm{~W} \mathrm{~m}^{-2}$ in winter in global average, with a local maximum of approximately $0.04 \mathrm{~W} \mathrm{~m}^{-2}$ at northern mid-latitudes in summer. More recently, using a 3-D Lagrangian model, Stevenson et al. (1997) calculated an ozone increase reaching up to $9 \%$ in the upper troposphere with a corresponding increase in the radiative forcing of $0.05 \mathrm{~W} \mathrm{~m}^{-2}$ as a global average (maximum value of $0.14 \mathrm{~W} \mathrm{~m}^{-2}$ at mid-latitudes in the northern hemisphere).

The calculated globally averaged climate forcing associated with the 1990 aircraft fleet (0.015-0.05 $\mathrm{W} \mathrm{m}^{-2}$ ) is significantly smaller that the total radiative perturbation which has been produced by other greenhouse gases (carbon dioxide, methane, nitrous oxide, and halocarbons) since pre-industrial time [2.4 $\mathrm{W} \mathrm{m}^{-2}$ with an accuracy of $15 \%$ (IPCC, 1994)]. It is also smaller than the radiative forcing (about $0.3-0.7 \mathrm{~W} \mathrm{~m}^{-2}$ ) produced by the ozone change resulting from changes in emissions of $\mathrm{CH}_{4}, \mathrm{NO}_{x}$ and $\mathrm{CO}$ since pre-industrial time (e.g. Hauglustaine et al., 1994b; Lelieveld and van Dorland, 1995; Chalita et al., 1996; Forster et al., 1996; Portmann et al., 1997). However, the comparison of the halocarbon forcing for the $1980-1990$ period in the $30-60^{\circ} \mathrm{N}$ latitude band of about $0.08 \mathrm{~W} \mathrm{~m}^{-2}$ (Ramaswamy et al., 1992) and the $\mathrm{O}_{3}$ forcing associated with aircraft emissions calculated for summer conditions at northern mid- latitudes $\left(0.04-0.14 \mathrm{~W} \mathrm{~m}^{-2}\right)$, stresses the potential importance of aircraft emissions on local radiative forcing.

Estimates of future ozone changes due to subsonic aircraft emissions and corresponding impact on the radiative forcing, strongly depend on the scenario adopted for the future aircraft fleet. Table 24 gives the globally averaged ozone radiative forcing for different assumed future scenarios of $\mathrm{NO}_{x}$ release from aircraft. Johnson et al. (1992) estimated a change in the radiative forcing of about $0.034 \mathrm{~W} \mathrm{~m}^{-2}$ for the decade 1990-2000. Assuming a local ozone increase $(8-12 \mathrm{~km}$, $30-50^{\circ} \mathrm{N}$ ) of $4-7 \%$ due to an estimated doubling of the subsonic aircraft $\mathrm{NO}_{x}$ emissions, Mohnen et al. (1993) calculated a radiative forcing of 0.04-0.07 $\mathrm{W} \mathrm{m}^{-2}$. Derwent (1994) calculated a radiative forcing of $0.006 \mathrm{~W} \mathrm{~m}^{-2}$ for an increase in aircraft emissions of about 10\%. Fuglestvedt et al. (1996) calculated a globally averaged forcing of about $0.02 \mathrm{~W} \mathrm{~m}^{-2}$, with a local maximum of about $0.06 \mathrm{~W} \mathrm{~m}^{-2}$ in summer at $40{ }^{\circ} \mathrm{N}$, for a $70 \%$ increase in aircraft emissions (ozone increase reaching up 4\%). Brasseur et al. (1996) estimated a perturbation of ozone over the next $20 \mathrm{yr}$ $\left(\mathrm{NO}_{x}\right.$ emission from aircraft increased by about $85 \%$ ) of approximately three-quarters of the increase for the period over which aviation has developed (ozone increase reaching about 3\%). Their results suggest a globally averaged forcing of about $0.011 \mathrm{~W} \mathrm{~m}^{-2}$ with a local maximum of about $0.03 \mathrm{~W} \mathrm{~m}^{-2}$ in northern mid-latitudes during summer for the period 1995-2015.

As a consequence of the increased hydroxyl radical $(\mathrm{OH})$ concentrations at higher $\mathrm{O}_{3}$ levels, an indirect radiative forcing is provided by changes in the methane concentration. Since the major sink of $\mathrm{CH}_{4}$ is increased, the methane lifetime (and hence its concentration) is decreased, and a negative forcing is provided. Hauglustaine et al. (1994a) and Johnson (1994) estimated an offset of the direct ozone forcing of, respectively, about 30 and 20\%. Fuglestvedt et al. (1996) and Brasseur et al. (1996) derived a smaller offset of about $4-7 \%$ of the direct ozone forcing. The reason for that deviation among models has been tentatively attributed to different $\mathrm{NO}_{x}$ background levels.

Sausen et al. (1997) introduced into the ECHAM4 model aircraft-induced ozone changes as a perturbation in the standard model ozone field. Four different $\mathrm{O}_{3}$ perturbations were applied: as simulated by the

Table 24. Globally averaged tropospheric ozone radiative forcing associated with various future scenarios of subsonic aircraft emission increase calculated by different models

\begin{tabular}{lcc}
\hline Reference & $\begin{array}{c}\text { Change in } \\
\mathrm{NO}_{x} \text { emission } \\
(\%)\end{array}$ & $\begin{array}{c}\text { Radiative } \\
\text { forcing } \\
\left(\mathrm{W} \mathrm{m} \mathrm{m}^{-2}\right)\end{array}$ \\
\hline Mohnen et al. (1993) & 100 & $0.04-0.07$ \\
Derwent (1994) & 10 & 0.006 \\
Fuglestvedt et al. (1996) & 70 & 0.02 \\
Brasseur et al. (1996) & 85 & 0.011 \\
\hline
\end{tabular}


MOGUNTIA and CTMK models, and both perturbations amplified by a factor of 5. In July, the maximum ozone changes were, respectively, 12 and 9 ppbv for the MOGUNTIA and CTMK models. The simulated equilibrium temperature change (Fig. 50) is small and mostly lies in the range of $0.2 \mathrm{~K}$ for July, with positive values below the tropopause and negative values above. By subsequently applying a fingerprint technique and a hierarchical Hotelling $T^{2}$-test, Sausen et al. (1997) showed that statistically the simulated climate change is significantly different from zero. The signal nonlinearly depends on the magnitude of the ozone increment. It is remarkable that the rather small amount of present-day aircraft emissions results in temperature changes in the range of $0.2 \mathrm{~K}$ close to the tropopause, which are about $5-10 \%$ of the response that the same model simulates at the same level for a doubling in $\mathrm{CO}_{2}$. It should be noted that the response of the model was damped by using a prescribed sea surface temperature (present day) as lower boundary condition.

Several authors also calculated the greenhouse warming potential (GWP) of aircraft emitted $\mathrm{NO}_{x}$ due to the additional $\mathrm{O}_{3}$ produced. The GWP is the time-integrated radiative forcing from the instantaneous release of $1 \mathrm{~g}$ of a trace gas expressed relative to that of $1 \mathrm{~g}$ of $\mathrm{CO}_{2}$ (for more details see IPCC, 1995). In the case of the GWP of aircraft-emitted $\mathrm{NO}_{x}$, a rather large range of values is given for a time horizon of $100 \mathrm{yr}: 140$ (Fuglestvedt et al., 1996), 166 (Michaelis, 1993), 210 (Johnson et al., 1992), 300 (Johnson, 1994), and 456 (Johnson and Derwent, 1996). If the emission index for $\mathrm{NO}_{x}$ was 15 (i.e. $15 \mathrm{~g}-\mathrm{NO}_{2}$ per $\mathrm{kg}$-fuel), $\mathrm{CO}_{2}$ and $\mathrm{NO}_{x}$ emissions by aircraft would have an equal impact for a GWP of 210 $\left(\mathrm{EI}-\mathrm{CO}_{2} / \mathrm{EI}_{-} \mathrm{NO}_{x}=3150 / 15=210\right)$. In the extreme case of the Johnson and Derwent (1996) result, each gram of $\mathrm{CO}_{2}$ emitted by an aircraft would have to be multiplied by a factor of approximately 3.2 in order to cover both, the warming effect of $\mathrm{CO}_{2}$ and $\mathrm{NO}_{x}$ (via $\mathrm{O}_{3}$ ) on a time horizon of $100 \mathrm{yr}$. The factor would be larger for a shorter time horizon. Finally, it should be mentioned that the GWP ignores spatial inhomogenities in the emissions. Hence, there is the need for the development of additional indices that better take into account the spatial structure of the aircraft emissions.

7.3.2. Changes in stratospheric ozone. Ozone depletion in the lower stratosphere causes an instantaneous radiative forcing at the tropopause from two competing effects. Less solar radiation is absorbed by ozone in the stratosphere and, consequently, there is an increase in the short-wave radiation reaching the surface-troposphere system leading to a positive forcing (warming). In addition, ozone depletion leads to a reduction of the downward infrared flux at the tropopause and hence provides a negative forcing (cooling). Since the solar contribution is dominant, the net instantaneous forcing is positive (WMO, 1994). However, the stratospheric temperature will adjust until a new radiative equilibrium is reached. In the layers affected by the ozone loss, the local heating rate is reduced, the temperature decreases and, consequently, the downward thermal radiation is reduced. In the case of adjusted stratospheric temperatures, an intercomparison between models suggests a negative net forcing, but with a substantial spread in the forcing (more than a factor of two) calculated by the different models (WMO, 1994; Shine et al., 1995). Similar to tropospheric ozone changes, the radiative forcing associated with stratospheric ozone perturbations is strongly dependent on the vertical profile of the ozone loss.

Schwarzkopf and Ramaswamy (1993) examined this problem by using 1978-1990 ozone changes derived from observations. Depending on various assumptions made for the vertical profile in the ozone change, they derived radiative forcings per Dobson unit change in stratospheric ozone ranging from 0.007 to $0.01 \mathrm{~W} \mathrm{~m}^{-2} / \mathrm{DU}$ in the tropics and from 0.003 to $0.008 \mathrm{~W} \mathrm{~m}^{-2} / \mathrm{DU}$ at mid-latitudes. Results obtained by Molnar et al. (1994) with a two-dimensional radiative-convective seasonal model reaffirm the sensitivity of the forcing to uncertainties in the vertical distribution of ozone depletion. Furthermore, Molnar et al. (1994) and Hansen et al. (1997) concluded that the radiative forcing associated with stratospheric ozone changes was not simply translatable into a surface air temperature response, as is the case for wellmixed gases.

Estimates of aircraft effects on stratospheric ozone depend on the number of aircraft, the altitude of operation, the exhaust emissions, the background chlorine, bromine and aerosol loadings, and on the photochemical model used for the assessment (Albritton et al., 1993). Recent studies suggest that, by the year 2015, supersonic and subsonic aircraft (assuming that about $40 \%$ of subsonic $\mathrm{NO}_{x}$ is released in the lower stratosphere) should decrease the total ozone column by less than $2 \%$ in the $40-50^{\circ} \mathrm{N}$ region (WMO, 1995). Based on Schwarzkopf and Ramaswamy (1993) results, this leads a local radiative forcing in the range -0.02 to $-0.06 \mathrm{~W} \mathrm{~m}^{-2}$.

These ozone changes (stratospheric ozone decrease and tropospheric ozone increase) have been introduced in the NASA Goddard Institute for Space Studies (GISS) three-dimensional climate/middle atmosphere model (Rind and Lonergan, 1995). An equilibrium climate simulation leads to a general stratospheric cooling of a few tenths of a degree, combined with a warming of the stratosphere in northern polar regions due to altered atmospheric circulation. The globally averaged surface temperature change is not significant, due to conflicting influences of stratospheric ozone reduction and tropospheric ozone increase, although a high-latitude cooling of close to $0.5^{\circ} \mathrm{C}$ occurred consistently in the simulation.

Additional complications in the determination of the ozone forcing arise from uncertainties in chemical feedbacks. As an example, depletion of stratospheric ozone would lead to an enhancement in tropospheric 

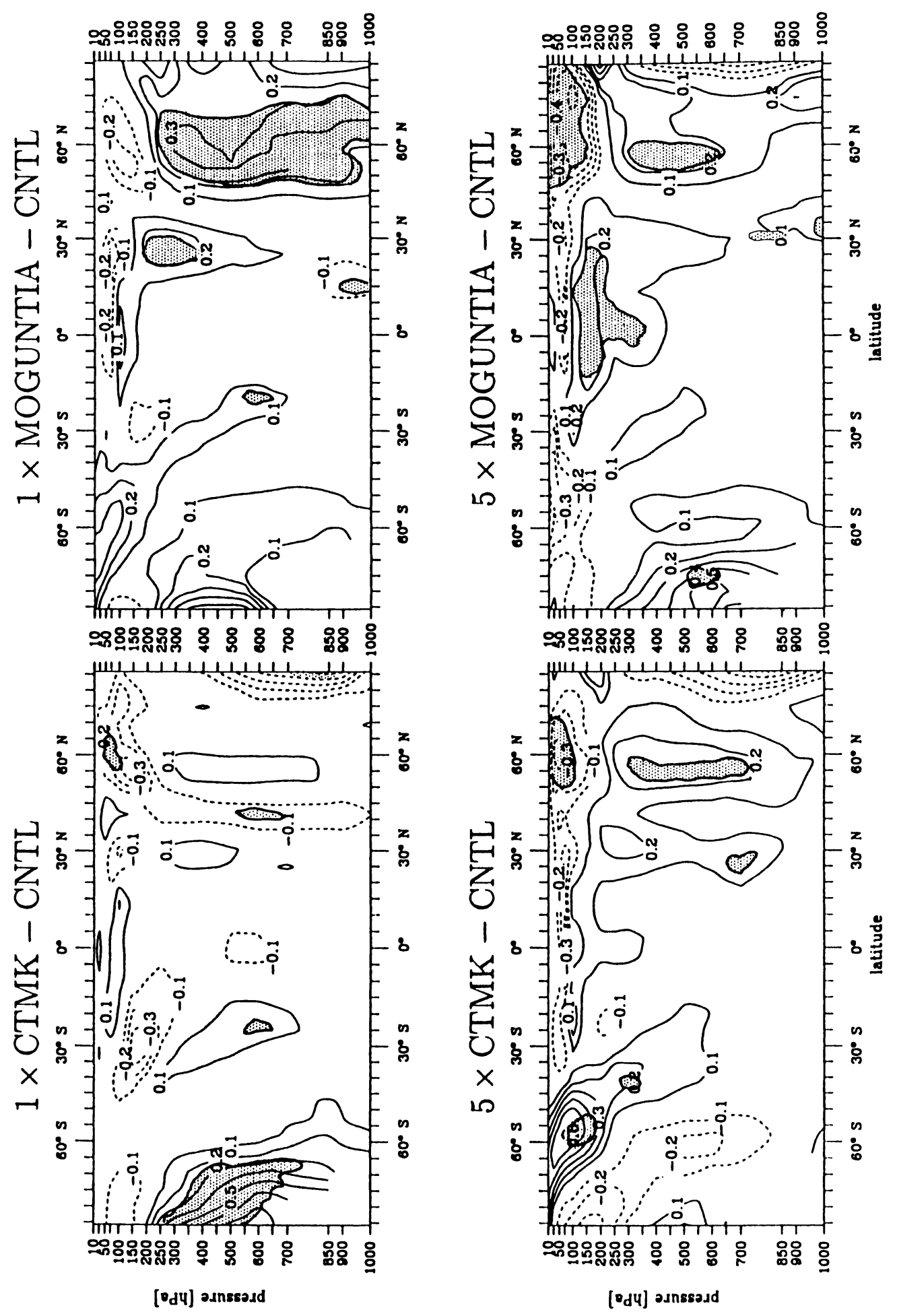
UV radiation, which increases the rate of production of $\mathrm{OH}$ and destruction of methane (Madronich and Granier, 1992; Toumi et al., 1994; Fuglestvedt et al., 1994) in the troposphere.

\subsection{Climatic impact of water and contrails}

Water vapour emissions by aircraft can potentially perturb climate in two different ways. First, water vapour is a radiatively active gas, and hence, additional water vapour in the atmosphere can directly modify the radiative budget (Section 7.4.1). Second, emissions of water vapour, soot and sulphur compounds can trigger additional cloud formation (contrails) which then indirectly change the radiative forcing and finally the state of the atmosphere (Section 7.4.2).

7.4.1. Changes in water vapour. The potential climatic effect of water vapour emissions by aircraft depends on the relative contribution of these emissions to the background water vapour. As the natural water vapour concentration strongly decreases with altitude, this effect is expected to be larger for high flying aircraft than for flights at lower levels. The current subsonic air traffic occurs near $10-13 \mathrm{~km}$, i.e. a considerable fraction of the time in the lower stratosphere of the northern hemisphere's extra-tropics. However, according to the estimates of Schumann (1994) and Fortuin et al. (1995), the enhancement in the water vapour abundance represents less than $1.5 \%$ of the background concentration (in the range of 10-40 ppm, see Dessler et al., 1995). The relative changes to the upper troposphere remain small, even if the emissions are confined to the most frequently used North Atlantic flight corridor. Fortuin et al. (1995) calculated the additional local heating in the extreme case to be below $0.24 \mathrm{~W} \mathrm{~m}^{-2}$. Hauglustaine and Granier (1995) show that the water vapour forcing is strongly dependent on latitude and smaller than the ozone radiative forcing.

Having this small perturbations of water vapour in mind (which may already be exaggerated due to the assumption of a lifetime of about half a year in the lowermost stratosphere), only very tiny perturbations in the climate due to water vapour released by subsonic aircraft can be expected. This is confirmed by GCM simulations. The present-day aircraft water emissions $\left(2 \times 10^{11} \mathrm{~kg} \mathrm{yr}^{-1}\right)$, as estimated by McInnes and Walker (1992), were inserted into the ECHAM GCM by Ponater et al. (1996). Feedbacks involving background water vapour and clouds were included. Nevertheless, no significant change of any relevant climate variable could be identified. This remains true when the water emissions are increased by factors of 10 or 100. Particularly, the cloud and temperature distributions, and the radiative balance at the top of the atmosphere show no organised response whatsoever. A factor of 1000 resulted in temperature changes which are locally in the range of natural variability. An emission increase of a factor of 10,000 provides a response that is clearly significant. However, such an enhancement of water vapour is highly artificial and far too strong compared to expected perturbations.

Rind et al. (1996) performed a similar experiment based on the GISS Global Climate Middle Atmosphere Model. They used the NASA present-day (1990) aircraft water vapour emissions and a projection to year 2015 with global emission rates of $1.7 \times 10^{11} \mathrm{~kg} \mathrm{yr}^{-1}$ and $3.8 \times 10^{11} \mathrm{~kg} \mathrm{yr}^{-1}$, respectively (Baughcum et al., 1993). Again, Rind et al. (1996) found no significant perturbation in climate for present-day emissions or for moderate amplifications of these emissions (factors of 3.5 and 35). Using a factor of 700 relative to the 1990 emissions, they obtained a significant modification of the climate. However, this factor is so high that there appears to be little change to be expected even in the far future. It should be stressed, however, that the temperature change pattern as simulated in the extreme case (factor 700) is different from an experiment in which $\mathrm{CO}_{2}$ is increased by a magnitude that leads to a similar global warming. The water vapour release experiments show a stronger upper tropospheric warming and a smaller high latitude surface temperature response than the $\mathrm{CO}_{2}$ experiment.

It should be noted that differences between the results of Ponater et al. (1996) and Rind et al. (1996) could be attributed to general differences in respective models, to different lifetimes of water vapour or/and to different ocean formulations (prescribed sea surface temperature vs slab ocean).

The effect of stratospheric emissions from a projected supersonic fleet was estimated by Rind and Lonergan (1995). As the applied GISS Global Middle Atmosphere Model requires a prescribed humidity above $100 \mathrm{hPa}$, additional water vapour could not be inserted as in the experiments described above. The prescribed stratospheric humidity was globally homogeneously enhanced by a constant factor. Considering the projected 2015 Mach 2.4 fleet (Albritton et al., 1993) a $7 \%$ increase in the background water vapour concentration was estimated. The middle atmosphere cooled by $0.5 \mathrm{~K}$ or less, whereas no significant surface temperature change could be detected. In a second experiment, the stratospheric water vapour content was doubled. This lead to a $2-3 \mathrm{~K}$ cooling of the middle atmosphere and a $0.5 \mathrm{~K}$ warming of the upper troposphere.

It can be concluded that, for what concerns the direct impact of water vapour, the present-day subsonic fleet has only a negligible impact upon climate. This remains true even for a fleet 10 times larger than the present fleet. However, the potential impact of a future fleet of supersonic transport on climate could be significant.

7.4.2. Effects of contrails. According to the Schmidt-Appleman criterion (Schmidt, 1941; Appleman, 1953; Busen and Schumann, 1995; Schumann, 1996; see also Section 5.4), short-lived contrails occur when the ambient air temperature is cooler than some threshold value, which depends on the flight level, 
ambient humidity and aircraft propulsion efficiency. A typical value is $-40^{\circ} \mathrm{C}$. Ponater et al. (1996) estimate that the upper bound for the global coverage by short-lived contrails should be close to $680 \mathrm{~km}^{2}$. This is only a fraction of less than $2 \times 10^{-5}$ of the area covered by frequently used flight routes. Hence, we can not expect any significant climate change caused by short-lived contrails.

The situation is different for persistent contrails. In addition to the criterion for short-lived contrails, persistent contrails require that the ambient air be supersaturated with respect to the ice phase and not saturated with respect to the water phase (Schumann, 1996; see also Section 5.4). Such situations typically occur ahead of cyclonic storms or downstream of convective complexes. Hence, persistent contrails are basically not formed from the water emitted by aircraft. Rather the emissions trigger the formation of cloud particles.

Based on simple estimates, Ponater et al. (1996) calculate that an area of $250,000 \mathrm{~km}^{2}$ of the globe is covered by persistent contrails. This corresponds to $0.04 \%$ of the Earth's surface, but as much as $0.56 \%$ of the area covered by frequently used flight routes. Based on ECMWF analyses for years 1990-1994 and on the assumption that the analysed relative humidities are accurate enough for a contrail diagnostic study, Brockhagen (1996) found that up to $6 \%$ of the area of the globe pass the criteria for persistent contrails, i.e. if aircraft were flying everywhere, $6 \%$ of the planet would be covered by contrails.

Observational contrail statistics on hemispheric scale for multi-year periods are not available. The visual inspection of satellite images of central Europe suggests that, on the average, $0.4 \%$ of the area is covered by contrails, i.e. high clouds that are line shaped (Schumann and Wendling, 1990). Similarly, Bakan et al. (1994) derived from seven years of NOAA/AVHRR infrared satellite images of the Eastern Atlantic/Western Europe an annual mean contrail coverage of about $0.5 \%$, with regional maxima in the North Atlantic flight corridor of more than $2 \%$. Both studies did not account for aged contrails which have grown to such a large size that they are no longer line shaped, nor for other "natural" clouds which have potentially been produced by aerosols emitted earlier by aircraft. Hence, the numbers provided above should be regarded as lower limits of the contrail coverage.

The radiative forcing of contrails strongly depends on the particle size spectrum and on the shape of the contrails (e.g. Fortuin et al., 1995). Young contrails differ in their size spectra from cirrus clouds (Strauss and Wendling, 1996). There is some debate whether the optical properties of persistent contrails are similar to cirrus clouds (e.g. Strauss, 1995) or whether the particle spectrum of contrails is shifted towards smaller size particles (Betancor et al., 1993). Using a radiative transfer model, Strauss (1995) calculated a surface temperature increase of $0.05 \mathrm{~K}$ for a contrail coverage of $0.4 \%$ and climatic conditions representative of southern Germany.

Ponater et al. (1996) used an idealised approach to simulate the large-scale climatic impact of contrails with the ECHAM general circulation model (Roeckner et al., 1992; Lohmann and Roeckner, 1995). In areas frequently affected by air traffic, the fractional cover of high clouds was enhanced (only for the calculation of the solar and thermal radiative forcings) by constant increments: either 2, 5 or $10 \%$ (e.g. if the natural cirrus coverage at the altitude considered was $8 \%$, the cloud coverage was enhanced to 10,13 and $18 \%$ ). It was assumed that contrails possess the same optical properties as natural high clouds in the same grid box. The cloud water mixing ratio was left unchanged except for those grid boxes containing no natural cirrus. The original values of cloud cover and cloud water were retained for all other processes included in the ECHAM model. As a result of feedback mechanisms, the internal cloud coverage was also changed.

The response was larger for July than for January. Therefore, we restrict our discussion to the July results. The radiative fluxes at the top of the atmosphere for the control run (without perturbation) and the changes in the three model experiments are displayed in Table 25 as averages of the globe, the northern extra-tropics and over the main flight routes. The net radiation at the top of the atmosphere, i.e. the difference of solar and terrestrial radiation, does not represent the radiative forcing; rather it is the equilibrium response accounting for internal feedback processes. Due to the natural variability of the atmosphere, the radiative fluxes are rather variable. Hence, the signal in the model simulations is superposed by noise. In order to avoid an interpretation of the (random) noise, only those changes which are statistically significant (on the 99\% level) are displayed in Table 25. Additionally, Table 26 shows $(99 \%)$ confidence limits for the changes in net radiation at the top of the atmosphere.

The case in which cirrus coverage is increased by $2 \%$ exhibits only few significant changes. The response depends nonlinearly on the amount of additional high cloud coverage, resulting in a reversal of the sign for the net radiation change when the cloud coverage increases from $+5 \%$ to $+10 \%$. The global mean net radiation response is $-1.0 \mathrm{~W} \mathrm{~m}^{-2}$ for the latter case. The change in sign of the net radiation change inhibits a down-scaling from the $10 \%$ case to the more realistic cases of 1 or $0.5 \%$ contrail coverage. Locally, over the main flight routes, the net radiation response can be fairly large: it varies from -9.3 to $+9.1 \mathrm{~W} \mathrm{~m}^{-2}$ when the cloud coverage increase varies from 10 to $5 \%$. Contrary to the response of the net flux at the top of the atmosphere, the change in the part of radiation which is directly absorbed within the atmosphere is always positive. The average over the flight routes varies from $+2.0 \mathrm{~W} \mathrm{~m}^{-2}$ for a cloud 
Table 25. July top of the atmosphere radiation in the control experiment and the response to a prescribed local increases of high cloud coverage at four model layers. Averages over the globe, the northern hemisphere extra-tropics and over main flight routes are given. Response values not statistical significant at the $99 \%$ level are omitted. The column "Control experiment" contains the mean value and the standard deviation

\begin{tabular}{|c|c|c|c|c|c|c|}
\hline Averaging domain & $\begin{array}{c}\text { Control } \\
\text { experiment }\end{array}$ & $\begin{array}{c}\text { Response to } \\
\mathrm{a}+10 \% \text { increase }\end{array}$ & a & $\begin{array}{l}\text { Response to } \\
+5 \% \text { increase }\end{array}$ & a & $\begin{array}{l}\text { Response to } \\
+2 \% \text { increase }\end{array}$ \\
\hline \multicolumn{7}{|c|}{ Absorbed solar radiation at the top of the atmosphere $\left(\mathrm{W} \mathrm{m}^{-2}\right)$} \\
\hline Globe & $233.6 \pm 0.5$ & -2.3 & & - & & - \\
\hline Northern extra-tropics & $301.9 \pm 1.3$ & -5.1 & & - & & - \\
\hline Flight routes & $320.4 \pm 3.3$ & -33.1 & & -5.6 & & -6.9 \\
\hline \multicolumn{7}{|c|}{ Thermal radiation at the top of the atmosphere $\left(\mathrm{W} \mathrm{m}^{-2}\right)$} \\
\hline Globe & $-236.6 \pm 0.5$ & +1.3 & & +0.7 & & - \\
\hline Northern extra-tropics & $-241.5 \pm 0.9$ & +2.4 & & +1.8 & & - \\
\hline Flight routes & $-243.9 \pm 2.2$ & +23.8 & & +14.6 & & +6.2 \\
\hline \multicolumn{7}{|c|}{ Net radiation at the top of the atmosphere $\left(\mathrm{W} \mathrm{m}^{-2}\right)$} \\
\hline Globe & $-3.4 \pm 0.6$ & -1.0 & & - & & - \\
\hline Northern extra-tropics & $60.4 \pm 1.2$ & -2.7 & & +2.4 & & - \\
\hline Flight routes & $76.4 \pm 2.2$ & -9.3 & & +9.1 & & - \\
\hline
\end{tabular}

Table 26. July confidence limits $(99 \%)$ for the changes in net radiation at the top of the atmosphere $\left(\mathrm{W} \mathrm{m}^{-2}\right)$ for prescribed local increases of high cloud coverage at four model layers. The confidence limits are given for the averages over the globe, the northern hemisphere extra-tropics and over main flight routes

\begin{tabular}{lccc}
\hline Averaging domain & $\begin{array}{c}\text { Response to a }+10 \% \\
\text { increase }\end{array}$ & $\begin{array}{c}\text { Response to a }+5 \% \\
\text { increase }\end{array}$ & $\begin{array}{c}\text { Response to a }+2 \% \\
\text { increase }\end{array}$ \\
\hline Globe & $-1.4 \cdots-0.6$ & $0.0 \cdots+0.8$ & $-0.4 \cdots+0.3$ \\
Northern extra-tropics & $-3.5 \cdots-1.9$ & $+1.6 \cdots+3.2$ & $-0.4 \cdots+1.2$ \\
Flight routes & $-10.7 \cdots-7.9$ & $+7.6 \cdots+10.6$ & $-2.2 \cdots+0.8$ \\
\hline
\end{tabular}

coverage increase of $2 \%$ to $14.4 \mathrm{~W} \mathrm{~m}^{-2}$ for a cloud coverage increase of $10 \%\left(+8.8 \mathrm{~W} \mathrm{~m}^{-2}\right.$ in the $+5 \%$ experiment).

The response of the net radiation, which is directly absorbed in the atmosphere, is large enough to cause a significant and consistent signal of the zonally averaged temperature (Fig. 51). The dominant feature is a general warming of the troposphere with a maximum at layers where the effective high cloud coverage has increased. Secondary features are a cooling at layers above the additional clouds and another slight cooling in the lower troposphere at subtropical latitudes. If cloud coverage is enhanced by $10 \%$, the temperature increase is significant over almost the whole extra-tropical troposphere above $500 \mathrm{hPa}$. A maximum of more than $4 \mathrm{~K}$ is reached at $55^{\circ} \mathrm{N}$ and $200 \mathrm{hPa}$. Apart from a much weaker peak value of about $1.6 \mathrm{~K}$ warming, the response is similar for a cloud coverage increase of $5 \%$. For an increase of $2 \%$, the overall response is still similar, but its significant part is confined to a narrow latitudinal band and only to a few vertical layers.

In conclusion, the Ponater et al. (1996) experiments show that the present contrails coverage (less than $2 \%$ ) leads to localised change of climate, but the experiments also show that contrails have the potential to significantly modify the climate of large areas. Nevertheless, there are several major caveats associated with their study. The sea surface temperature was fixed at present-day values. Probably, stronger signals would arise, if the sea surface temperature was allowed to adjust to the changed forcing. Contrails were prescribed as fixed high cloud increments without regarding the state of the background atmosphere. It was assumed that contrails and high clouds have similar optical properties.

Finally, since the contrail formation according to the Schmidt/Appleman criterion is strongly altitude dependent, the climatic impact of air traffic via contrails might be reduced by choosing different flight levels (below or above the altitudes which are most favourable for contrails). However, this argument needs to be evaluated by GCM simulations.

\subsection{Climatic impact of soot and sulphur emissions}

Aircraft also emit sulphur (mostly as $\mathrm{SO}_{2}$ with a small fraction as $\mathrm{H}_{2} \mathrm{SO}_{4}$ ) and soot with average emission indices of approximately $\mathrm{EI}\left(\mathrm{SO}_{2}\right)=1 \mathrm{~g} \mathrm{~kg}^{-1}$ fuel and $\mathrm{EI}(\mathrm{soot})=0.02 \mathrm{~g} \mathrm{~kg}^{-1}$ fuel, respectively. The contribution of these compounds to climate change is rather unclear. Aerosols released by aircraft or formed in the wake of aircraft can impact the climate in various ways. Their role in triggering contrails has already been discussed in Section 7.4. By contributing significantly to the background aerosols of the atmosphere, they may also have an impact on the background cloud coverage. However, the magnitude of this effect remains unknown. 

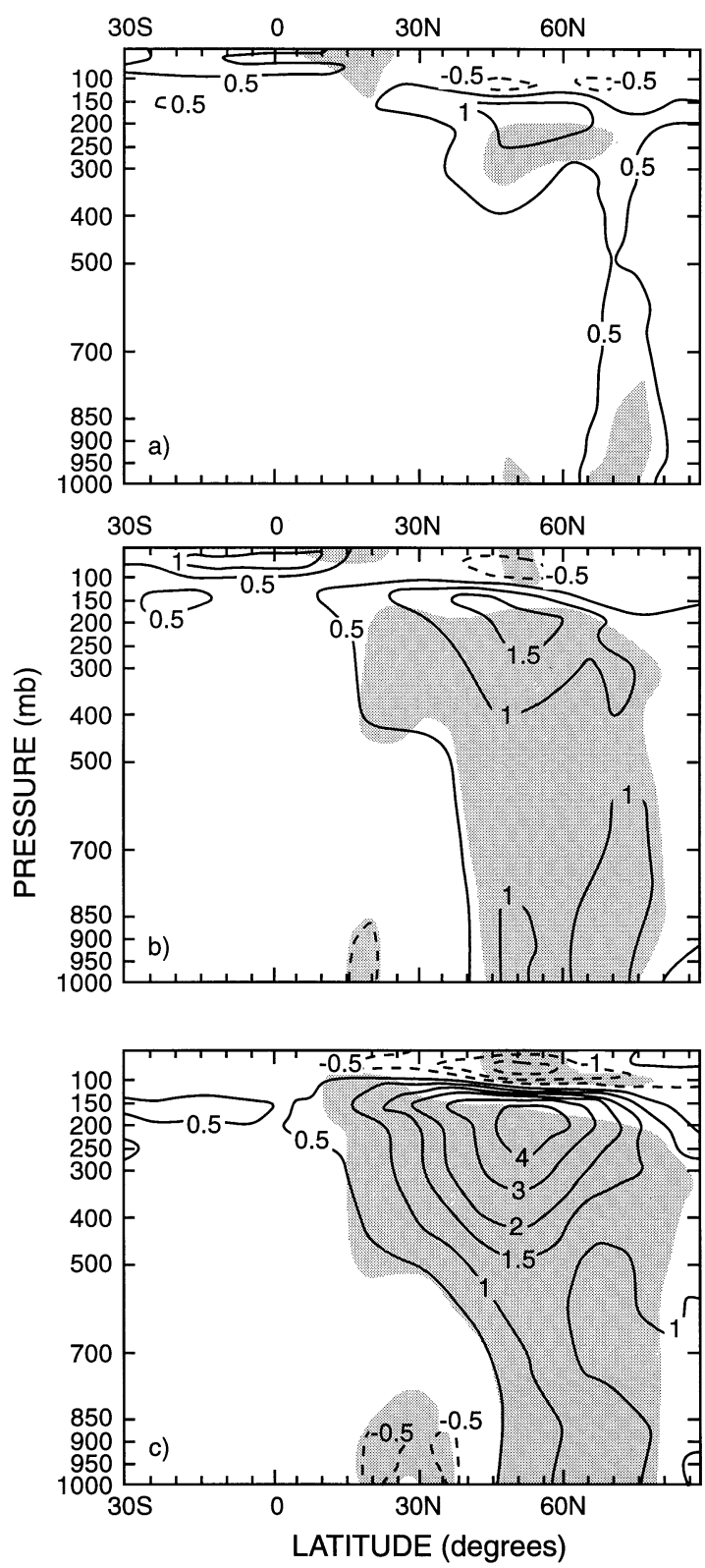

Fig. 51. July response of the zonal mean temperature to a prescribed local enhancement of high clouds. Panels a, $\mathrm{b}$ and $\mathrm{c}$ refer to increments of 2, 5 and $10 \%$, respectively. Units are K. Shaded areas indicate a response passing the statistical significance test at the $99 \%$ level (from Ponater et al., 1996).
The aerosols (soot and sulphates) from aircraft also have a direct radiative effect. As soot absorbs solar radiation and sulphates do not, their radiative forcing is rather different. Fortuin et al. (1994) estimate a radiative forcing of sulphate aerosols in the range of -0.12 to $-0.40 \mathrm{~W} \mathrm{~m}^{-2}$, for the North Atlantic flight corridor, depending on season and relative change in background conditions.

A further impact of aircraft soot and sulphur emissions is indirect: the aircraft-induced aerosols provide surfaces for heterogeneous chemical reactions, which in turn may modify the evolution of the chemical composition of the gaseous aircraft emissions and of the background atmosphere. However, currently not much is known about the large-scale impact of these processes.

\subsection{Summary}

The contributions of various aircraft emissions to the radiative forcing are summarised in Table 27. The level of confidence is also indicated. Apart from contrails only the direct radiative effects are considered.

\section{CONCLUSIONS}

The gradual development over the past decades of a large fleet of commercial aircraft has introduced the potential for environmental perturbations at the global scale. Suggestions have been made that, with increasing air traffic, aircraft operations have already produced and will produce in the future significant changes in the abundance of upper-tropospheric/ lower-stratospheric ozone as well as in the radiative forcing of the climate system. Additional impacts include potential changes in the level of biologically harmful UV-B radiation, in air quality and consumption of crude oil resources. The purpose of this report was to review our knowledge of the chemical and physical processes in the atmosphere and their related perturbations resulting from subsonic and supersonic aircraft operations.

As a result of extensive research performed by the scientific community in Europe, the United States, and elsewhere, our understanding of tropospheric and stratospheric processes has improved substantially over the last years, even if large uncertainties remain and will have to be addressed in the future. For

Table 27. Radiative forcing due to the present subsonic air traffic (global means)

\begin{tabular}{|c|c|c|c|c|c|c|}
\hline & $\mathrm{CO}_{2}$ & $\mathrm{H}_{2} \mathrm{O}$ & $\mathrm{O}_{3}$ & Contrails & Sulphur & Soot \\
\hline Sign & + & + & + & + & - & + \\
\hline $\begin{array}{l}\text { Range of published } \\
\text { results }\left(\mathrm{W} \mathrm{m}^{-2}\right)\end{array}$ & $0.01-0.03$ & Negligible & $0.015-0.05$ & $\begin{array}{l}\text { Possibly large } \\
\text { large order of } 0.1\end{array}$ & 0.0 to -0.01 & Unknown \\
\hline Level of confidence & High & High & Low & Very low & Very low & Very low \\
\hline
\end{tabular}


example, much progress has been made in our understanding of the chemical mechanisms that determine the balance of ozone in the lower stratosphere including the role played by heterogeneous reactions. We have also acquired a better knowledge on the processes that control ozone in the upper troposphere, even if the budget of ozone precursors is not yet well quantified and the exchange mechanisms of chemical constituents from the stratosphere to the troposphere remain poorly understood.

\subsection{Aircraft emissions}

As a result of scientific programs aimed at assessing the potential impact of aircraft on the atmosphere, new and important information has been obtained in recent years. For example, global databases providing the three-dimensional distribution of aircraft emissions have been established and recently improved with regard to traffic considerations. Methodologies developed to established such emission inventories have been evaluated through a comparison between predicted and measured data. The latest versions of the inventories established for $\mathrm{NO}_{x}$ by ANCAT (Europe) and NASA (U.S.) do not anymore differ substantially (10-20\% only); in addition, the uncertainty associated with the estimated aircraft emissions has become smaller than the uncertainty associated with several other sources. About 20\% uncertainty still exists because of differences between the computed fuel consumption and the unknown actual fuel consumption (the IEA values are $20 \%$ larger than the values used in the emission databases). It is estimated that the aircraft source of $\mathrm{NO}_{x}$ represents approximately $1-2 \%$ of the total (natural and anthropogenic) source; its importance arises from the fact that this source is located in the upper troposphere, where the chemical lifetime of $\mathrm{NO}_{x}$ is considerably larger than near the surface, the production of ozone per $\mathrm{NO}$ molecule released is high, and the radiative (greenhouse) effect of additional ozone molecules is larger than at lower altitudes.

\subsection{Aircraft plumes and contrails}

Much progress has also been made regarding the chemical composition and fate of individual aircraft plumes and contrails. The measurements show that aircraft plumes get diluted through mixing by 5 orders of magnitude relative to the concentration at the engine exit within a few (2-3) hours. They can be detected in terms of $\mathrm{NO}_{x}$ and condensation nuclei at time scales up to $1 \mathrm{~d}$. Recently, for the first time, the amount of particles released by aircraft engines has been estimated on the basis of atmospheric measurements. A better description of the dispersion in the atmosphere of the chemical jet behind the aircraft has also been obtained. Recent in situ measurements show that the conversion of reactive $\mathrm{NO}_{x}$ into less reactive nitrogen reservoirs (such as $\mathrm{HNO}_{3}, \mathrm{HNO}_{4}$, etc.) is limited (less than 10-20\% within $4 \mathrm{~h}$ ). On this basis, aircraft engines can be viewed as an atmospheric $\mathrm{NO}_{x}$ source for global models. Soot emitted by engines probably interact with $\mathrm{HNO}_{3}, \mathrm{H}_{2} \mathrm{SO}_{4}$ and $\mathrm{H}_{2} \mathrm{O}$ to form contrail particles which serve as ice nuclei for the formation of cirrus clouds. Preliminary studies suggest that the concentration of condensation nuclei in aircraft corridors is enhanced by $10-30 \%$ over background aerosol load.

\subsection{Impact on stratospheric ozone}

The large-scale impact of the current and future fleets of supersonic aircraft on stratospheric ozone has been assessed extensively in the past on the basis of model calculations. Early models suggested that the oxides of nitrogen released by high altitude aircraft would deplete ozone substantially in the future, and, assuming a fleet of 500 aircraft $\left(7.7 \times 10^{10} \mathrm{~kg}\right.$ fuel per year, emission index of $15 \mathrm{~g} \mathrm{NO} \mathrm{kg}^{-1}$ fuel) cruising at $20 \mathrm{~km}$ altitude, would lead to a reduction in the global average ozone column of approximately $12 \%$ with a worst-case reduction of $25 \%$ near the flight corridor (CIAP, 1975). Since the formulation of these early estimates, more stringent technology targets (e.g. emission index of $5 \mathrm{~g} \mathrm{NO} \mathrm{kg}^{-1}$ fuel) have been adopted for future engines. In addition, our understanding of the processes controlling ozone has improved substantially: the importance of heterogeneous chemical reactions has been emphasised, including the key mechanisms on the surface of PSC particles responsible for the depletion by anthropogenic chlorine of polar ozone during winter and springtime. The causes for the observed mid-latitude ozone depletion, however, are not yet fully established, even though the role of industrially manufactured halocarbons is believed to be important. The impact of aviation in this observed ozone depletion is unknown, but, according to state-of-the-art atmospheric models, is probably small. These models, when accounting for the effects of sulphate aerosols present in the stratosphere, suggest that the response of ozone to $\mathrm{NO}_{x}$ emissions by supersonic aircraft is negative (decrease) in the middle stratosphere and positive (increase) below. Changes in the local concentration do not exceed a few percent. The perturbation of a projected fleet of 500 high altitude transport (supersonic aircraft) on the ozone column could be slightly negative or positive (depending on latitude and season) but should not exceed a few percent. The impact on UV-B levels at the Earth"s surface should not be larger than $1-2 \%$. The perturbation on the ozone abundance and UV-B level is predicted to be smaller when the cruise altitude of aircraft is 20 rather than $24 \mathrm{~km}$. The change in the occurrence frequency of PSCs resulting from the release in the polar stratosphere of water and nitrogen oxides by future high altitude aircraft could be significant (typically a factor of 2 increase), but the corresponding impact on polar ozone remains uncertain, although perhaps significant. More work is needed to clarify this question. After all, the increased fuel consumption and $\mathrm{CO}_{2}$ emissions induced by a fleet of supersonic 
aircraft may be the final limiting factor for this kind of technology.

\subsection{Impact on tropospheric ozone}

The impact of aircraft emission on tropospheric ozone has also been investigated. Laboratory data, atmospheric measurements (e.g. over the North Atlantic), and modelling studies suggest that the release of $\mathrm{NO}_{x}$ by subsonic aircraft engines in the upper troposphere could perturb the chemical composition of this region of the atmosphere. However, due to the limited amount of observations of the $\mathrm{NO}_{x}$ abundance currently available in the free troposphere, and the uncertainties in the global $\mathrm{NO}_{x}$ budget (including natural sources such as the lightning source), the magnitude of the aircraft effects remains difficult to establish. State-of-the-art calculations based on the most reliable estimates of $\mathrm{NO}_{x}$ emissions by the current fleet of commercial aircraft show, however, that the $\mathrm{NO}_{x}$ abundance near $200 \mathrm{hPa}$ should have increased by $20-50 \%$, with a corresponding increase in the ozone concentration of $4-8 \%$ during summertime when photochemical activity is highest. These values are smaller than predicted a few years ago, because of smaller emission, and because the 3D models tend to give somewhat smaller ozone changes than $1 \mathrm{D}$ or $2 \mathrm{D}$ models. The $\mathrm{NO}_{x}$ emissions from subsonic aviation cause an increase of the ozone concentration also in the lower stratosphere. The cross-over point between ozone photochemical production and destruction varies in altitude when the background abundance of $\mathrm{NO}_{x}, \mathrm{CO}$ and $\mathrm{CH}_{4}$ increases. No experimental data are available to confirm this model estimate. In addition, the validity of these model predictions remains limited by the inaccuracies in the parameterization of several atmospheric processes including convective exchanges in the troposphere and the uncertain residence times of emitted species in the lower stratosphere, as well as by uncertainties on natural budgets of chemical compounds such as $\mathrm{NO}_{x}$. Based on stateof-the-art models, it can provisionally be concluded that the radiative warming caused by the increase in tropospheric ozone should be smaller than $0.1 \mathrm{~W} \mathrm{~m}^{-2}$, and probably smaller than $0.05 \mathrm{~W} \mathrm{~m}^{-2}$ for the current fleet of aircraft.

\subsection{Climatic impacts}

The release of $\mathrm{CO}_{2}$ into the atmosphere by the current fleet of aircraft represents annually $2-3 \%$ of all anthropogenic $\mathrm{CO}_{2}$ emissions. The corresponding global radiative forcing (greenhouse effect) calculated by models is only of the order of $0.03 \mathrm{~W} \mathrm{~m}^{-2}$. However, the contribution of aviation $\mathrm{CO}_{2}$ is expected to grow faster $\left(3-4 \% \mathrm{yr}^{-1}\right)$ than $\mathrm{CO}_{2}$ emissions from other sources $\left(1.5 \% \mathrm{yr}^{-1}\right)$. Long-term increase in fuel consumption is unknown, but a fivefold increase in $\mathrm{CO}_{2}$ emissions by year 2100 is possible. The relative contribution of aviation to the $\mathrm{CO}_{2}$ problem is therefore expected to increase during the 21 st century. The chemical and radiative impact of other carbon-con- taining engine exhaust compounds such as carbon monoxide or hydrocarbons is believed to be insignificant both in the troposphere and in the stratosphere.

The increase in the abundance of lower stratospheric water vapour caused by aircraft operations is expected to be too small to produce a detectable climate effect. Calculations based on climate models suggest, however, that the formation of persistent contrails and high-level clouds (cirrus) in the upper troposphere could produce a response in the temperature pattern. This effect would, however, become statistically significant only for contrail coverage larger than present-day amounts. It should be emphasised that, due to the complexity of the microphysical processes involved, which are not accurately formulated in climate models, these predictions should be considered as highly uncertain. For example, the amount of cirrus clouds generated by contrails is not known and the sign of the radiative forcing (cooling or warming) is uncertain. Even if the climate impact produced by aircraft-induced cloud coverage is insignificant on the global scale, it could be substantial regionally. More work is clearly needed to determine accurately the size of the areas affected by persistent contrail formation, the potential change in the cirrus cloud coverage and in the radiative properties of the cloud particles resulting from aircraft operation.

The radiative (besides cloud nucleating) effects of soot particles released by aircraft in the atmosphere are not well quantified. These particles which absorb solar radiation tend to warm up the atmosphere. The mass of soot release by aircraft is too small to cause appreciable changes in the soot loading of the upper troposphere at global scales. But aviation soot may be important in flight corridors and under certain weather conditions with little transport from the surface. Their contribution to the global radiative budget is therefore believed to be insignificant. These particles, however, provide sites on which heterogeneous reactions may occur. The importance of this effect for the chemical composition of the upper troposphere and lower stratosphere is poorly known.

From several studies conducted over the last years, it has been realised that a substantial fraction of the sulphur contained in the fuel and released by the aircraft engines is rapidly converted into sulphuric acid, with further conversion within seconds in small liquid acid particles. These particles have the potential to increase the optical reflectivity of clouds, and hence to decrease solar heating. The magnitude of this cooling effect is however uncertain, though probably not significantly larger (on the global scale) than 0.1 $\mathrm{W} \mathrm{m}^{-2}$. The role of these particles in relation to the chemistry in the plume remains also to be understood.

\subsection{Future changes}

Climatic and atmospheric changes expected in the future depend on the evolution of the fleet and on future engine technology. Global air traffic has been increasing by $6-8 \% \mathrm{yr}^{-1}$ over the last decade and is 
expected to further increase by $5-6 \% \mathrm{yr}^{-1}$ in the next $20 \mathrm{yr}$. Studies conducted by aviation specialists suggest that the number of passengers-kilometres could increase by a factor $2.5-4.0$ by year 2015 with a corresponding increase of a factor 2-3 in fuel consumption and $\mathrm{CO}_{2}$ emissions. The average emission index of $\mathrm{NO}_{x}$ for aircraft engines has increased in the last decades; there is, however, a potential for a reduction of this index in the future as new engines (with lower emissions of hydrocarbons and carbon monoxide) are being introduced. $\mathrm{NO}_{x}$ emissions by aircraft are, however, expected to increase in the future because of increase in fuel consumption.

\subsection{Uncertainties and research needs}

In spite of considerable progress made to better quantify the atmospheric impact of present and future fleet of aircraft, many uncertainties remain. The conclusions presented in this report should therefore be regarded as interim findings, which will be susceptible of changing as new scientific information becomes available. As indicated earlier, more reliable predictions of future changes in the concentration of ozone in the lower stratosphere and upper troposphere will only be possible if fundamental processes occurring in the atmosphere are better understood through carefully designed field and laboratory experiments. Among the questions that require urgent attention are (1) the atmospheric distribution and the global budget of chemical compounds (including the natural sources and sinks processes) which affect the production and destruction of atmospheric ozone; (2) the chemical and photochemical processes that determine the partitioning between reactive species in the lower stratosphere and upper atmosphere, including heterogeneous chemical conversion mechanisms; (3) the dynamical processes that determine the transport at different scales of chemical compounds, including cross-tropopause exchanges and convective motions; (4) the impact of soot and acids on particle formation and related changes in cloudiness and chemistry; (5) evaluations of the climatic impact of the changes in composition and cloudiness relative to the impact of $\mathrm{CO}_{2} ;$ (6) the precise composition of aircraft exhaust as regard to particle formation processes. Since it remains difficult to establish experimentally the response of the atmosphere to chemical emissions by the current fleet of commercial aircraft, observational approaches based on careful analyses of case studies with detailed knowledge of meteorological situations should be favoured. Models are needed for the interpretation of these atmospheric measurements and are the only tools available to make predictions of future perturbations. Because global chemical transport models of the atmosphere and climate models are still in their infancy, further evaluations and improvements of these models are required.

Acknowledgements - The authors wish to thank the DG XII of the European Commission for providing the stimulus to write this assessment and for supporting its preparation within the Environment and Climate Research Programme. They would like also to acknowledge the contributions of T. K. Berntsen at the University of Oslo, Norway; W. M. F. Wauben at KNMI in the Netherlands; J.-F. Müller at the Belgian Institute for Space Aeronomy; V. Grewe, M. Dameris and I. Köhler at DLR in Germany for the model calculations performed specifically for this report. This assessment has been greatly improved by the comments and suggestions made by a panel of reviewers including Dr D. Cadet, CNRS, France; Prof. O. Hov, NILU, Norway; Dr H. Kelder, KNMI, The Netherlands; Dr B. Kärcher, Universität of Munchen, Germany; Dr J. Pyle, University of Cambridge, UK; Dr K. Shine, University of Reading, UK; and Prof. R. Wayne, University of Oxford, UK. Finally, the authors express their gratitude to Ms Donna Sanerib for having co-ordinated the technical preparation of the manuscript at the National Center for Atmospheric Research (NCAR, Boulder, CO), and to Ms. Suzanne Whitman and Mr. Mike Shibao for their expert drafting of most figures.

\section{REFERENCES}

Airbus (1997) Global market forecast 1997-2016, Confirming very large demand. Toulouse, France.

Albritton, D. L., Brune, W. H., Douglas, R. D., Dryer, F. L., Ko, M. K. W., Kolb, C. E., Miake-Iye, R. C., Prather, M. J., Ravishankara, A. R., Rood, R. B., Stolarski, R. S., Watson, R. T. and Wuebbles, D. J. (1993) The atmospheric effects of stratospheric aircraft. Interim Assessment Report of the NASA High Speed Research Program, NASA Reference Publication 1333.

Albritton, D., Amanatidis, G., Angeletti, G., Crayston, J., Lister, D., McFarland, M., Miller, J., Ravishankara, A., Sabogal, N., Sundararaman, N. and Wesoky, H. (1997) Global atmospheric effects of aviation. Proceedings of the Symposium, Virginia Beach, Virginia, 15-19 April 1996, NASA CP-3351.

Amanatidis, G. T. and Angeletti, G. (1997) European Commission research on aircraft impacts in the atmosphere. Proceedings of the International Colloquium on Impact of Aircraft Emissions Upon the Atmosphere, Paris, 15-18 October 1996, ONERA, pp. 51-55.

ANAE (1994) Space, aeronautics and atmospheric effects. International Colloquium, Toulouse, 15-17 March 1994, Academie Nationale de l'Air et de l'Espace, Association Aéronautique et Astronautique de France. Cepadues-Ed., 111, rue Nicolas-Vauquelin, 31100 Toulouse, France, pp. 446.

ANCAT (1995) A global inventory of aircraft $\mathrm{NO}_{x}$ emissions - a first version (1994) prepared for the AERONOX research project. In The Impact of $N O_{x}$ Emissions from Aircraft Upon the Atmosphere at Flight Altitudes 8-15 km (AERONOX), ed U. Schumann, pp. 129-194.

Anderson, M. R., Miake-Lye, R. C., Brown, R. C. and Kolb, C. E. (1996) Calculation of exhaust plume structure and emissions of the ER 2 aircraft in the stratosphere. Journal of Geophysical Research 101, 4025-4032.

Appleman, H. (1953) The formation of exhaust condensation trails by jet aircraft. Bulletin of the American Meteorological Society 34, 14-20.

Appenzeller, C., Holton, J. R. and Rosenlof, K. H. (1996) Seasonal variation of mass transport across the tropopause. Journal of Geophysical Research 101, 15,071-15,078.

Arnold, F., Schneider, J., Gollinger, K., Schlager, H., Schulte, P., Whitefield, P. D., Hagen, D. E. and van Velthoven, P. (1997) Observation of upper tropospheric sulfur dioxideand acetone-pollution: potential implications for hydroxyl radical and aerosol formation. Geophysical Research Letters 24, 57-60. 
Arnold, F., Wohlfrom, K.-H., Klemm, M., Schneider, J., Gollinger, K., Schumann, U. and Busen, R. (1996a) Gaseous ion-composition measurements in the young exhaust plume of a jet aircraft at cruising altitudes: implications for aerosols and gaseous sulphuric acid. Proceedings of the International Colloquium Impact of Aircraft Emissions upon the Atmosphere, Paris, 15-18 October 1996, ONERA, pp. 569-574.

Arnold, F., Klemm, M., Schneider, J., Bürger, V., DrosteFranke, B., Kirchner, G., Preissler, B., Jung, A. and Dann, W. (1996b) Trace gas measurments by aircraft based ion molecule reaction mass spectrometry. In Pollution from Aircraft Emissions in the North Atlantic Flight Corridor (POLINAT), ed U. Schumann. Air Pollution Research Report 58, European Commission EUR 16978 EN, ISSN 1018-5593, pp. 48-69.

Arnold, F., Schneider, J., Klemm, M., Scheid, J., Stilp, T., Schlager, H., Schulte, P. and Reinhardt, M. E. (1994) Mass spectrometric measurements of $\mathrm{SO}_{2}$ and reactive nitrogen gases in exhaust of commercial jet airliners at cruise altitude. Report of the DLR Mitt. 94-06, Dtsch. Forsch. für Luft- und Raumfahrt, Köln, pp. 323-328.

Arnold, F., Scheid, J., Stilp, Th., Schlager, H. and Reinhardt, M. E. (1992) Measurements of jet aircraft emissions at cruise altitude I: The odd-nitrogen gases $\mathrm{NO}, \mathrm{NO}_{2}, \mathrm{HNO}_{2}$ and $\mathrm{HNO}_{3}$. Geophysical Research Letters 19, 2421-2424.

BAe/Airbus (1995) World Civil Jet Market Forecast, 1995-2014. Bristol, UK.

Bakan, S., Betancor, M., Gayler, V., Graß1, H. (1994) Contrail frequency over Europe from NOAA-satellite images. Annales Geophysicae 12, 962-968.

Baker, M. B. (1997) Cloud microphysics and climate. Science 276, 1072-1078.

Baughcum, S. L., Chan, D. M., Happenny, S. M., Henderson, S. C., Hertel, P. S., Higman, T., Maggiora, D. R. and Oncina, C. A. (1993) Emissions scenarios development: scheduled 1990 and projected 2015 subsonic, Mach 2. 0 and Mach 2. 4 aircraft. The Atmospheric Effects of Stratospheric Aircraft: A Third Program Report. NASA References Publication 1313, pp. 89-131.

Baughcum, S. L. and Henderson, S. C. (1995) Aircraft emission inventories projected in year 2015 for a high speed civil transport (HSCT) universal airline network. NASA Contractor Report 4659.

Baughcum, S. L., Tritz, T. G., Henderson, S. C. and Pickett, D. C. (1996a) Scheduled civil aircraft emissions inventories for 1992: database development and analysis. NASA Contractor Report 4700.

Baughcum, S. L., Henderson, S. C. and Tritz, T. G. (1996b) Scheduled civil aircraft emissions inventories for 1976 and 1984: database development and analysis. NASA Contractor Report 4722.

Baumgardner, D. and Cooper, W. A. (1994) Airborne measurements in jet contrails: characterisation of the microphysical properties of aircraft wakes and exhausts. Report of the DLR Mitt. 94-06, Dtsch. Forsch. für Luftund Raumfahrt, Köln, pp. 418-423.

Beier, K. and Schreier, F. (1994) Modelling of aircraft exhaust emissions and infrared-spectra for measurements of nitrogen oxide. Annales Geophysicae 12, 920-943.

Bekki, S. (1997) On the possible role of aircraft-generated soot in the middle latitude ozone depletion. Journal of Geophysical Research 102, 10,751-10,758.

Berntsen, T. and Isaksen, I. S. A. (1997) A global 3-D chemical transport model for the troposphere: 1. Model description and $\mathrm{CO}$ and ozone results. Journal of Geophysical Research (in press).

Berntsen, T., Isaksen, I. S. A., Wang, W.-C. and Liang, X.-Z. (1996) Impacts from increased anthropogenic sources in Asia on tropospheric ozone and climate: a global 3-D model study. Tellus 48B, 13-32.

Betancor-Gothe, M. and Graß1, H. (1993) Satellite remote sensing of the optical depth and mean crystal size of thin cirrus and contrails. Theoretical Applied Climatology 48, 101-113.

Blake, D. F. and Kato, K. (1996) Latitudinal distribution of black carbon in the upper troposphere and lower stratosphere. Journal of Geophysical Research 100, 7195-7202.

Bockhorn (ed) (1994) Soot Formation in Combustion-Mechanisms and Models, Springer Series in Chemical Physics, Vol. 59. Springer, Berlin.

Boeing (1997) Current market outlook. World Air Travel Demand and Aeroplane Supply Requirements. Seattle, Washington, DC.

Borrmann, S., Solomon, S., Dye, J. E. and Luo, B. (1996) The potential of cirrus clouds for heterogeneous chlorine activation. Geophysical Research Letters 23, 2133-2136.

Bowman (1992) Control of combustion-generated nitrogen oxide emissions: technology driven by regulation. 24th Symposium (International) Combustion, The Combustion Institute, Pittsburgh.

Brasseur, G. and Solomon, S. (1986) Aeronomy of the Middle Atmosphere, pp. 441. Reidel Publishing Company, Netherlands.

Brasseur, G., Müller, J.-F. and Granier, C. (1996) Atmospheric impact of $\mathrm{NO}_{x}$ emissions by subsonic aircraft: a three-dimensional model study. Journal of Geophysical Research 101, 1423-1428.

Brewer, A. W. (1946) Condensation trails. Weather 1, 34-40.

Brockhagen, D. (1996) Statistische Untersuchungen der Bedingungen für das Auftreten von Kondensstreifen. Schriftlich Hausarbeit, Institut für Theoretische Physik, Universität zu Köln, Germany, 68 pp.

Brost, R. A., Feichter, J. and Heimann, M. (1991) Threedimensional simulation of ${ }^{7} \mathrm{Be}$ in a global climate model. Journal of Geophysical Research 96, 22,423-22,445.

Brown, R. C., Miake-Lye, R. C., Anderson, M. R. and Kolb, C. E. (1997) Aircraft sulphur emissions and the formation of visible contrails. Geophysical Research Letters 24, 385-388.

Brown, R. C., Miake-Lye, R. C., Anderson, M. R., Kolb, C. E. and Resch, T. J. (1996a) Aerosol dynamics in near field aircraft plumes. Journal of Geophysical Research 101, 22,939-22,953.

Brown, R. C., Anderson, M. R., Miake-Lye, R. C., Kolb, C. E., Sorokin, A. A. and Buriko, Y. Y. (1996b) Aircraft exhaust sulphur emissions. Geophysical Research Letters 23, 3603-3606.

Brown, R. C., Miake-Lye, R. C., Anderson, M. R. and Kolb, C. E. (1996c) Effect of aircraft exhaust sulphur emissions on near field plume aerosols. Geophysical Research Letters 23, 3607-3610.

Busen, R. (1995) Flugzeugmessungen zur Entstehung und Auflösung von Kondensstreifen. DLR-Mitt. 95-05, DLR Oberpfaffenhofen, Wessling, Germany, pp. 65.

Busen, R. and Schumann, U. (1995) Visible contrail formation from fuels with different sulphur contents. Geophysical Research Letters 22, 1357-1360.

Busen, R., Baumgardner, D., Borrmann, S., Hagen, D., Kuhn, M., Petzold, A., Schröder, F., Schumann, U., Ström, J. and Whitefield, P. (1996) Experiments on contrail formation from fuels with different sulphur content. Proceedings of the International Colloquium on Impact of Aircraft Emissions upon the Atmosphere, Paris, 15-18 October 1996, ONERA, pp. 149-154.

Carleton, A. M. and Lamb, P. J. (1986) Jet contrails and cirrus cloud: a feasibility study employing high-resolution satellite imagery. Bulletin of the American Meteorological Society 67, 301-309.

Carroll, M. A., Montzka, D. D., Hübler, G., Kelly, K. K. and Gregory, G. L. (1990) In situ measurements of $\mathrm{NO}_{x}$ in the airborne arctic stratospheric expedition. Geophysical Research Letters 17, 493-496.

Chalita, S., Hauglustaine, D. A., Le Treut, H. and Müller, J.-F. (1996) Radiative forcing due to increased tropospheric ozone concentrations. Atmospheric Environment 30, 1641-1646. 
Champagne, D. L. (1971) Standard measurement of aircraft gas turbine engine exhaust smoke. ASME 71-GT-88; Presented at the Gas Turbine Conference \& Products Show. Houston, Texas.

Chang, J., Brost, R., Isaksen, I., Madronich, S., Middleton, P., Stockwell, W. R. and Walcek, C. (1987) A three-dimensional Eulerian acid deposition model: physical concepts and formulation. Journal of Geophysical Research 92, $14,681-14,700$

Charlson, R. J., Schwartz, S. E., Hales, J. M., Cess, R. D., Coakley, Jr. J. A., Hansen, J. E. and Hoffman, D. J. (1992) Climate forcing by anthropogenic aerosols. Science 255, 423-430.

Chen, P. (1995) Isentropic cross-tropopause mass exchange in the extratropics. Journal of Geophysical Research 100, $16,661-16,673$.

CIAP (1975) Climatic Impact Assessment Program. Final Report. U.S. Department of Transportation. DOT-TST$75-51$ to 53 (8 volumes).

Clean Air Act (1970) (i) Part B: Aircraft emission standards. USA Public Law 88-206, 77 Stat 392, 1965 and (ii) Section 231 as amended by Public Law 91-604, 91st Congress HR 17255 .

COMESA (1976) The report of the committee on meteorological effects of stratospheric aircraft. Parts 1 and 2 . Meteorological Office, Bracknell, U.K.

Costen, R. C., Tennille, G. M. and Levine, J. S. (1988) Cloud pumping in a one-dimensional model. Journal of Geophysical Research 93, 15,941-15,954.

Cottington, R. V. (ed.) (1997) Measurement of trace species in the exhaust of aero engines (AEROTRACE). Final Report to the Commission of the European Communities, AERA-CT94-0003 (to be published).

COVOS, Final Report of Comité d'Etudes sur les Conséquences des Vols Stratosphériques.

Crow, S. C. (1970) Stability theory for a pair of travelling vortices. AIAA J. 8, 2172-2179.

Crutzen, P. J., Lelieveld, J. and Brühl, C. (1994) Oxidation processes in the atmosphere and the role of human activities: observations and model results. In Environmental Oxidants, eds J. O. Nriagu and M. S. Simmons, pp. 63-93. Wiley, New York.

Crutzen, P. J. (1971) Ozone production rates in an oxygen, hydrogen, nitrogen-oxide atmosphere. Journal of Geophysical Research 76, 1173-1177.

Cubasch, U., Hasselmann, K., Höck, H., Maier-Reimer, E., Mikolajewicz, U., Santer, B. D. and Sausen, R. (1992) Time-dependent greenhouse warming computations with a coupled ocean-atmosphere model. Climate Dynamics 8, 55-69.

Dameris, M., Grewe, V., Köhler, I., Sausen, R., Brühl, C., Grooss, J.-U. and Steil, B. (1998) Impact of aircraft $\mathrm{NO}_{x}$ emissions on tropospheric and stratospheric ozone. Part II: 3-D model results. Atmospheric Environment 32, in press.

Danilin, M. Y., Ebel, A., Elbern, H. and Petry, H. (1994) Evolution of the concentrations of trace species in an aircraft plume: trajectory study. Journal of Geophysical Research 99, 18,951-18,972.

Danilin, M. Y., Krüger, B. C. and Ebel, A. (1992) Short-term atmospheric effects of high-altitude emissions. Annales Geophysicae 10, 904-911.

DeMott, P. J. (1990) An exploratory study of ice nucleation by soot aerosols. Journal of Applied Meteorology 29, 1072-1079.

Dentener, F. J. and Crutzen, P. J. (1993) Reaction of $\mathrm{N}_{2} \mathrm{O}_{5}$ on tropospheric aerosols: Impact on the global distributions of $\mathrm{NO}_{x}, \mathrm{O}_{3}$ and $\mathrm{OH}$. Journal of Geophysical Research 98, 7149-7163.

Derwent, R. G. (1982) Two-dimensional model studies of the impact of aircraft exhaust emissions on tropospheric ozone. Atmospheric Environment 16, 1997-2007.

Derwent, R. (1994) The estimation of global warming potentials for a range of radiatively active gases. In Non- $\mathrm{CO}_{2}$
Greenhouse Gases: Why and How to Control? eds J. Van Ham et al., pp. 289-299. Kluwer, Dordrecht.

Dessler, A. E., Hintsa, E. J., Weinstock, E. M., Anderson, J. G. and Chan, K. R. (1995) Mechanisms controlling water vapour in the lower stratosphere: a tale of two stratospheres. Journal of Geophysical Research 100, 23,167-23,172.

Deutscher Bundestag (ed) (1994) Mobilität und Klima. Wege $\mathrm{zu}$ einer klimaverträglichen Verkehrspolitik. EnqueteKommission: "Schutz der Erdatmosphäre" des Deutscher Bundestag, Economia Verlag, Bonn, pp. 390.

Dickerson, R. R. et al. (1987) Thunderstorms: an important mechanism in the transport of air pollutants. Science $\mathbf{2 3 5}$, 460-465.

Diehl, K., Mitra, S. K. and Pruppacher, H. R. (1995) A laboratory study of the uptake of $\mathrm{HNO}_{3}$ and $\mathrm{HCl}$ vapour by snow crystals and ice spheres at temperatures between 0 and - 40 degree C. Atmospheric Environment 29, 975-981.

Donaldson, C. P. du and Bilanin, A. J. (1975) Vortex wakes of conventional aircraft. AGARD-AG-204.

Dowling, D. R. and Radke, L. F. (1990) A summary of physical properties of cirrus clouds. Journal of Applied Meteorology 29, 970-978.

Drummond, J., Ehhalt, D. H. and Volz, A. (1988) Measurements of nitric oxide between $0-12 \mathrm{~km}$ altitude and $67 \mathrm{deg}$ $\mathrm{N}$ and 60 deg S latitude obtained during STRATOZ III. Journal of Geophysical Research 93, 15831-15849.

DTI (1996) Analysis of IATA, ICAO and IEA/OECD traffic and fuel data. Personal communication, October 1996.

Dürbeck, T. and Gerz, T. (1995) Large-eddy simulation of aircraft exhaust plumes in the free atmosphere: effective diffusivities and cross-sections. Geophysical Research Letters 22, 3203-3206.

Dürbeck, T. and Gerz, T. (1996) Dispersion of aircraft exhausts in the free atmosphere. Journal of Geophysical Research 101, 26,007-26,015.

Ebel, A., Elbern, H., Hendricks, J. and Meyer, R. (1996) Stratosphere-troposphere exchange and its impact on the structure of the lower stratosphere. Journal of Geomagnetism and Geoelectricity 48, 135-144.

Ehhalt, D. H., Rohrer, F. and Wahner, A. (1992) Sources and distribution of $\mathrm{NO}_{x}$ in the upper troposphere at northern mid-latitudes. Journal of Geophysical Research 97, 3725-3738.

Ehhalt, D. H. and Rohrer, F. (1995) The impact of commercial aircraft on tropospheric ozone. In The Chemistry of the Atmosphere - Oxidants \& Oxidation in the Earth's Atmosphere. 7th BOC Priestley Conference, ed A. R. Bandy, Lewisburg, Pennsylvania, 1994. The Royal Society of Chemistry, Special Publication No. 170, pp. 105-120.

Emmons, L. K., Carroll, M. A., Hauglustaine, D. A., Brasseur, G. P., Atherton, C., Penner, J., Sillman, S., Levy, I. H., Rohrer, F., Wauben, W. M. F., van Velthoven, P. F. J., Wang, Y., Jacob, D., Bakwin, D., Dickerson, R., Doddridge, B., Gerbig, C., Honrath, R., Hübler, G., Jaffe, D., Kondo, Y., Munger, J. W., Torres, A. and Volz-Thomas, A. (1997) Climatologies of $\mathrm{NO}_{x}$ and $\mathrm{NO}_{y}$ : A comparison of data and models. Atmospheric Environment 31, 1851-1904.

Fahey, D. W., Keim, E. R., Woodbridge, E. L., Gao, R. S., Boering, K. A., Daube, B. C., Wofsy, S. C., Lohmann, R. P., Hintsa, E. J., Dessler, A. E., Webster, C. R., May, R. D., Brock, C. A., Wilson, J. C., Miake-Lye, R. C., Brown, R. C., Rodriquez, J. M., Loewenstein, M, Profitt, M. H., Stimpfle, R. M., Bowen, S. W. and Chan, K. R. (1995a) In situ observations in aircraft exhaust plumes in the lower stratosphere at midlatitudes. Journal of Geophysical Research 100, 3065-3074.

Fahey, D. W., Keim, E. R., Boering, K. A., Brock, C. A., Wilson, J. C., Johnston, H. H., Anthony, S., Hanisco, T. F., Wennberg, P. O. Miake-Lye, R. C., Salawitch, R. J., Louisnard, N., Woodbridge, E. L., Gao, R. S., Donnelly, S. G., Wamsley, R. C., Del Megro, L. A., Solomon, S., Daube, B. C., Wofsy, S. C., Webster, C. R., May, R. D., 
Kelly, K. K., Loewenstein, M., Podolske, J. R. and Chan, K. R. (1995b) Emission measurements of the Concorde supersonic aircraft in the lower stratosphere. Science $\mathbf{2 7 0}$, $70-74$.

Farago, Z. (1991) Fuel sulphur content, sulphur-oxide emissions and corrosion in oil heating plants. Combustion Science Technology 79, 73-96.

Feichter, J., Brost, R. A. and Heimann, M. (1991) Threedimensional modeling of the concentration and deposition of ${ }^{210} \mathrm{~Pb}$ aerosols. Journal of Geophysical Research 96, $22,447-22,460$

Flatøy, F. and Hov, Ø. (1996) Three-dimensional model studies of the effect of $\mathrm{NO}_{x}$ emissions from aircraft on ozone in the upper troposphere over Europe and the North Atlantic. Journal of Geophysical Research 101, 1401-1422.

Forster, P. M. and Shine, K. P. (1997) Radiative forcing and temperature trends from stratospheric ozone changes. Journal of Geophysical Research 102, 841-855.

Forster, P. M., Johnson, C. E., Law, K. S., Pyle, J. A. and Shine, K. P. (1996) Further estimates of radiative forcing due to tropospheric ozone. Geophysical Research Letters 23, 3321-3324.

Fortuin, J. P. F., van Dorland, R., Wauben, W. M. F. and Kelder, H. (1995) Greenhouse effects of aircraft emissions as calculated by a radiative transfer model. Annales Geophysicae 13, 413-418.

Franzkowiak, V., Petry, H. and Ebel, A. (1996) On the influence of temporal and spatial resolution of aircraft emission inventories for mesoscale modelling of pollutant dispersion. Proceedings of the International Colloquium on Impact of Aircraft Emissions upon the Atmosphere, Paris, 15-18 October 1996, ONERA, pp. 551-556.

Frenzel, A. and Arnold, F. (1994) Sulphuric acid cluster ion formation by jet engines: implications for sulphuric acid formation and nucleation. Report of the DLR-Mitt. 94-06, Dtsch. Forsch. für Luft- und Raumfahrt, Köln, pp. 106-112.

Freudenthaler, V., Homburg, F. and Jäger, H. (1995) Contrail observations by ground-based scanning lidar: crosssectional growth. Geophysical Research Letters 22, 3501-3504.

Freudenthaler, V., Homburg, F. and Jäger, H. (1996) Optical parameters of contrails from lidar measurements: linear depolarisation. Geophysical Research Letters 23, 3715-3718.

Fritts, D. C. and Nastrom, G. D. (1992) Sources of mesoscale variability of gravity waves. Part II. Frontal, convective, and jet stream excitation. Journal of Atmospheric Sciences 49, 111-127.

Fuglestvedt, J. S., Berntsen, T. K. and Isaksen, I. S. A. (1993) Response in tropospheric $\mathrm{O}_{3}, \mathrm{OH}$ and $\mathrm{CH}_{4}$ to changed emission of important trace gases. Centre for Climate and Energy Research Oslo (CICERO), Report 4.

Fuglestvedt, J. S., Jonson, J. E. and Isaksen, I. S. A. (1994) Effects of reductions in stratospheric ozone on tropospheric chemistry through changes in photolysis rates. Tellus 46, 172-192.

Fuglestvedt, J. S., Isaksen, I. S. A. and Wang, W.-C. (1996) Estimates of indirect global warming potentials for $\mathrm{CH}_{4}$, $\mathrm{CO}$ and $\mathrm{NO}_{x}$. Climate Change 34, 405-437.

Galinas, R. J. and Walton, J. J. (1974) Dynamic-kinetic evolution of a single plume of interacting species. Journal of Atmospheric Sciences 31, 1807-1813.

Gardner, R. M., Adams, K., Cook, T., Deideweg, F., Ernedahl, S., Falk, R., Fleuti, E., Herms, E., Johnson, C., Lecht, M., Lee, D., Leech, M., Lister, D., Masse, B., Metcalfe, M., Newton, P., Schmitt, A., Vandenbergh, C. and van Drimmelen, R. (1997a) The ANCAT/EC global inventory of $\mathrm{NO}_{x}$ emissions from aircraft. Atmospheric Environment 31, 1751-1766.

Gardner, R. M. (ed.) (1997b) ANCAT/EC2 aircraft emission inventories for 1991/1992 and 2015. Report of the Second Version. (submitted).
Gardner, R. M., Adams, J. K., Cook, T., Falk, R. S., Fleuti, E., Forsch, W., Larson, L.-C., Lecht, M., Lee, D. S., Leech, M., Lister, D. H., Masse, B., Morris, K., Newton, P. J., ten Have, H., Schmitt, A., Vandenburgh, C. (1995) A global inventory of aircraft $\mathrm{NO}_{x}$ emissions. In The Impact of $\mathrm{NO}_{x}$ Emissions from Aircraft upon the Atmosphere at Flight Altitudes 8-15 km, ed U. Schumann, pp. 129-194.

Garnier, F., Baudoin, C., Woods, P. and Louisnard, N. (1997) Engine emission alteration in the near field of an aircraft. Atmospheric Environment 31, 1767-1781.

Gathen, P. von der, et al. (1995) Observational evidence for chemical ozone depletion over the Arctic in winter 1991-1992. Nature 375, 131-134.

Gayet, J.-F., Febvre, G., Brogniez, G., Chepfer, H., Renger, W. and Wendling, P. (1996) Microphysical and optical properties of cirrus and contrails: cloud field study on 13 October 1989. Journal of Atmospheric Sciences 53, $126-138$.

Gerz, G. and Ehret, T. (1997) Wingtip vortices and exhaust jets during the jet regime of aircraft wakes. Aerospace Science and Technology (in press).

Gerz, T. and Palma, J. (1994) Influence of atmospheric turbulence on the development of an idealised aeroplane wake: numerical studies. DLR-Mitt. 94-06, Dtsch. Forsch. für Luft- und Raumfahrt, Köln, Germany, pp. 309-314.

Gerz, T. and Ehret, T. (1996) Wake dynamics and exhaust distribution behind cruising aircraft. The Characterisation and Modification of Wakes from Lifting Vehicles in Fluids. AGARD Conference Proceedings CP-584, 20-23 May Trondheim, Norway, pp. 35.1-35.12.

Gierens, K. (1996) Numerical simulations of persistent contrails. Journal of Atmospheric Sciences 53, 3333-3348.

Gierens, K. and Schumann, U. (1996) Colours of contrails from fuels with different sulphur contents. Journal of Geophysical Research 101, 16,731-16,736.

Girling, S. P., Hurley, C. D., Mitchell, J. P. and Nichols, A. L. (1990) Development and characterisation of a smoke generator for the calibration of aerosol emissions from gas turbine engines. Aerosol Science and Technology 13, 8-19.

Graf, H. F., Kirchner, I., Sausen, R. and Schubert, S. (1992) The impact of upper tropospheric aerosol on the global circulation. Annales Geophysicae 10, 698-707.

Granier, C., Hao, W.-M., Brasseur, G. and Müller, J.-F. (1996) Land use practices and biomass burning: Impact on the chemical composition of the atmosphere. In Proceedings of the Chapman Conference on Biomass Burning and Global Change, ed J. Levine, (accepted for publication).

Grant, L. O. and Corrin, M. L. (1973) Raw and iodine treated automobile exhaust as a source of ice nuclei. Journal of Weather Modification 5, 238-248.

Grewe, V., Dameris, M., Sausen, R. and Steil, B. (1998) The impact of stratospheric dynamics and chemistry on northern hemisphere mid-latitude ozone loss. Journal of Geophysical Research (submitted).

Grooss, J.-U., Brühl, C. and Peter, T. (1998) Impact of aircraft emissions on tropospheric and stratospheric ozone. Part I: Chemistry and 2-D model results. Atmospheric Environment 32, in press.

Gultepe, I. and Starr, D. O. (1995) Dynamical structure and turbulence in cirrus clouds: aircraft observations during FIRE. Journal of Atmospheric Sciences 52, 4159-4182.

Hadaller, O. J. and Momenthy, A. M. (1989) The characteristics of future fuels. Boeing Publication D6-54940, Seattle, Washington, DC.

Hagen, D. E., Whitefield, P. D. and Schlager, H. (1996) Particulate emissions in the exhaust plume from commercial jet aircraft under cruise conditions. Journal of Geophysical Research 101, 19,551-19,557.

Hagen, D. E., Trueblood, M. B. and Whitefield, P. D. (1992) A field sampling of jet exhaust aerosols. Particulate Science and Technology 10, 53-63. 
Hagen, D. E., Whitefield, P. D., Hopkins, A. R., Paldino, J. D. and Trueblood, M. B. (1996) Aerosol sampling measurements (including $\mathrm{CO}_{2}$ diagnostic test. Appendix E. (in Howard RP).

Hallett, J., Hudson, J. G. and Rogers, C. F. (1990) Characterisation of combustion aerosols for haze and cloud formation. Aerosol Science and Technology 10, 70-83.

Hanisco, T. F. et al. (1997) The role of $\mathrm{HO}_{x}$ in super- and subsonic aircraft exhaust plumes. Geophysical Research Letters 24, 65-68.

Hansen, J., Sato, M. and Ruedy, R. (1997) Radiative forcing and climate response. Journal of Geophysical Research 102, 6831-6864.

Hanson, D. and Mauersberger, K. (1988) Laboratory studies of nitric acid trihydrate: implications for the south polar stratosphere. Geophysical Research Letters 15, $855-858$.

Harris, B. W. (1990) Conversion of sulphur dioxide to sulphur trioxide in gas turbine exhaust. Journal of Engineering for Gas Turbine Power 112, 585-589.

Haschberger, P. and Lindermeir, E. (1996) Spectrometric inflight measurement of aircraft exhaust emissions: first results of the June 1995 campaign. Journal of Geophysical Research 101, 25,995-26,006.

Hasselmann, K., Hasselmann, S., Giering, R., Ocana, V. and von Storch, H. (1997) Sensitivity study of optimal $\mathrm{CO}_{2}$ emission paths using a simplified structural integrated assessment model (SIAM). Climatic Change 37, 345-386.

Hasselmann, K., Sausen, R., Maier-Reimer, E. and Voss, R. (1993) On the cold start problem in transient simulations with coupled atmosphere-ocean models. Climate Dynamics 9, 53-61.

Hauglustaine, D. A., Granier, C., Brasseur, G. P. and Mégie, G. (1994a) Impact of present aircraft emissions of nitrogen oxides on tropospheric ozone and climate forcing. Geophysical Research Letters 21, 2031-2034.

Hauglustaine, D. A., Granier, C., Brasseur, G. P. and Mégie, G. (1994b) The importance of atmospheric chemistry in the calculation of radiative forcing on the climate system. Journal of Geophysical Research 99, 1173-1186.

Hauglustaine, D. A. and Granier, C. (1995) Radiative forcing by tropospheric ozone changes due to increased emissions of $\mathrm{CH}_{4}, \mathrm{CO}$, and $\mathrm{NO}_{x}$. In Atmospheric Ozone as a Climate Gas: General Circulation Model Simulations. eds W.-C. Wang and I. S. A. Isaksen, pp. 189-204. Springer, Berlin.

Hauglustaine, D. A., Ridley, B. A., Solomon, S., Hess, P. G. and Madronich, S. (1996) $\mathrm{HNO}_{3} / \mathrm{NO}_{x}$ ratio in the remote troposphere during MLOPEX 2: evidence for nitric acid reduction on carbonaceous aerosols? Geophysical Research Letters 23, 2609-2612.

Haynes, B. S. and Wagner, H. G. (1981) Soot formation. Progress in Energy Combustion Science 7, 229-273.

Heimann, M. (1995) The global atmospheric tracer model TM2: DKRZ TM2 model documentation. Max-Planck-Institut fuer Meteorologie, Hamburg, Technical Report No. 10.

Heimann, M. and Feichter, J. (1990) A comparison of threedimensional atmospheric transport models by means of simulations of ${ }^{222} \mathrm{Rn}$. Large-Scale Atmospheric Modelling Report No. 8, Meteorologisches Institut der Universität Hamburg, Germany, 29 pp.

Held, M. (ed.) (1990) Ökologische folgen des Fluguerkhrs Tutzinger Materialie No. 66, Ev. Akad. Tutzing, Postfach 227, 82327 Tutzing, ISSN 0930-7850, pp. 59.

Heymsfield, A. J. and Sabin, R. M. (1989) Cirrus crystal nucleation by homogeneous freezing of solution droplets. Journal of Atmospheric Sciences 46, 2252-2264.

Hidalgo, H. and Crutzen, P. J. (1977) The tropospheric and stratospheric composition perturbed by $\mathrm{NO}_{x}$ emissions of high altitude aircraft. Journal of Geophysical Research 82, 5833-5866.

High-Speed Research Program/Atmospheric Effects of Stratospehric Aircraft (1993) The atmospheric effects of stratospheric aircraft: a third program report, eds
R. Stolarski and H. Wesosky, NASA Reference Publication 1313, 413 pp.

Hofmann, D. J. and Rosen, J. M. (1978) Balloon observations of a particle layer injected by a stratospheric aircraft at $23 \mathrm{~km}$. Geophysical Research Letters 5, 511-514.

Hoinka, K. P., Reinhardt, M. E. and Metz, W. (1993) North Atlantic air traffic within the lower stratosphere: cruising times and corresponding emissions. Journal of Geophysical Research 98, 23,113-23,131.

Holton, J. R., Haynes, P. H., McIntyre, M. E., Douglas, A. R., Rood, R. B. and Pfister, L. (1995) Stratosphere-troposphere exchange. Review of Geophysics 33, 403-439.

Hough, A. M. (1991) Development of a two-dimensional global tropospheric model: Model chemistry. Journal of Geophysical Research 96, 7325-7362.

Howard, R. P. (ed) (1996) Experimental characterisation of gas turbine emissions at simulated flight altitude conditions. U. S. Air Force, AEDC-TR-96-3.

Hunter, S. C. (1982) Formation of $\mathrm{SO}_{3}$ in gas turbines. Journal of Engineering Power 104, 44-51.

Hurley, C. D. (1996) Measurement of particulates from an engine combustor. In Impact of Aircraft Emissions Upon the Atmosphere, Proceedings of the International Colloquium on the Impact of Aircraft Emissions on the Atmosphere, Paris, 15-18 October 1996, ONERA.

Hurley, C. D. (1993) Smoke measurements inside a gas turbine combustor. AIAA Paper 93-2070. Presented at the 29th Joint Propulsion Conference, Monterey, CA, U.S.A., 28-30, June.

IATA (1993) World air transport statistics.

ICAO (1981) Annex 16, Vol. II, Environmental Protection: Aircraft Engine Emissions, 1st Edn, Montreal.

ICAO (1993a) Annex 16, Vol. II, Environmental Protection: Aircraft Engine Emissions, 2nd Edition, Montreal.

ICAO (1993b) Civil aviation statistics of the world. ICAO Statistics Year Book, Doc series 9180, Montreal.

ICAO (1995a) CAEP/Working Group 3 Meeting, Bonn, Germany 1995: Combined Report of the Certification \& Technology Subgroups, Working Paper 2, Montreal.

ICAO (1995b) Aircraft engine exhaust emissions databank, (i) 1st Edn, Doc 9646-AN/943, 1995 and (ii) Addendum 1; CAEP/3 - IP/13, Montreal.

ICAO (1995c), Committee on aviation environmental protection. Report of the Third Meeting; DOC 9675, CAEP/3, Montreal.

ICAO (1995d), CAEP/Working group 3 meeting, Bonn, Germany 1995. Report of the Emissions Inventory Subgroup, Working Paper 3, 1995, Montreal.

IEA (1993) International Energy Agency, Oil and gas information. Annual.

IPCC (1992) Radiative forcing of climate, in climate change 1992. The Supplementary Report to the IPCC Scientific Assessment, Cambridge University Press.

IPCC (1995) Climate Change 1994: Radiative Forcing of Climate and an Evaluation of the IPCC IS92 Emission Scenarios, eds J. T. Houghton, L. G. Meira Filho, J. Bruce, H. Lee, B. A. Callander, E. F. Haites, N. Harris and K. Maskell. Cambridge University, Cambridge, U.K.

IPCC (1996) Climate Change, 1995: The Science of Climate Change, eds J. T. Houghton, L. G. Meira, Filho, B. A. Callander, N. Harris, A. Kattenberg and K. Maskell. Cambridge University Press, Cambridge, U.K.

Isaksen I. S. A. (ed) (1988) Tropospheric Ozone. Regional and Global Scale Interactions, NATO ASI Series. Reidel, Dordrecht.

Isaksen, I. S. A. (1980) The tropospheric ozone budget and possible man-made effects. In Proceedings of the Quadrennial Ozone Symposium, WMO, Boulder, 4-9 July.

Isaksen, I. S. A. (1981) Tropospheric ozone budget and possible man made effects. In Quadrennial International Ozone Symposium, VII, ed J. London, pp. 845-852. IAMAP, NCAR, Boulder, CO. 
Jackman, C. H., Fleming, E. L., Chandra, S., Considine, D. B. and Rosenfield, J. E. (1996) Past, present, and future ozone trends with comparisons to observed trends. Journal of Geophysical Research 110, 28,753-28,767.

Jaffe, D., Berntsen, T. and Isaksen, I. S. A. (1997) A global 3-D chemical transport model: 2. Nitrogen oxides, and non-methane hydrocarbons. Journal of Geophysical Research (in press).

Jenkins, G. (1996) Aviation fuels business, world-wide. Sunningdale Publications U. K., ISBN 1872546110.

Johnson, C. (1994) Global warming from aircraft $\mathrm{NO}_{x}$ emissions. In Impact of Emissions from Aircraft and Spacecraft upon the Atmosphere, eds U. Schumann and D. Wurzel, Köln, pp. 223-228.

Johnson, C. E., Henshaw, J. and McInnes, G. (1992) Impact of aircraft and surface emissions of nitrogen oxides on tropospheric ozone and global warming. Nature 355, 69-71.

Johnson, C. and Derwent, R. G. (1996) Relative radiative forcing consequences of global emissions of hydrocarbons, carbon monoxide and $\mathrm{NO}_{x}$ from human activities estimated with a zonally averaged two-dimensional model. Climate Change 34, 439-462.

Johnston, H. S. (1971) Reduction of stratospheric ozone by nitrogen oxides catalysts from supersonic transport exhaust. Science 173, 517-522.

Kärcher, B. (1997) On the potential importance of sulphurinduced activation of soot particles in nascent jet aircraft exhaust plumes. Atmospheric Research (in press).

Kärcher, B. (1996) Aircraft-generated aerosols and visible contrails. Geophysical Research Letters 23, 1933-1936.

Kärcher, B. (1995) A trajectory box model for aircraft exhaust plumes. Journal of Geophysical Research 100, 18,835-18,844.

Kärcher, B. (1994) Transport of exhaust products in the near trail of a jet engine under atmospheric conditions. Journal of Geophysical Research 99, 14,509-14,517.

Kärcher, B. and Peter, T. (1995) Impact of aircraft emissions on stratospheric ozone: a research strategy. Physical Chemical Earth 20, 123-131.

Kärcher, B., Peter, T. and Ottmann, R. (1995) Contrail formation: Homogeneous nucleation of $\mathrm{H}_{2} \mathrm{SO}_{4} / \mathrm{H}_{2} \mathrm{O}$ droplets. Geophysical Research Letters 22, 1501-1504.

Kärcher, B., Hirschberg, M. M. and Fabian, P. (1996a) Small-scale chemical evolution of aircraft exhaust species at cruising altitudes. Journal of Geophysical Research 101, 15,169-15,190.

Kärcher, B., Peter, Th., Biermann, U. M. and Schumann, U. (1996b) The initial composition of jet condensation trails. Journal of Atmospheric Science 53, 3066-3083.

Kärcher, B. and Fahey, D. W. (1997) The role of sulphur emission in volatile particle formation in jet aircraft exhaust plumes. Geophysical Research Letters 24, 389-392.

Karol, I. L. and Ozolin, Y. E. (1994) Small- and mediumscale effects of high-flying aircraft exhausts in the atmospheric composition. Annales Geophysicae 12, 979-985.

Kasibhatla, P. S. (1993) $\mathrm{NO}_{\mathrm{y}}$ from subsonic aircraft emissions: A global 3-dimensional study. Geophysical Research Letters 21, 1707-1710.

Katzman, H. and Libby, W. F. (1975) Hydrocarbon emissions from jet engines operated at simulated high-altitude supersonic flight conditions. Atmospheric Environment 9, 839-842.

Keim, E. R. et al. (1996) Observations of large reductions in the $\mathrm{NO} / \mathrm{NO}_{\mathrm{y}}$ ratio near the mid-latitude tropopause and the role of heterogeneous chemistry. Geophysical Research Letters 23, 3223-3226.

Klemm, O., Schlager, H., Slemr, F., Stockwell, W. R. and Ziereis, H. (1996) Messung der Verteilung flugzeugbedingter Spurengase in der oberen Troposphäre Atmosphärische Umweltforschung, Garmisch-Partenkirchen, Germany.

Knollengerg, R. G. (1972) Measurements of the growth of the ice budget in a persisting contrail. Journal of Atmospheric Science 29, 1367-1374.
Köhler, I., Sausen, R. and Reinberger, R. (1997) On the contribution of aircraft emission to the atmospheric $\mathrm{NO}_{x}$ content. Atmospheric Environment 31, 1801-1808.

Komhyr, W. D., Oltmans, S. J., Franchois, P. R., Evans, W. F. J. and Matthews, W. A. (1989) The latitudinal distribution of ozone to $35 \mathrm{~km}$ altitude from ECC ozonesonde observations, 1985-1987. In Ozone in the Atmosphere, eds R. D. Bojkov and P. Fabian, pp. 147-150. A. Deepak, Hampton, Virginia.

Kraus, A. B., Rohrer, F., Grobler, E. S. and Ehhalt, D. H. (1996) The global tropospheric distribution of $\mathrm{NO}_{x}$ estimated by a three-dimensional chemical tracer model. Journal of Geophysical Research 101, 18,587-18,604.

Kuo, K. K. (1986) Principles of Combustion. Wiley, New York.

Lacis, A. A., Wuebbles, D. J. and Logan, J. A. (1990) Radiative forcing of climate by changes in the vertical distribution of ozone. Journal of Geophysical Research 95, 9971-9981.

Lamarque, J.-F. and Hess, P. G. (1994) Cross-tropopause mass exchange and potential vorticity budget in a simulated tropopause folding. Journal of Atmospheric Science 51, 2246-2269.

Lamarque, J.-F., Brasseur, G. P. and Hess, P. G. (1996) Three-dimensional study of the relative contributions of the different nitrogen sources in the troposphere. Journal of Geophysical Research 101, 22,955-22,968.

Langner, J. and Rodhe, H. (1991) A global three-dimensional model of the tropospheric sulphur cycle. Journal of Atmospheric Chemistry 13, 225-263.

Lary, D. J., Lee, A. M., Toumi, R., Newchurch, M., Pirre, M. and Renard, J. B. (1997) Carbon aerosols and atmospheric photochemistry. Journal of Geophysical Research 102, 3671-3682.

Lawrence, M. G., Chameides, W. L., Kasibhatla, P. S., Levy, H. and Moxim, W. (1995) Lightning and atmospheric chemistry: The rate of atmospheric NO production. In Handbook of Atmospheric Electrodynamics, ed H. Volland, Vol. 1. CRC Press, Boca Raton, Florida.

Lazano, E. R., Melvin, W. W. and Hochheiser, S. (1968) Air pollution emissions from jet engines. Journal of Air Pollution Control Association 18, 392-394.

Lee, D. S., Köhler, I., Grobler, E., Rohrer, F., Sausen, R., Gallardo-Klenner, L., Olivier, J. G. J., Dentener, F. J. and Bouwman, A. F. (1997) Estimations of global $\mathrm{NO}_{x}$ emissions and their uncertainties. Atmospheric Environment 31, 1735-1749.

Lelieveld, J. and Crutzen, P. J. (1994) Role of deep cloud convection in the ozone budget of the troposphere. Science 264, 1759-1761.

Lelieveld, J., Arnold, F., Bregman, B., Bürger, V., Crutzen, P., Fischer, H., Waibel, A., Siegmund, P. and Van Velthoven, P. (1997) Chemical perturbation of the lowermost stratosphere through exchange with the troposphere. Geophysical Research Letters 24, 603-606.

Lelieveld, J. and van Dorland, R. (1995) Ozone chemistry in the troposphere and consequent radiative forcing of climate. In Atmospheric Ozone as a Climate Gas: General Circulation Model Simulations, eds W.-C. Wang and I. S. A. Isaksen, pp. 373-396. Springer, Berlin.

Lewellen, D. C. and Lewellen, W. S. (1996) Large-eddy simulation of the vortex pair break-up in aircraft wakes. $A I A A$ J. 34, 2337-2345.

Lilenfeld, H. V., Whitefield, P. D. and Hagen, D. E. (1996) Soot emissions from jet aircraft. ICAS-96-4. 1. 3. Proceedings of the 20th Congress of the International Council of the Aeronautical Sciences, 8-13 September, Sorrento, Italy.

Lister, D. H., Ayeh, E., Baudoin, C., Burbank, J., Deidewig, F., Falk, R. S., Kapernaum, M., Kleffmann, J., Kluge, V., Kurtenbach, R., Lecht, M., Metcalfe, M., Sami, A., Wahl, C., Wiesen, P. and Zazarlis, N. (1995) Sub-project 1: engine exhaust emissions. In The Impact of $N O_{x}$ Emissions from Aircraft upon the Atmosphere at Flight Altitudes 8-15 km (AERONOX), ed U. Schumann, pp. 33-127. 
Liu, S. C., Kley, D., McFarland, M., Mahlman, J. D. and Levy, H. (1980) On the origin of tropospheric ozone. Journal of Geophysical Research 85, 7546-7552.

Liu, S. C., McAffee, J. R. and Cicerone, R. (1984) Radon 222 and tropospheric vertical transport. Journal of Geophysical Research 89, 7291-7297.

Liu, S. C., Trainer, M., Fehsenfeld, F. C., Parrish, D. D., Williams, E. J., Fahey, D. W., Hübler, G. and Murphy, P. C. (1987) Ozone production in the rural troposphere and the implications for regional and global ozone production. Journal of Geophysical Research 92, 4191-4207.

Lohmann, U. and Roeckner, E. (1995) The influence of cirrus cloud-radiative forcing on climate and climate sensitivity in a general circulation model. Journal of Geophysical Research 100, 16,305-16,323.

Louisnard, N., Baudoin, C., Billet, G., Garnier, F., Hills, D., Mentel, T., Mirabel, P., Petit, J. C., Schultz, L., Taleb, D., Thlibi, J., Wahner, A. and Woods, P. (1995) Physics and chemistry in the aircraft wake. In AERONOX-The Impact of $\mathrm{NO}_{x}$ Emissons from Aircraft upon the Atmosphere at Flight Altitudes 8-15 km, ed U. Schumann, pp. 195-309. European Commission and DLR, EUR 16206 EN.

Luther, F. M., Chang, J. S., Duewer, W. M., Penner, J. E., Tarp, R. L. and Wuebbles, D. J. (1979) Potential environmental effects of aircraft emissions. UCRL-52861. Lawrence Livermore Laboratory. University of California, Livermore, California.

Madronich, S. and Granier, C. (1992) Impact of recent total ozone changes on tropospheric ozone photodissociation, hydroxyl radical and methane trends. Geophysical Research Letters 19, 465-467.

Mahlman, J. D. (1997) Dynamics of transport processes in the upper troposphere. Science 276, 1079-1083.

Mannstein, J. (1996) Contrail observations from space using NOAA-AVHRR data. Proceedings of the International Colloquium on Impact of Aircraft Emissions Upon the Atmosphere, Paris, 15-18 October 1996, ONERA, pp. 427-431.

McGraw, R. (1995) Two-dimensional kinetics of binary nucleation in sulphuric acid-water mixtures. Journal of Chemical Physics 102, 2098-2108.

McInnes, G. and Walker, C. T. (1992) The global distribution of aircraft pollution emissions. Warren Spring Lab., Report No. LR 872 (AP).

Meijer, E. W., Beck, J. P. and Velders, G. J. M. (1996) Modelling gas-phase and heterogeneous conversions of nitrogen oxides in the exhaust plume of an aircraft. RIVM Report No. 72201 010, pp. 79.

Metwally, M. (1995) Jet aircraft engine emissions database development. 1992 military, charter and non-scheduled traffic. NASA Contractor Report 4686.

Miake-Lye, R. C., Martinez-Sanchez, M., Brown, R. C. and Kolb, C. E. (1993) Plume and wake dynamics, mixing, and chemistry behind a high speed civil transport aircraft. Journal of Aircraft 30, 467-479.

Michaelis, L. (1993) Global warming impacts of transport. The Science of the Total Environment 134, 117-124.

Mirabel, P. and Katz, J. L. (1974) Binary homogeneous nucleation as a mechanism for the formation of aerosols. Journal of Chemical Physics 60, 1138-1144.

Mohnen, V. A., Goldstein, W. and Wang, W.-C. (1993) Tropospheric ozone and climate change. Air and Waste 43, 1332-1344.

Molnar, G. I., Ko, M. K. W., Zhou, S., Sze, N. D. (1994) Climatic consequence of observed ozone loss in the 1980s: Relevance to the greenhouse problem. Journal of Geophysical Research 99, 25,755-25,760.

Möllhoff, M., Hendricks, J., Lippert, E., Petry, H. and Sausen, R. (1996) Model analysis of the chemical conversion of exhaust species in the expanding plumes of subsonic aircraft. Proceedings of the International Colloquium on Impact of Aircraft Emissions upon the Atmosphere, Paris, 15-18 October 1996, ONERA, pp. 521-526.
Moxim, W. J., Levy, H. II, and Kasibhatla, P. S. (1996) Simulated global tropospheric PAN: its transport and impact on $\mathrm{NO}_{x}$. Journal of Geophysical Research 101, $12,621-12,638$.

Müller, J.-F. (1992) Geographical distribution and seasonal variation of surface sources and deposition velocities of atmospheric trace gases. Journal of Geophysical Research 97, 3787-3804.

Müller, J.-F. and Brasseur, G. (1995) IMAGES: A threedimensional chemical transport model of the global troposphere. Journal of Geophysical Research 100, 16,445-16,490.

NASA (1995) Scientific assessment of the atmospheric effects of stratospheric aircraft. NASA Reference Publication 1381, November 1995.

National Research Council (1994) Atmospheric effects of stratospheric aircraft-an evaluation of NASA's Interim Assessment, National Academy Press, Washington, DC.

Oltmans, S. J. and Levy, H. II (1994) Surface ozone measurements from a global network. Atmospheric Environment 28, 9-24.

Oltmans, S. J., Komhyr, W. D., Frnchois, P. R. and Matthew, W. A. (1989) Tropospheric ozone: Variations from surface and ECC ozonesonde observations. In Ozone in the Atmosphere eds R. D. Bojkov and P. Fabian, pp. 539-543. A. Deepak, Hampton, Virginia.

Ovarlez, J., Overlez, H., Philippe, R.-M. and Landais, E. (1996) Water vapour measurements during the POLINAT campaign. In Pollution from Aircraft Emissions in the North Atlantic Flight Corridor (POLINAT), ed U. Schumann, pp. 70-81. Air Pollution Research Report 58, European Commission EUR 16978 EN,ISSN 1018-5593.

Paladino, J. D. (1997) The efficiency of the smoke meter at characterising engine emissions. NASA Contractor Report 202317.

Parungo, F., Kopcewicz, B., Nagamoto, C., Schnell, R., Sheridan, P., Zhu, C. and Harris, J. (1992) Aerosol particles in the Kuwait oil fire plumes: their morphology, size distribution, chemical composition, transport, and potential effect on climate. Journal of Geophysical Research 97, $15,867-15,882$.

Penkett, S. A., Jones, B. M. R., Brice, K. A. and Eggleton, A. E. J. (1979) The importance of atmospheric ozone and hydrogen peroxide in oxidising sulphur dioxide in cloud and rain water. Atmospheric Environment 13, 323-337.

Pepper, W. et al. (1992) Emission scenarios for the IPCC: an update - assumptions, methodologies and results. Prepared for the IPCC, Working Group 1.

Peter, T., Brühl, C. and Crutzen, P. J. (1991) Increase in the PSC-formation probability caused by high-flying aircraft. Geophysical Research Letters 18, 1465-1468.

Petzold, A. and Schröder, F. (1998) Jet engine exhaust aerosol characterisation. Aerosol Science and Technology 28, 62-76.

Petzold, A., Busen, R., Schröder, F. P., Baumann, R., Kuhn, M., Ström, J., Hagen, D. E., Whitefield, P., Baumgardner, D., Arnold, F., Borrmann, S. and Schumann, U. (1997) Near field measurements on contrail properties from fuels with different sulfur content. Journal of Geophysical Research 102, 29,867-29,881.

Pham, M., Müller, J.-F., Brasseur, G., Granier, C. and Mégie, G. (1995) A three-dimensional study of the tropospheric sulfur cycle. Journal Geophysical Research 100, 26,061-26,092.

Pham, M., Müller, J.-F., Brasseur, G., Granier, C. and Mégie, G. (1996) A 3D model study of the global sulphur cycle: contributions of anthropogenic and biogenic sources. Atmospheric Environment 30, 1815-1822.

Pickering, K. E., Thompson, A., Scala, J. R., Tao, W.-K., Dickerson, R. R. and Simpson, J. (1992) Free tropospheric ozone production following entrainment of urban plumes into deep convection. Journal of Geophysical Research 97, 17,985-18,000. 
Pitari, G., Rizi, V., Ricciardulli, L. and Visconti, G. (1993) High-speed civil transport impact: The role of sulphate, nitric acid trihydrate and ice aerosols studied with a twodimensional model including aerosol physics. Journal of Geophysical Research 98, 23,141.

Pitchford, M., Hudson, J. G. and Hallett, J. (1991) Size and critical supersaturation for condensation of jet engine exhaust particles. Journal of Geophysical Research 96, 20,787-20,793.

Ponater, M., Brinkop, S., Sausen, R. and Schumann, U. (1996) Simulating the global atmospheric response to aircraft water vapour emissions and contrails: a first approach using a GCM. Annales Geophysicae 14, 957-959.

Poppoff, I. G., Farlow, H. N. and Anderson, L. B. (1974) Studies of aircraft wake chemistry and dispersion. Acta Astronomica 1, 157-178.

Portmann, R. W., Solomon, S., Fishman, J., Olson, J., Kiehl, J. T. and Briegleb, B. (1997) Radiative forcing of the Earth's climate system due to tropical tropospheric ozone production. Journal of Geophysical Research 102, 9409-9417.

Poulida, O., Dickerson, R. R. and Heymsfield, A. (1996) Stratosphere-troposphere exchange in a mid-latitude mesoscale convective complex. 1. Observations. Journal of Geophysical Research 101, 6823-6836.

Prather, M. J. et al. (1992) The atmospheric effects of stratospheric aircraft: a first program report. NASA Reference Publication 1272.

Prather, M. (1986) Numerical advection by conservation of second-order moments. Journal of Geophysical Research 91, 6671-6681.

Prather, M., McElroy, M., Wofsy, S., Russel, G. and Rind, D. (1987) Chemistry of the global troposphere: Fluorocarbons as tracers of air motion. Journal of Geophysical Research 92, 6579-6613.

Prinn, R. G., Weiss, R. F., Miller, B. R., Huang, J., Alyea, F. N., Cunnold, D. M., Fraser, P. J., Hartley, D. E. and Simmonds, P. G. (1995) Atmospheric trends and lifetime of $\mathrm{CH}_{3} \mathrm{CCl}_{3}$ and global $\mathrm{OH}$ concentrations. Science 269, 187-192.

Pueschel, R. F. (1996) Stratospheric aerosols: Formation, properties, effects. Journal of Aerosol Science 27, 383-402.

Quackenbush, T. R., Teske, M. E. and Bilanin, A. J. (1996) Dynamics of exhaust plume entrainment in aircraft vortex wakes. AIAA Paper 96-0747.

Ramaswamy, V., Schwarzkopf, M. D. and Shine, K. P. (1992) Radiative forcing of climate from halocarbon-induced global stratospheric ozone loss. Nature 355, 819-812.

Reichardt, J., Ansmann, A., Serwazi, M., Weitkamp, C. and Michaelis, W. (1996) Unexpectedly low ozone concentration in midlatitude tropospheric ice clouds: a case study. Geophysical Research Letters 23, 1929-1932.

Rickard, G. (1996) The quality of aviation fuel available in the United Kingdom. Annual Survey 1995. DRA/ LS4/TR96/044/1. DERA Farnborough, U. K.

Rickey, J. E. (1995) The effects of altitude conditions on the particle emissions of a J85-GE-5L turbojet engine. NASA Technical Memorandum 106669.

Ridley, B. A., Walega, J. G., Dye, J. and Grahek, F. E. (1994) Distributions of $\mathrm{NO}, \mathrm{NO}_{x}, \mathrm{NO}_{y}$ and $\mathrm{O}_{3}$ to $12 \mathrm{~km}$ altitude during the summer monsoon season over New Mexico. Journal of Geophysical Research 99, 25,519-25,534.

Rind, D. and Lonergan, P. (1995) Modeled impacts of stratospheric ozone and water vapor perturbations with implications for high-speed civil transport aircraft. Journal of Geophysical Research 100, 7381-7396.

Rind, D., Lonergan, P. and Shah, K. (1996) Climatic effect of water vapor release in the upper troposphere. Journal of Geophysical Research 101, 29,395-29,406.

Ristori, A. and Baudoin, C. (1996) Measurements of nitrogen species $\mathrm{NO}_{\mathrm{y}}$ at the exhaust of an aircraft engine combus- tor. Impact of Aircraft Emissions Upon the Atmosphere. Proceedings of the International Colloquium on Impact of Aircraft Emissions upon the Atmosphere, Paris, 15-18 October 1996, ONERA.

Rodriguez, J. M., Shia, R.-L., Ko, M. K. W., Heisey, C. W., Weisenstein, D. K., Miake-Lye, R. C. and Kolb, C. E. (1994) Subsidence of aircraft engine exhaust in the stratosphere: Implications for calculated ozone depletions. Geophysical Research Letters 21, 69-72.

Roeckner, E., Arpe, K., Bengtsson, L., Brinkop, S., Dumenil, L., Esch, M., Kirk, E., Lunkeit, F., Ponater, M., Rockel, B., Sausen, R., Schubert, S. and Windelband, M. (1992) Simulation of the present-day climate with the ECHAM model: impact of model physics and resolution. Max Planck Institüt für Meteorologie, Report No. 93, Hamburg, ISSN 0937-1060, $171 \mathrm{pp}$.

Roelofs, G.-J. and Lelieveld, J. (1997) Model study of the influence of cross-tropopause $\mathrm{O}_{3}$ transports on tropospheric $\mathrm{O}_{3}$ levels. Tellus (in press).

Roelofs, G.-J., Lelieveld, J. (1995) Distribution and budget of $\mathrm{O}_{3}$ in the troposphere calculated with a chemistry general circulation model. Journal of Geophysical Research 100, 20,983-20,998.

Rohrer, F., Brüning, D. and Ehhalt, D. H. (1996) Tropospheric mixing ratios of $\mathrm{NO}$ obtained during TROPOZ II in the latitude region $67^{\circ} \mathrm{N}-56^{\circ} \mathrm{S}$. Journal of Geophysical Research 102, 25,429-25,449.

Rohrer, F., Ehhalt, D. H., Grobler, E. S., Kraus, A. B. and Wahner, A. (1993) Model calculations of the impact of nitrogen oxides emitted by aircraft in the upper troposphere at northern mid-latitudes. Proceedings of the 6th European Symposium on the Physio-Chemical Behaviour of Atmospheric Pollutants. Varese, Italy.

Rolls-Royce, (1986) The jet engine. Published by RollsRoyce plc, Derby, U.K., ISBN 0902121049.

Rosen, J. M. and Greegor, R. (1974) Jet engine soot emission measured at altitude. Journal of Aircraft 11, 243-245.

Rossow, W. B. and Schiffer, R. A. (1991) ISCCP cloud data products. Bulletin of American Meterological Society 72, $2-20$.

Ruggaber, A., Dlugi, R. and Nakajima, T. (1994) Modelling radiation quantities and photolysis frequencies in the troposphere. Journal Atmospheric Chemistry 18, $171-210$.

SAE (1991) Aircraft gas turbine engine exhaust smoke measurement. ARP 1179B, Warrendale, Pennsylvania.

SAE (1994) Gas turbine performance, station identification and nomenclature; Aerospace Recommended Practice, ARP 755B, Warrendale, Pennsylvania.

Salby, M. L. (1996) Fundamentals of Atmospheric Physics. Academic Press, San Diego, California.

Sassen, K., Starr, D. O'C., Mace, G. G., Poellot, M. R., Melfi, S. H., Eberhard, W. L., Spinhirne, J. D., Eloranta, E. W., Hagen, D. E. and Hallett, J. (1995) The 5-6 December 1991 FIRE IFOII jet stream cirrus case study: possible influences of volcanic aerosols. Journal of Atmospheric Science 52, 97-123.

Sausen, R. and Köhler, I. (1994) Simulating the global transport of nitrogen oxides emissions from aircraft. Annales Geophysicae 12, 394-402.

Sausen, R., Feneberg, B. and Ponater, M. (1997) Climatic impact of aircraft induced ozone changes. Geophysical Research Letters 24, 1203-1206.

Sausen, R., Collins, W. J., Johnson, C., Kelder, H., Kingdon, R., Köhler, I., Kraabol, A. G., Kraus, A., Marizy, C., Ramaroson, R., Rohrer, F., Scheele, M. P., Stevenson, D., Stordal, F., Strand, A., van Velthoven, P. F. J. and Wauben, W. M. F. (1995) Global atmospheric model simulations. In The Impact of $\mathrm{NO}_{x}$ Emissions from Aircraft Upon the Atmosphere at Flight Altitudes 8-15 km (AERO$N O X$ ), ed U. Schumann. Final Report to the Commission of European Communities, EUR 16209 EN, European Commission, Brussels. 
Schilling, V., Siano, S. and Etling, D. (1996) Dispersion of aircraft emissions due to wake vortices in stratified shear flows: A two-dimensional numerical study. Journal of Geophysical Research 101, 20,965-20,974.

Schlager, H., Schulte, P., Ziereis, H., Arnold, F., Ovarlez, J., van Velthoven, P., Schumann, U. (1996) Airborne observations of large scale accumulations of air traffic emissions in the North Atlantic flight corridor within a stagnant anticyclone. Proceedings of the International Colloquium on Impact of Aircraft Emissions upon the Atmosphere, Paris, 15-18 October 1996, ONERA, pp. 247-252.

Schlager, H., Schulte, P., Ziereis, H., Konopka, P., Schumann, U., Feigl, C., Marquardt, R. and Huntrieser, H. (1996) Aircraft-borne measurements of $\mathrm{NO}_{x}, \mathrm{O}_{3}$ and $\mathrm{CO}_{2}$. In Pollution from Aircraft Emissions in the North Atlantic Flight Corridor (POLINAT), ed U. Schumann. Air Pollution Research Report 58, European Commission EUR 16978 EN, ISSN 1018-5593, 20-47.

Schlager, H., Konopka, P., Schulte, P., Schumann, U., Ziereis, H., Arnold, F., Klemp, M., Hagen, D., Whitefield, P. and Ovarlez, J. (1997) In situ observations of air traffic emission signatures in the North Atlantic flight corridor. Journal of Geophysical Research 102, 10,739-10,750.

Schmidt, E. (1941) Die Entstehung von Eisnebel aus den Auspuffgasen von Flugmotoren. Schriften der Deutschen Akademie der Luftfahrtforschung. Verlag R. Oldenbourg. München and Berlin, Heft 44, 1-15.

Schulte, P. and Schlager, H. (1996) In-flight measurements of cruise altitude nitric oxide emission indices of commercial jet aircraft. Geophysical Research Letters 23, 165-168.

Schulte, P., Schlager, H., Schumann, U., Baughcum, S. L. and Deidewig, F. (1997) $\mathrm{NO}_{x}$ emission indices of subsonic long-range jet aircraft at cruise altitude: in situ measurements and predictions. Journal of Geophysical Research 102, 21,431-21,442.

Schumann, U., Dörnbrack, A., Dürbeck, T. and Gerz, T. (1997) Large-eddy simulation of turbulence in the free atmosphere and behind aircraft. Progress Fluid Dynamics 20, 1-10.

Schumann, U., Schlager, H., Arnold, F., Baumann, R. Haschberger, P. and Klemm, O. (1998) Dilution of aircraft exhaust plumes at cruise altitudes. Atmospheric Environment 32, in press.

Schumann, U. (1997) The impact of nitrogen oxide emissions from aircraft upon the atmosphere at flight altitudes-Results from the AERONOX project. Atmospheric Environment 31, 1723-1733.

Schumann, U. (1996a) On conditions for contrail formation from aircraft exhausts. Meteorology Z. 5, 4-23.

Schumann, U. (1996b) Particle formation in jet aircraft exhausts and contrails for different sulphur containing fuels. In Nucleation and Atmospheric Aerosols 1996, eds M. Kulmala and P. E. Wagner, pp. 296-299. Pergamon, Oxford.

Schumann, U. (ed) (1996c) Pollution from aircraft emissions in the North Atlantic corridor (POLINAT). Final Report to the Commission of the European Communities. EC Publication EUR 16978 EN.

Schumann, U. et al. (1996d) Pollution from aircraft emissions in the north Atlantic flight corridor-Overview on the results of the POLINAT project. Proceedings of the International Colloquium on Impact of Aircraft Emissions Upon the Atmosphere, Paris, 15-18 October 1996, ONERA, pp. 63-68.

Schumann, U. (ed) (1995) AERONOX - the impact of NO emissions from aircraft upon the atmosphere at flight altitude $8-15 \mathrm{~km}$. Final Report to the Commission of the European Communities (CEC Contract EV5V-CT910044), pp. 477.

Schumann, U. (1994) On the effect of emissions from aircraft engines on the state of the atmosphere. Annales Geophysicae 12, 365-384.

Schumann, U. (ed) (1990) Air traffic and the environmentbackground, tendencies and potential global atmospheric effects. Proceedings of a DLR International Colloquium, Bonn, November 15-16, 1990, Lecture Notes in Engineering Vol. 60, Springer, Berlin, pp. 170.

Schumann, U. and Konopka, P. (1994) A simple estimate of the concentration field in a flight corridor. Report of the DLR Mitt. 94-06, Dtsch. Forsch. für Luft-und Raumfahrt, Köln, pp. 354-359.

Schumann, U., Ström, J., Busen, R., Baumann, R., Gierens, K., Krautstrunk, M. Schröder, F. P. and Stingl, J. (1996) In situ observations of particles in jet aircraft exhausts and contrails for different sulphur containing fuels. Journal of Geophysical Research 101, 6853-6869.

Schumann, U., Konopka, P., Baumann, R., Busen, R., Gerz, T., Schlager, H., Schulte, P. and Volkert, H. (1995) Estimate of diffusion parameters of aircraft exhaust plumes near the tropopause from nitric oxide and turbulence measurements. Journal of Geophysical Research 100, $14,147-14,162$.

Schumann, U. and Wendling, P. (1990) Determination of contrails from satellite data and observational results. Lecture Notes in Engineering, Vol. 60, pp. 138-153. Springer, Berlin.

Schwarzkopf, M. D. and Ramaswamy, V. (1993) Radiative forcing due to ozone in the 1980s: dependence on altitude of ozone change. Geophysical Research Letters 20, 205-208.

Shine, K. P., Briegleb, B. P., Grossman, A. S., Hauglustaine, D., Mao, H. Ramaswamy, V., Schwarzkopf, M. D., Van Dorland, R. and Wang, W.-C. (1995) Radiative forcing due to changes in ozone: A comparison of different codes. In Atmospheric Ozone as a Climate Gas: General Circulation Model Simulations, eds W.-C. Wang and I. S. A. Isaksen, pp. 373-396. Springer, Berlin.

Singh, H. B. et al. (1996) Reactive nitrogen and ozone over the western Pacific: distribution, partitioning and sources. Journal of Geophysical Research 101, 1793-1808.

Singh, H. B., Kanakidou, M., Crutzen, P. J. and Jacob, D. J. (1995) High concentrations and photochemical fate of oxygenated hydrocarbons in the global troposphere. Nature 378, 50-54.

Singh, H. B. et al. (1990) PAN measurements during CITE 2: atmospheric distribution and precursor relationships. Journal of Geophysical Research 95, 10,163-10,178.

Smolarkiewicz, P. and Rasch, P. (1991) Monotone advection on the sphere: an Eulerian versus semi-Lagrangian approach. Journal of Atmospheric Science 48, 793-810.

Solomon, S., Garcia, R. R. and Ravishankara, A. R. (1994) On the role of iodine in ozone depletion. Journal of Geophysical Research 99, 20,491-20,499.

SORG (1988) Stratospheric ozone 1988. U.K. Stratospheric Ozone Review Group, Second Report. HMSO London.

Spicer, C. W. et al. (1990) Aircraft emissions characterisation: F101 and F110 engines. Battelle Report ESL-TR-89-13.

Spicer, C. W., Holdren, M. W., Riggin, R. M. and Lyon, T. F. (1994) Chemical composition and photochemical reactivity of exhaust from aircraft turbine engines. Annales de Geophysique 12, 944-955.

Spicer, C. W., Holdren, M. W., Smith, D. L., Hughes, D. P. and Smith, M. D. (1992) Chemical composition of exhaust from aircraft turbine engines. Journal of Engineering in Gas Turbines Power 114, 111-117.

Steil, B., Dameris, M., Brühl, C., Crutzen, P. J., Grewe, V., Ponater, M. and Sausen, R. (1998) Development of a chemistry module for GCMs: first results of a multiannual integration. Annales Geophysicae 16, 205-208.

Stevenson, D. S., Collins, W. C., Johnson, C. E. and Derwent, R. G. (1997) The impact of aircraft nitrogen oxide emissions on tropospheric ozone studied with a 3-D Lagrangian model including fully diurnal chemistry. Atmospheric Environment 31, 1837-1850.

Stolarski, R. S. and Wesoky, H. W. (eds) (1993) The atmospheric effects of stratospheric aircraft: A Second Program Report, NASA Reference Publication 1313. 
Stolarski, R. S. and Wesoky, H. W. (eds) (1995) The atmospheric effects of stratospheric Aircraft: A Fourth Program Report, NASA Reference Publication 1359.

Strauss, B. (1995) Uber den Einfluss natürlicher and anthropogener Eiswolken auf das regionale Klima-mit besonderer Berücksichtigung des mikrophysikalischen Einflusses. DLR FB 94-23, ISSN 0939-2963, 96 pp.

Thompson, A. M., Friedl, R. R. and Wesoky, H. L. (eds) (1996) Atmospheric effects of aviation. First Report of the Subsonic, NASA Reference Publication 1385.

Toumi, R., Bekki, S. and Law, K. (1994) Indirect influence of ozone depletion on climate forcing by clouds. Nature $\mathbf{3 7 2}$, 348-351.

Turco, R. P., Toon, O. B., Pollack, J. B., Whitten, R. C., Poppoff, I. G. and Hamill, P. (1980) Stratospheric aerosol modification by supersonic transport and space shuttle operations - climate implications. Journal of Applied Meteorology 19, 78-89.

Turman, B. N. and Edgar, B. C. (1982) Global lightning distributions at dawn and dusk. Journal of Geophysical Research 87, 1191-1206.

Twomey, S. A., Piepgras, M. and Wolfe, T. L. (1984) An assessment of the impact of pollution on global cloud albedo. Tellus 36B, 356-366.

Ulbrich, U., Graf, H.-F. and Kirchner, I. (1995) The impact of El Niño and volcanic forcing on the atmospheric energy cycle and the zonal mean atmospheric circulation. Contributions to Atmospheric Physics 68, 59-74.

Van Velthoven, P. F. J. and Kelder, H. (1996) Estimates of stratosphere-troposphere exchange: Sensitivity to model formulation and horizontal resolution. Journal of Geophysical Research 101, 1429-1434.

Van Velthoven, P. F. J., Sausen, R, Johnson, C. E., Kelder, H., Kingdon, R., Köhler, I., Kraus, A., Ramaroson, R., Rohrer, F., Strand, A. and Wauben, W. M. F. (1997) The passive transport of $\mathrm{NO}_{x}$ emissions from aircraft with a hierarchy of models. Atmospheric Environment 31, 1783-1799.

Vedantham, A. and Oppenheimer, M. (1994) Aircraft Emissions and the Global Atmosphere; Long Term Scenarios. Environmental Defence Fund, New York.

Velders, G. J. M., Heijboer, L. M. and Kelder, H. (1994) The simulation of the transport of the aircraft emissions by a three-dimensional global model. Annales Geophysicae 12, 385-393.

Wahner, A., Rohrer, F., Ehhalt, D. H., Ridley, B. and Atlas, E. (1994) Global measurements of photochemical active compounds. Proceedings of 1st IGAC Scientific Conference: Global Atmospheric-Biospheric Chemistry. Eilat, Israel, pp. 205-222.

Wang, W.-C. Pinto, J. P. and Yung, Y. L. (1980) Climatic effects due to halogenated compounds in the Earth's atmosphere. Journal of Atmospheric Science 37, 333-338.

Warnatz, J., Maas, U. and Dibble, R. W. (1996) Combustion: Physical and Chemical Fundamentals, Modelling and Simulation, Experiments, Pollutant Formation. Springer, Berlin.

Wauben, W. M. F., van Velthoven, P. F. J. and Kelder, H. (1994) Chemistry and transport of $\mathrm{NO}_{x}$ aircraft emissions in a global 3-D chemical transport model. In International Scientific Colloquium on the Impact of Emissions from Aircraft and Spacecraft upon the Atmosphere, eds U. Schumann and D. Wurzel, DLR Mitteilungen 94-06, Cologne.

Wauben, W. M. F., van Velthoven, P. F. J. and Kelder, H. (1997a) A 3-D chemistry transport model study of changes in atmospheric ozone due to aircraft $\mathrm{NO}_{x}$ emissions. Atmospheric Environment 31, 1819-1836.

Wauben, W. M. F., van Velthoven, P. F. J. and Kelder, H. (1997b) The impact of air traffic in the NAFC during POLINAT: model results and measurements. In Pollution from Aircraft Emissions in the North Atlantic Flight Corridor (POLINAT), Final Report to the CEC (in press).

Wauben, W. M. F., Fortuin, J. P. F., van Velthoven, P. F. J. and Kelder, H. (1997c) Validation of modelled ozone dis- tributions with sonde and satellite observations. Journal of Geophysical Research (submitted).

Wauben, W. M. F., Bintanja, R., van Velthoven, P. F. J. and Kelder, H. (1997d) On the magnitude of transport out of the Antarctic polar vortex. Journal of Geophysical Research 102, 1229-1238.

Webster, C. R., May, R. D., Toohey, D. W., Avalone, L. M., Anderson, J. G., Newman, P. A., Lait, L. R., Schoeberl, M. R., Elkins, J. W. and Chan, K. R. (1993) Chlorine chemistry on polar stratospheric cloud particles in the Arctic winter. Science 261, 1130-1134.

Weibrink, G. and Zellner, R. (1994) Chemistry in plumes of high-flying aircraft with $\mathrm{H}_{2}$ combustion engines: A modelling study. Annales Geophysicae 12, 403-408.

Weinheimer, A. J., Walega, J. G., Ridley, B. A., Gary, B. L., Blake, D. R., Blake, N. J., Rowland, F. S., Sachse, G. W., Anderson, B. E. and Collins, J. E. (1994) Meridional distribution of $\mathrm{NO}_{x}, \mathrm{NO}_{y}$ and other species in the lower stratosphere and upper troposphere during AASE II. Geophysical Research Letters 21, 2583-2586.

Whitefield, P. D., Hagen, D. E., Lilenfeld, H. V. and Trueblood, M. B. (1996) Ground based particulate emission measurements on the Concorde Olympus engines. Proceedings of the Combustion Institute Symposium, St. Louis.

Wiesen, P., Kleffmann, J., Kurtenbach, R., Wahl, C. and Kapernaum, M. (1996a) Measurement of trace species in the exhaust of a reverse flow combustor. Proceedings of the International Colloquium on Impact of Aircraft Emissions Upon the Atmosphere, Paris, 15-18 October 1996, ONERA.

Wiesen, P., Kleffmann, J., Kurtenbach, R. and Becker, K. H. (1996b) Emission of nitrous oxide and methane from aero engines: monitoring by tuneable diode laser spectroscopy. Infrared Physics and Technology 37, 75-81.

Wiesen, P., Kleffmann, J., Kurtenbach, R. and Becker, K. H. (1994) Emission of nitrous oxide and methane from aero engines. Geophysical Research Letters 21, 2027-2030.

World Meteorological Organisation (WMO) (1992) Scientific Assessment of Ozone Depletion: 1991. WMO Report No. 25, Geneva, Switzerland.

World Meteorological Organisation (WMO) (1995) Scientific Assessment of Ozone Depletion: 1994. WMO Global Ozone Research and Monitoring Project, Report No. 37, Geneva, Switzerland.

Wuebbles, D. J., Maiden, D., Seals, Jr., R. K., Baughcum, S. L., Metwally, M., Mortlock, A. (1993) Emissions scenarios development. Report of the Emissions Scenarios Committee. In The Atmospheric Effects of Stratospheric Aircraft, eds R. Stolarski and H. L. Wesoky, NASA Reference Publication 1313, pp. 63-208.

Wuebbles, D. J., Baugchum, S. L., Metwally, M. and Seals, Jr. R. K. (1993) Emissions scenarios development: overview and methodology. In The Atmospheric Effects of Stratospheric Aircraft, eds R. Stolarski and H. L. Wesoky, pp. 65-85, NASA Reference Publication 1313.

Zhao, J. and Turco, R. P. (1995) Nucleation simulation in the wake of a jet aircraft in stratospheric flight. Journal of Aerosol Science 26, 779-795.

Zheng, J., Weinheimer, A. J., Ridley, B. A., Liu, S. C., Sachse, G. W., Anderson, B. E. and Collins, J. W. Jr. (1995) An analysis of aircraft exhaust plumes from accidental encounters. Geophysical Research Letters 21, 2579-2582.

Zheng, J., Weinheimer, A. J., Ridley, B. A., Liu, S. C., Sachse, G. W., Anderson, B. E. and Collins, Jr. J. E. (1996) Analysis of small- and large-scale increase of reactive nitrogen observed during the Second Airborne Arctic Stratospheric Expedition. Journal of Geophysical Research 101, 28,805-28,816.

Ziereis, H., Schlager, H., Schulte, P. and Klemm, O. (1997) Aircraft observations of the $\mathrm{NO}_{x}$ abundance and variability in the upper troposphere over the North Atlantic. Proceedings of the Quadrennial Ozone Symposium, L’Aquilla, Italy, September 1996 (in press). 


\section{APPENDIX: BRIEF DESCRIPTION OF THE MODELS} USED IN SECTION 6

\section{A.1. The Oslo model}

The University of Oslo chemical tracer model (OsloCTM-1) is a global off-line 3-D chemical tracer model. The transport parameterization is based on the NASA/GISS CTM (Prather et al., 1987), with a horizontal resolution of $8 \times 10^{\circ}$ latitude vs longitude. In the vertical the model domain is divided into nine layers (modified sigma coordinates) from the surface to $10 \mathrm{hPa}$. One year of output meteorological data every $8 \mathrm{~h}$ from the NASA/GISS GCM $\left(4 \times 5^{\circ}\right.$ resolution) is used as input to drive the model. The transport includes advection, which is solved by the accurate "secondorder moment" scheme (Prather, 1986), and convection. Redistribution of tracers by transport is calculated with a $1 \mathrm{~h}$ time step.

A comprehensive photochemical scheme with about 50 species and 110 thermal reactions has been included in the model (Berntsen et al., 1996; Berntsen and Isaksen, 1997; Jaffe et al., 1997). The chemistry is applied to the tropospheric layers (1-7, at mid- and high latitudes, and 1-8 in the tropics). In the stratosphere, concentrations of ozone and $\mathrm{NO}_{y}$ species have been fixed according to observations. The chemistry scheme is solved by a QSSA-method including iterations for short-lived species, with $30 \mathrm{~min}$ time step. The model includes parameterizations of dry and wet deposition, emissions, and cloud effects on photolysis rates.

\section{A.2. The KNMI model}

The three-dimensional chemistry transport model of the KNMI (CTMK) has been adapted from the global tracer transport model TM2 (Heimann, 1995). CTMK calculates the horizontal and vertical transport of tracers on the basis of archived 12-hourly output from the European Centre for Medium-Range Weather Forecasts (ECMWF) model (Van Velthoven and Kelder, 1996). CTMK was run with a horizontal resolution of $8 \times 10^{\circ}$ and vertically, the model had 15 sigma-levels extending from the surface up to $5 \mathrm{hPa}$. The meteorological data are integrated/interpolated to this grid and updated every $12 \mathrm{~h}$. Advection is calculated with the slopes scheme of Russell and Lerner (1981). The subscale convection fluxes are evaluated according to the scheme of Tiedtke (1989) and the parameterization of Louis (1979) is used for diffusion.

CTMK contains a chemical scheme adopted from the MOGUNTIA model (Crutzen and Zimmermann, 1991). It evaluates the daytime chemistry of 13 trace gases by using the temperature and relative humidity fields from the ECMWF analyses. Day-time averaged photolysis rates for $\mathrm{O}_{3}, \mathrm{NO}_{2}, \mathrm{H}_{2} \mathrm{O}_{2}, \mathrm{HNO}_{3}, \mathrm{CH}_{3} \mathrm{OOH}$, and $\mathrm{HCHO}$ are used, which have been computed with the method described in Bruehl and Crutzen (1989). A total of 25 chemical reactions are considered together with dry deposition for $\mathrm{O}_{3}, \mathrm{NO}_{2}$, $\mathrm{H}_{2} \mathrm{O}_{2}, \mathrm{HNO}_{3}, \mathrm{CH}_{3} \mathrm{OOH}$ and $\mathrm{NO}$, and wet deposition for $\mathrm{H}_{2} \mathrm{O}_{2}, \mathrm{HNO}_{3}$, and $\mathrm{CH}_{3} \mathrm{OOH}$. Climatological precipitation data are used for the parameterization of the wet deposition. The nighttime chemistry includes, besides the deposition, an off-line parameterized heterogeneous reaction. This parameterization, which is based on the work of Dentener and Crutzen (1993), converts $\mathrm{NO}_{2}$ and $\mathrm{O}_{3}$ into $\mathrm{HNO}_{3}$. The gases with relatively long lifetimes, i.e. $\mathrm{O}_{3}, \mathrm{NO}_{x}\left(=\mathrm{NO}+\mathrm{NO}_{2}\right)$, $\mathrm{H}_{2} \mathrm{O}_{2}, \mathrm{CH}_{4}, \mathrm{CO}, \mathrm{HNO}_{3}$, and $\mathrm{CH}_{3} \mathrm{OOH}$, are transported in CTMK, whereas $\mathrm{HCHO}, \mathrm{HO}_{2}, \mathrm{CH}_{3} \mathrm{O}_{2}, \mathrm{O}\left({ }^{1} \mathrm{D}\right), \mathrm{OH}$ and the partitioning of $\mathrm{NO}_{x}$ in $\mathrm{NO}$ and $\mathrm{NO}_{2}$ are calculated assuming a quasi-steady state.

A zonally and monthly mean ozone climatology is prescribed above $50 \mathrm{hPa}$ according to Fortuin and Langematz (1995). This is needed since the chemistry module contains only the relevant processes for the troposphere and lower stratosphere. The global annual net ozone flux downward through the $125 \mathrm{hPa}$ level generated by CTMK is 1280 $\mathrm{Tg}_{-} \mathrm{O}_{3}$ (cf. Wauben et al., 1997c).

CTMK has been used for many studies such as investigations of the atmospheric effects of aircraft emissions (cf. AERONOX, 1995; Wauben et al., 1997a). A validation of CTMK modelled ozone distributions with sonde and satellite observations is performed by Wauben et al. (1997c). The study showed generally good agreement between observed and modelled ozone values, especially the day-to-day variability of the ozone fields was well represented by the model. However, descrepancies at the surface (seasonal variations not well reproduces due to the neglect of NMHC chemistry or as a result of emissions) and near the tropopause (general over estimation of ozone due to STE) were identified. A check on the validity of the chemistry module has been done by comparison of modelled instantaneous tracer fields and in situ measurements performed in the framework of the EU-POLINAT campaigns. The agreement is generally good for ozone, but worse for the nitrogen oxides and nitric acid indicating the inadequate representation of the $\mathrm{NO}_{y}$ chemistry near the tropopause (Wauben et al., 1997b). However, a comparison of modelled $\mathrm{NO}_{x}$ data with an available climatology of observations showed that the methane oxidation chemistry in CTMK did not deviate systematically from the observations nor the results obtained by other models using more extensive photochemical schemes and reproduces the main observed features (Emmons et al., 1997).

CTMK has been run for a period of $2 \mathrm{yr}$. The first year was used to initialize the model. The results of the second year, obtained with the meteorological data for 1990, were analysed.

\section{A.3. The IMAGES model}

The IMAGES model is a three-dimensional chemical transport model for the troposphere. It calculates the monthly averaged distributions of 56 chemical species, including $\mathrm{O}_{3}, \mathrm{HO}_{x}$, nitrogen oxides, sulphur oxides, methane, and several non-methane hydrocarbons. Its horizontal resolution is $5^{\circ}$ in latitude and in longitude. In the vertical, the model has 25 sigma layers between the Earth's surface and the lower stratosphere (50 mb) (Müller and Brasseur, 1995; Pham et al., 1995).

The transport of the species is solved as follows. A semiLagrangian scheme (Smolarkiewicz and Rasch, 1991) is used to calculate the advection by monthly averaged winds. The wind fields, as well as temperature and water vapor are a 1985-1989 average taken from an analysis of the ECMWF. The impact of wind variability at time scales smaller than one month are taken into account by the introduction of a diffusion term in the continuity equation. The diffusion coefficients are estimated from the ECMWF wind variances. Vertical mixing in the planetary boundary layer is also represented as diffusion. The effect of deep convection on vertical transport is parameterized following the scheme of Costen et al. (1989). Cloud updrafts are parameterized using the cumulo-nimbus coverage and top altitudes estimated by the ISCCP project (Rossow and Schiffer, 1991). Convection intensity is adjusted so that the model reproduces the observations for radon at mid-latitudes in summer (Liu et al., 1984)

The chemical scheme includes more than 150 reactions, including simplified oxidation schemes for ethane, propylene, propane, isoprene, etc. The photodissociation rates are interpolated from a look-up table. This table consists of $\mathbf{J}$ values for discrete values of the zenith angle, altitude, ozone column, albedo, and 500 and $200 \mathrm{mb}$ temperatures. The table was calculated using the eight-stream discrete ordinates radiative model. The effect of clouds in the model is parameterized following Chang et al. (1987) and using the cloud cover and optical depth estimated by ISCCP.

The surface emissions and deposition velocities used in IMAGES are based on an inventory of the sources by Müller 
(1992) (see also Müller and Brasseur, 1995), and on the GEIA inventory, with several modifications. The biomass burning emissions are based on a newer inventory by Hao et al. (1996). The ocean source of $\mathrm{CO}$ has been reduced to $20 \mathrm{Tg} \mathrm{yr}^{-1}$, whereas the car exhaust emissions of $\mathrm{CO}$ and hydrocarbons have been increased.

The production of NO by lightning discharges is taken to be $5 \mathrm{TgN} \mathrm{yr}^{-1}$ globally, distributed as the satellite-derived flash frequencies of Turman and Edgar (1982). The emission is assumed to be constant with altitude between the surface and the top altitude of cumulo-nimbus. The washout scheme is based on the ISCCP cloud data set and climatological precipitation rates. The conversion of $\mathrm{N}_{2} \mathrm{O}_{5}$ to $\mathrm{HNO}_{3}$ on aerosols is parameterized using the model-calculated sulphate distribution.

The time step for integration is $6 \mathrm{~h}$ except during 3 days at the beginning of each month of simulation. These 3 days are calculated using a time step of half an hour and diurnally varying photorates. The diurnal behaviour of the concentrations is saved and used afterwards to correct the chemical reaction rates, in order to properly account for the effect of the diurnal cycle.

The IMAGES model has been used to study the budget of important tropospheric species and their evolution since pre-industrial times (Müller and Brasseur, 1995), the sulphur cycle (Pham et al., 1995, 1996), the impact of biomass burning (Hao et al., 1996), and the impact of subsonic aircrafts (Brasseur et al., 1996).

\section{A.4. The DLR model}

Detailed descriptions of the spectral atmospheric circulation model ECHAM3 and of the chemical module CHEM are given by Roeckner et al. (1992) and Steil et al. (1998), respectively. The climate model ECHAM3 is running with a time step of $40 \mathrm{~min}$. and a horizontal resolution of $5.6^{\circ}$ latitude $\times 5.6^{\circ}$ longitude (T21). The atmosphere is divided in 19 layers from the surface to the top layer, which is centred at $10 \mathrm{hPa}(30 \mathrm{~km})$, yielding a vertical resolution in the upper troposphere and lower stratosphere of approximately $2 \mathrm{~km}$.
Subscale processes, like radiation, cloud formation, precipitation, convection, horizontal and vertical diffusion are parameterized. Tracers are transported using a semi-Lagrangian advection scheme.

ECHAM has successfully been applied for various studies on climate sensitivity and climate change (e.g. Cubasch et al., 1992; Graf et al., 1992; Ulbrich et al., 1995), and in tracer transport studies (e.g. Heimann and Feichter, 1990; Brost et al., 1991; Feichter et al., 1991; Sausen and Köhler, 1994).

The chemical module is based on the "family-concept" and includes 37 species and more than 100 chemical reactions relevant for stratospheric and tropospheric ozone chemistry. Four heterogeneous reactions on polar stratospheric clouds (PSCs) and sulphate aerosol are implemented to realize chlorine activation and denoxification in polar stratospheric winter regions. PSCs are parameterized according to Hanson and Mauersberger (1988) including a nucleation barrier (Peter et al., 1991). The aerosol surface areas are prescribed using background aerosol conditions ("baseline" scenario; WMO, 1992). The model takes into accounts surface emissions, emissions by lightning, dry and wet deposition, and sedimentation of PSC particles. The chlorine and greenhouse gas background concentrations assumed in the model correspond to the years 1992 and 2015, respectively.

A comparison of the modelled PSC frequency with observations, the distribution of ozone and some other trace gases is given in Steil et al. (1998). The interhemispheric differences in the intensity of PSC formation and ozone depletion is well reproduced. The calculated mean total ozone and vertical ozone distribution agrees fairly well with observations. Differences mainly occur in the winter and spring season in middle and high latitudes in the Northern Hemisphere. As the modelled polar night jet is overestimated, the poleward transport of ozone rich airmasses in the lower stratosphere is reduced. This causes higher (lower) total ozone values in middle (higher) latitudes compared with observations and therefore a reduced interannual variability in PSC ozone depletion is found (Grewe et al., 1998). 